\title{
Barrett's esophagus and esophageal and gastric cancer subtypes : an epidemiologic perspective
}

Citation for published version (APA):

Steevens, J. (2010). Barrett's esophagus and esophageal and gastric cancer subtypes : an epidemiologic perspective. [Doctoral Thesis, Maastricht University]. Datawyse / Universitaire Pers Maastricht. https://doi.org/10.26481/dis.20101201js

Document status and date:

Published: 01/01/2010

DOI:

10.26481/dis.20101201js

Document Version:

Publisher's PDF, also known as Version of record

\section{Please check the document version of this publication:}

- A submitted manuscript is the version of the article upon submission and before peer-review. There can be important differences between the submitted version and the official published version of record.

People interested in the research are advised to contact the author for the final version of the publication, or visit the DOI to the publisher's website.

- The final author version and the galley proof are versions of the publication after peer review.

- The final published version features the final layout of the paper including the volume, issue and page numbers.

Link to publication

\footnotetext{
General rights rights.

- You may freely distribute the URL identifying the publication in the public portal. please follow below link for the End User Agreement:

www.umlib.nl/taverne-license

Take down policy

If you believe that this document breaches copyright please contact us at:

repository@maastrichtuniversity.nl

providing details and we will investigate your claim.
}

Copyright and moral rights for the publications made accessible in the public portal are retained by the authors and/or other copyright owners and it is a condition of accessing publications that users recognise and abide by the legal requirements associated with these

- Users may download and print one copy of any publication from the public portal for the purpose of private study or research.

- You may not further distribute the material or use it for any profit-making activity or commercial gain

If the publication is distributed under the terms of Article $25 \mathrm{fa}$ of the Dutch Copyright Act, indicated by the "Taverne" license above, 
Barrett's esophagus and esophageal and gastric cancer subtypes:

an epidemiologic perspective 
(C) Jessie Steevens, Maastricht 2010

Layout: Tiny Wouters

Cover design: Bram Steevens

Production: Datawyse, Universitaire Pers Maastricht

ISBN: 978-90-5278-994-1

This Ph.D. research was supported by the Dutch Cancer Society (KWF Kankerbestrijding). The studies presented in this thesis were conducted at the Department of Epidemiology, GROW - School for Oncology and Developmental Biology, Maastricht University Medical Centre +.

Financial support for the printing of this thesis was kindly provided by the Department of Epidemiology and the Dutch Cancer Society. 


\title{
Barrett's esophagus and esophageal and gastric cancer subtypes: an epidemiologic perspective
}

\author{
Proefschrift \\ ter verkrijging van de graad van doctor aan de Universiteit Maastricht \\ op gezag van de Rector Magnificus, Prof. mr. G.P.M.F Mols, \\ volgens het besluit van het college van Decanen, \\ in het openbaar te verdedigen \\ op woensdag 1 december 2010 om 12:00 uur \\ door
} Jessie Steevens

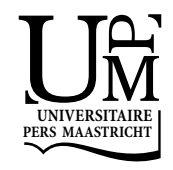


Promotor

Prof. dr. ir. P.A. van den Brandt

\section{Copromotores}

Dr. L.J. Schouten

Dr. ir. R.A. Goldbohm, TNO Kwaliteit van Leven, Leiden

\section{Beoordelingscommissie}

Prof. dr. F.T. Bosman (voorzitter)

Prof. dr. M.A. van Baak

Prof. dr. L.J. Murray, Queen's University Belfast, Belfast, Northern Ireland

Dr. J. de Nooijer

Prof. dr. P.D. Siersema, Universitair Medisch Centrum Utrecht, Utrecht 


\section{CONTENTS}

$\begin{array}{lll}\text { Chapter } 1 & \text { General introduction } & 7\end{array}$

Chapter 2 A prospective cohort study on overweight, smoking, 23 alcohol consumption, and risk of Barrett's esophagus Submitted

Chapter 3 Toenail selenium status and the risk of Barrett's esophagus: the Netherlands Cohort Study

Cancer Causes Control 2010; in press

Chapter $4 \quad$ Cancer incidence and cause-specific mortality in a population-based cohort of patients with Barrett's esophagus Submitted

Chapter 5 Trends in incidence of esophageal and stomach cancer subtypes in Europe

Eur J Gastroenterol Hepatol 2010;22:669-678

Chapter 6 Alcohol consumption, cigarette smoking and risk of subtypes of esophageal and gastric cancer: a prospective cohort study Gut 2010;59:39-48

Chapter 7 Selenium status and the risk of esophageal and gastric cancer subtypes: the Netherlands Cohort Study Gastroenterology 2010;138:1704-1713

Chapter $8 \quad$ Vegetables and fruits consumption and risk of esophageal and gastric cancer subtypes in the Netherlands Cohort Study Submitted

Chapter 9 General discussion

Summary / Samenvatting

Dankwoord 

General introduction 
Chapter 1 
Cancer has become a disease that affects many people in the world. The International Agency for Research on Cancer estimated that 12.7 million new cancer cases and 7.6 million cancer deaths occurred in $2008 .{ }^{1}$ In the Netherlands, cancer has become the most important cause of death in $2008 .^{2}$ In that year, over 40,000 persons died of cancer, which was approximately $30 \%$ of all deaths. ${ }^{3}$

This thesis is concerns two types of cancer: cancer of the esophagus and cancer of the stomach, also called gastric cancer. Within esophageal and gastric cancer one can discern subtypes. Besides these cancers, this thesis also examines Barrett's esophagus $(\mathrm{BE})$, a precursor of adenocarcinoma of the esophagus.

\section{ESOPHAGEAL AND GASTRIC CANCER}

\section{Incidence and mortality}

Esophageal cancer was estimated to be the $8^{\text {th }}$ most common cancer worldwide with regard to new cases, and the $6^{\text {th }}$ most common cause of death from cancer in 2008. Cancer of the stomach is more common being the $4^{\text {th }}$ cancer with regard to new cases, and the $2^{\text {nd }}$ leading cause of cancer death in the world. ${ }^{1}$

Geographically, esophageal and gastric cancer are not distributed evenly (Figures 1.1 and 1.2). Esophageal cancer is specifically common in Asia (Iran, China, Japan, Korea), Southern and Eastern Africa (Uganda, Zimbabwe), USA (Blacks), and France. Typically, in these high risk populations the majority of esophageal cancers is of the squamous cell type, in contrast to low risk populations, where adenocarcinomas are more common. ${ }^{4}$ Incidence rates for gastric cancer are highest in Eastern Asia (China, Japan, Korea), Eastern Europe, Italy, Portugal and Latin America. ${ }^{1,5}$ In the Netherlands, 1876 and 2020 persons were diagnosed with esophageal and gastric cancer, respectively, and 1558 and 1424 patients died of these cancers in $2008 .^{6}$

\section{Course of the diseases}

Symptoms that indicate the presence of esophageal cancer are dysphagia, weight loss, and pain on swallowing foods. ${ }^{8}$ The most common symptoms that precede a diagnosis of gastric cancer are weight loss, abdominal pain, nausea, and dysphagia. ${ }^{9}$ Patients are often not diagnosed with esophageal or gastric cancer until the cancer has reached an advanced stage. Partly due to this late diagnosis, treatment options are limited and curative treatments are often not possible. ${ }^{10}$ The late diagnosis therefore lies at the bottom of the very high mortality rate of both cancers. One year after diagnosis, $42 \%$ of the esophageal cancer patients and $45 \%$ of the gastric cancer patients are still alive. Only $14 \%$ of esophageal and $21 \%$ of gastric cancer patients survive five years. ${ }^{6}$ These Dutch rates are comparable with European survival rates. ${ }^{11}$ 


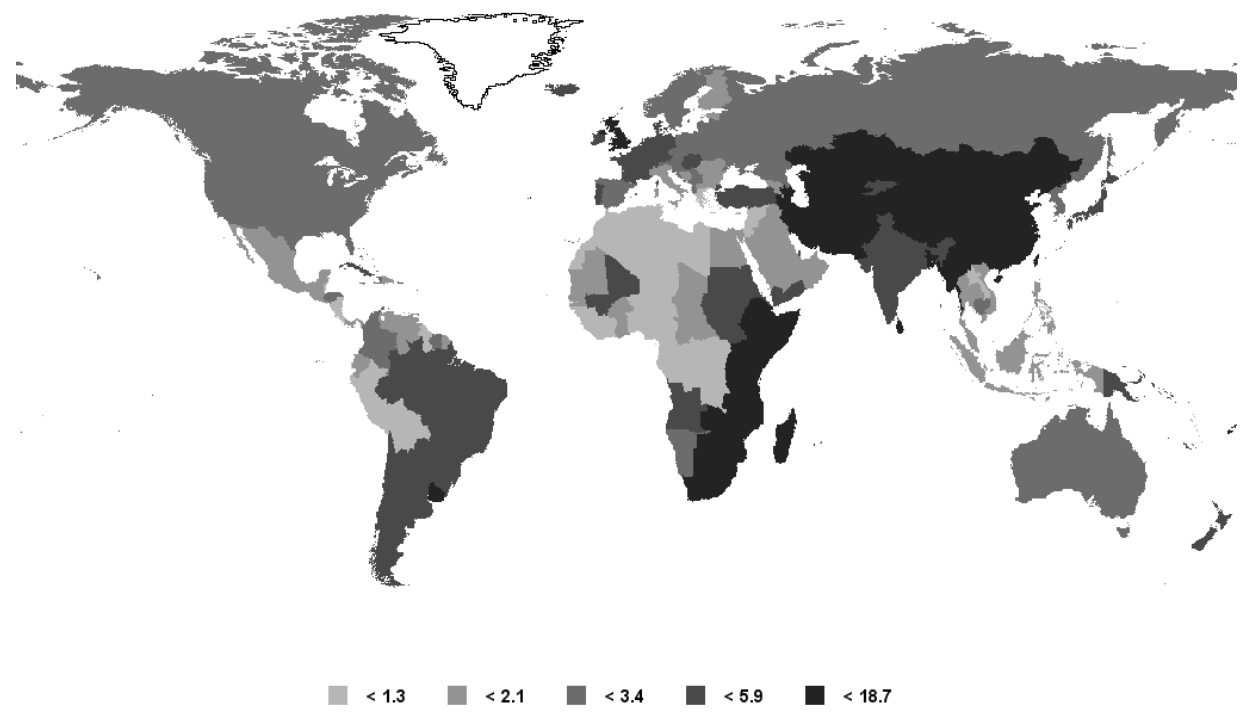

Figure 1.1 Estimated worldwide incidence rates (per 100,000) of esophageal cancer (both sexes, all ages), age-standardized to the world population. Source: Globocan $2008 .^{7}$

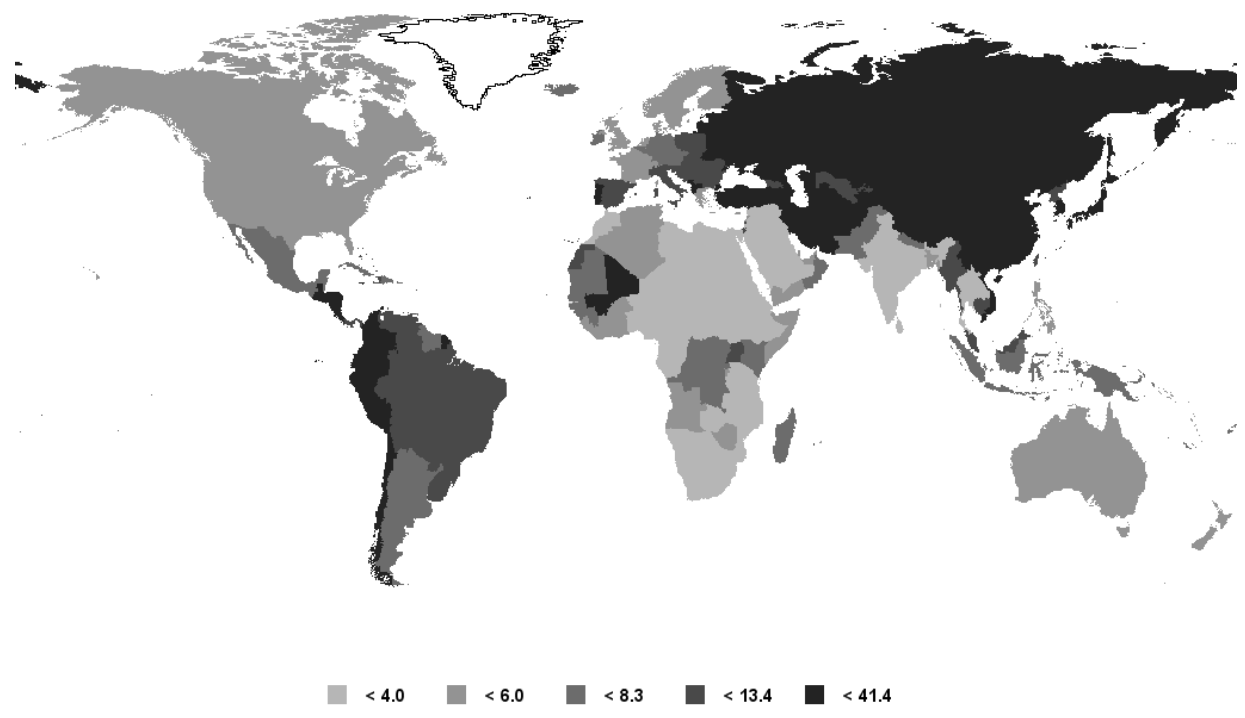

Figure 1.2 Estimated worldwide incidence rates (per 100,000) of gastric cancer (both sexes, all ages), agestandardized to the world population. Source: Globocan $2008 .^{7}$ 


\section{Classification of esophageal and gastric cancers}

Cancers of the esophagus and stomach can be classified in several ways. In the International Classification of Diseases for Oncology (ICD-O), ${ }^{12}$ tumors are classified according to their topography and histology.

For the esophagus, there are two possible topographic classifications: cervical, thoracic, and abdominal part of the esophagus, or upper, middle, and lower third of the esophagus. The latter classification is most commonly used in research, and shown in Figure 1.3. Another classification is based on the type of tissue from which the tumor originates: a histological classification. The two most common histological types of esophageal cancer are esophageal squamous cell carcinoma and esophageal adenocarcinoma. Esophageal squamous cell carcinoma most often occurs in the middle third of the esophagus, while the large majority of esophageal adenocarcinomas arise in the lower third. ${ }^{13}$

The ICD-O topographic classification of gastric cancer discerns tumors of the cardia, fundus, body, pyloric antrum, and pylorus (Figure 1.3). Additionally, tumors can be classified as located in the lesser or greater curvature of the stomach. ${ }^{12}$ The large majority of all gastric cancers are adenocarcinomas. ${ }^{13}$

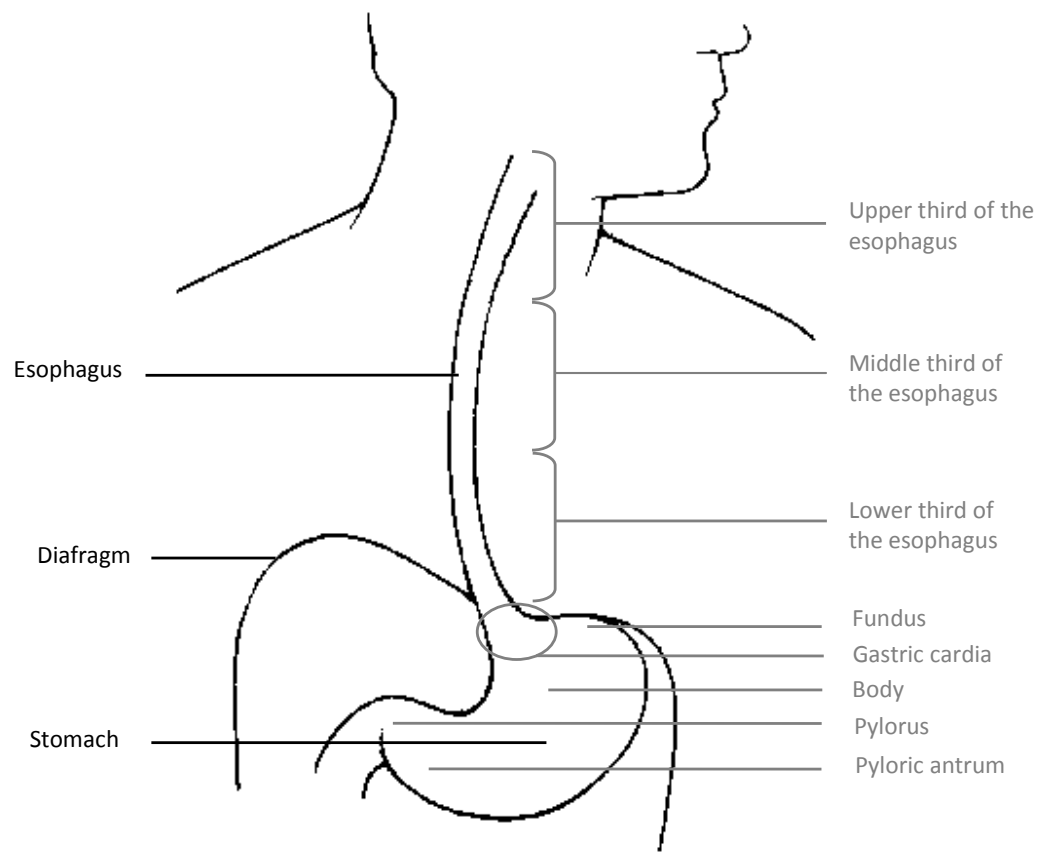

Figure 1.3 The esophagus and stomach. 


\section{Trends in incidence rates}

Incidence rates of esophageal and gastric cancer have been carefully monitored for decades. Before 1940, gastric cancer was the leading cause of cancer death in men in the USA. In the next decades, however, this cancer became less and less common. Between 1950 and the 1970s, gastric cancer mortality had started to decline quite sharply in several countries, including the USA, Scandinavian countries, Western European countries, and Australia., ${ }^{44}$ Later publications observed, however, that this decline in gastric cancer did not concern the cardia, the proximal part of the stomach. ${ }^{15}$ In fact, some reported that the incidence of gastric cardia cancer had risen in the 1960s through 1980s in the USA, the UK, Denmark, and Sweden. ${ }^{16-19}$ Moreover, these and other studies also observed sharp increases in the incidence of adenocarcinomas of the esophagus. ${ }^{16-18,20}$ In contrast, stable or declining incidence rates have been reported for the other histological type of esophageal cancer: squamous cell carcinoma. ${ }^{16,17,21-23}$

The question continually is, however, whether these observed changes in incidence are true increases in the disease. In the course of time the attention for subtypes of esophageal and gastric cancer has grown, which may have influenced clinicians and pathologists. Also, the quality of registration of tumor histology and subsite has improved greatly., ${ }^{54-28}$ These developments may have contributed to the observed changes. In general, it is thought that at least a past of the observed increase in adenocarcinomas of the esophagus and gastric cardia and decrease in other gastric adenocarcinomas is real. ${ }^{16,19,20,22,23}$

As a result of the trends in incidence rates, the ratio of esophageal squamous cell carcinoma (ESCC) to esophageal adenocarcinoma (EAC) has changed in USA whites from $83 / 17$ in 1974 to $41 / 59$ in $1995 .{ }^{29}$ In contrast, in USA blacks the ratio remained stable at $97 / 3$ during this period. ${ }^{29}$ In the Netherlands this ratio changed from 55/45 to 34/66 between 1989 and 2003. ${ }^{6}$ Thus, in the USA and the Netherlands, EAC has become the most common histological type of esophageal cancer. Conversely, this was not observed in China, a high risk area of esophageal cancer, where ESCC accounted for nearly $100 \%$ of esophageal cancers, at least in the period $1988-2003 .^{30}$ The subsite distribution of gastric cancers has also changed over time as a consequence of the incidence trends. In the USA, the percentage GCA of all gastric tumors increased from $8 \%$ to $15 \%$ in black men and from $30 \%$ to $47 \%$ in white men between 1974 and $1995 .{ }^{29}$ In contrast, in the Netherlands this percentage remained stable around $25 \%$ between 1990 and $2007 .^{31}$ A relatively high percentage of GCA tumors is seen in China: in 1993 GCA cases accounted for $30 \%$ of gastric cancers, and this increased to $37 \%$ in $2004 .{ }^{32}$ Thus, the geographical differences in the percentage of GCA cases are less striking than the differences in the ratio of ESCC to EAC.

In the future, it remains important to keep monitoring trends in the incidence of esophageal and gastric cancer subtypes. High quality and detailed data are required for this monitoring. Interpretation of these trends should be done carefully by taking into account changes in diagnosis and registration of these cancers. A further aim is to 
explain the observed trends and to identify risk factors for these diseases. Primary prevention is specifically important given the poor prognosis, as well as identification of high-risk individuals and early detection (secondary prevention) of esophageal and gastric cancer.

\section{BARRETT'S ESOPHAGUS}

Barrett's esophagus (BE), also referred to as columnar lined esophagus, is a so-called precancerous lesion for esophageal adenocarcinoma. In persons with $\mathrm{BE}$, the normal multi-layer squamous epithelium of the esophagus is replaced by a single layer of columnar epithelium. When a patient is undergoing endoscopy of the esophagus, this metaplasia is visible. The columnar epithelium has a red color as opposed to the light pink color of the normal squamous epithelium (Figure 1.4). ${ }^{33} \mathrm{BE}$ is located in the lower third of the esophagus.

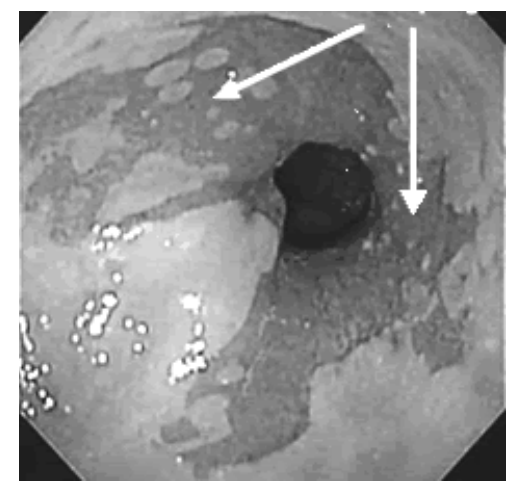

Figure 1.4 Endoscopic picture of Barrett's esophagus. Arrows indicate columnar epithelium. Source: ${ }^{39}$

\section{Definition and diagnosis of the disease}

The condition BE was named after Norman Barrett, a surgeon who described it in $1950 .^{34}$ The definition of $\mathrm{BE}$ has been debated and has changed over time. ${ }^{33,35}$ Currently there are two different accepted case definitions. The American College of Gastroenterology definition is as follows: "Barrett's esophagus is a change in the distal esophageal epithelium of any length that can be recognized as columnar type mucosa at endoscopy and is confirmed to have intestinal metaplasia by biopsy of the tubular esophagus." ${ }^{36}$ The British Society of Gastroenterology defines Barrett's esophagus as "an oesophagus in which any portion of the normal squamous lining has been replaced 
by a metaplastic columnar epithelium which is visible macroscopically. In order to make a positive diagnosis of "Barrett's oesophagus", a segment of columnar metaplasia of any length must be visible endoscopically above the oesophago-gastric junction and confirmed or corroborated histologically." ${ }^{37,38}$ Thus, in contrast to the American definition, the British definition does not require identification of specialized intestinal metaplasia. The British Society of Gastroenterology reasons that intestinal metaplasia can always be found, providing a sufficient number of biopsies is taken over an adequate time-scale. ${ }^{37}$

\section{Incidence rates}

After it was observed that the incidence of esophageal adenocarcinoma was rising in various countries, researchers hypothesized that this increase was preceded by a similar rise in the incidence of BE. Substantial increases in diagnosis of BE have indeed been described in Scotland, the USA, and the Netherlands. ${ }^{40-42}$

In the Netherlands, the world standardized incidences rates of BE increased from 12.7 to 18.4 per 100,000 men and from 6.5 to 8.6 per 100,000 women between 1992 and 2003. This increase is not explained by an increase in the number of biopsies taken, or by an increased proportion of $\mathrm{BE}$ patients that undergo endoscopy. Therefore, a real increase in the incidence of BE seems likely. ${ }^{42}$

\section{Progression and surveillance}

As mentioned earlier, BE is a precancerous lesion, or precursor lesion. For three decades, it has been known that patients diagnosed with $B E$ are at increased risk of esophageal adenocarcinoma. ${ }^{43}$ However, the exact size of this risk remains uncertain. The risk of progression has been estimated by several researchers and the reported risk estimates are highly variable, depending on the study population, selection of patients, and follow-up time. ${ }^{44}$ Large studies with complete follow-up that quantify this risk are requested. Another question that remains to be answered is whether patients with $B E$ are maybe also at increased risk of other cancers and other diseases.

The progression of BE can be identified pathologically. The successive steps are BE without dysplasia, low-grade dysplasia, high-grade dysplasia and finally adenocarcinoma (Figure 1.1). ${ }^{45}$

Studying BE is interesting and important, because it may yield new insights into the etiology of the disease, which is important for primary prevention. Ultimately, research should lead to the identification of persons at highest risk of developing esophageal adenocarcinoma. Through endoscopic surveillance of patients with BE, esophageal adenocarcinoma may be diagnosed in an earlier stage. This may lead to improved treatment options and prognosis. 


\section{RELEVANCE OF CANCER SUBTYPES AND PRECURSOR LESIONS}

So far, we described two indications for a different etiology of esophageal squamous cell carcinoma (ESCC) vs. esophageal adenocarcinoma (EAC), and gastric cardia adenocarcinoma (GCA) vs. gastric non-cardia adenocarcinoma (GNCA). These are the differences in trends in incidence rates and the differences in the geographical distribution of these cancer subtypes.

A third indication for a different etiology is the observed sex difference in the occurrence of these cancers. All subtypes of esophageal and gastric cancer occur more frequently in men than women, at least in most parts of the world. ${ }^{13}$ But more importantly, the ratio of the incidence in men to that in women, the male-to-female ratio, is much higher for EAC (between 6:1 and 8:1), ${ }^{46-48}$ compared with ESCC (between $2: 1$ and $3: 1){ }^{46,49}$ For $B E$, the male-to-female ratio is usually around $2: 1{ }^{50} \mathrm{~A}$ different male-to-female ratio is also observed for the gastric cancer subtypes. The ratio is between 3:1 and 5:1 for GCA, ${ }^{46,48,51,52}$ whereas it is around 2:1 for GNCA. ${ }^{18,51}$

Until recently, relatively little attention was directed towards differences between the histologic types of esophageal cancer and the majority of existing epidemiologic studies have not distinguished between the major histologic types of esophageal cancer. This also applies to the subsite division of gastric cancer.

$B E$ has started to receive more attention since a rise in incidence of EAC has been observed in several countries. BE is an interesting precursor lesion, because it is very well visible through endoscopy and can thus be monitored and studied relatively easily. It thus provides a good model for the investigation of cancer development. One thing we should keep in mind is that BE is only diagnosed if a person presents with reflux symptoms or if endoscopy is performed on different medical grounds and BE is found by chance. Thus, some cases of asymptomatic BE remain undetected. The estimates of the proportion of asymptomatic individuals that have BE vary widely: between 1 and $25 \%{ }^{53-55}$

Precancerous lesions have also been identified for $\mathrm{ESCC}^{56} \mathrm{GCA}^{57}$ and $\mathrm{GNCA}^{58}$ These are, however, not the focus of this thesis.

\section{RISK FACTORS FOR ESOPHAGEAL AND GASTRIC CANCERS AND BARRETT'S ESOPHAGUS}

\section{Demographic factors}

As with nearly all cancers, older age is a strong risk factor for esophageal and gastric cancers, ${ }^{13}$ as well as for $\mathrm{BE} .{ }^{59}$ As described above, men are at higher risk of all esophageal and gastric cancer subtypes and BE than women. In the USA, BE and EAC are more common among Caucasians, while ESCC is more common among blacks. ${ }^{13}$ 


\section{Medical factors}

Several medical conditions and medications have been associated with risk of BE and esophageal and gastric cancer. The most important risk factor for BE and EAC is gastroesophageal reflux disease (GERD), ${ }^{60}$ which is defined as chronic symptoms or mucosal damage produced by the abnormal reflux of gastric contents (including acid) into the esophagus. ${ }^{61}$ GERD may also increase risk of GCA, although probably less strongly than for $\mathrm{BE}$ and EAC. ${ }^{62}$ Gastro-esophageal reflux can be increased in the presence of a hiatal hernia, which means that the upper part of the stomach protrudes into the chest cavity through a hole in the diafragm. ${ }^{13}$ Not only reflux of acid can increase risk of esophageal cancer: ingestion of caustic substances, particularly lye, very strongly increase the risk of ESCC. ${ }^{63}$

ESCC risk is also higher in subjects with achalasia and tylosis. Achalasia is an esophageal motility disorder involving the smooth muscle layer of the esophagus and the lower esophageal sphincter (LES). Patients with achalasia have difficulty swallowing and suffer from regurgitation. ${ }^{63}$ Tylosis is a rare disease associated with hyperkeratosis of the palms of the hands and soles of the feet. The inherited type of tylosis (Howell-Evans syndrome) has been most strongly linked to ESCC. ${ }^{63}$

There is also evidence for a relationship between some medications and risk of $\mathrm{BE}$ or esophageal or gastric cancer. Medications that relax the LES may contribute to increased risk of BE and EAC via increased chance of gastro-esophageal reflux. These medications include the commonly used nitroglycerin, aminophyllines, beta-adrenergic agonists, anticholinergics and benzodiazepines. ${ }^{64,65}$ Nonsteroidal anti-inflammatory drugs (NSAIDs) on the other hand, may be preventive for EAC and maybe also for ESCC and GNCA, ${ }^{13,66-68}$ possibly because they stimulate apoptosis and inhibit angiogenesis. ${ }^{66}$

Infection with Helicobacter (H.) pylori has been identified as the strongest risk factor for gastric cancer. ${ }^{13}$ However, this is probably only true for GNCA. In contrast, $\mathrm{H}$. pylori appears to protect against EAC and GCA. ${ }^{13,47}$ Infection with Epstein-Barr virus has also been suggested to play a role in some gastric tumors. ${ }^{13}$ Other medical conditions that have been suggested to increase risk of gastric cancer include pernicious anemia, peptic ulcer disease, and prior gastric surgery. ${ }^{52}$ Further, persons with a family history of gastric cancer have been observed to have an increased risk to develop gastric cancer. $^{13}$

\section{Lifestyle and dietary habits}

Several aspects of lifestyle have been studied in relation to risk of developing esophageal and gastric cancer. Most studies have not separately studied the cancer subtypes. Very little information is available on possible relationships between lifestyle and diet and the risk to develop BE.

Smoking and alcohol consumption have been studied most, and have been found to increase risk of ESCC. Smoking is also associated with EAC and gastric cancers, but probably less strongly. The association between alcohol consumption and risk of EAC 
and gastric cancers is not entirely clear yet. ${ }^{13}$ Further, being overweight may increase a person's risk of EAC and GCA. ${ }^{13,69}$

Higher incidence rates of ESCC and gastric cancer have been observed among the lower socioeconomic groups. This observation may be explained partly by risk factors strongly associated with low socioeconomic status (SES), such as infection with $\mathrm{H}$. pylori and smoking. On the other hand, the association with SES may also reflect yet unrecognized exposures, as the association between SES and ESCC risk remained after adjustment for known risk factors. ${ }^{13}$

Vegetables, fruits, and some vitamins and carotenoids may decrease risk of esophageal and gastric cancer. Foods containing dietary fiber may decrease risk of esophageal cancer. On the other hand, there is some indication for a positive association between processed meat and esophageal and gastric cancer. Esophageal cancer risk may also be increased by eating red meat and drinking maté and very hot drinks. Salt, salted foods, chili, smoked foods, and grilled or barbecued animal food may increase gastric cancer risk. ${ }^{69}$

\section{RATIONALE AND AIM OF THIS THESIS}

As explained in the previous paragraphs, there has been little epidemiologic research into the risk factors for subtypes of esophageal and gastric cancer. The data on BE is even more limited. Very few studies have looked into the etiology of this condition. Besides, most evidence on BE and esophageal and gastric cancer subtypes to date comes from cross-sectional and case-control studies. These study designs are susceptible to methodological limitations. The prospective cohort study design is less susceptible to biases and therefore generally has a higher validity. The research described in this thesis is carried out within a prospective cohort study: the Netherlands Cohort Study on diet and cancer (NLCS).

Our study could make an important contribution to the epidemiological body of evidence on the development of BE and the subtypes of esophageal and gastric cancer. The cancers of main interest in this thesis are ESCC, EAC, and GCA. GNCA will be described only for comparison with these cancers. The main focus of this thesis is on the role of lifestyle and nutritional factors in the etiology of these diseases. These factors can potentially be modified and can thus have a role in primary prevention.

Additionally, we will use the data of the NLCS to follow-up BE patients for occurrence of EAC, other cancers and cause-specific mortality, as we indicated that data are lacking on these topics. The large size and complete follow-up make the NLCS suitable for these analyses.

Finally, we will also study changes in the incidence of esophageal and gastric cancers in time, because of the need to keep monitoring trends for above-mentioned reasons. We will do this with data from European countries, and examine whether there are differences in trends between countries. 


\section{STUDY DESIGN}

The research described in this thesis is based on a prospective cohort study: the Netherlands Cohort Study on diet and cancer (NLCS). The NLCS was initiated in September $1986 .{ }^{70}$ A total of 120,852 men and women aged 55-69 years participated in this study. These subjects were randomly selected from Dutch municipal population registries. At baseline, all subjects filled out a questionnaire on dietary habits, lifestyle, and other risk factors for cancer. According to the case-cohort approach, ${ }^{71}$ data are processed and analyzed for a random sample of the cohort (the subcohort) and cases. The subcohort consists of 5,000 men and women who were sampled at baseline. This subcohort is followed-up for vital status and migration and is used to estimate the person-time at risk for the total cohort. Incident cases of BE and cancer were identified in the whole cohort. The identification of BE cases took place through linkage with data from PALGA (the nationwide registry for histopathology and cytopathology in the Netherlands). The existence of this unique nationwide pathology registry offered us the opportunity to study BE within a prospective cohort study. A pathologist reviewed and coded further details and characteristics of the BE cases from the PALGA data. The cohort was also followed-up for cancer incidence, and this was done through linkage with PALGA and the Netherlands Cancer Registry. ${ }^{72}$ Further, the cohort has been followed-up for vital status through record linkage with the Central Bureau of Genealogy and automated municipal population registries. For deceased cohort members we also obtained information on the cause of death from Statistics Netherlands.

The research described in this thesis was based on 16.3-year follow-up data of the cohort (September 17, 1986 through December 31, 2002).

\section{OUTLINE OF THE THESIS}

This thesis begins with two studies on the etiology of BE. Chapter 2 describes the associations between the lifestyle factors overweight, smoking, and alcohol consumption and the risk to develop BE. Our study on selenium status and its relationship with risk of $\mathrm{BE}$ is presented in chapter 3 . Chapter 4 focuses on the question whether cancer incidence and total and cause-specific mortality are increased in patients with BE. Trends in the incidence of esophageal and gastric cancer subtypes in European countries are investigated in chapter 5 . The next three chapters are about several possible risk factors of esophageal and gastric cancer subtypes: alcohol consumption and cigarette smoking (chapter 6); selenium status (chapter 7), and vegetables and fruits consumption (chapter 8). Finally, chapter 9 concludes the thesis with a discussion of the main findings and some methodological aspects. 


\section{REFERENCES}

1. Ferlay J, Shin HR, Bray F, Forman D, Mathers C, Parkin DM. Estimates of worldwide burden of cancer in 2008: GLOBOCAN 2008. Int J Cancer 2010.

2. http://www.cbs.nl/en-GB/menu/themas/gezondheid-

welzijn/publicaties/artikelen/archief/2009/2009-2687-wm.htm?Languageswitch=on (accessed on June 22, 2010).

3. http://statline.cbs.nl/StatWeb/publication/?DM=SLEN\&PA=7052ENG\&D1=7-8\&D2=0\&D3=a\&D4= I\&LA=EN\&HDR=G3,G1,G2\&STB=T\&VW=T (accessed on June 22, 2010).

4. Boyle P, Levin B. World Cancer Report. Lyon, 2008.

5. Curado MP, Edwards B, Shin HR, Storm H, Ferlay J, Heanue M, Boyle P. Cancer incidence in five continents. Volume IX. Lyon: IARC Scientific publications no. 160, 2007.

6. www.ikcnet.nl (accessed August 08, 2010).

7. http://globocan.iarc.fr (accessed June 23, 2010).

8. Enzinger PC, Mayer RJ. Esophageal cancer. N Engl J Med 2003;349:2241-2252.

9. Wanebo HJ, Kennedy BJ, Chmiel J, Steele G, Jr., Winchester D, Osteen R. Cancer of the stomach. A patient care study by the American College of Surgeons. Ann Surg 1993;218:583-592.

10. Bird-Lieberman EL, Fitzgerald RC. Early diagnosis of oesophageal cancer. Br J Cancer 2009;101:1-6.

11. Berrino F, De Angelis R, Sant M, Rosso S, Bielska-Lasota M, Coebergh JW, Santaquilani M. Survival for eight major cancers and all cancers combined for European adults diagnosed in 1995-99: results of the EUROCARE-4 study. Lancet Oncol 2007;8:773-783.

12. http://apps.who.int/classifications/apps/icd/icd10online/index.htm?gc15.htm+ (accessed July 30, 2010).

13. Schottenfeld D, Fraumeni JF, Jr. Cancer epidemiology and prevention. Oxford University Press, 2006.

14. Howson CP, Hiyama T, Wynder EL. The decline in gastric cancer: epidemiology of an unplanned triumph. Epidemiol Rev 1986;8:1-27.

15. Levi F, La Vecchia C, Te VC. Descriptive epidemiology of adenocarcinomas of the cardia and distal stomach in the Swiss Canton of Vaud. Tumori 1990;76:167-171.

16. Blot WJ, Devesa SS, Kneller RW, Fraumeni JF, Jr. Rising incidence of adenocarcinoma of the esophagus and gastric cardia. Jama 1991;265:1287-1289.

17. Powell J, McConkey CC. The rising trend in oesophageal adenocarcinoma and gastric cardia. Eur J Cancer Prev 1992;1:265-269.

18. Moller $\mathrm{H}$. Incidence of cancer of oesophagus, cardia and stomach in Denmark. Eur J Cancer Prev 1992;1:159-164.

19. Hansson LE, Sparen P, Nyren O. Increasing incidence of carcinoma of the gastric cardia in Sweden from 1970 to 1985 . Br J Surg 1993;80:374-377.

20. Hesketh PJ, Clapp RW, Doos WG, Spechler SJ. The increasing frequency of adenocarcinoma of the esophagus. Cancer 1989;64:526-530.

21. Blot WJ, Devesa SS, Fraumeni JF, Jr. Continuing climb in rates of esophageal adenocarcinoma: an update. Jama 1993;270:1320.

22. Zheng T, Mayne ST, Holford TR, Boyle P, Liu W, Chen Y, Mador M, Flannery J. Time trend and ageperiod-cohort effects on incidence of esophageal cancer in Connecticut, 1935-89. Cancer Causes Control 1992;3:481-492.

23. Harrison SL, Goldacre MJ, Seagroatt V. Trends in registered incidence of oesophageal and stomach cancer in the Oxford region, 1974-88. Eur J Cancer Prev 1992;1:271-274.

24. Waterhouse J, Muir C, Shanmugaratnam K, Powell J. Cancer incidence in five continents. Volume IV. Lyon: IARC Scientific publication no. 42, 1982.

25. Muir C, Waterhouse J, Mack T, Powell J, Whelan S. Cancer incidence in five continents. Volume V. Lyon: IARC Scientific publication no. 88, 1987.

26. Ferlay J, Muir CS, Whelan SL, Gao Y-T. Cancer incidence in five continents. Volume VI. Lyon: IARC Scientific publications no. 120, 1992.

27. Parkin DM, Whelan SL, Ferlay J, Raymond L, Young J. Cancer incidence in five continents. Volume VII. Lyon: IARC Scientific publications no. 143, 1997. 
28. Parkin DM, Whelan SL, Ferlay J, Teppo L, Thomas DB. Cancer incidence in five continents. Volume VIII. Lyon: IARC Scientific publications no. 155, 2002.

29. Devesa SS, Blot WJ, Fraumeni JF, Jr. Changing patterns in the incidence of esophageal and gastric carcinoma in the United States. Cancer 1998;83:2049-2053.

30. He YT, Hou J, Chen ZF, Qiao CY, Song GH, Meng FS, Jin HX, Chen C. Trends in incidence of esophageal and gastric cardia cancer in high-risk areas in China. Eur J Cancer Prev 2008;17:71-76.

31. Dassen AE, Lemmens VE, van de Poll-Franse LV, Creemers GJ, Brenninkmeijer SJ, Lips DJ, Vd Wurff AA, Bosscha K, Coebergh JW. Trends in incidence, treatment and survival of gastric adenocarcinoma between 1990 and 2007: a population-based study in the Netherlands. Eur J Cancer 2010;46:11011110 .

32. Zhou Y, Zhang Z, Zhang Z, Wu J, Ren D, Yan X, Wang Q, Wang Y, Wang H, Zhang J, Zhu X, Yang Y, Luo C, Guo X, Tang C, Qiao L. A rising trend of gastric cardia cancer in Gansu Province of China. Cancer Lett 2008;269:18-25.

33. Spechler SJ. Clinical practice. Barrett's Esophagus. N Engl J Med 2002;346:836-842.

34. Barrett NR. Chronic peptic ulcer of the oesophagus and 'oesophagitis'. Br J Surg 1950;38:175-182.

35. Cameron AJ. The history of Barrett esophagus. Mayo Clin Proc 2001;76:94-96.

36. Wang KK, Sampliner RE. Updated guidelines 2008 for the diagnosis, surveillance and therapy of Barrett's esophagus. Am J Gastroenterol 2008;103:788-797.

37. Watson A, Shepherd NA. The definition of "Barrett's" columnar-lined esophagus. British Society of Gastroenterology. Guidelines for the diagnosis and management of Barrett's columnar-lined esophagus. Loughborough: Q3 print, 2005:4-6.

38. Playford RJ. New British Society of Gastroenterology (BSG) guidelines for the diagnosis and management of Barrett's oesophagus. Gut 2006;55:442-443.

39. http://www.amc.edu/patient/services/BARRX/barretts_esophagus_definition.html (accessed June 24, 2010).

40. Prach AT, MacDonald TA, Hopwood DA, Johnston DA. Increasing incidence of Barrett's oesophagus: education, enthusiasm, or epidemiology? Lancet 1997;350:933.

41. Conio M, Cameron AJ, Romero Y, Branch CD, Schleck CD, Burgart LJ, Zinsmeister AR, Melton $L$, 3rd, Locke GR, 3rd. Secular trends in the epidemiology and outcome of Barrett's oesophagus in Olmsted County, Minnesota. Gut 2001;48:304-309.

42. Post PN, Siersema PD, van Dekken H. Rising incidence of clinically evident Barrett's oesophagus in The Netherlands: a nation-wide registry of pathology reports. Scand J Gastroenterol 2007;42:17-22.

43. Naef AP, Savary M, Ozzello L. Columnar-lined lower esophagus: an acquired lesion with malignant predisposition. Report on 140 cases of Barrett's esophagus with 12 adenocarcinomas. J Thorac Cardiovasc Surg 1975;70:826-835.

44. Yousef F, Cardwell C, Cantwell MM, Galway K, Johnston BT, Murray L. The incidence of esophageal cancer and high-grade dysplasia in Barrett's esophagus: a systematic review and meta-analysis. Am J Epidemiol 2008;168:237-249.

45. Flejou JF. Barrett's oesophagus: from metaplasia to dysplasia and cancer. Gut 2005;54 Suppl 1:i6-12.

46. van Blankenstein $M$, Looman CW, Hop WC, Bytzer P. The incidence of adenocarcinoma and squamous cell carcinoma of the esophagus: Barrett's esophagus makes a difference. Am J Gastroenterol 2005;100:766-774.

47. Lagergren J. Adenocarcinoma of oesophagus: what exactly is the size of the problem and who is at risk? Gut 2005;54 Suppl 1:i1-5.

48. El-Serag HB, Mason AC, Petersen N, Key CR. Epidemiological differences between adenocarcinoma of the oesophagus and adenocarcinoma of the gastric cardia in the USA. Gut 2002;50:368-372.

49. Cook MB, Chow WH, Devesa SS. Oesophageal cancer incidence in the United States by race, sex, and histologic type, 1977-2005. Br J Cancer 2009;101:855-859.

50. Cook MB, Wild CP, Forman D. A systematic review and meta-analysis of the sex ratio for Barrett's esophagus, erosive reflux disease, and nonerosive reflux disease. Am J Epidemiol 2005;162:1050-1061.

51. Wu H, Rusiecki JA, Zhu K, Potter J, Devesa SS. Stomach carcinoma incidence patterns in the United States by histologic type and anatomic site. Cancer Epidemiol Biomarkers Prev 2009;18:1945-1952.

52. Forman D, Burley VJ. Gastric cancer: global pattern of the disease and an overview of environmental risk factors. Best Pract Res Clin Gastroenterol 2006;20:633-649. 
53. Ward EM, Wolfsen HC, Achem SR, Loeb DS, Krishna M, Hemminger LL, DeVault KR. Barrett's esophagus is common in older men and women undergoing screening colonoscopy regardless of reflux symptoms. Am J Gastroenterol 2006;101:12-17.

54. Gerson LB, Shetler K, Triadafilopoulos G. Prevalence of Barrett's esophagus in asymptomatic individuals. Gastroenterology 2002;123:461-467.

55. Fan X, Snyder N. Prevalence of Barrett's esophagus in patients with or without GERD symptoms: role of race, age, and gender. Dig Dis Sci 2009;54:572-577.

56. Wang GQ, Abnet CC, Shen Q, Lewin KJ, Sun XD, Roth MJ, Qiao YL, Mark SD, Dong ZW, Taylor PR, Dawsey SM. Histological precursors of oesophageal squamous cell carcinoma: results from a 13 year prospective follow up study in a high risk population. Gut 2005;54:187-192.

57. El-Serag HB, Sonnenberg A, Jamal MM, Kunkel D, Crooks L, Feddersen RM. Characteristics of intestinal metaplasia in the gastric cardia. Am J Gastroenterol 1999;94:622-627.

58. Correa P. A human model of gastric carcinogenesis. Cancer Res 1988;48:3554-3560.

59. Wong A, Fitzgerald RC. Epidemiologic risk factors for Barrett's esophagus and associated adenocarcinoma. Clin Gastroenterol Hepatol 2005;3:1-10.

60. Shaheen N, Ransohoff DF. Gastroesophageal reflux, barrett esophagus, and esophageal cancer: scientific review. Jama 2002;287:1972-1981.

61. DeVault KR, Castell DO. Updated guidelines for the diagnosis and treatment of gastroesophageal reflux disease. Am J Gastroenterol 2005;100:190-200.

62. Lagergren J, Bergstrom R, Lindgren A, Nyren O. Symptomatic gastroesophageal reflux as a risk factor for esophageal adenocarcinoma. N Engl J Med 1999;340:825-831.

63. http://www.uptodateonline.com/online/content/search.do (accessed June 26, 2010).

64. Lagergren J, Bergstrom R, Adami HO, Nyren O. Association between medications that relax the lower esophageal sphincter and risk for esophageal adenocarcinoma. Ann Intern Med 2000;133:165-175.

65. WHO Collaborating Centre for Drug Statistics Methodology. http://www.whocc.no/atcddd/ welcome.html (accessed 15 Oct, 2009).

66. Epplein M, Nomura AM, Wilkens LR, Henderson BE, Kolonel LN. Nonsteroidal Antiinflammatory Drugs and Risk of Gastric Adenocarcinoma: The Multiethnic Cohort Study. Am J Epidemiol 2009.

67. Sadeghi S, Bain CJ, Pandeya N, Webb PM, Green AC, Whiteman DC. Aspirin, nonsteroidal antiinflammatory drugs, and the risks of cancers of the esophagus. Cancer Epidemiol Biomarkers Prev 2008;17:1169-1178.

68. Duan L, Wu AH, Sullivan-Halley J, Bernstein L. Nonsteroidal Anti-inflammatory Drugs and Risk of Esophageal and Gastric Adenocarcinomas in Los Angeles County. Cancer Epidemiol Biomarkers Prev 2008;17:126-134.

69. World Cancer Research Fund, American Institute for Cancer Research. Food, nutrition, physical activity and the prevention of cancer: a global perspective. AICR, 2007.

70. van den Brandt PA, Goldbohm RA, van 't Veer P, Volovics A, Hermus RJ, Sturmans F. A large-scale prospective cohort study on diet and cancer in The Netherlands. J Clin Epidemiol 1990;43:285-295.

71. Barlow WE, Ichikawa L, Rosner D, Izumi S. Analysis of case-cohort designs. J Clin Epidemiol 1999;52:1165-1172.

72. van den Brandt PA, Schouten LJ, Goldbohm RA, Dorant E, Hunen PM. Development of a record linkage protocol for use in the Dutch Cancer Registry for Epidemiological Research. Int J Epidemiol 1990;19:553-558. 


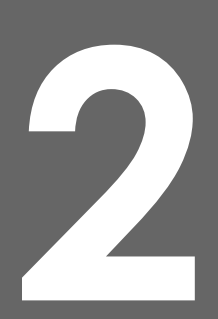

\section{A prospective cohort study on overweight, smoking, alcohol consumption, and risk of Barrett's esophagus}

Jessie Steevens Leo J Schouten Ann LC Driessen Clément JR Huysentruyt Yolande CA Keulemans R Alexandra Goldbohm Piet A van den Brandt 


\section{ABSTRACT}

\section{Background}

Barrett's esophagus (BE) is a precursor lesion of esophageal adenocarcinoma. Besides gastroesophageal reflux, possible risk factors for $B E$ include overweight, cigarette smoking, and alcohol consumption. Our objective was to study these associations using prospective data.

\section{Methods}

The prospective Netherlands Cohort Study, initiated in 1986, consists of 120,852 men and women, aged 55-69 years at baseline. At baseline, all subjects completed a questionnaire on dietary habits and lifestyle. After 16.3 years of follow-up, $370 \mathrm{BE}$ cases with specialized intestinal metaplasia and 3866 subcohort members were available for case-cohort analysis. Cox proportional hazards models were used to calculate incidence rate ratios (RR) and $95 \%$ confidence intervals $(\mathrm{CI})$.

\section{Results}

Body mass index at baseline was associated with risk of $B E$ in women [multivariable adjusted RR per $1 \mathrm{~kg} / \mathrm{m}^{2}, 1.07(1.03-1.11)$ ] but not in men [RR per $1 \mathrm{~kg} / \mathrm{m}^{2}, 0.99$ (0.93-1.05)]. The association in women was not specifically due to abdominal overweight. Former cigarette smokers were at increased risk of $B E(R R=1.33,95 \% \mathrm{Cl}$ 1.00-1.77), but current smokers were not. Smoking duration showed a positive association with BE risk ( $p$ trend=0.03). For alcohol consumption, the RR per 10 grams ethanol/day was 0.95 (0.87-1.03).

\section{Conclusions}

Increased body mass index was a risk factor for BE in women, but not in men. Several aspects of cigarette smoking were positively associated with BE risk. Alcohol consumption was not associated with an increased risk of BE.

\section{Impact}

Future research should focus on risk factors for development as well as for progression of $B E$ to esophageal adenocarcinoma. 


\section{INTRODUCTION}

Barrett's esophagus (BE) is a condition of the distal esophagus characterized by a replacement of the normal stratified squamous epithelium with a single layer of columnar epithelium. Histological confirmation based on biopsies is required for diagnosis. According to the USA definition of BE the presence of goblet cells, indicating specialized intestinal metaplasia (SIM), is required. ${ }^{1}$ The UK definition is less stringent: the presence of any type of metaplasia is sufficient for a diagnosis of BE. ${ }^{2}$ Both the USA and UK definitions may have been used in the Netherlands.

$\mathrm{BE}$ is primarily of interest because it is associated with an increased risk of esophageal adenocarcinoma, a cancer with high mortality. The estimates of this risk of esophageal adenocarcinoma vary between 4.1 and 6.1 per 1000 person-years. ${ }^{3}$

The most recognized and strong risk factor for $\mathrm{BE}$ is chronic gastroesophageal reflux. ${ }^{4}$ Additionally, overweight, cigarette smoking, and alcohol consumption might be associated with risk of $\mathrm{BE}$. These factors are interesting as they are potentially modifiable. However, the body of evidence on the role of these factors in the etiology of $B E$ is sparse. Especially data from prospective cohort studies is lacking.

The possible role of overweight in the etiology of BE has been investigated in several epidemiological studies. Null associations ${ }^{5,6}$ as well as positive associations ${ }^{7-9}$ have been found in case-control studies. The only prospective cohort study, which was conducted among women, reported a positive association. ${ }^{10}$ The relationship between cigarette smoking and risk of BE has been studied in some case-control studies, ${ }^{6,8,11,12}$ while no cohort studies have reported on this relationship. Some observed a positive association, $^{6,8}$ while other studies did not observe an association. ${ }^{5,12}$ Alcohol consumption and its possible relationship with BE has been studied in a few casecontrol studies. Null-associations with alcohol have been observed, ${ }^{11,13}$ and one study ${ }^{14}$ found alcohol to be a risk factor. Inverse associations have been reported for wine consumption. $^{11,13}$

The aim of this study was to investigate the associations between overweight, smoking, and alcohol consumption and risk of BE, within the prospective Netherlands Cohort Study (NLCS) on diet and cancer.

\section{METHODS}

\section{Study design and subjects}

The NLCS was started in September 1986. Cohort members were selected at random from 204 Dutch municipal registries, and 58279 men and 63573 women aged 55-69 were enrolled in the study. All members of the cohort completed a self-administered questionnaire. A detailed study design has previously been published. ${ }^{15}$ 
For efficiency, we used a case-cohort approach ${ }^{16}$ for data processing and analysis. Cases were derived from the entire cohort, while the number of person-years at risk in the entire cohort was estimated from a subcohort of 5000 subjects. This subcohort was selected at random from the full cohort at baseline.

The subcohort was followed-up for vital status, first actively by biennially contacting the subcohort members, and later by linkage to the Dutch municipal population registries. After 16.3 years (September 1986 to December 2002), only one male subcohort member was lost to follow-up. We excluded subcohort members who reported having prevalent BE or cancer (other than skin cancer) $(n=230)$ at baseline (Figure 2.1).

The Medical Ethics Committee of Maastricht University, the Netherlands, has approved the study.

\section{Follow-up}

Incident BE cases in the total cohort were detected by computerized record linkage to the nationwide network and registry of histopathology and cytopathology in the Netherlands (PALGA). ${ }^{17}$ This network was founded in 1971, and an increasing number of laboratories joined PALGA such that it covered all 204 municipalities from which the cohort members were sampled since 1991. At each of the 64 pathology laboratories in the Netherlands, summaries of all pathology reports are generated automatically. Each summary contains a so-called PALGA diagnosis that describes topography, morphology, function, procedure, and disease. These excerpts are transferred to a central databank. ${ }^{17}$ The linkage with PALGA was carried out for 16.3 years of follow-up.

Subsequently, one pathologist (A.D.) and one pathologist in training (C.H.), who were blinded to the exposure status of the cases, reviewed the excerpts of all pathology records. Excluded were cases with an uncertain diagnosis of $B E(n=106)$ and cases that had prevalent cancer or BE at baseline $(n=76)$. Additionally, we excluded cases with a diagnosis of esophageal or gastric cancer before or less than a half year after the diagnosis of $B E(n=58)$, and cases with a diagnosis specifying the presence of only non-intestinal type metaplasia ( $n=108$ ) (Figure 2.1).

Two definitions of BE were used: our primary case definition included only subjects with esophageal SIM $(n=456)$. The secondary case definition included subjects (a) fulfilling the primary case definition or (b) with a pathology report stating 'Barrett's', without a description of the type of metaplasia (total $n=626$ ).

\section{Exposure data}

All cohort members completed a self-administered questionnaire at baseline. This questionnaire contained a 150-item food frequency questionnaire (FFQ), including detailed questions on alcohol consumption, and questions on various other cancer risk factors. 
Overweight was measured by several variables: BMI at baseline, BMI at age 20 years, BMI change, and pant/skirt size (as a proxy for waist circumference ${ }^{18}$ ). BMI at baseline and $\mathrm{BMI}$ at age 20 years were calculated using weight at baseline and weight at age 20 years, respectively, divided by height at baseline squared $\left(\mathrm{kg} / \mathrm{m}^{2}\right)$. Subjects with missing values for BMI at baseline were excluded from all analyses. Subjects with a BMI under 18.5 were excluded, because there were no cases in this category. BMI change since age 20 years was calculated as BMI at baseline minus BMI at age 20 years. Recently, the use of self-reported pant/skirt size as a proxy measure for waist circumference was validated in the NLCS. ${ }^{18}$

Questions were asked about the following aspects of cigarette smoking: whether the subject was a smoker at baseline, age at smoking initiation, age at smoking cessation, the number of cigarettes smoked daily and the number of smoking years (excluding stopping periods). Based on these questions, the following variables were constructed: smoking status (never/former/current), current smoking (yes/no), frequency ( $n$ cigarettes/day), duration ( $n$ years), pack-years of cigarette smoking $(n)$ and time since cessation (years).

The habitual consumption of alcohol during the year preceding the start of the study was measured by six items in the questionnaire: (a) beer, (b) red wine, (c) white wine, (d) sherry and other fortified wines, (e) liquor types containing on average $16 \%$ alcohol and (f) (Dutch) gin, brandy and whiskey. Questions were asked about the frequency of consumption and the number of glasses consumed on each drinking occasion. For analysis, we combined (b), (c) and (d) into 'wine', and (e) and (f) into 'liquor'. Mean daily alcohol consumption was calculated using the Dutch foodcomposition table. ${ }^{19}$ For 'beer' and 'other alcoholic beverages', participants could indicate whether five years ago, they drunk (a) more than, (b) equal amounts of or (c) less than today. The fourth answering option was (d) 'I never use this'. Using these questions, we selected participants with a stable alcohol consumption to perform a sensitivity analysis.

The FFQ has been validated against a 9-day diet record, and the Spearman correlation coefficient between the alcohol intake assessed by the questionnaire and that estimated by the diet record was 0.89 for all subjects and 0.85 for users of alcoholic beverages. ${ }^{20}$ The reproducibility of the FFQ was established and the testretest correlation was 0.90 for alcohol intake, and this correlation declined only 0.01 0.02 per year. $^{21}$ This indicates that the single FFQ measurement was able to rank subjects according to alcohol intake and this ability dropped only slightly over time. The single FFQ measurement that is used in our cohort study can characterize dietary habits for a period of at least 5 years. ${ }^{21}$

Questionnaire data were key-entered and processed in a standardized manner, blinded with respect to case/subcohort status in order to minimize observer bias in coding and data interpretation. 


\begin{tabular}{|c|c|c|}
\hline \multicolumn{3}{|c|}{ Netherlands Cohort Study on diet and cancer (58 279 men and 62573 women) } \\
\hline$\downarrow$ & \multicolumn{2}{|c|}{$\downarrow$} \\
\hline $\begin{array}{l}\text { Subcohort randomly drawn } \\
\text { from total cohort }\end{array}$ & \multicolumn{2}{|c|}{ Record linkage with PALGA until 31-12-2002 } \\
\hline \multirow[t]{3}{*}{$\downarrow$} & \multicolumn{2}{|c|}{$\begin{array}{c}\downarrow \\
1954 \text { reports from } 974 \text { cases }\end{array}$} \\
\hline & \multicolumn{2}{|c|}{ Review by pathologist: exclusion of uncertain diagnoses } \\
\hline & \multicolumn{2}{|c|}{$\downarrow$} \\
\hline \multicolumn{3}{|c|}{ Exclusion of prevalent cancer and BE cases at baseline } \\
\hline \multirow[t]{2}{*}{$\downarrow$} & \multicolumn{2}{|c|}{$\begin{array}{c}\downarrow \\
792 \text { cases }\end{array}$} \\
\hline & \multicolumn{2}{|c|}{$\begin{array}{l}\text { Exclusion of cases with esophageal or gastric cancer before or }<1 / 2 \text { year } \\
\text { after Barrett's diagnosis, and cases with only non-intestinal metaplasia }\end{array}$} \\
\hline $\begin{array}{l}4770 \\
\text { Subcohort members }\end{array}$ & $\begin{array}{c}\downarrow \\
456 \text { Barrett's esophagus cases } \\
\text { with SIM }\end{array}$ & $\begin{array}{c}\downarrow \\
626 \text { Barrett's esophagus cases with } \\
\text { SIM or unknown metaplasia }\end{array}$ \\
\hline \multicolumn{3}{|c|}{ Exclusion if incomplete or inconsistent dietary data } \\
\hline $\begin{array}{c}\downarrow \\
4434\end{array}$ & $\begin{array}{c}\downarrow \\
425\end{array}$ & $\begin{array}{c}\downarrow \\
582\end{array}$ \\
\hline \multicolumn{3}{|c|}{ Exclusion of first two years of follow-up } \\
\hline $\begin{array}{c}\downarrow \\
4348\end{array}$ & $\begin{array}{c}\downarrow \\
415\end{array}$ & $\begin{array}{c}\downarrow \\
565\end{array}$ \\
\hline \multicolumn{3}{|c|}{ Exclusion if missing data on confounders } \\
\hline $\begin{array}{c}\downarrow \\
3866\end{array}$ & $\begin{array}{c}\downarrow \\
370\end{array}$ & $\begin{array}{c}\downarrow \\
500\end{array}$ \\
\hline
\end{tabular}

Figure 2.1 Flow diagram of subcohort members and Barrett's esophagus cases on whom the analyses were based. PALGA, nationwide network and registry of histo- and cytopathology in the Netherlands; SIM, specialized intestinal metaplasia.

\section{Statistical analysis}

To evaluate the potential influence of prediagnostic $B E$ at baseline on smoking and alcohol consumption habits and BMI, BE cases were categorized according to the year of follow-up in which they were diagnosed. A t-test was used to compare the differences in mean levels of these exposures between early (0-2 y) and late (2-16.3 y) follow-up. For the t-test, the exposures were In (natural logarithm) transformed to normalize the distributions. The average daily alcohol consumption among early cases ( $2.8 \mathrm{~g}$ ethanol) was statistically significantly lower when compared with late cases (10.2 $\mathrm{g}$ ethanol, figures for cases with SIM). Therefore, we decided to exclude these early cases from all analyses, to prevent bias. Additionally, subcohort members and cases with inconsistent or incomplete dietary questionnaire data ${ }^{20}$ and those with missing data on the confounders were excluded. Complete data were available for 3866 subcohort members, $370 \mathrm{BE}$ cases fulfilling the primary case definition, and $500 \mathrm{BE}$ cases fulfilling the secondary case definition (Figure 2.1). 
The multivariable regression models included the following variables: age, sex, BMI $\left(\mathrm{kg} / \mathrm{m}^{2}\right)$, cigarette smoking (current, frequency and duration), and alcohol consumption (g/day). Exact model specifications can be found in the table footnotes. The following variables were potential confounders, but were not included in the models because they did not change the incidence rate ratio (RR) by $>5 \%$ : highest level of education, family history of esophageal or gastric cancer, reported long-term (>0.5 y) use of nonsteroidal anti-inflammatory drugs (NSAIDs) or aspirin, or lower esophageal sphincter relaxing medication, ${ }^{22,23}$ non-occupational physical activity, daily intakes of vegetables and fruit.

Multivariable adjusted incidence rate ratios (RR) and corresponding 95\% confidence intervals $(\mathrm{Cl})$ were estimated using Cox proportional hazards models. ${ }^{24}$ The Stata 9.2 statistical software package (StataCorp, College Station, Texas, USA) was used for analysis. Standard errors were estimated using the robust Huber-White sandwich estimator to account for additional variance introduced by sampling from the cohort. This method is equivalent to the variance-covariance estimator by Barlow. ${ }^{25}$ We tested the proportional hazards assumption using the scaled Schoenfeld residuals. ${ }^{26}$ Tests for dose-response trends were assessed by fitting ordinal exposure variables as continuous terms. Two-sided $\mathrm{p}$ values are reported throughout the article. Interaction with sex was assessed by including a cross-product term in the model. If the interaction was statistically significant, we only presented results stratified by sex.

\section{RESULTS}

\section{Characteristics}

With respect to the characteristics mentioned in Table 2.1, there were no important differences between the BE cases fulfilling the primary and secondary case definitions. The most marked differences between subcohort members and cases are the following. Cases were more likely to be men and former smokers than subcohort members, while cases had a slightly lower ethanol intake. The BMI at baseline and the change in BMI from age 20 were somewhat higher among cases than among the subcohort. Furthermore, cases were somewhat less physically active and consumed somewhat less fruit and vegetables than the subcohort. NSAIDs and aspirin, and lower esophageal sphincter relaxing medication were more likely used by cases than subcohort members.

\section{Cox regression results}

All results from Cox regression analyses were very similar for BE cases defined by primary and secondary case definitions. We therefore only showed the results based on the BE cases that met the primary case definition. Likewise, only multivariable 
adjusted results are shown, as these were very similar to the age-adjusted results (see Supplemental Tables 2.1, 2.2, 2.3).

Table 2.1 Characteristics of cases and subcohort members in the Netherlands Cohort Study (1986-2002).

\begin{tabular}{|c|c|c|c|}
\hline \multirow[t]{3}{*}{ Characteristic } & \multirow{3}{*}{$\begin{array}{l}\text { Subcohort } \\
(n=3866)^{a} \\
\text { Mean (SD) }\end{array}$} & \multicolumn{2}{|c|}{ Barrett's esophagus cases } \\
\hline & & $\underset{(n=370)^{a}}{\operatorname{SIM}}$ & $\begin{array}{l}\text { SIM or unknown } \\
\text { metaplasia } \\
(n=500)^{a}\end{array}$ \\
\hline & & Mean (SD) ${ }^{b}$ & Mean (SD) ${ }^{\mathrm{b}}$ \\
\hline Age at baseline (years) & $61.3(4.2)$ & $61.1(4.3)$ & $61.3(4.2)$ \\
\hline Men (\%) & 49.0 & 57.3 & 56.2 \\
\hline \multicolumn{4}{|l|}{ Cigarette smoking status } \\
\hline Never smoker (\%) & 37 & 33 & 33 \\
\hline Former smoker (\%) & 36 & 46 & 44 \\
\hline Current smoker (\%) & 37 & 21 & 23 \\
\hline \multicolumn{4}{|l|}{ Ever cigarette smokers: } \\
\hline Frequency of cigarette smoking (n/day) & $15.3(10.3)$ & $16.0(10.8)$ & $16.1(10.4)$ \\
\hline Duration of cigarette smoking (years) & $31.5(12.2)$ & $30.8(11.8)$ & $30.9(12.0)$ \\
\hline Pack-years of cigarette smoking (n) & $22.6(17.8)$ & $22.6(16.7)$ & $22.9(16.8)$ \\
\hline Abstainer from alcohol (\%) & 23 & 20 & 21 \\
\hline \multicolumn{4}{|l|}{ Alcohol consumers: } \\
\hline Ethanol intake (g/day) & $13.5(15.0)$ & $12.9(15.0)$ & $13.1(14.9)$ \\
\hline Beer intake (glasses/day) & $0.3(0.8)$ & $0.3(0.7)$ & $0.3(0.7)$ \\
\hline Wine intake (glasses/day) & $0.5(0.8)$ & $0.5(0.7)$ & $0.5(0.8)$ \\
\hline Liquor intake (glasses/day) & $0.5(0.8)$ & $0.5(0.8)$ & $0.5(0.8)$ \\
\hline $\mathrm{BMI}$ at baseline $(\mathrm{kg} / \mathrm{m} 2)$ & $25.1(3.0)$ & $25.4(2.8)$ & $25.5(2.8)$ \\
\hline BMI at age 20 years $\left(\mathrm{kg} / \mathrm{m}^{2}\right)$ & $21.5(2.6)$ & $21.6(2.5)$ & $21.6(2.6)$ \\
\hline BMI change from age 20 to baseline $\left(\mathrm{kg} / \mathrm{m}^{2}\right)$ & $3.6(3.3)$ & $3.8(3.0)$ & $3.8(3.1)$ \\
\hline Non-occupational physical activity (min/day) & $74(61)$ & $69(53)$ & $70(55)$ \\
\hline Fruit consumption (g/day) & $178(120)$ & $171(118)$ & $172(116)$ \\
\hline Vegetable consumption (g/day) & $195(82)$ & $189(77)$ & $184(76)$ \\
\hline \multicolumn{4}{|l|}{ Highest level of education } \\
\hline Primary (\%) & 28 & 28 & 31 \\
\hline Lower vocational (\%) & 22 & 20 & 20 \\
\hline Secondary and medium vocational (\%) & 36 & 36 & 34 \\
\hline University and higher vocational (\%) & 14 & 16 & 15 \\
\hline Family history of esophageal or gastric cancer (\%) & 7 & 7 & 7 \\
\hline Use of NSAIDs and aspirin $(\%)^{c}$ & 7 & 10 & 10 \\
\hline Use of LES relaxing medication (\%) ${ }^{c}$ & 14 & 17 & 18 \\
\hline
\end{tabular}

a Presented are the number of subcohort members or cases with complete data on age, sex, cigarette smoking (current yes/no, number of cigarettes smoked daily, number of smoking years), alcohol consumption and body mass index. Subcohort members and cases with incomplete or inconsistent questionnaire data are excluded, as well as the first two years of follow-up; ${ }^{\text {b }}$ For categorical variables a percentage is presented; ' Self reported use during more than 0.5 year; BMI, body mass index; IQR, interquartile range; LES, lower esophageal sphincter; NSAIDs, non-steroidal anti-inflammatory drugs; SD, standard deviation; SIM, specialized intestinal metaplasia. 


\section{Overweight}

Women who were overweight (BMI: $25-<30$ ) or obese (BMI: $\geq 30$ ) at baseline were at increased risk of BE. Compared with normal weight (BMI 18.5-<25) women, the RRs were $1.73(95 \% \mathrm{Cl} 1.22-2.44)$ for overweight and 1.67 (95\% $\mathrm{Cl} 0.96-2.90)$ for obese women. The results for men were significantly different from those for women $(p$ interaction=0.01). Men who were overweight or obese at baseline were not at increased risk of $\mathrm{BE}$ : RRs were 0.85 (95\% Cl 0.63-1.14) and 1.21 (95\% Cl 0.60-2.47), respectively (Table 2.2).

An interaction with sex was also found for BMI at age 20 ( $p$ interaction=0.01). A positive association was found for women (RR for $B M I \geq 25$ at age $20 \mathrm{y}=1.56,95 \% \mathrm{Cl}$ 0.79-3.10), $p$ trend=0.05], while an inverse association was found for men (RR for BMI $\geq 25$ at age $20 \mathrm{y}=0.37,95 \% \mathrm{Cl} 0.15-0.87, \mathrm{p}$ trend=0.02). A change in $\mathrm{BMI}$ during adulthood was not associated with risk of $B E$ in men, but a positive trend was observed in women ( $p$ trend=0.01), mainly because women who lost weight during adulthood were at decreased risk $(R R=0.33,95 \% \mathrm{Cl} 0.15-0.75)$ when compared with those who gained $0-<4$ BMI points.

When RRs for BMI at baseline were additionally adjusted for pant/skirt size, the associations for women were somewhat attenuated, and for men the associations were similar when compared with analyses without adjustment for pant/skirt size. Analyses with pant/skirt size as independent variable showed a positive association in women ( $p$ trend=0.01), which disappeared after adjustment for BMI at baseline. For men, no association was observed for pant/skirt size ( $p$ trend=0.73), and adjustment for $\mathrm{BMI}$ at baseline did not change this observation (Table 2.2).

\section{Cigarette smoking}

In the multivariable regression analyses on cigarette smoking (Table 2.3), we did not observe any statistically significant differences between associations for men and women, which permitted us to report the results for both sexes combined. Nearly all RRs associated with aspects of cigarette smoking were above unity, although these were mostly not statistically significant. Former smokers were at highest risk of $\mathrm{BE}$ ( $R R=1.33,95 \% \mathrm{Cl} 1.00-1.77)$ when compared with never smokers, but current smokers were not at higher risk. Smoking frequency was found to be related to a nonsignificantly higher risk of $B E$ ( $p$ trend=0.46). A longer duration of cigarette smoking was associated with an increasing risk of $B E$ ( $p$ trend=0.03). Results on the association between pack-years of smoking and BE showed increased RRs, but only for subjects who had smoked $20-<40$ pack-years the RR was statistically significant ( $R R=1.50,95 \%$ $\mathrm{Cl}$ 1.04-2.17, $\mathrm{p}$ trend=0.08). The results of analyses on smoking cessation did not indicate a lower risk of BE with increasing duration of smoking cessation ( $p$ trend=0.82). 


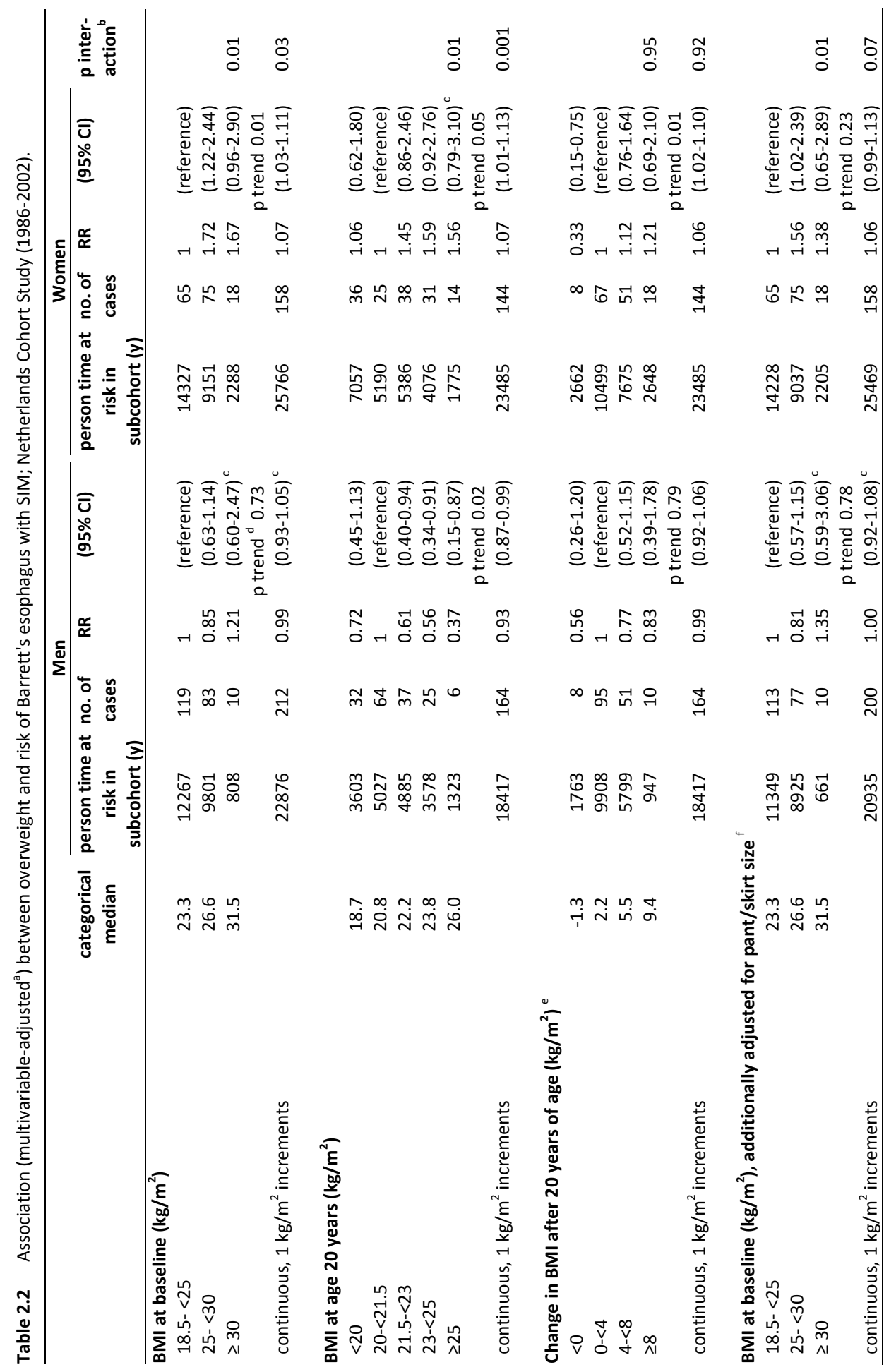




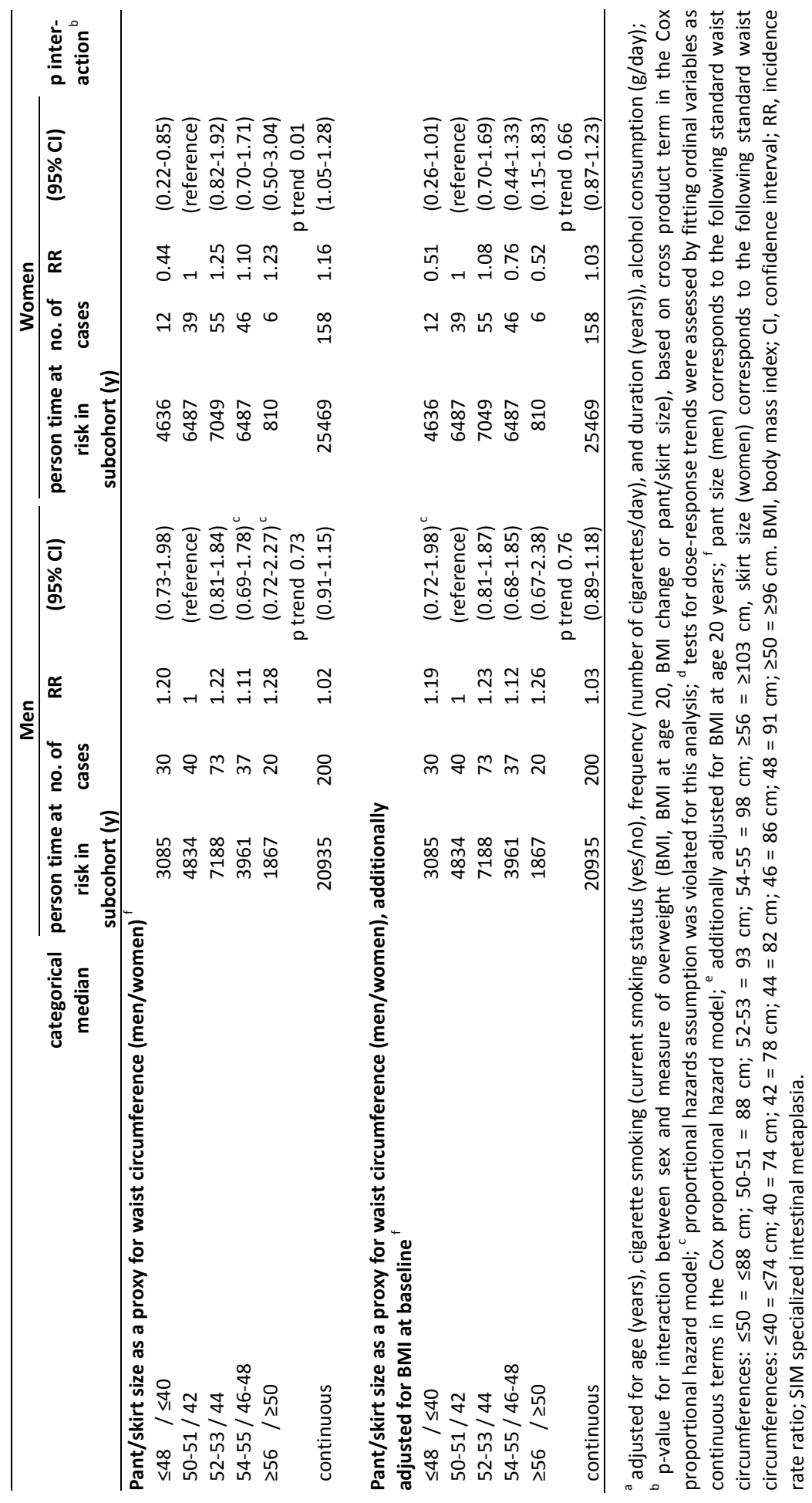




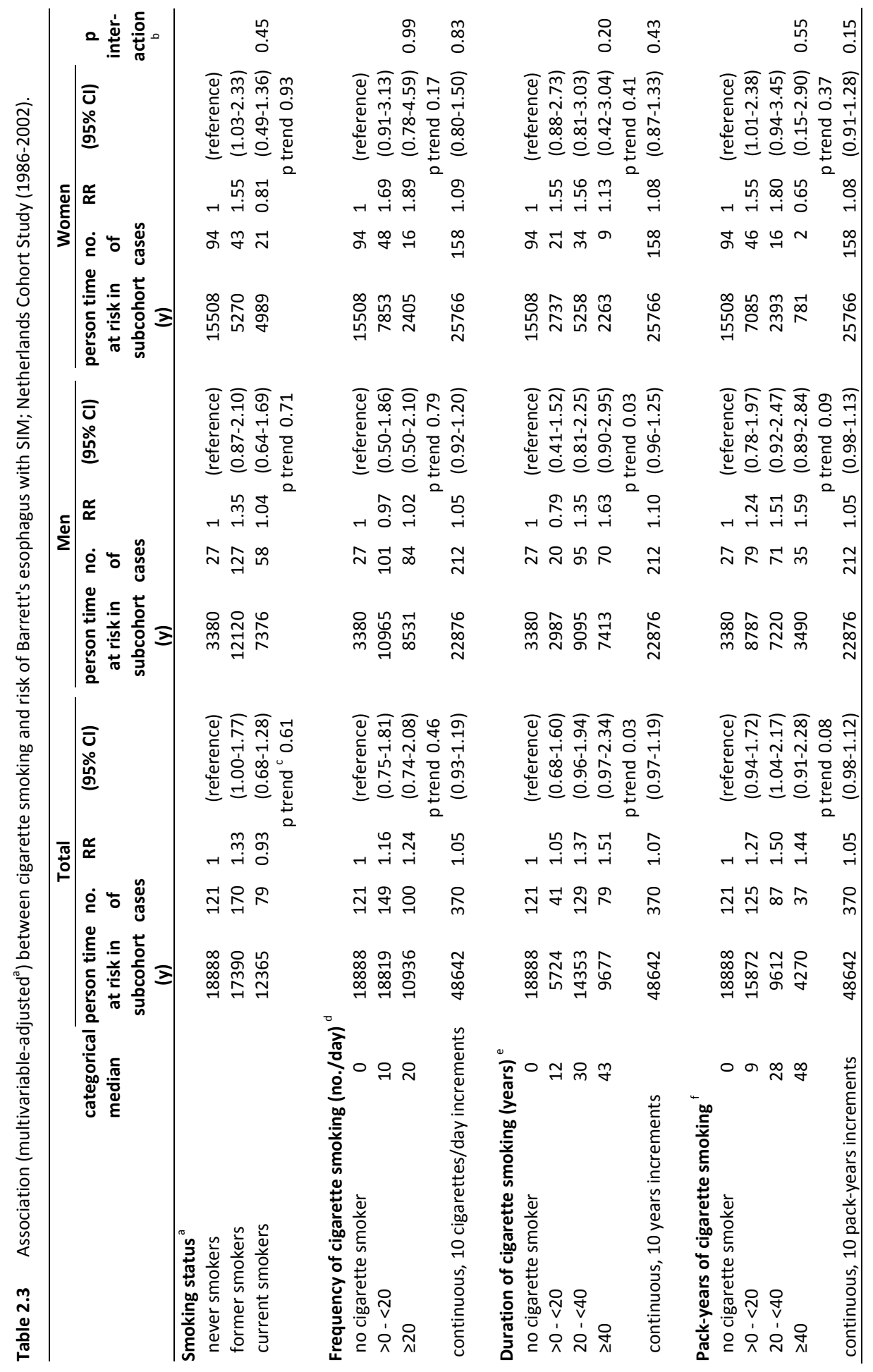




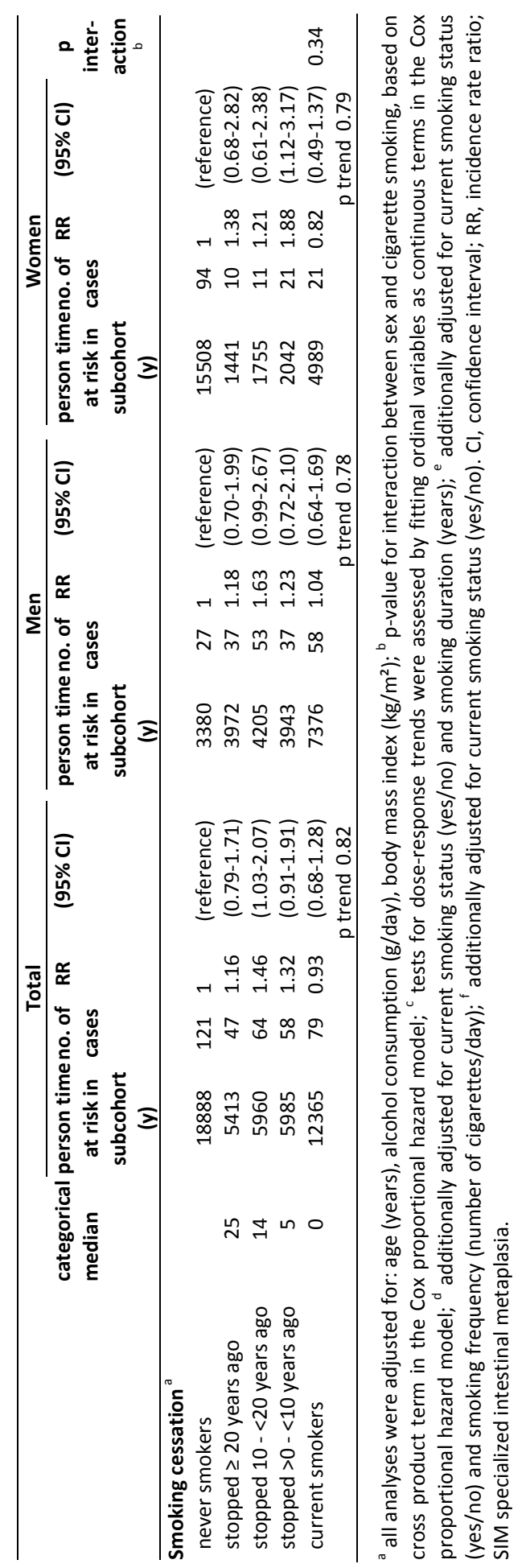




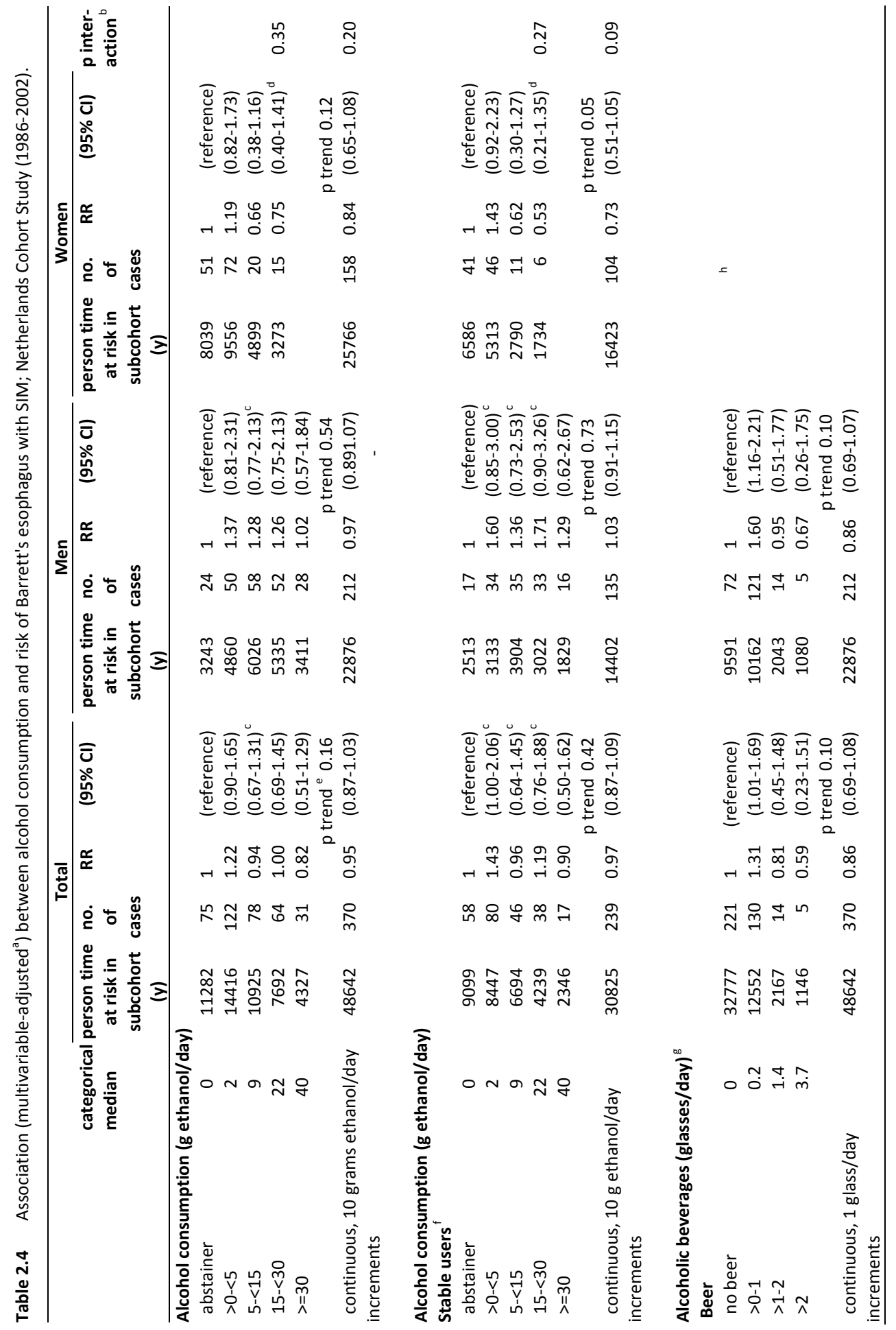




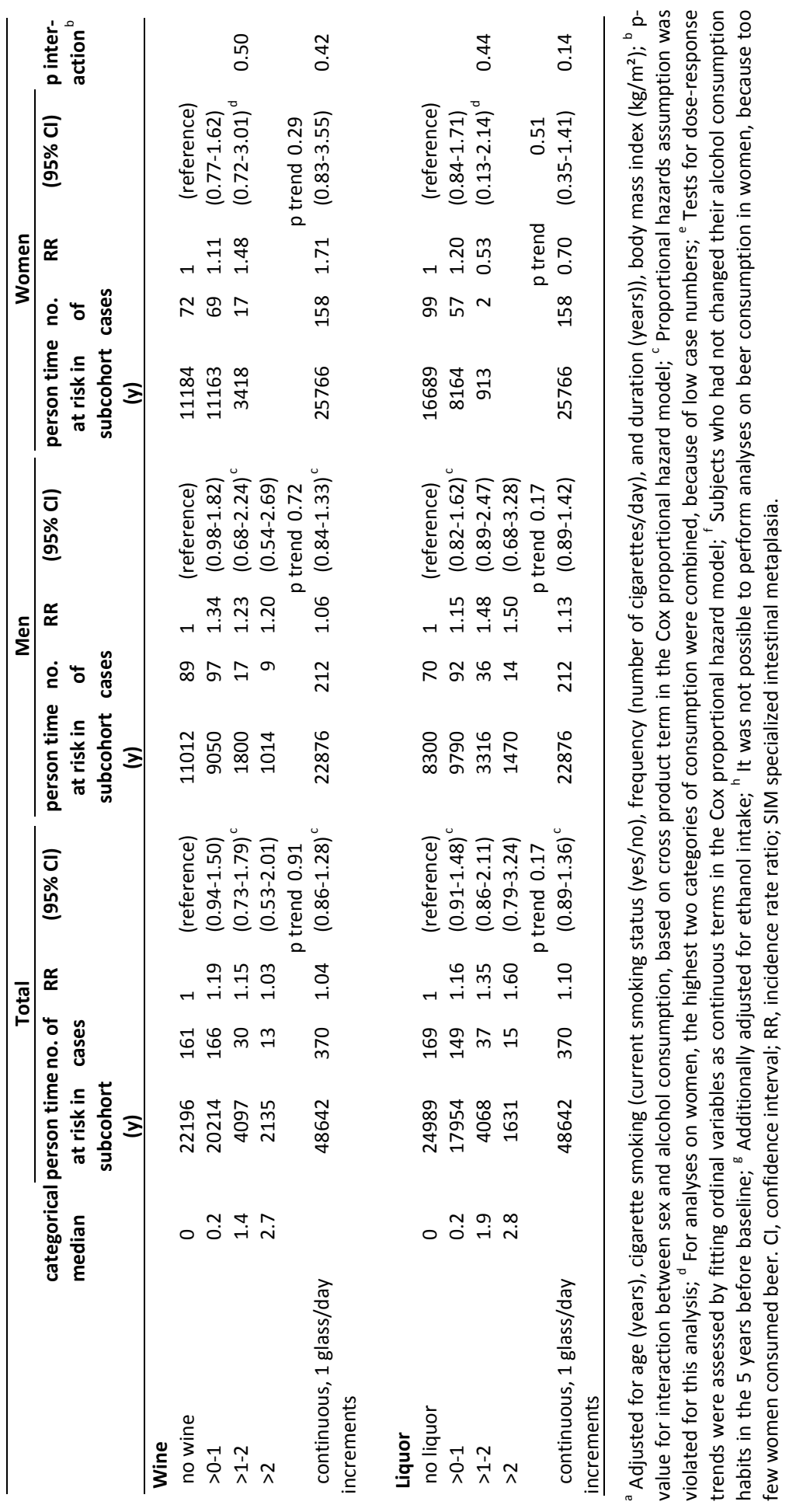




\section{Alcohol consumption}

As can be seen in Table 2.4, there was no interaction between sex and alcohol consumption in the analyses of BE risk. Analyses of the association between alcohol intake and risk of $B E$ indicated no increased risk. Subjects in the highest category of intake ( $\geq 30$ g ethanol/day) had an RR of 0.82 (95\% Cl 0.51-1.29) when compared with abstainers. A sensitivity analysis was performed based on subjects who had a stable alcohol consumption in the period starting 5 years before baseline until baseline. This analysis included approximately $65 \%$ of the study population. Broadly speaking, the results were comparable with those based on the total study population.

Also shown in Table 2.4 are RRs associated with consumption of alcoholic beverages, adjusted for ethanol intake. The RRs for beer and wine consumption do not shown clear inverse or positive associations. Increasing liquor consumption was associated with a non-significantly increased risk of BE (RR for $>2$ glasses/day=1.60, $95 \% \mathrm{Cl}$ 0.79-3.24, $\mathrm{p}$ trend=0.17).

\section{DISCUSSION}

In this large prospective cohort study, overweight was found to be a risk factor for BE in women, but not in men. Several aspects of cigarette smoking were associated with an increase in risk of $\mathrm{BE}$, while alcohol consumption was not associated with risk of $\mathrm{BE}$.

\section{Overweight}

Our observation of a positive association between increased BMI and risk of BE in women, is comparable with a recent observation in another prospective cohort study among women. They found obese women to be at increased risk of BE (OR 1.52, 95\% $\mathrm{Cl}$ 1.02-2.28). However, no association with overweight was found in that study (OR $0.92,95 \% \mathrm{Cl} 0.66-1.27)$, while we did find a positive association with overweight. Three case-control studies showed an increased risk of BE for overweight and obese persons. $^{7-9}$ These studies were based on predominantly male populations $(60-100 \%$ male cases), thus it is likely that overweight and obese men were at increased risk, even though no separate results by sex were presented. We did not observe an increased risk in men. Previously, a positive association between overweight and risk of esophageal adenocarcinoma has also been described, in the NLCS (in women only) ${ }^{27}$ and a meta-analysis. ${ }^{28}$

Several possible biological mechanisms may be involved in the association between overweight and development of BE. Some studies observed that adjustment for gastroesophageal reflux disease caused attenuation or disappearance of the effect of increased BMI on BE risk, ${ }^{6,29}$ whereas in other studies this adjustment did not affect the RRs. ${ }^{5,10}$ Therefore, it is probable that the BMI acts through other mechanisms besides gastroesophageal reflux disease, as was also suggested recently in a 
comprehensive review. ${ }^{30}$ Another possible mechanism relates to the distribution of body fat. Abdominal fat is more metabolically active than subcutaneous fat, and secretes several factors that may be involved in systemic inflammation and cancer development. $^{30,31}$ Two case-control studies observed positive associations between measures of abdominal overweight and BE risk. ${ }^{8,32}$ In our study, we did not observe an increased risk of $\mathrm{BE}$ for women with abdominal overweight, when total overweight was accounted for. However, the use of clothing size measures as a proxy for waist circumference may not have been optimal. Results from the Nurses' Health Study did not show an association for abdominal overweight either. ${ }^{10}$ Thus, there are some inconsistencies between observations on the role of abdominal overweight in the development BE.

\section{Cigarette smoking}

Our observation that several aspects of cigarette smoking were associated with an increased risk of $\mathrm{BE}$ are in agreement with results from some previous case-control studies. $^{6,8}$ In an earlier analysis within the NLCS, we investigated the association of cigarette smoking with risk of esophageal adenocarcinoma. ${ }^{33}$ The association of cigarette smoking with esophageal adenocarcinoma was stronger (RR for $\geq 40$ packyears $=2.93(95 \% \mathrm{Cl} 1.59-5.40)$ than the association with its precursor BE. This difference in strength of the associations with $\mathrm{BE}$ and esophageal adenocarcinoma is consistent with the literature. e.g. $5,8,12,34,35$ This observation may indicate that smoking plays a role in the later stages of esophageal carcinogenesis: in the progression of BE to esophageal adenocarcinoma. In a population of BE patients, risk of progression was indeed found to be increased for patients who had smoked, although this was not statistically significant $\left(\mathrm{RR}=1.53\left(95 \% \mathrm{Cl}\right.\right.$ 0.68-6.44). ${ }^{36}$ Further investigation into this topic may yield interesting insights.

\section{Alcohol consumption}

Our finding that there was no association between alcohol intake and risk of BE is consistent with results from most studies. ${ }^{8,11,13}$ Also, the findings are analogous to the null association between alcohol and risk of esophageal adenocarcinoma. ${ }^{33,34,37}$

Wine consumption has been reported to be inversely associated with BE risk. ${ }^{11,13}$ However, within the NLCS, we could not confirm this association. The fact that we adjusted for total ethanol intake while the other two studies adjusted for beer and liquor intake, cannot explain the different findings, as there were no associations with ethanol, beer or liquor.

\section{Strengths and limitations}

An important strength of this study is its prospective character. The advantage of the prospective design is the relative insensitivity for selection and information bias 
compared with a case-control design. Second, this study is one of the largest with respect to the number of $B E$ cases, specifically the number of female cases. This large number of cases allowed the investigation of interaction and separate analyses for men and women. A third strength is the availability of extensive information about the exposure variables investigated, which allowed a detailed look at these exposures.

There are also some limitations to our study. The first is the lack of information on the presence of gastroesophageal reflux disease and the use of medications for this disease. Consequently, we were not able to investigate possible confounding effects of these factors or their possible intermediate role in the associations investigated. Second, the use of clothing size as a proxy measure for waist circumference is suboptimal compared with measurement of waist circumference. Third, subcohort members who were not diagnosed with BE were assumed to be disease-free, but we were unable to verify this assumption. Therefore, there may be some BE cases missing in our dataset, which may have reduced the power. Finally, the power of the study also may have been reduced due to the incomplete coverage of the NLCS population by PALGA before 1991. Due to this incompleteness we may have missed some BE cases or the registered incidence date may be later than the true incidence date. We estimated that we may have missed $3 \%$ of the BE cases in our cohort at most.

\section{Recommendations for further research}

Most studies that investigated overweight, smoking, and alcohol consumption in relation to the risk of $\mathrm{BE}$, had a case-control design. Reversed causation can be a problem in studies investigating etiology, specifically in studies with a case-control design. This is illustrated by our finding that cases diagnosed during the first 2 years of follow-up reported different alcohol consumption habits at baseline than later cases. Only one prospective cohort study previously reported on overweight and risk of BE, while we are the first prospective cohort study to report on alcohol and smoking. We therefore suggest that additional cohort studies investigate these factors in association with BE risk. Future studies should, whenever possible, investigate whether associations differ by sex. Differences in associations between sexes may help to explain the higher male-to-female ratio in esophageal adenocarcinoma compared with $\mathrm{BE}$. As mentioned before, studying risk factors for progression of BE to esophageal adenocarcinoma also deserves further attention. 


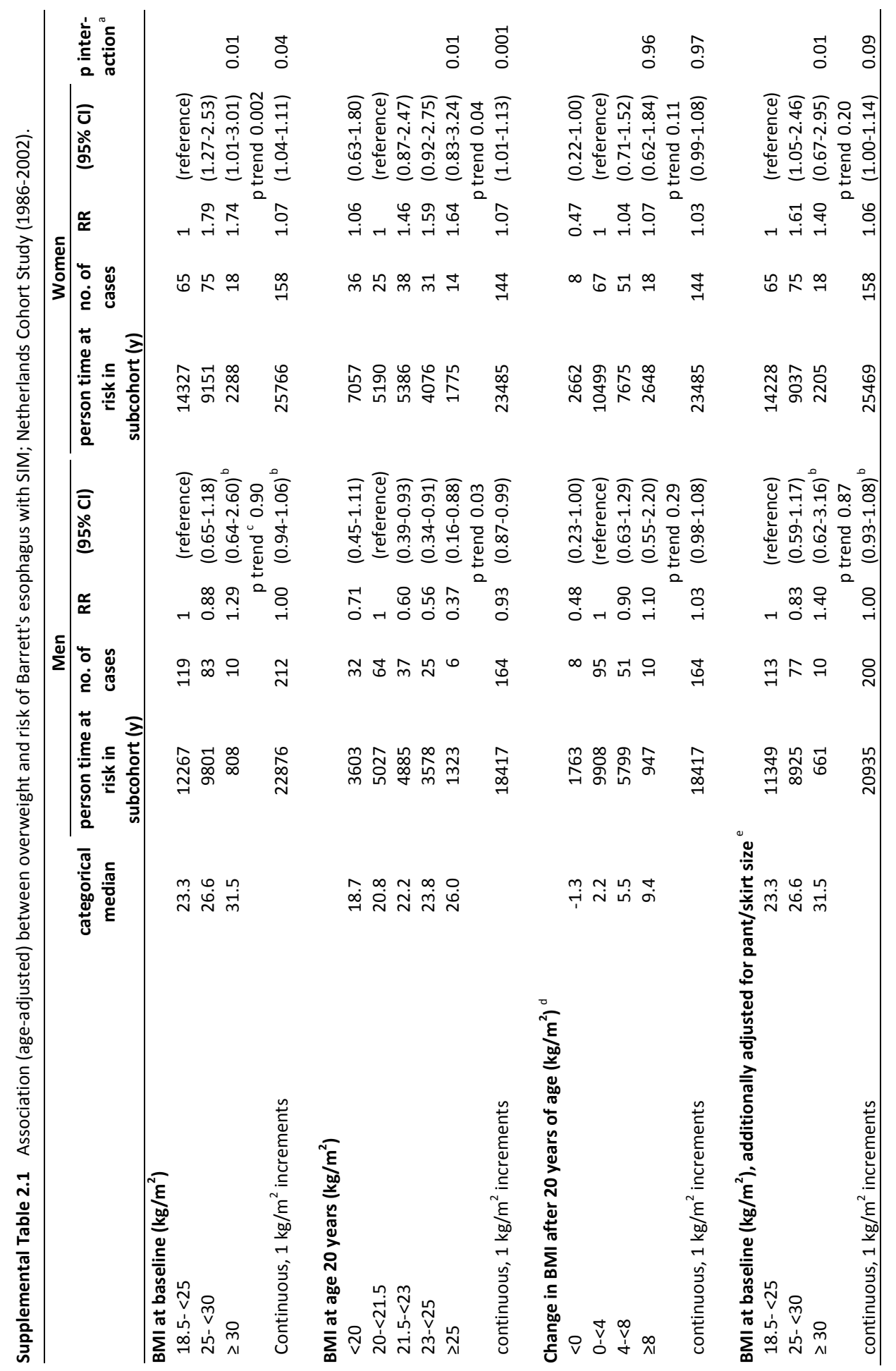




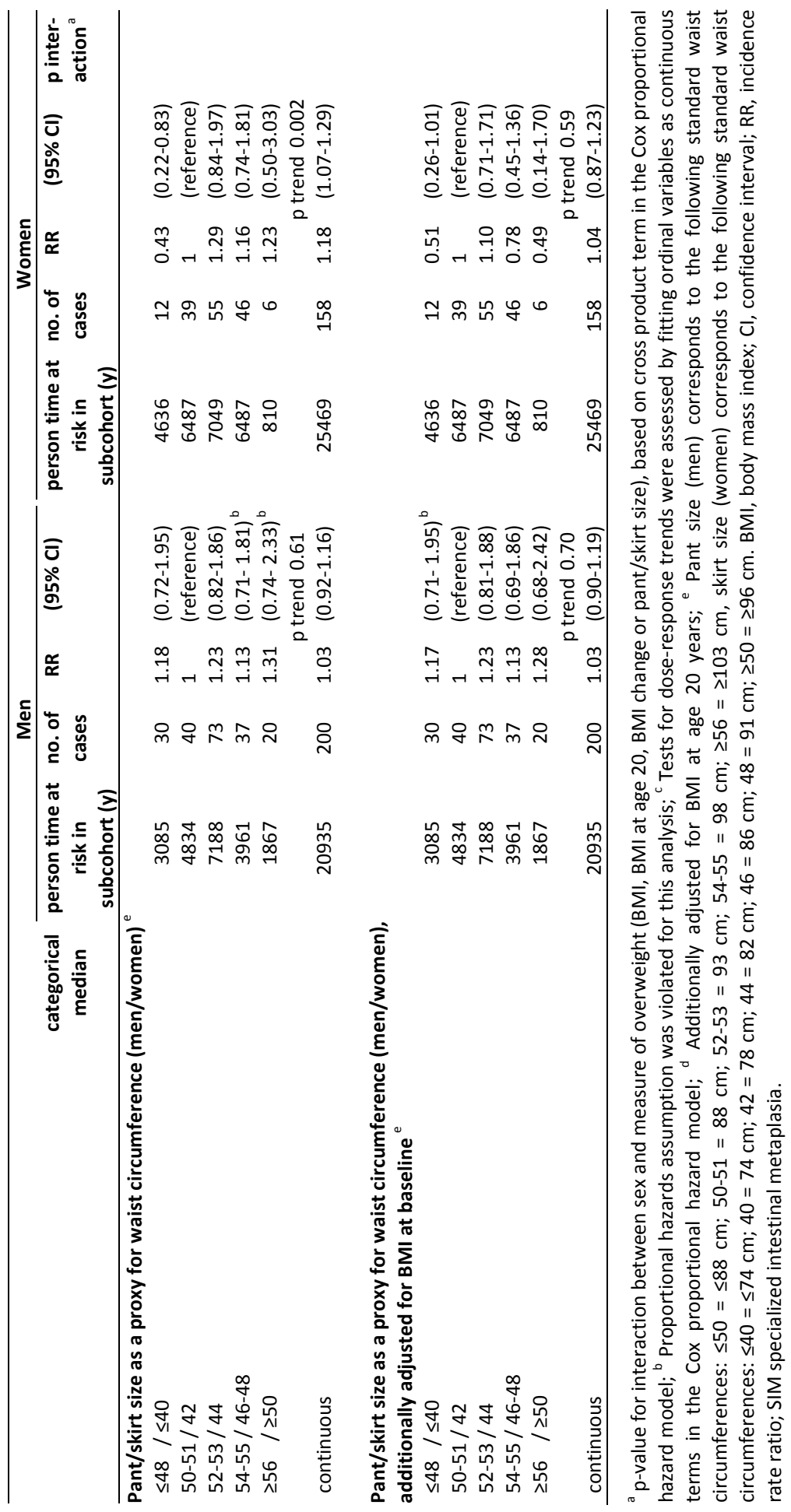




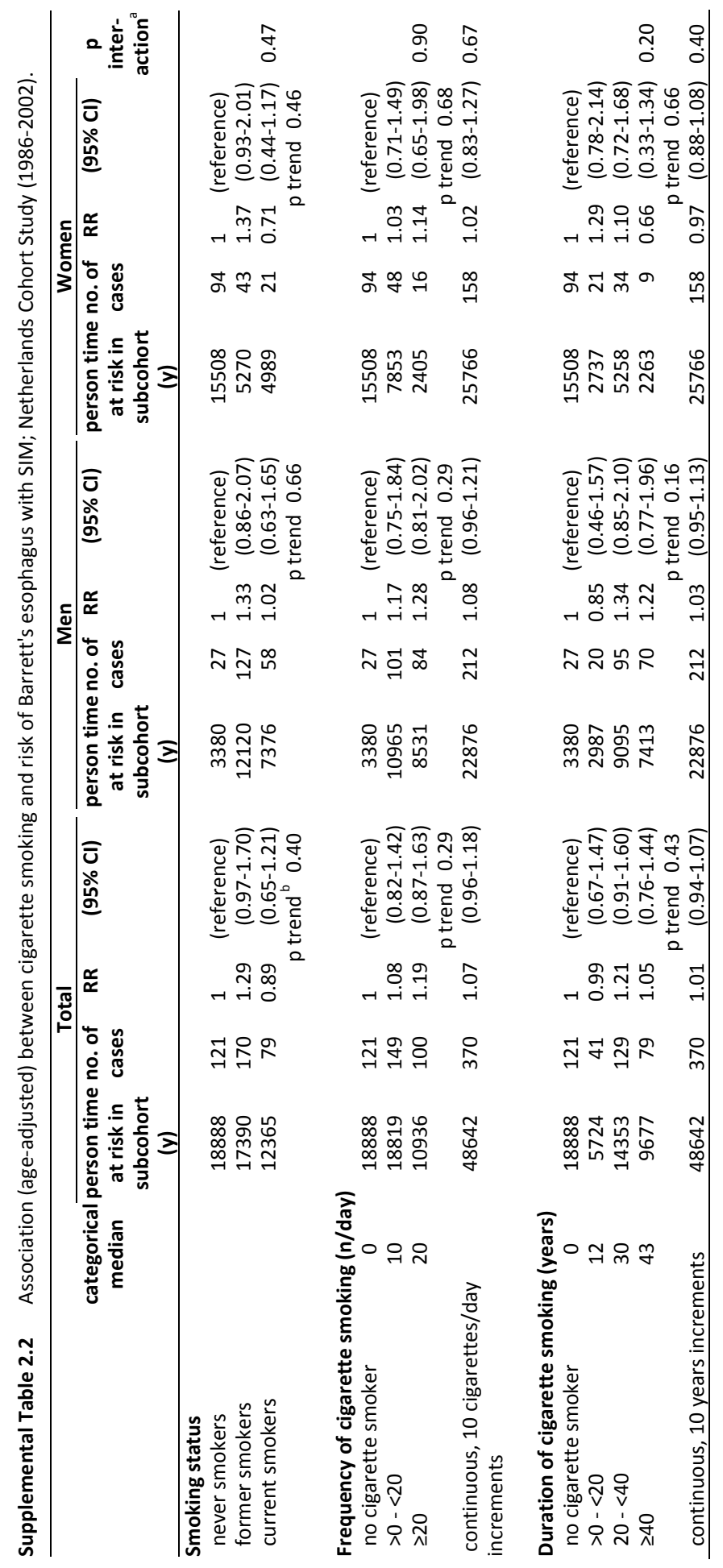




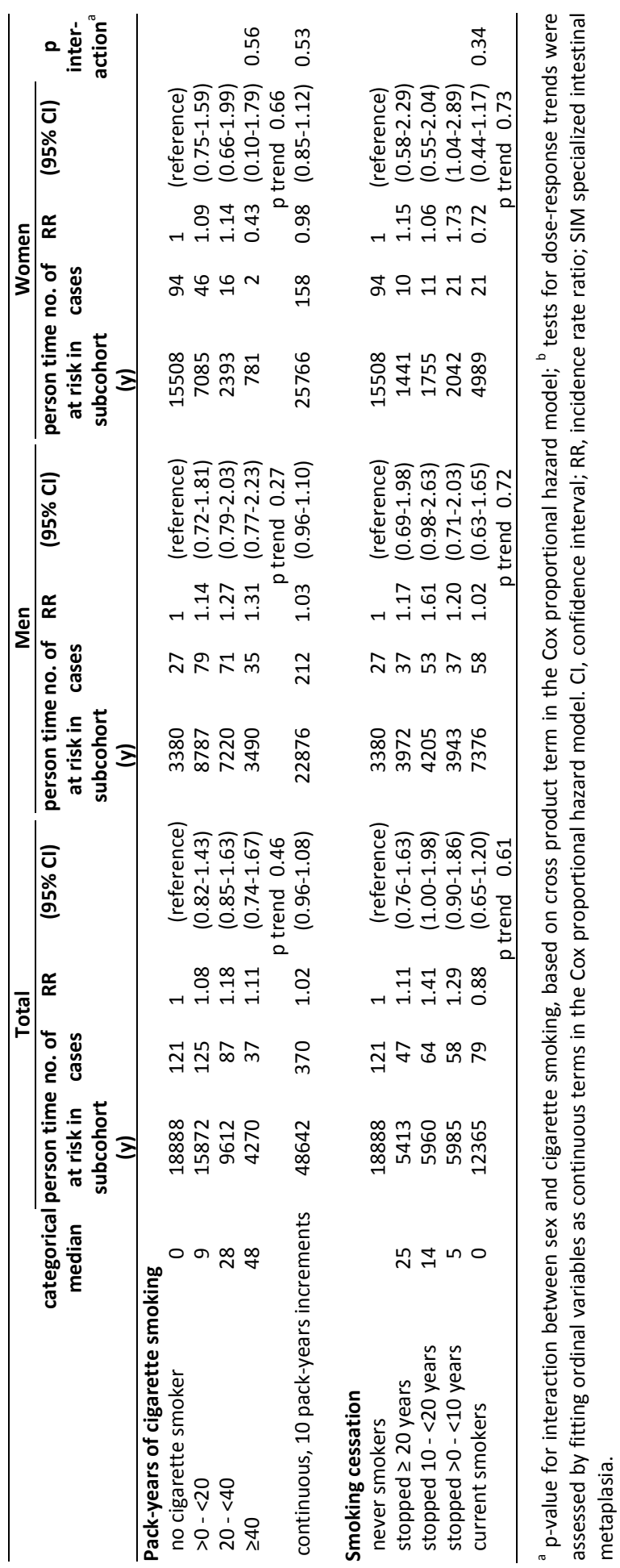




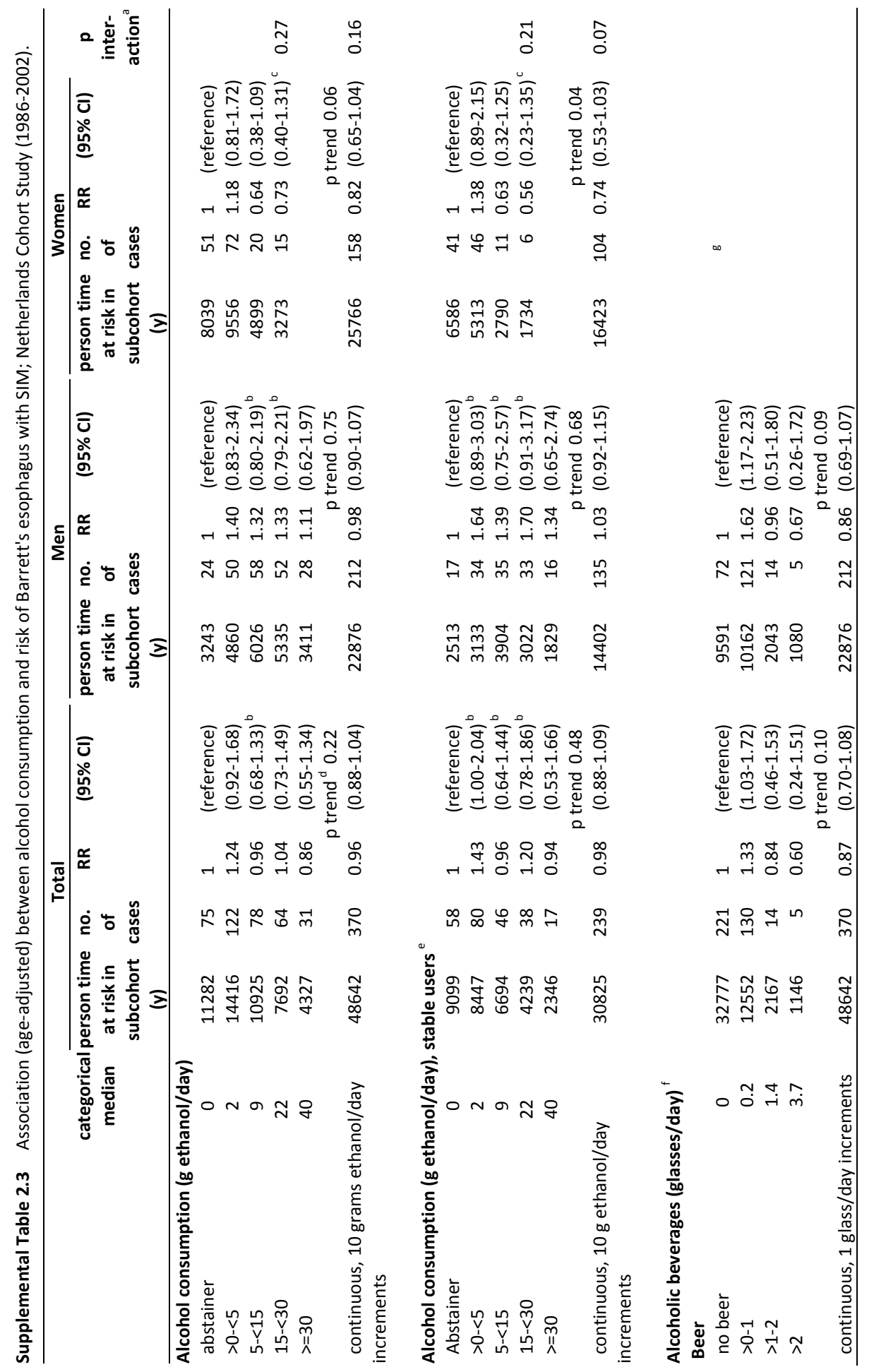




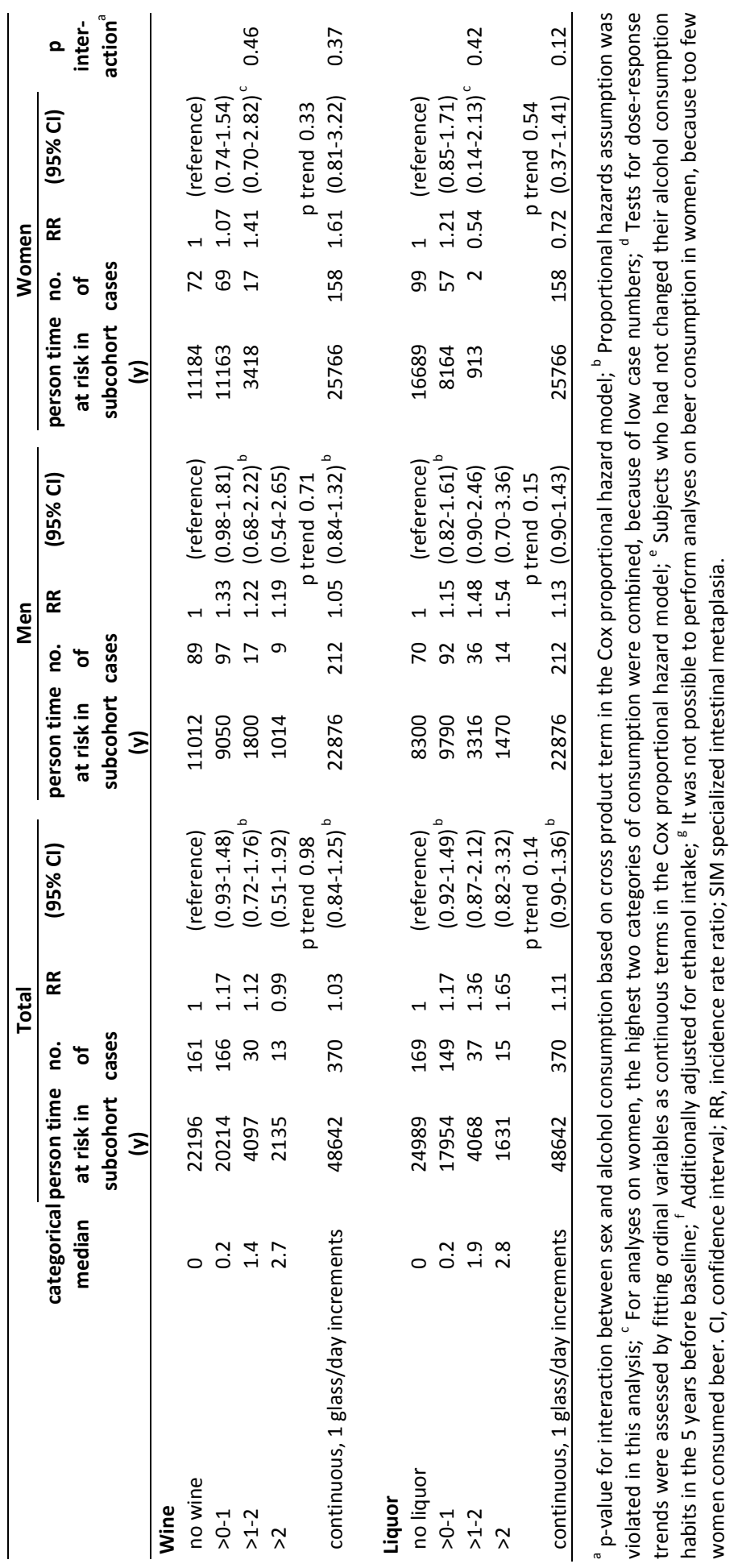




\section{REFERENCES}

1. Wang KK, Sampliner RE. Updated guidelines 2008 for the diagnosis, surveillance and therapy of Barrett's esophagus. Am J Gastroenterol 2008;103:788-797.

2. Playford RJ. New British Society of Gastroenterology (BSG) guidelines for the diagnosis and management of Barrett's oesophagus. Gut 2006;55:442-443.

3. Yousef F, Cardwell C, Cantwell MM, Galway K, Johnston BT, Murray L. The incidence of esophageal cancer and high-grade dysplasia in Barrett's esophagus: a systematic review and meta-analysis. Am J Epidemiol 2008;168:237-249.

4. Wild CP, Hardie LJ. Reflux, Barrett's oesophagus and adenocarcinoma: burning questions. Nat Rev Cancer 2003;3:676-684.

5. Anderson LA, Watson RG, Murphy SJ, Johnston BT, Comber H, Mc Guigan J, Reynolds JV, Murray LJ. Risk factors for Barrett's oesophagus and oesophageal adenocarcinoma: results from the FINBAR study. World J Gastroenterol 2007;13:1585-1594.

6. Smith KJ, O'Brien SM, Green AC, Webb PM, Whiteman DC. Current and past smoking significantly increase risk for Barrett's esophagus. Clin Gastroenterol Hepatol 2009;7:840-848.

7. Bu X, Ma Y, Der R, Demeester T, Bernstein L, Chandrasoma PT. Body mass index is associated with Barrett esophagus and cardiac mucosal metaplasia. Dig Dis Sci 2006;51:1589-1594.

8. Edelstein ZR, Farrow DC, Bronner MP, Rosen SN, Vaughan TL. Central adiposity and risk of Barrett's esophagus. Gastroenterology 2007;133:403-411.

9. Stein DJ, El-Serag HB, Kuczynski J, Kramer JR, Sampliner RE. The association of body mass index with Barrett's oesophagus. Aliment Pharmacol Ther 2005;22:1005-1010.

10. Jacobson BC, Chan AT, Giovannucci EL, Fuchs CS. Body mass index and Barrett's oesophagus in women. Gut 2009;58:1460-1466.

11. Anderson LA, Cantwell MM, Watson RG, Johnston BT, Murphy SJ, Ferguson HR, McGuigan J, Comber $\mathrm{H}$, Reynolds JV, Murray LJ. The association between alcohol and reflux esophagitis, Barrett's esophagus, and esophageal adenocarcinoma. Gastroenterology 2009;136:799-805.

12. Kubo A, Levin TR, Block G, Rumore G, Quesenberry CP, Jr., Buffler P, Corley DA. Cigarette smoking and the risk of Barrett's esophagus. Cancer Causes Control 2009;20:303-311.

13. Kubo A, Levin TR, Block G, Rumore GJ, Quesenberry CP, Jr., Buffler P, Corley DA. Alcohol types and sociodemographic characteristics as risk factors for Barrett's esophagus. Gastroenterology 2009;136:806-815.

14. Akiyama $\mathrm{T}$, Inamori $\mathrm{M}$, lida $\mathrm{H}$, Mawatari H, Endo H, Hosono K, Yoneda K, Fujita K, Yoneda M, Takahashi H, Goto A, Abe Y, Kobayashi N, Kubota K, Saito S, Nakajima A. Alcohol consumption is associated with an increased risk of erosive esophagitis and Barrett's epithelium in Japanese men. BMC Gastroenterol 2008;8:58.

15. van den Brandt PA, Goldbohm RA, van 't Veer P, Volovics A, Hermus RJ, Sturmans F. A large-scale prospective cohort study on diet and cancer in The Netherlands. J Clin Epidemiol 1990;43:285-295.

16. Barlow WE, Ichikawa L, Rosner D, Izumi S. Analysis of case-cohort designs. J Clin Epidemiol 1999;52:1165-1172.

17. Casparie M, Tiebosch AT, Burger G, Blauwgeers $H$, van de Pol A, van Krieken JH, Meijer GA. Pathology databanking and biobanking in The Netherlands, a central role for PALGA, the nationwide histopathology and cytopathology data network and archive. Cell Oncol 2007;29:19-24.

18. Hughes LA, Schouten $\amalg$, Goldbohm RA, van den Brandt PA, Weijenberg MP. Self-reported clothing size as a proxy measure for body size. Epidemiology 2009;20:673-676.

19. Nevo table: Dutch food composition table, 1986-1987. (Dutch). Voorlichtingbureau Voor de Voeding, 1986.

20. Goldbohm RA, van den Brandt PA, Brants HA, van't Veer P, Al M, Sturmans F, Hermus RJ. Validation of a dietary questionnaire used in a large-scale prospective cohort study on diet and cancer. Eur J Clin Nutr 1994;48:253-265.

21. Goldbohm RA, van 't Veer P, van den Brandt PA, van 't Hof MA, Brants HA, Sturmans F, Hermus RJ. Reproducibility of a food frequency questionnaire and stability of dietary habits determined from five annually repeated measurements. Eur J Clin Nutr 1995;49:420-429. 
22. Lagergren J, Bergstrom R, Adami HO, Nyren O. Association between medications that relax the lower esophageal sphincter and risk for esophageal adenocarcinoma. Ann Intern Med 2000;133:165-175.

23. WHO Collaborating Centre for Drug Statistics Methodology. http://www.whocc.no/atcddd/welcome. html (accessed 15 Oct, 2009).

24. Cox DR. Regression models and life-tables (with discussion). J R Stat Soc Ser B 1972;34:187-220.

25. Barlow WE. Robust variance estimation for the case-cohort design. Biometrics 1994;50:1064-1072.

26. Schoenfeld D. Partial residuals for the proportional hazards regression model. Biometrica 1982;69: 239-241.

27. Merry AH, Schouten L, Goldbohm RA, van den Brandt PA. Body mass index, height and risk of adenocarcinoma of the oesophagus and gastric cardia: a prospective cohort study. Gut 2007;56: 1503-1511.

28. Kubo A, Corley DA. Body mass index and adenocarcinomas of the esophagus or gastric cardia: a systematic review and meta-analysis. Cancer Epidemiol Biomarkers Prev 2006;15:872-878.

29. Cook MB, Greenwood DC, Hardie $\amalg$, Wild CP, Forman D. A systematic review and meta-analysis of the risk of increasing adiposity on Barrett's esophagus. Am J Gastroenterol 2008;103:292-300.

30. Reid BJ, Li X, Galipeau PC, Vaughan TL. Barrett's oesophagus and oesophageal adenocarcinoma: time for a new synthesis. Nat Rev Cancer 2010;10:87-101.

31. Murray L, Romero Y. Role of obesity in Barrett's esophagus and cancer. Surg Oncol Clin N Am 2009;18:439-452.

32. Corley DA, Kubo A, Levin TR, Block G, Habel L, Zhao W, Leighton P, Quesenberry C, Rumore GJ, Buffler PA. Abdominal obesity and body mass index as risk factors for Barrett's esophagus. Gastroenterology 2007;133:34-41; quiz 311.

33. Steevens J, Schouten LJ, Goldbohm RA, van den Brandt PA. Alcohol consumption, cigarette smoking and risk of subtypes of oesophageal and gastric cancer: a prospective cohort study. Gut 2010;59:39-48.

34. Freedman ND, Abnet CC, Leitzmann MF, Mouw T, Subar AF, Hollenbeck AR, Schatzkin A. A prospective study of tobacco, alcohol, and the risk of esophageal and gastric cancer subtypes. Am J Epidemiol 2007;165:1424-1433.

35. Veugelers PJ, Porter GA, Guernsey DL, Casson AG. Obesity and lifestyle risk factors for gastroesophageal reflux disease, Barrett esophagus and esophageal adenocarcinoma. Diseases of the Esophagus 2006;19:321-328.

36. Gatenby PA, Caygill CP, Ramus JR, Charlett A, Watson A. Barrett's columnar-lined oesophagus: demographic and lifestyle associations and adenocarcinoma risk. Dig Dis Sci 2008;53:1175-1185.

37. Lindblad M, Rodriguez LA, Lagergren J. Body mass, tobacco and alcohol and risk of esophageal, gastric cardia, and gastric non-cardia adenocarcinoma among men and women in a nested case-control study. Cancer Causes Control 2005;16:285-294. 


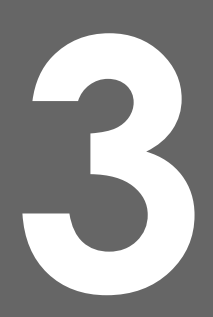

\title{
Toenail selenium status and the risk of Barrett's esophagus: the Netherlands Cohort Study
}

\author{
Jessie Steevens \\ Leo J Schouten \\ Ann LC Driessen \\ Clément JR Huysentruyt \\ Yolande CA Keulemans \\ R Alexandra Goldbohm \\ Piet A van den Brandt
}




\section{ABSTRACT}

\section{Objective}

To investigate the association between selenium and the risk of Barrett's esophagus $(\mathrm{BE})$, the precursor lesion of esophageal adenocarcinoma.

\section{Methods}

Data from the prospective Netherlands Cohort Study were used. This cohort study was initiated in 1986, when 120,852 subjects aged 55-69 years completed a questionnaire on dietary habits and lifestyle, and provided toenail clippings for the determination of baseline selenium status. After 16.3 years of follow-up, 253 BE cases (identified through linkage with the nationwide Dutch pathology registry) and 2039 subcohort members were available for case-cohort analysis. Cox proportional hazards models were used to calculate incidence rate ratios (RR).

\section{Results}

The multivariable adjusted RR for the highest versus the lowest quartile of toenail selenium was $1.06(95 \% \mathrm{Cl}$ 0.71-1.57). No dose-response trend was seen ( $\mathrm{p}$ trend=0.99). No association was found in subgroups defined by sex, smoking status, body mass index (BMI), or intake of antioxidants. For BE cases that later progressed to high-grade dysplasia or adenocarcinoma, the RR for a selenium level above the median vs. below the median was 0.64 (95\% $\mathrm{Cl} 0.24-1.76)$.

\section{Conclusions}

In this large prospective cohort study, we found no evidence of an association between selenium and risk of $\mathrm{BE}$. 


\section{INTRODUCTION}

Barrett's esophagus (BE) is a disease of the distal esophagus. Normally, the esophagus is lined with stratified squamous epithelium, which is replaced by a single layer of columnar epithelium (metaplasia) in BE patients. Diagnostic criteria for BE differ across the world. In the USA, the presence of goblet cells (indicating specialized intestinal metaplasia, SIM) is required for the diagnosis of $\mathrm{BE}^{1}{ }^{1}$ while in the UK any type of metaplasia is sufficient for the diagnosis of BE. ${ }^{2}$ In the Netherlands, both definitions have been used by different pathologists over time.

BE is most common in middle-aged Caucasian men ${ }^{3}$ and in the Netherlands, the incidence is rising among men and women. ${ }^{4} \mathrm{BE}$ has primarily been of interest because patients are at increased risk to develop adenocarcinoma of the esophagus. The reported risk of esophageal adenocarcinoma in BE patients is highly variable between publications and was found in a recent meta-analysis to be between 4.1/1,000 and $6.1 / 1,000$ person-years. ${ }^{5}$ Patients in whom high-grade dysplasia is present in the $\mathrm{BE}$ tissue are at highest risk of developing esophageal adenocarcinoma. ${ }^{6}$

Gastroesophageal reflux disease has been identified as a strong risk factor for $\mathrm{BE}$, and possibly overweight or obesity are risk factors as well. ${ }^{7}$ Lifestyle factors, including diet, may also play a role in BE etiology, ${ }^{7-9}$ but little information is available on this topic.

One dietary factor of interest is selenium, a trace element, which has been investigated for its possible role in cancer etiology. Selenium is involved in various anticarcinogenic processes and may act at a number of stages in cancer development. ${ }^{10}$ Selenium is incorporated into some selenoproteins including glutathione peroxidases (GPX), which are antioxidant enzymes and protect against oxidative damage. Selenium is further involved in alteration of DNA methylation, blockage of the cell cycle, induction of apoptosis and inhibition of angiogenesis. ${ }^{10}$ Selenium has been associated with several cancers: it may protect against prostate, lung, gastric, and colorectal cancer. ${ }^{11-13}$ Moreover, we recently found evidence suggestive of an inverse association with esophageal adenocarcinoma. This association was found in women, never smokers, and persons with a low intake of antioxidants. ${ }^{14}$ We identified only one study that looked into the association between selenium and $B E$. That study found a lower average serum selenium concentration among patients with $\mathrm{BE}$ than among controls, indicating a possible inverse association. Unfortunately, no measure of relative risk or multivariable adjusted results were presented. Two cross-sectional studies among BE cases in the USA found indications for an inverse association between serum selenium and markers of progression of BE. ${ }^{15,16}$ Further, a recent study reported promotor hypermethylation of the gene coding for the selenoprotein GPx3 in Barrett's esophagus tissue, thereby epigenetically inactivating this gene. ${ }^{17}$ We hypothesize that selenium status is inversely associated with risk of BE, if selenium is involved early in the process of carcinogenesis. 
The selenium content of our food may vary considerably between varieties of the same type of food, depending on the soil where the food was grown. ${ }^{18}$ For that reason, selenium intake from diet cannot be estimated reliably using questionnaires. Selenium status is therefore often measured using biomarkers. In this study, we used toenails as a biomarker of selenium intake. Toenails are a suitable biomarker, because they reflect the intake of selenium for a period up to one year. ${ }^{19,20}$

Within the prospective Netherlands Cohort Study on diet and cancer, we investigated whether toenail selenium levels were inversely associated with risk of BE.

\section{MATERIALS AND METHODS}

\section{Study design and participants}

The prospective Netherlands Cohort Study on diet and cancer was started in September 1986, when 58,279 Dutch men and 62,573 women aged 55-69 were enrolled. The subjects were selected at random from 204 Dutch municipal registries. All cohort members completed a self-administered questionnaire and were requested to provide toenail clippings at baseline. The study was described in detail before. ${ }^{21}$

A case-cohort approach ${ }^{22}$ was used for data processing and analysis for efficiency; case subjects were derived from the entire cohort, and the number of person-years at risk for the entire cohort was estimated from a subcohort of 3,500 subjects who were selected at random from the full cohort at baseline.

The subcohort was followed-up for vital status and after 16.3 years (September 1986 to December 2002), only one male subcohort member was lost to follow-up. We excluded subcohort members who reported having prevalent BE or cancer (other than skin cancer) at baseline (Figure 3.1).

The Medical Ethics Committee of Maastricht University, the Netherlands, has approved the study.

\section{Follow-up for BE incidence}

Incident BE cases in the total cohort were detected by computerized record linkage to the nationwide network and registry of histopathology and cytopathology in the Netherlands (PALGA). ${ }^{23}$ This network was founded in 1971, and an increasing number of laboratories joined PALGA such that it has a nationwide coverage since 1991. Due to this incomplete coverage, we may have missed BE cases diagnosed between baseline (1986) and 1991. We calculated how many cases we may have missed by multiplying the mean number of cases per year during the period a lab was connected by the number of years the lab was not connected to PALGA. This was done for each lab. This way we calculated that we may have missed approximately $3 \%$ of BE cases. At each of the 64 pathology laboratories in the Netherlands, excerpts of all pathology reports are 
generated automatically. Each excerpt contains a so-called PALGA diagnosis that describes topography, morphology, function, procedure, and disease. These excerpts are transferred to a central databank. ${ }^{23}$ The linkage with PALGA was carried out for 16.3 years of follow-up. ${ }^{24}$ All links were then manually checked for false-positives.

Thereafter, one pathologist (A.L.C.D.) and one pathologist in training (C.J.R.H.), who were blinded to the exposure status (i.e. the selenium status) of the cases, reviewed the excerpts of all pathology records to extract information on the initial date of diagnosis of $\mathrm{BE}$, the type of metaplasia, and the degree of dysplasia. Excluded were $\mathrm{BE}$ cases with an uncertain diagnosis, or a diagnosis specifying the presence of only non-intestinal type metaplasia. Also excluded were cases with a diagnosis of esophageal or gastric cancer before or less than a half year after the diagnosis of BE, and BE cases that were prevalent at baseline (Figure 3.1).

\begin{tabular}{|c|c|c|}
\hline \multicolumn{3}{|c|}{ Netherlands cohort study on diet and cancer (58,279 men and 62,573 women) } \\
\hline$\downarrow$ & & $\downarrow$ \\
\hline $\begin{array}{l}\text { Subcohort randomly } \\
\text { drawn from total cohort }\end{array}$ & \multicolumn{2}{|c|}{ Record linkage with PALGA until 31-12-2002 } \\
\hline \multirow[t]{4}{*}{$\downarrow$} & \multicolumn{2}{|c|}{$\begin{array}{l}\downarrow \\
2,376 \text { reports from } 1,185 \text { cases }\end{array}$} \\
\hline & \multicolumn{2}{|c|}{ Exclusion of false-positive links } \\
\hline & \multicolumn{2}{|c|}{$\begin{array}{c}\downarrow \\
1,954 \text { reports from } 974 \text { cases } \\
\end{array}$} \\
\hline & \multicolumn{2}{|c|}{ Review by pathologist: exclusion of uncertain diagnoses } \\
\hline 3,500 & \multicolumn{2}{|c|}{$\downarrow$} \\
\hline \multicolumn{3}{|c|}{ Exclusion of prevalent cancer and Barrett's esophagus cases at baseline } \\
\hline \multirow[t]{2}{*}{$\downarrow$} & \multicolumn{2}{|c|}{$\begin{array}{c}\downarrow \\
792 \text { cases }\end{array}$} \\
\hline & \multicolumn{2}{|c|}{$\begin{array}{l}\text { Exclusion of cases with esophageal or gastric cancer before or }<1 / 2 \\
\text { year after Barrett's diagnosis, and cases with only non-intestinal } \\
\text { metaplasia }\end{array}$} \\
\hline $\begin{array}{c}3,342 \\
\text { subcohort members }\end{array}$ & $\begin{array}{l}\downarrow \\
456 \text { Barrett's esophagus } \\
\text { cases with specialized } \\
\text { intestinal metaplasia }\end{array}$ & $\begin{array}{c}\downarrow \\
626 \text { Barrett's esophagus cases with } \\
\text { specialized intestinal metaplasia or } \\
\text { unknown metaplasia }\end{array}$ \\
\hline \multicolumn{3}{|c|}{$\begin{array}{l}\text { Exclusion if toenail clippings were not provided, }<10 \mathrm{mg} \text { of toenail clippings were available for } \\
\text { selenium determination, or if problems occurred with selenium determination }\end{array}$} \\
\hline$\downarrow$ & $\downarrow$ & $\downarrow$ \\
\hline 2,423 & 285 & 397 \\
\hline \multicolumn{3}{|c|}{ Exclusion if incomplete or inconsistent dietary data ${ }^{a}$} \\
\hline$\downarrow$ & $\downarrow$ & $\downarrow$ \\
\hline 2,294 & 285 & 397 \\
\hline \multicolumn{3}{|c|}{ Exclusion if missing data on confounders } \\
\hline$\stackrel{\downarrow}{2,039}$ & $\begin{array}{c}\downarrow \\
253\end{array}$ & $\begin{array}{c}\downarrow \\
346\end{array}$ \\
\hline
\end{tabular}

Figure 3.1 Flow diagram of subcohort members and Barrett's esophagus cases on whom the analyses were based. ${ }^{a}$ For reasons of efficiency, toenail material of Barrett's esophagus cases were not sent to laboratory for instrumental neutron activation analysis for determination of selenium levels, if they had incomplete or inconsistent questionnaire data. Therefore, this exclusion criterion did not anymore lead to exclusion of cases at this stage. 
Two definitions of BE were used: our primary case definition included only subjects with esophageal SIM. The secondary case definition included subjects (a) fulfilling the primary case definition or (b) with a pathology report stating 'Barrett's', without a description of the type of metaplasia. Furthermore, BE cases may progress to high-grade dysplasia or esophageal adenocarcinoma. We followed the BE cases until December 31, 2002 and we identified the subgroup of BE cases who showed one of these complications. For analyses of $\mathrm{BE}$ cases who progressed to esophageal adenocarcinoma, we selected only $\mathrm{BE}$ cases in whom the adenocarcinoma was diagnosed more than a half year after the diagnosis of BE. This time lag was chosen to be more sure that this was a new diagnosis of cancer that followed the BE.

\section{Exposure data}

In our cohort, about $75 \%$ of the subjects provided toenail clippings. Toenail selenium determinations were carried out by the Reactor Institute Delft (Delft University of Technology, Delft, the Netherlands). The determination was based on instrumental neutron activation analysis of the $77 \mathrm{mSe}$ isotope (half-life $17.5 \mathrm{~s}$ ). Each sample went through 6 cycles of $17 \mathrm{~s}$ irradiation at a thermal neutron flux of $3 \times 10^{16} \mathrm{~m}^{-2} \mathrm{~s}^{-1}, 3 \mathrm{~s}$ decay, and $17 \mathrm{~s}$ counting at $1 \mathrm{~cm}$ from a $40 \%$ germanium detector. This method, its accuracy and precision, and the use in the Netherlands Cohort Study have been described in more detail previously. ${ }^{25-28}$

In 1992, the toenail selenium determinations for the subcohort members were carried out (for the purpose of analysis of the association between selenium and risk of several cancers). In 2008, the toenail selenium determinations were carried out for the BE cases. In 1992, the 'SBP' facility was used for instrumental neutron activation analysis, and since 1996 the 'CAFIA' facility has been used. To assess the comparability of these two methods, the toenail selenium levels for 40 subcohort members were assessed in 1996 with the 'CAFIA' facility in addition to the original assessment with the 'SBP' facility. ${ }^{25}$ The mean (SD) selenium level assessed by the 'CAFIA' facility [0.552 $(0.05) \mu \mathrm{g} / \mathrm{g}$ ] was comparable with mean selenium levels assessed by the 'SBP' facility $[0.551(0.04) \mu \mathrm{g} / \mathrm{g}]$ for these subjects. The Pearson correlation coefficient between toenail selenium levels assessed by the 'CAFIA' facility and those estimated by the 'SBP' facility was $0.95(\mathrm{p}<0.01){ }^{25}$ It was concluded that both methods were comparable.

In 1992, all toenail clippings provided were sent to the Reactor Institute Delft for selenium determination. This determination however, yields unreliable results if the nails weigh $<10 \mathrm{mg}$ and these measurements were thus excluded. In 2007, we discovered that toenail clippings can also be used as a source of DNA. ${ }^{29}$ We therefore separated and saved 10-20 mg of toenail clippings from the BE cases. If afterwards, more than $10 \mathrm{mg}$ of toenail clippings were left, we sent them to the Reactor Institute Delft for selenium determination. In case there were problems with the determination of toenail selenium the subject was excluded (Figure 3.1). 
The self-administered questionnaire, which was filled out by all cohort members at baseline, consisted of a 150-item food frequency questionnaire (FFQ) and other questions, e.g. on smoking, education, height, weight, and use of medication. The FFQ asked about habitual consumption in the year before the start of the study. We calculated mean daily nutrient intakes using the Dutch food-composition table ${ }^{30}$. The questionnaire data were key entered and processed in a standardized manner, blinded with respect to cases/subcohort status to minimize observer bias in coding and interpretation of the data.

\section{Statistical analysis}

To evaluate the potential influence of prediagnostic BE at baseline on toenail selenium levels, cases were categorized according to the year of follow-up in which they were diagnosed. The mean toenail selenium levels of the cases according to the year of follow-up were compared and differences were tested using a t-test. For the t-test, selenium levels were In-transformed to normalize the distribution. For the case-cohort analysis, toenail selenium levels were categorized into quartiles according to the distribution in the subcohort. For continuous analysis, a $0.06 \mu \mathrm{g} / \mathrm{g}$ increment in toenail selenium was chosen. This is equal to the average size of the two central quartiles.

We excluded subjects who had inconsistent or incomplete dietary questionnaire data, because dietary data were needed as potential confounders and in subgroup analyses. ${ }^{31}$ Subjects with missing data on the confounders were also excluded (Figure 3.1).

The following variables were considered confounders and included in the multivariable regression model: age, sex, cigarette smoking (current yes/no, number of cigarettes/day, and number of smoking years), alcohol consumption (g/day), and body mass index $\left(\mathrm{kg} / \mathrm{m}^{2}\right)$. The following variables were considered potential confounders, but were not included in the models because they did not change the incidence rate ratio $(R R)$ by $>5 \%$ : highest level of education, family history of esophageal or gastric cancer, reported long-term (>0.5 years) use of nonsteroidal anti-inflammatory drugs or aspirin, or lower esophageal sphincter relaxing medication, ${ }^{32}$ non-occupational physical activity, daily intakes of the antioxidants vitamin $C$, vitamin $E, \alpha$-carotene, $\beta$ carotene, $\beta$-cryptoxanthin, lycopene, and lutein/ zeaxanthin. Figure 3.1 shows that complete data were available for 2039 subcohort members, 253 BE cases fulfilling the primary case definition and $346 \mathrm{BE}$ cases fulfilling the secondary case definition.

Multivariable adjusted RR and corresponding 95\% confidence intervals $(\mathrm{Cl})$ were estimated using Cox proportional hazards models ${ }^{33}$ in Stata 9.2 (StataCorp, College Station, Texas, USA). Standard errors were estimated using the robust Huber-White sandwich estimator to account for additional variance introduced by sampling from the cohort. This method is equivalent to the variance-covariance estimator by Barlow. ${ }^{34}$ We tested the proportional hazards assumption using the scaled Schoenfeld residuals. ${ }^{35}$ Tests for dose-response trends were assessed by fitting ordinal exposure 
variables as continuous terms. Two-sided $P$ values are reported throughout the article. The significance level $\alpha$ was set at 0.05 .

We investigated possible interactions between toenail selenium status and sex, cigarette smoking status, BMI, and intakes of several antioxidants by estimating RR in strata of these exposures. The $p$ value for interaction was assessed by including a cross-product term in the model. To evaluate potential differences in the association during early and late follow-up, we stratified our analysis by follow-up period. Finally, we analyzed the subgroup of BE cases that progressed to high-grade dysplasia and/or esophageal adenocarcinoma during follow-up until 2002, as this is the group most relevant with respect to disease burden. Because of the low number of cases in this subgroup ( $n=21)$, we used two instead of four exposure categories: above and below the median selenium concentration.

\section{RESULTS}

\section{Descriptives}

Table 3.1 shows the mean toenail selenium levels of BE cases, stratified by two-year follow-up periods in which they were diagnosed. The toenail selenium levels in the first two follow-up years were lower than in later follow-up years, and this difference was borderline statistically significant $(p=0.07)$ for BE cases with SIM. As this difference may indicate an effect of prediagnostic disease on toenail selenium levels, we decided to exclude the first two years of follow-up from the analysis to prevent bias.

Table 3.1 Toenail selenium levels $(\mu \mathrm{g} / \mathrm{g})$ in Barrett's esophagus cases according to sex and time between baseline and diagnosis; Netherlands Cohort Study (1986-2002, n=120,852).

\begin{tabular}{|c|c|c|c|c|c|c|c|c|}
\hline \multirow{4}{*}{ Cases $^{\mathrm{a}}$} & \multicolumn{8}{|c|}{ Barrett's esophagus } \\
\hline & \multicolumn{4}{|c|}{ SIM } & \multicolumn{4}{|c|}{ SIM or unknown metaplasia } \\
\hline & \multicolumn{4}{|c|}{ Toenail selenium level $(\mu \mathrm{g} / \mathrm{g})$} & \multicolumn{4}{|c|}{ Toenail selenium level $(\mu \mathrm{g} / \mathrm{g})$} \\
\hline & No. cases & mean & SD & $p^{b}$ & No. cases & mean & SD & $\mathrm{p}^{\mathrm{b}}$ \\
\hline All cases & 285 & 0.563 & 0.097 & & 397 & 0.562 & 0.112 & \\
\hline Men & 163 & 0.556 & 0.100 & & 226 & 0.558 & 0.127 & \\
\hline Women & 122 & 0.571 & 0.093 & & 171 & 0.568 & 0.087 & \\
\hline \multicolumn{9}{|c|}{ Follow-up year in which case was diagnosed } \\
\hline $0-2$ & 5 & 0.488 & 0.047 & 0.07 & 10 & 0.536 & 0.099 & 0.39 \\
\hline$>2-4$ & 17 & 0.531 & 0.086 & & 31 & 0.566 & 0.210 & \\
\hline$>4-6$ & 17 & 0.540 & 0.087 & & 28 & 0.553 & 0.091 & \\
\hline$>6-8$ & 38 & 0.557 & 0.058 & & 54 & 0.552 & 0.068 & \\
\hline$>8-10$ & 50 & 0.573 & 0.113 & & 71 & 0.565 & 0.102 & \\
\hline$>10-12$ & 55 & 0.555 & 0.096 & & 74 & 0.561 & 0.120 & \\
\hline$>12-14$ & 54 & 0.585 & 0.107 & & 69 & 0.572 & 0.103 & \\
\hline$>14-17$ & 49 & 0.568 & 0.099 & & 60 & 0.565 & 0.094 & \\
\hline
\end{tabular}

${ }^{a}$ Mean (SD) selenium levels in subcohort members were $0.547(0.126) \mu \mathrm{g} / \mathrm{g}$ for men $(\mathrm{n}=1212)$ and 0.575 (0.109) $\mu \mathrm{g} / \mathrm{g}$ for women $(\mathrm{n}=1244) ;{ }^{\mathrm{b}}$ T-test of mean toenail selenium levels (In-transformed) for cases diagnosed in the first 2 years of follow-up versus levels for cases diagnosed during the remainder of followup years. 
Characteristics of the subcohort and BE cases are described in Table 3.2. Subcohort members had a median toenail selenium level of $0.553 \mu \mathrm{g} / \mathrm{g}$, with lower levels in men (median $0.539 \mu \mathrm{g} / \mathrm{g}$ ) than in women $(0.564 \mu \mathrm{g} / \mathrm{g}$ ). The median toenail selenium levels in the two BE case groups were comparable $(0.552$ and $0.553 \mu \mathrm{g} / \mathrm{g})$. With respect to other characteristics, there were more men and former smokers among the cases, when compared with the subcohort. Furthermore, cases had somewhat lower intakes of carotenoids, and were more likely to be long-term users of non-steroidal anti-inflammatory drugs/aspirin and lower esophageal sphincter relaxing medication.

\section{Main analysis}

Table 3.3 presents multivariable adjusted RR of BE according to toenail selenium levels. The RR of BE with SIM was 1.06 (95\% Cl: 0.71, 1.57) for the highest versus the lowest quartile of toenail selenium, and no dose-response trend was observed ( $p$ trend=0.99). Multivariable analyses stratified by sex showed some differences in associations for men (RR quartile 4 vs. quartile $1=1.31,95 \% \mathrm{Cl}$ : $0.78,2.21$ ) and women (RR quartile 4 vs. quartile $1=0.85,95 \% \mathrm{Cl}: 0.46,1.57)$, but the interaction between toenail selenium and sex was not statistically significant ( $p$ interaction=0.18). The results were all comparable to the age- and sex-adjusted results (Table 3.3). When we used the less stringent secondary case definition of $\mathrm{BE}$, the results were very similar to those based on the primary case definition (Table 3.3).

\section{Interaction and subgroup analyses}

When analyses were performed in strata of smoking status, body mass index, or daily intake of antioxidants, no statistically significant or important differences in associations were observed between strata, and the RR were all around unity. Again, results were similar for the two BE case groups (see Supplemental Table 3.1). Analyses stratified by follow-up period (early vs. late follow-up) showed no statistically significant associations or dose-response trends in either period (data not shown).

An inverse association was found between toenail selenium and risk of BE that progressed to high-grade dysplasia and/or adenocarcinoma (Table 3.4). The multivariable RR for a toenail selenium level above the median vs. below the median was 0.64 , although the confidence interval was relatively wide $(95 \% \mathrm{Cl}: 0.24,1.76)$, due to the low case number in this analysis $(n=21)$. 
Table 3.2 Characteristics of cases and subcohort members in the Netherlands Cohort Study (1986-2002, $n=120,852$ ).

\begin{tabular}{|c|c|c|c|}
\hline \multirow{3}{*}{ Characteristic } & \multirow{2}{*}{$\frac{\text { Subcohort }}{(n=2039)^{a}}$} & \multicolumn{2}{|c|}{ Barrett's esophagus cases } \\
\hline & & \multirow{2}{*}{$\begin{array}{l}\text { SIM }(n=253)^{a} \\
\text { Median (IQR) }\end{array}$} & \multirow{2}{*}{$\begin{array}{c}\text { SIM or unknown } \\
\text { metaplasia }(n=346) \\
\text { Median (IQR) }\end{array}$} \\
\hline & Median (IQR) & & \\
\hline \multicolumn{4}{|l|}{ Toenail selenium level $(\mu \mathrm{g} / \mathrm{g})$} \\
\hline total & $0.553(0.498-0.613)$ & $0.552(0.501-0.615)$ & $0.553(0.500-0.607)$ \\
\hline men & $0.539(0.483-0.602)$ & $0.551(0.495-0.615)$ & $0.544(0.492-0.605)$ \\
\hline \multirow[t]{2}{*}{ women } & $0.564(0.514-0.623)$ & $0.555(0.508-0.622)$ & $0.565(0.509-0.613)$ \\
\hline & Mean (SD) ${ }^{b}$ & Mean (SD) ${ }^{b}$ & Mean (SD) ${ }^{b}$ \\
\hline Age at baseline (years) & $61.2(4.2)$ & $60.8(4.2)$ & $61.1(4.1)$ \\
\hline Men (\%) & 49 & 59 & 58 \\
\hline \multicolumn{4}{|l|}{ Cigarette smoking status } \\
\hline never smoker (\%) & 38 & 30 & 31 \\
\hline former smoker (\%) & 37 & 51 & 48 \\
\hline current smoker (\%) & 25 & 19 & 21 \\
\hline \multicolumn{4}{|l|}{ Ever cigarette smokers: } \\
\hline Frequency of cigarette smoking (n/day) & $15.2(10.3)$ & $16.6(11.6)$ & $16.5(11.1)$ \\
\hline Duration of cigarette smoking (years) & $31.0(12.2)$ & $30.4(11.8)$ & $30.7(12.0)$ \\
\hline Ethanol intake (g/day) & $10.2(14.3)$ & $10.8(15.0)$ & $10.8(15.0)$ \\
\hline Body mass index $\left(\mathrm{kg} / \mathrm{m}^{2}\right)$ & $25.0(3.1)$ & $25.3(2.9)$ & $25.3(2.8)$ \\
\hline $\begin{array}{l}\text { Non-occupational physical activity } \\
\text { (min/day) }\end{array}$ & $73(58)$ & $69(53)$ & $70(55)$ \\
\hline \multicolumn{4}{|l|}{ Highest level of education } \\
\hline primary (\%) & 27 & 27 & 30 \\
\hline lower vocational (\%) & 22 & 20 & 20 \\
\hline secondary and medium vocational (\%) & 37 & 36 & 35 \\
\hline university and higher vocational (\%) & 14 & 17 & 15 \\
\hline Vitamin C intake (mg/day) & $104(42)$ & $101(44)$ & $100(43)$ \\
\hline Vitamin E intake (mg/day) & $14(6)$ & $14(6)$ & $13(6)$ \\
\hline$\alpha$-carotene intake ( $\mu \mathrm{g} /$ day) & $711(588)$ & $670(502)$ & $670(512)$ \\
\hline$\beta$-carotene intake ( $\mu \mathrm{g} /$ day) & 3001 (1589) & $2821(1382)$ & $2805(1398)$ \\
\hline$\beta$-cryptoxanthin intake ( $\mu \mathrm{g} /$ day) & $181(165)$ & $177(167)$ & $176(166)$ \\
\hline Lycopene intake ( $\mu \mathrm{g} / \mathrm{day})$ & $1214(1773)$ & $1203(2469)$ & $1125(2202)$ \\
\hline Lutein/zeaxanthin intake ( $\mu \mathrm{g} /$ day) & $2518(1079)$ & $2353(904)$ & $2341(925)$ \\
\hline $\begin{array}{l}\text { Family history of esophageal or gastric } \\
\text { cancer (\%) }\end{array}$ & 8 & 8 & 8 \\
\hline $\begin{array}{l}\text { Use of non-steroidal anti-inflammatory } \\
\text { drugs and aspirin (\%) }{ }^{c}\end{array}$ & 7 & 11 & 10 \\
\hline $\begin{array}{l}\text { Use of lower esophageal sphincter } \\
\text { relaxing medication (\%) }\end{array}$ & 14 & 19 & 20 \\
\hline
\end{tabular}

IQR, interquartile range. ${ }^{a}$ Presented are the number of subcohort members or cases with complete data on toenail selenium level, age, sex, cigarette smoking (current yes/no, number of cigarettes smoked daily, number of smoking years), alcohol consumption and body mass index. Subcohort members and cases with incomplete or inconsistent questionnaire data are excluded; ${ }^{b}$ For categorical variables a percentage is presented; ' Self reported use during more than 0.5 year. 


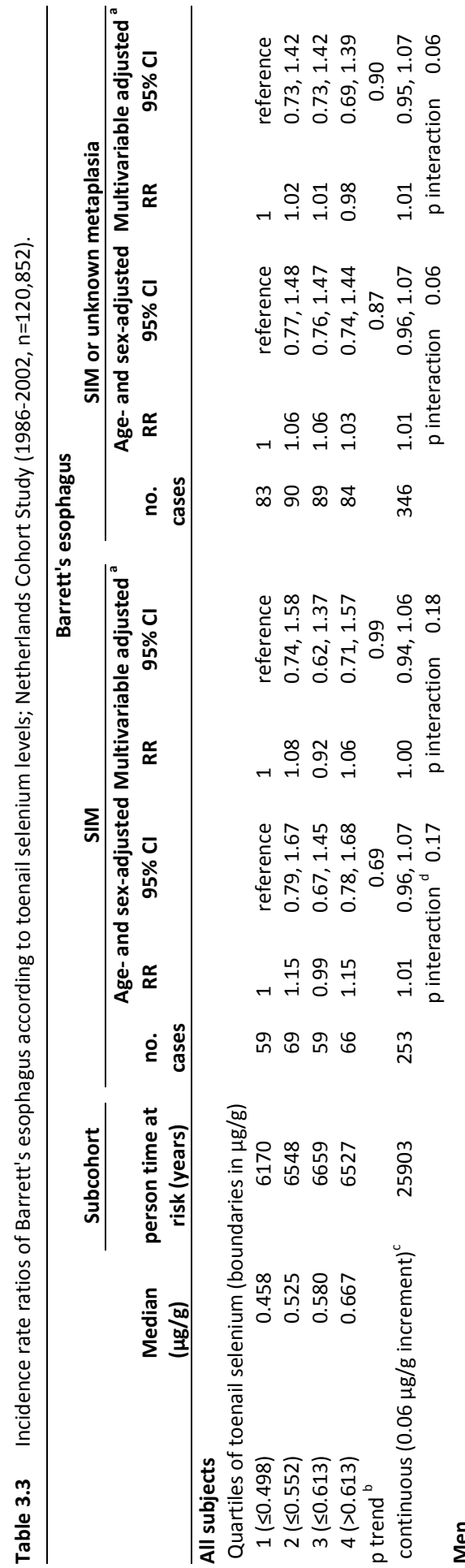

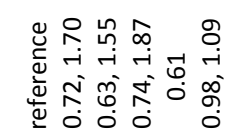

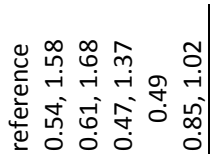

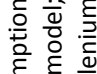

동워

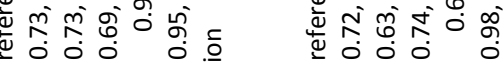

육 ᄋ̊ํㅇ

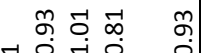

응 둥

नति

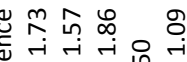

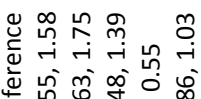

은 든

홍응 음

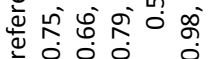

巡

중

등 웡

흠.. 흠

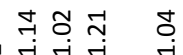

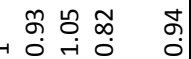

을

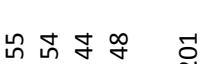

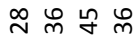

त

중 흥 훈

นึน

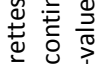
要 to $\frac{\tilde{u}}{0} \dot{\underline{\omega}}$

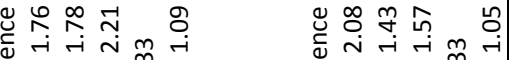

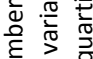

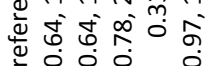

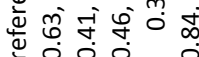

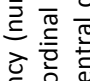

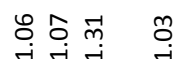

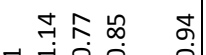

흘

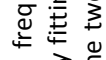

음로

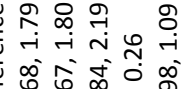

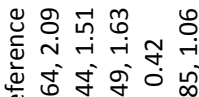

政。

岕岕芯

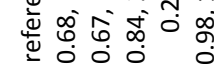

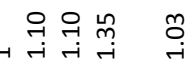

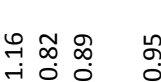

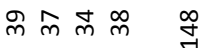

กิ ก ก ก

号

0
0
0

它 을

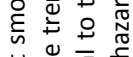

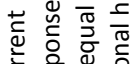

言这品.

然

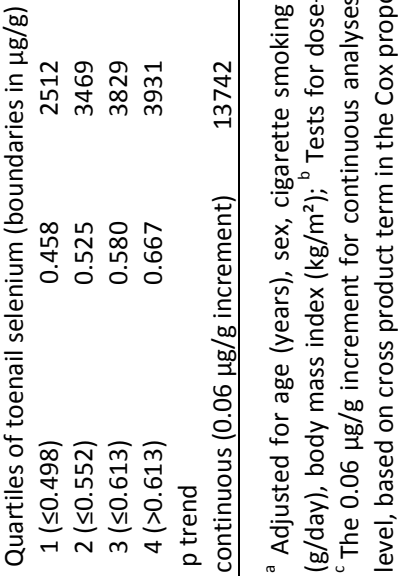


Table 3.4 Incidence rate ratios of Barrett's esophagus cases who developed high grade dysplasia or adenocarcinoma according to toenail selenium levels; Netherlands Cohort Study (1986-2002, $n=120,852)$.

\begin{tabular}{|c|c|c|c|c|c|c|c|}
\hline & \multirow[b]{3}{*}{$\begin{array}{l}\text { Median within } \\
\text { category } \mu \mathrm{g} / \mathrm{g}\end{array}$} & \multirow{3}{*}{$\begin{array}{c}\text { Subcohort } \\
\\
\text { person time } \\
\text { at risk } \\
\text { (years) }\end{array}$} & \multicolumn{5}{|c|}{$\begin{array}{l}\text { Barrett's esophagus with high grade dysplasia } \\
\text { and/or adenocarcinoma }\end{array}$} \\
\hline & & & \multirow[b]{2}{*}{$\begin{array}{l}\text { no. } \\
\text { cases }\end{array}$} & \multicolumn{2}{|c|}{$\begin{array}{c}\text { Age- and } \\
\text { sex-adjusted }\end{array}$} & \multicolumn{2}{|c|}{$\begin{array}{c}\text { Multivariable } \\
\text { adjusted }^{\text {a }}\end{array}$} \\
\hline & & & & $\mathbf{R R}$ & $95 \% \mathrm{Cl}$ & $\mathbf{R R}$ & $95 \% \mathrm{Cl}$ \\
\hline \multicolumn{8}{|c|}{ Categories of toenail selenium, based on a median split (boundary in $\mu \mathrm{g} / \mathrm{g}$ ) } \\
\hline $1(\leq 0.552)$ & 0.497 & 12717 & 13 & 1 & reference & 1 & reference \\
\hline $2(>0.552)$ & 0.615 & 13185 & 8 & 0.63 & $0.26,1.56$ & 0.64 & $0.24,1.76$ \\
\hline $\begin{array}{l}\text { Continuous } \\
\text { Increment) }\end{array}$ & $\mu \mathrm{g} / \mathrm{g}$ & 25903 & 21 & 1.10 & $0.99,1.22$ & 1.11 & $0.99,1.24$ \\
\hline
\end{tabular}

a adjusted for age (years), sex, cigarette smoking (current smoking status (yes/no), frequency (number of cigarettes/day), and duration (years)), alcohol consumption (g/day), body mass index $\left(\mathrm{kg} / \mathrm{m}^{2}\right){ }^{\text {b }}{ }^{\text {The RRs of }}$ the continuous analyses are influenced by one case with a very high toenail selenium level $(1.612 \mu \mathrm{g} / \mathrm{g})$. When this case was excluded, the age- and sex-adjusted RR was $0.96(95 \% \mathrm{Cl} 0.79-1.17)$ and the multivariable adjusted RR was 0.96 (95\% $\mathrm{Cl} 0.77-1.20)$.

\section{DISCUSSION}

To our knowledge, this is the second investigation, and first cohort study, into the possible role of selenium in the etiology of $\mathrm{BE}$, a precursor lesion of esophageal adenocarcinoma. The results from this prospective cohort study do not support our hypothesis that an inverse association might exist. Neither did we find evidence of an association in subgroups defined by sex, smoking status, BMI, intake of antioxidants or follow-up period.

The Dutch population that was used in this study, has a low to moderate toenail selenium level (mean: $0.564 \mu \mathrm{g} / \mathrm{g}$ in the subcohort) when compared with mean levels found in other populations (general population or control subjects): China (Sichuan province) $0.211 \mu \mathrm{g} / \mathrm{g}^{36}$ Finland $0.47 \mu \mathrm{g} / \mathrm{g}^{37}$ USA $0.83-0.92 \mu \mathrm{g} / \mathrm{g}^{38}$ Colombia $0.945 \mu \mathrm{g} / \mathrm{g}^{39}$ and USA (South Dakota/Wyoming) $1.517 \mu \mathrm{g} / \mathrm{g} .{ }^{19}$

In the Netherlands, both the USA and UK case definitions of BE may have been used. The use of these definitions may have changed over time and different pathologists may have used different definitions.

The first strength of our study is its prospective character, which brings the advantage of measuring the selenium status before the diagnosis of BE. This method makes it unlikely that the exposure was changed due to the disease or knowledge of the diagnosis, and therefore it lowers the chance of reversed causation. A second strength is the size of the study. This study had $80 \%$ power to detect an RR of 0.63 for 
all BE cases and an RR of 0.59 for BE cases with SIM. ${ }^{40}$ Thirdly, we had the possibility to adjust for confounding by several lifestyle factors. A fourth strength is the use of toenail clippings for the measurement of selenium exposure, because selenium levels in clippings from all toes represent an exposure period of up to one year. Measuring long-term exposure is important as it more likely represents the exposure in the etiologically relevant time window compared with a measure of short-term exposure.

A limitation of our study is the lack of information about gastroesophageal reflux disease and medications related to this disease. In the baseline questionnaire one question concerned the long-term use of medications and the disease for which these were prescribed. However, we believe that the reported use of reflux medication and antacids, and presence of gastroesophageal reflux disease were substantially lower than the actual frequency. This prohibited us to use this information in the analysis. Consequently, we were not able to evaluate if gastroesophageal reflux disease is a confounder or intermediate factor in the relation between selenium and BE. We therefore suggest that this study is replicated in a population for which information on gastroesophageal reflux is available, to evaluate its possible role as confounder or intermediate factor. A second limitation is the single measurement of the exposure. Selenium exposure may have changed during follow-up due to changed selenium levels in foods or changed dietary habits. Third, we did not have the opportunity to verify the absence of $B E$ in the subcohort members who were not diagnosed with $B E$. BE usually occurs in patients with gastroesophageal reflux disease, but it has also been described in asymptomatic individuals, who are therefore not diagnosed with the disease. Three studies investigated the prevalence of $\mathrm{BE}$ among asymptomatic individuals in the USA and reported prevalences ranging from $1 \%$ to $25 \% .{ }^{41-43}$ However, in our cohort study, any undiagnosed BE cases would most likely not have influenced the RR. This is because the imperfect sensitivity (i.e. false-negatives) is combined with good specificity (i.e. few false positives), and the chance of diagnosis is likely independent of selenium status. The misclassification of the disease status then is nondifferential and will not influence the RR. ${ }^{44}$ Still, a consequence of undiagnosed cases is a reduced power to detect an existing association. A fourth limitation, related to the third, is caused by the incomplete coverage of the Netherlands by PALGA before 1991 . There may have been some BE cases that were diagnosed in laboratories when these had not yet joined PALGA. If these cases were not followed-up, we missed their diagnosis. If they were followed-up after the laboratory joined PALGA, the incidence date we registered is more recent than the true incidence date. We assessed that we may have missed $3 \%$ of the BE cases in our cohort at most.

If, in line with our null findings there is truly no association between toenail selenium and the risk of $\mathrm{BE}$, this does not preclude a possible association between selenium and progression of BE to high-grade dysplasia or adenocarcinoma. We observed an RR well below unity for subjects with a toenail selenium level above the median in those $B E$ cases who progressed to high-grade dysplasia and/or esophageal adenocarcinoma. This RR, however, was based on few cases and was not statistically 
significant. In a previous analysis we found indications for an inverse association between selenium and risk of esophageal adenocarcinoma in some subgroups: women, never smokers, and low antioxidant consumers. ${ }^{14}$ These above-mentioned observations are in agreement with observations by two other studies that found indications for a role of selenium in later stages of the carcinogenesis of esophageal adenocarcinoma. ${ }^{15,16}$ Selenium might be an interesting preventive agent for progression to esophageal adenocarcinoma in patients with $\mathrm{BE}$, but this requires a larger body of evidence.

In conclusion, no evidence of an inverse association between toenail selenium and risk of BE was found in this study. An inverse association might exist for BE cases that progress to high-grade dysplasia and/or esophageal adenocarcinoma, but results from other studies are needed before any firm conclusions can be drawn. Preferably, future studies should have a prospective character and should have the possibility to investigate the role of gastroesophageal reflux in this association. Also, it would be informative to study the relation between selenium and risk of BE in a population with selenium levels that are lower or higher compared with our study population. 
Supplemental Table 3.1 Association ${ }^{a}$ between toenail selenium levels and risk of Barrett's esophagus stratified by cigarette smoking status, body mass index and intake levels of antioxidants; Netherlands Cohort Study (1986-2002, n=120,852)

\begin{tabular}{|c|c|c|c|c|c|c|c|}
\hline & \multirow{3}{*}{$\begin{array}{c}\text { Subcohort } \\
\text { person time } \\
\text { at risk } \\
\text { (years) }\end{array}$} & \multicolumn{6}{|c|}{ Barrett's esophagus } \\
\hline & & \multicolumn{3}{|c|}{ SIM } & \multicolumn{3}{|c|}{ SIM or unknown metaplasia } \\
\hline & & $\begin{array}{c}\text { no. } \\
\text { cases }\end{array}$ & $\mathbf{R R}^{\mathbf{b}}$ & $95 \% \mathrm{Cl}$ & $\begin{array}{c}\text { no. } \\
\text { cases }\end{array}$ & $\mathbf{R R}^{\mathbf{b}}$ & $95 \% \mathrm{Cl}$ \\
\hline \multicolumn{8}{|c|}{ Cigarette smoking status } \\
\hline Never smoker & 10157 & 77 & 0.98 & $0.87,1.10$ & 108 & 0.95 & $0.86,1.05$ \\
\hline Former smoker & 9358 & 128 & 1.00 & $0.92,1.08$ & 165 & 1.00 & $0.93,1.08$ \\
\hline \multirow[t]{2}{*}{ Current smoker } & 6389 & 48 & 1.07 & $0.88,1.29$ & 73 & 1.14 & $0.91,1.43$ \\
\hline & & \multicolumn{2}{|c|}{ p interaction } & 0.78 & \multicolumn{2}{|c|}{ p interaction } & 0.35 \\
\hline \multicolumn{8}{|c|}{ Body mass index $\left(\mathrm{kg} / \mathrm{m}^{2}\right)$} \\
\hline$<25$ & 13930 & 131 & 1.01 & $0.96,1.07$ & 178 & 1.01 & $0.95,1.06$ \\
\hline \multirow[t]{2}{*}{$\geq 25$} & 11973 & 122 & 0.96 & $0.83,1.10$ & 168 & 0.99 & $0.86,1.14$ \\
\hline & & \multicolumn{2}{|c|}{ p interaction } & 0.73 & \multicolumn{2}{|c|}{ p interaction } & 0.79 \\
\hline \multicolumn{8}{|c|}{ Antioxidant intake } \\
\hline \multicolumn{8}{|c|}{ Vitamin C intake $(\mathrm{mg} / \mathrm{d})$} \\
\hline $\operatorname{low}(\leq 97)$ & 12700 & 139 & 1.01 & $0.95,1.09$ & 189 & 1.01 & $0.94,1.07$ \\
\hline \multirow[t]{2}{*}{ high (>97) } & 13204 & 114 & 0.99 & $0.90,1.08$ & 157 & 1.01 & $0.91,1.12$ \\
\hline & & \multicolumn{2}{|c|}{ p interaction } & 0.76 & \multicolumn{2}{|c|}{ p interaction } & 0.90 \\
\hline \multicolumn{8}{|c|}{ Vitamin E intake $(\mathrm{mg} / \mathrm{d})$} \\
\hline $\operatorname{low}(\leq 12)$ & 12901 & 113 & 1.01 & $0.90,1.13$ & 166 & 1.06 & $0.95,1.19$ \\
\hline \multirow[t]{2}{*}{ high (> 12) } & 13002 & 140 & 0.99 & $0.92,1.07$ & 180 & 0.96 & $0.89,1.04$ \\
\hline & & \multicolumn{2}{|c|}{ p interaction } & 0.78 & \multicolumn{2}{|c|}{ p interaction } & 0.16 \\
\hline \multicolumn{8}{|c|}{$\alpha$-carotene intake $(\mu \mathrm{g} / \mathrm{d})$} \\
\hline $\operatorname{low}(\leq 573)$ & 12708 & 132 & 1.04 & $0.93,1.16$ & 183 & 1.03 & $0.94,1.14$ \\
\hline \multirow[t]{2}{*}{ high (> 573) } & 13195 & 121 & 0.97 & $0.89,1.06$ & 163 & 0.99 & $0.90,1.08$ \\
\hline & & \multicolumn{2}{|c|}{ p interaction } & 0.37 & \multicolumn{2}{|c|}{ p interaction } & 0.46 \\
\hline$\beta$-carotene intak & & & & & & & \\
\hline low $(\leq 2680)$ & 12817 & 139 & 1.01 & $0.95,1.08$ & 196 & 1.01 & $0.95,1.07$ \\
\hline high (> 2680) & 13086 & 114 & 0.97 & $0.88,1.08$ & 150 & 1.00 & $0.88,1.12$ \\
\hline & & $p$ int & raction & 0.62 & p int & raction & 0.78 \\
\hline$\beta$-cryptoxanthin & $(\mu \mathrm{g} / \mathrm{d})$ & & & & & & \\
\hline $\operatorname{low}(\leq 130)$ & 12669 & 129 & 1.01 & $0.91,1.13$ & 176 & 1.03 & $0.92,1.15$ \\
\hline high (> 130) & 13234 & 124 & 0.99 & $0.92,1.07$ & 170 & 0.99 & $0.92,1.06$ \\
\hline & & $p$ int & raction & 0.60 & p int & raction & 0.48 \\
\hline Lycopene intake & & & & & & & \\
\hline $\operatorname{low}(\leq 823)$ & 12857 & 141 & 0.98 & $0.89,1.07$ & 203 & 0.96 & $0.89,1.04$ \\
\hline high (> 823) & 13046 & 112 & 1.04 & $0.94,1.14$ & 143 & 1.08 & $0.97,1.20$ \\
\hline & & $\mathrm{p}$ int & raction & 0.46 & p int & raction & 0.13 \\
\hline Lutein/Zeaxanth & $e(\mu \mathrm{g} / \mathrm{d})$ & & & & & & \\
\hline $\operatorname{low}(\leq 2360)$ & 12876 & 146 & 1.00 & $0.92,1.08$ & 198 & 0.99 & $0.92,1.07$ \\
\hline high (> 2360) & 13027 & 107 & 1.01 & $0.91,1.12$ & 148 & 1.02 & $0.92,1.14$ \\
\hline & & p int & raction & 0.66 & p int & raction & 0.60 \\
\hline
\end{tabular}

\footnotetext{
${ }^{a}$ Adjusted for age (years), sex, cigarette smoking (current smoking status (yes/no), frequency (number of cigarettes/day), and duration (years)), alcohol consumption (g/day), body mass index $\left(\mathrm{kg} / \mathrm{m}^{2}\right)$, if applicable; ${ }^{\mathrm{b}} \mathrm{RR}$ per $0.06 \mu \mathrm{g} / \mathrm{g}$ increment of toenail selenium. This increment is equal to the average size of the two central quartiles; ' $\mathrm{p}$-value for interaction between sex and toenail selenium level, based on cross product term in the Cox proportional hazard model.
} 


\section{REFERENCES}

1. Wang KK, Sampliner RE. Updated guidelines 2008 for the diagnosis, surveillance and therapy of Barrett's esophagus. Am J Gastroenterol 2008;103:788-797.

2. Playford RJ. New British Society of Gastroenterology (BSG) guidelines for the diagnosis and management of Barrett's oesophagus. Gut 2006;55:442-443.

3. Falk GW. Barrett's esophagus. Gastroenterology 2002;122:1569-1591.

4. Post PN, Siersema PD, van Dekken H. Rising incidence of clinically evident Barrett's oesophagus in The Netherlands: a nation-wide registry of pathology reports. Scand J Gastroenterol 2007;42:17-22.

5. Yousef F, Cardwell C, Cantwell MM, Galway K, Johnston BT, Murray L. The incidence of esophageal cancer and high-grade dysplasia in Barrett's esophagus: a systematic review and meta-analysis. Am J Epidemiol 2008;168:237-249.

6. Rastogi A, Puli S, El-Serag HB, Bansal A, Wani S, Sharma P. Incidence of esophageal adenocarcinoma in patients with Barrett's esophagus and high-grade dysplasia: a meta-analysis. Gastrointest Endosc 2008;67:394-398.

7. Wild CP, Hardie LJ. Reflux, Barrett's oesophagus and adenocarcinoma: burning questions. Nat Rev Cancer 2003;3:676-684.

8. Anderson LA, Watson RG, Murphy SJ, Johnston BT, Comber H, Mc Guigan J, Reynolds JV, Murray LJ. Risk factors for Barrett's oesophagus and oesophageal adenocarcinoma: results from the FINBAR study. World J Gastroenterol 2007;13:1585-1594.

9. Kubo A, Levin TR, Block G, Rumore GJ, Quesenberry CP, Jr., Buffler P, Corley DA. Dietary patterns and the risk of Barrett's Esophagus. Am J Epidemiol 2008;167:839-846.

10. Rayman MP. Selenium in cancer prevention: a review of the evidence and mechanism of action. Proc Nutr Soc 2005;64:527-542.

11. Navarro Silvera SA, Rohan TE. Trace elements and cancer risk: a review of the epidemiologic evidence. Cancer Causes Control 2007;18:7-27.

12. World Cancer Research Fund, American Institute for Cancer Research. Food, nutrition, physical activity and the prevention of cancer: a global perspective. AICR, 2007.

13. Clark LC, Combs GF, Jr., Turnbull BW, Slate EH, Chalker DK, Chow J, Davis LS, Glover RA, Graham GF, Gross EG, Krongrad A, Lesher JL, Jr., Park HK, Sanders BB, Jr., Smith CL, Taylor JR. Effects of selenium supplementation for cancer prevention in patients with carcinoma of the skin. A randomized controlled trial. Nutritional Prevention of Cancer Study Group. Jama 1996;276:1957-1963.

14. Steevens J, van den Brandt PA, Goldbohm RA, Schouten LJ. Selenium status and the risk of esophageal and gastric cancer subtypes: the Netherlands cohort study. Gastroenterology 2010;138:1704-1713.

15. Rudolph RE, Vaughan TL, Kristal AR, Blount PL, Levine DS, Galipeau PC, Prevo LJ, Sanchez CA, Rabinovitch PS, Reid BJ. Serum selenium levels in relation to markers of neoplastic progression among persons with Barrett's esophagus. J Natl Cancer Inst 2003;95:750-757.

16. Moe GL, Kristal AR, Levine DS, Vaughan TL, Reid BJ. Waist-to-hip ratio, weight gain, and dietary and serum selenium are associated with DNA content flow cytometry in Barrett's esophagus. Nutr Cancer 2000;36:7-13.

17. Peng DF, Razvi M, Chen H, Washington K, Roessner A, Schneider-Stock R, El-Rifai W. DNA hypermethylation regulates the expression of members of the Mu-class glutathione S-transferases and glutathione peroxidases in Barrett's adenocarcinoma. Gut 2009;58:5-15.

18. Willett WC, Buzzard IM. Foods and nutrients. In: Willett WC, ed. Monographs in Epidemiology and Biostatistics. Volume 30. Nutritional epidemiology. New York: Oxford Universtiy Press, 1998:18-32.

19. Longnecker MP, Stram DO, Taylor PR, Levander OA, Howe M, Veillon C, McAdam PA, Patterson KY, Holden JM, Morris JS, Swanson CA, Willett WC. Use of selenium concentration in whole blood, serum, toenails, or urine as a surrogate measure of selenium intake. Epidemiology 1996;7:384-390.

20. Hunter DJ, Morris JS, Chute CG, Kushner E, Colditz GA, Stampfer MJ, Speizer FE, Willett WC. Predictors of selenium concentration in human toenails. Am J Epidemiol 1990;132:114-122.

21. van den Brandt PA, Goldbohm RA, van 't Veer P, Volovics A, Hermus RJ, Sturmans F. A large-scale prospective cohort study on diet and cancer in The Netherlands. J Clin Epidemiol 1990;43:285-295.

22. Barlow WE, Ichikawa L, Rosner D, Izumi S. Analysis of case-cohort designs. J Clin Epidemiol 1999;52:1165-1172. 
23. Casparie M, Tiebosch AT, Burger G, Blauwgeers H, van de Pol A, van Krieken JH, Meijer GA. Pathology databanking and biobanking in The Netherlands, a central role for PALGA, the nationwide histopathology and cytopathology data network and archive. Cell Oncol 2007;29:19-24.

24. van den Brandt PA, Schouten LJ, Goldbohm RA, Dorant E, Hunen PM. Development of a record linkage protocol for use in the Dutch Cancer Registry for Epidemiological Research. Int J Epidemiol 1990;19:553-558.

25. Zeegers MP, Goldbohm RA, Bode P, van den Brandt PA. Prediagnostic toenail selenium and risk of bladder cancer. Cancer Epidemiol Biomarkers Prev 2002;11:1292-1297.

26. Bode P. Automation and quality assurance in the Neutron Activation Facilities in Delft. J Radioanal Nucl Chem 2000;245:127-132.

27. van den Brandt PA, Goldbohm RA, van't Veer P, Bode P, Hermus RJ, Sturmans F. Predictors of toenail selenium levels in men and women. Cancer Epidemiol Biomarkers Prev 1993;2:107-112.

28. van den Brandt PA, Goldbohm RA, van 't Veer P, Bode P, Dorant E, Hermus RJ, Sturmans F. A prospective cohort study on toenail selenium levels and risk of gastrointestinal cancer. J Natl Cancer Inst 1993;85:224-229.

29. van Breda SG, Hogervorst JG, Schouten LJ, Knaapen AM, van Delft JH, Goldbohm RA, van Schooten FJ, van den Brandt PA. Toenails: an easily accessible and long-term stable source of DNA for genetic analyses in large-scale epidemiological studies. Clin Chem 2007;53:1168-1170.

30. Nevo table: Dutch food composition table, 1986-1987. (Dutch). Voorlichtingbureau Voor de Voeding, 1986.

31. Goldbohm RA, van den Brandt PA, Brants HA, van't Veer P, Al M, Sturmans F, Hermus RJ. Validation of a dietary questionnaire used in a large-scale prospective cohort study on diet and cancer. Eur J Clin Nutr 1994;48:253-265.

32. Lagergren J, Bergstrom R, Adami HO, Nyren O. Association between medications that relax the lower esophageal sphincter and risk for esophageal adenocarcinoma. Ann Intern Med 2000;133:165-175.

33. Cox DR. Regression models and life-tables. J Roy Statistical Society 1972;34:187-220.

34. Barlow WE. Robust variance estimation for the case-cohort design. Biometrics 1994;50:1064-1072.

35. Schoenfeld D. Partial residuals for the proportional hazards regression model. Biometrika 1982;69:239-241.

36. Gao S, Jin Y, Hall KS, Liang C, Unverzagt FW, Ji R, Murrell JR, Cao J, Shen J, Ma F, Matesan J, Ying B, Cheng Y, Bian J, Li P, Hendrie HC. Selenium level and cognitive function in rural elderly Chinese. Am J Epidemiol 2007;165:955-965.

37. Ovaskainen ML, Virtamo J, Alfthan G, Haukka J, Pietinen P, Taylor PR, Huttunen JK. Toenail selenium as an indicator of selenium intake among middle-aged men in an area with low soil selenium. Am J Clin Nutr 1993;57:662-665.

38. Garland M, Morris JS, Rosner BA, Stampfer MJ, Spate VL, Baskett CJ, Willett WC, Hunter DJ. Toenail trace element levels as biomarkers: reproducibility over a 6-year period. Cancer Epidemiol Biomarkers Prev 1993;2:493-497.

39. Koriyama C, Campos FI, Yamamoto M, Serra M, Carrasquilla G, Carrascal E, Akiba S. Toenail selenium levels and gastric cancer risk in Cali, Colombia. J Toxicol Sci 2008;33:227-235.

40. Cai J, Zeng D. Sample size/power calculation for case-cohort studies. Biometrics 2004;60:1015-1024.

41. Fan X, Snyder N. Prevalence of Barrett's esophagus in patients with or without GERD symptoms: role of race, age, and gender. Dig Dis Sci 2009;54:572-577.

42. Gerson LB, Shetler K, Triadafilopoulos G. Prevalence of Barrett's esophagus in asymptomatic individuals. Gastroenterology 2002;123:461-467.

43. Ward EM, Wolfsen HC, Achem SR, Loeb DS, Krishna M, Hemminger LL, DeVault KR. Barrett's esophagus is common in older men and women undergoing screening colonoscopy regardless of reflux symptoms. Am J Gastroenterol 2006;101:12-17.

44. Rothman KJ, Greenland S. Precision and validity in epidemiologic studies. In: Rothman KJ, Greenland S, eds. Modern epidemiology. Second ed. Philadelphia: Lippincott, 1998:115-134. 


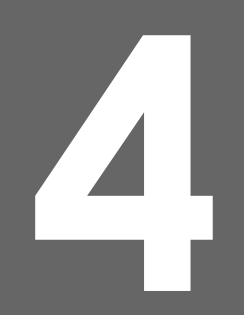

\title{
Cancer incidence and cause-specific mortality in a population-based cohort of patients with Barrett's esophagus
}

\author{
Leo J Schouten \\ Jessie Steevens \\ Clément JR Huysentruyt \\ Ceciel E Coffeng \\ Yolande CA Keulemans \\ Flora E van Leeuwen \\ Ann LC Driessen \\ Piet A van den Brandt
}




\section{ABSTRACT}

\section{Objective}

Barrett's esophagus (BE) is associated with an increased risk of esophageal adenocarcinoma, but evidence with respect to incidence of other cancers and overall mortality is inconsistent.

\section{Methods}

The Netherlands Cohort Study was initiated in 1986, when 120,852 participants aged 55-69 years at baseline were included. Until December 2002, 626 incident BE cases (excluding non-intestinal metaplasia) were identified by record linkage with the nationwide Pathology Registry. Cancer and mortality follow-up of this cohort of BE cases was established by record linkage to the Netherlands Cancer Registry and Statistics Netherlands. The expected number of cases was calculated using national cancer incidence and mortality data.

\section{Results}

After a median follow-up of 5.7 years of the BE cohort, 13 esophageal and 5 gastric cancer cases were recorded. The Observed/Expected (O/E) ratios for esophageal and gastric cancer were 10.0 (95\% Confidence Interval (Cl), 5.3-17.1) and $1.8(95 \% \mathrm{Cl}$, 0.6-4.2), respectively.

Total cancer incidence (excluding esophageal and gastric cancer) in the BE cohort was nearly statistically significantly increased: O/E-ratio $1.3(95 \% \mathrm{Cl}, 1.0-1.6)$. Of the subtypes, small intestinal and pancreatic cancer incidence were increased, but not statistically significantly after exclusion of the first six months of follow-up.

During follow-up 225 BE cases died. Mortality of all causes (excluding esophageal and gastric cancer) was not increased: O/E-ratio $1.0(95 \% \mathrm{Cl}, 0.9-1.2)$, neither was mortality according to main causes of death.

\section{Conclusion}

In this population-based cohort of BE cases esophageal cancer incidence was increased. Total cancer incidence and overall mortality were not increased. 


\section{INTRODUCTION}

Barrett's esophagus (BE) is an abnormal appearing distal esophageal lining with replacement of the normal squamous epithelium by specialized or intestinal columnar epithelium. ${ }^{1}$ BE is thought to be a pre-cancerous condition and patients with BE have an increased risk to develop esophageal adenocarcinoma. ${ }^{2}$ Although many studies have investigated the risk of esophageal adenocarcinoma in patients with $B E,{ }^{3,4}$ most follow-up studies are small and have been conducted in selected patient series. Larger studies with complete follow-up and a strict definition of BE have found lower risks of esophageal adenocarcinoma compared to studies with a smaller study-size. ${ }^{4,5}$ Incidence of gastric cancer was also increased in some studies, possibly due to misclassification of junctional tumors. ${ }^{3}$ The number of studies examining incidence rates of other cancers and mortality is limited. There are indications that colorectal cancer risk is increased in patients with $\mathrm{BE}$, but this may be due to selected patient series and detection bias. ${ }^{6,7}$

Several studies have observed increased mortality rates among BE cases. $^{8-11}$ However, the only population-based cohort that studied mortality did not observe an increased risk. $^{12}$

We therefore decided to study cancer incidence and overall mortality in the population-based Netherlands Cohort Study on Diet and Cancer. By record-linkage to the Netherlands nationwide pathology registry, cases of $\mathrm{BE}$ in the cohort were identified. By follow-up of these cases we were able to study whether cancer incidence and cause-specific mortality were increased in this population-based cohort of $\mathrm{BE}$ cases.

\section{PATIENTS AND METHODS}

\section{Study design and subjects}

The Netherlands Cohort Study was started in September 1986, when 58,279 Dutch men and 62,573 women aged 55-69 years were enrolled. The subjects were selected at random from 204 Dutch municipal population registries. All cohort members completed a self-administered questionnaire. The study design has been described in detail before. $^{13}$

Incident BE cases in the total cohort were identified by computerized recordlinkage to the nationwide network and registry of histopathology and cytopathology in the Netherlands (PALGA) using the search term "Barrett" or the search terms "metaplasia" combined with "esophagus". ${ }^{5}$ The linkage was carried out for the period until 31 December 2002, using the linkage protocol that we described before. ${ }^{14}$ All links were checked for false-positives (see Figure 4.1). Thereafter, one pathologist (A.L.C.D.) and one pathologist in training (C.J.R.H.) reviewed the available summary and 
conclusion of the pathology records from PALGA to extract information on the date of diagnosis of $B E$, the type of metaplasia, and the presence and degree of dysplasia.

Excluded were $B E$ cases with an uncertain diagnosis or with a diagnosis specifying the presence of only non-intestinal metaplasia. Also excluded were BE cases with prevalent cancer (self-reported) or prevalent BE (if known) in September 1986. To eliminate the possibility that the diagnosis of BE was related to (preclinical) symptoms of esophageal or gastric cancer, we excluded BE cases with a diagnosis of esophageal or gastric cancer before or less than a half year after the diagnosis of BE (leaving 626 cases). This constituted a population-based cohort of BE cases. The Medical Ethics Committee of Maastricht University, the Netherlands, has approved the study.

\begin{tabular}{|c|c|c|}
\hline \multicolumn{3}{|c|}{$\begin{array}{l}\text { Netherlands Cohort Study on Diet and Cancer } \\
(58,279 \text { men and } 62,573 \text { women })\end{array}$} \\
\hline \multicolumn{3}{|c|}{$\downarrow$} \\
\hline \multicolumn{3}{|c|}{ Record linkage with PALGA until 31-12-2002 } \\
\hline \multicolumn{3}{|c|}{2376 reports from $1185 \mathrm{BE}$ cases } \\
\hline \multicolumn{3}{|c|}{$\downarrow$} \\
\hline \multicolumn{3}{|c|}{ Exclusion of false-positive linkages } \\
\hline \multicolumn{3}{|c|}{1954 reports from $974 \mathrm{BE}$ cases } \\
\hline \multicolumn{3}{|c|}{$\downarrow$} \\
\hline \multicolumn{3}{|c|}{ Review by pathologist: exclusion of uncertain diagnoses } \\
\hline \multicolumn{3}{|c|}{$868 \mathrm{BE}$ cases } \\
\hline \multicolumn{3}{|c|}{$\downarrow$} \\
\hline \multicolumn{3}{|c|}{ Review by pathologist: exclusion of non-intestinal metaplasia } \\
\hline \multicolumn{3}{|c|}{$742 \mathrm{BE}$ cases } \\
\hline \multicolumn{3}{|c|}{$\downarrow$} \\
\hline \multicolumn{3}{|c|}{ Exclusion of prevalent cancer and BE cases at baseline } \\
\hline \multicolumn{3}{|c|}{$680 \mathrm{BE}$ cases } \\
\hline \multicolumn{3}{|c|}{$\downarrow$} \\
\hline \multicolumn{3}{|c|}{$\begin{array}{l}\text { Exclusion of esophageal and gastric cancer cases } \\
\text { before or }<1 / 2 \text { year after the BE diagnosis }\end{array}$} \\
\hline \multicolumn{3}{|c|}{$626 \mathrm{BE}$ cases } \\
\hline$\downarrow$ & $\downarrow$ & $\downarrow$ \\
\hline $\begin{array}{l}\text { Exclusion of first half } \\
\text { year of follow-up }\end{array}$ & $\begin{array}{l}\text { Exclusion of cancer and } \\
\text { BE cases }\end{array}$ & \\
\hline$\downarrow$ & $\downarrow$ & \\
\hline $\begin{array}{l}\text { Analysis of esophageal } \\
\text { and gastric cancer } \\
\text { incidence }\end{array}$ & $\begin{array}{l}\text { Analysis of cancer } \\
\text { incidence }\end{array}$ & Analysis of mortality \\
\hline $605 \mathrm{BE}$ cases & $561 \mathrm{BE}$ cases & 626 BE cases \\
\hline
\end{tabular}

Figure 4.1 Flow diagram of Barrett's esophagus (BE) cases on whom the analyses were based. 


\section{Follow-up for cancer incidence and cause-specific mortality}

For the analyses with respect to esophageal and gastric cancer incidence, total cancer incidence, and overall mortality, three different datasets were constructed from the BE cohort. Because we had excluded all esophageal or gastric cancer in the first half year of follow-up after BE diagnosis, the follow-up for esophageal and gastric cancer started a half year after BE diagnosis (leaving 605 patients at risk). For the follow-up of cancer incidence, BE cases with cancer (other than non-melanoma skin cancer) diagnosed before the BE diagnosis were excluded (leaving 561 patients). No additional exclusion criterion was necessary for the dataset for the mortality follow-up (626 patients).

Follow-up for vital status was established by record linkage with the Central Bureau of Genealogy and the automated municipal population registries. Follow-up for vital status was complete for all 626 members of the Barrett's cohort at 1 May 2005.

Follow-up for cancer incidence in $B E$ cases was performed by record linkage to the Netherlands Cancer Registry and PALGA. ${ }^{14}$ For the cancer incidence analyses, follow-up data were available until 31 December 2003. In this analysis only the first occurrence of a primary cancer was counted.

We were able to obtain the cause of death from Statistics Netherlands (until 1 May 2005). Causes of death were coded in the International Classification of Diseases (ICD)-9 until December 1995 and ICD-10 from January 1996. Only the primary cause of death was used in the analysis.

\section{Statistical analysis}

Cancer incidence in the Barrett's cohort was compared with the incidence in the Dutch population. Time at risk began at diagnosis of BE (or a half year after BE diagnosis in the esophageal and gastric cancer analysis) and ended on the date of cancer diagnosis, the date of death, or the last date of the follow-up for cancer incidence (31 December 2003), whichever occurred first. The expected numbers of cancer, taking into account the person-years of observation in the Barrett's cohort, were computed with the use of sex-, age-, and calendar year - specific cancer incidence rates from the Eindhoven Cancer Registry up to 1990 or, ${ }^{15}$ for the period after 1990, from the Netherlands Cancer Registry. ${ }^{16,17}$

Mortality in the Barrett's cohort was compared with mortality in the Dutch population. Time at risk began at diagnosis of $\mathrm{BE}$ and ended on the date of death or the last date of the follow-up for mortality (1 May 2005), whichever occurred first. For the mortality analysis sex-, age- and calendar year -specific mortality rates were obtained from Statistics Netherlands.

The Observed/Expected (O/E) ratios for cancer incidence and cause-specific mortality were calculated as the ratio of the observed number of cancer cases or deaths to the expected number, and the $95 \%$ confidence intervals $(\mathrm{Cl})$ were calculated based on the Poisson distribution. ${ }^{18}$ The absolute excess risk of cancer was calculated by subtracting the expected number of cases from the observed number, divided by 
the person-years at risk. All analyses were conducted using a statistical program written in SPSS developed by the Netherlands Cancer Institute. ${ }^{19}$

\section{RESULTS}

The dataset for esophageal and gastric cancer incidence included $605 \mathrm{BE}$ cases, the dataset for incidence of other cancers included 561 persons, while the dataset for mortality follow-up counted 626 persons (see Table 4.1). The majority of the BE cases was male and the mean age at diagnosis of Barrett's esophagus was slightly higher than 71 years. In $73-74 \%$ of the BE cases, the histology was specified as intestinal metaplasia, while in the remaining cases the histology was unspecified. Dysplasia was reported not to be present in $81 \%$ of the cases, while high-grade dysplasia was rare (1\%). The median follow-up duration was 5.7 years in the esophageal and gastric cancer analysis, 5.4 years in the cancer incidence analysis and 6.8 years in the mortality analysis.

Table 4.1 Baseline characteristics of cohort of patients with Barrett's esophagus for cancer incidence and mortality analysis. Netherlands Cohort Study.

\begin{tabular}{|c|c|c|c|c|c|c|}
\hline \multirow[b]{2}{*}{ Characteristic } & \multicolumn{2}{|c|}{$\begin{array}{l}\text { Esophageal and gastric } \\
\text { cancer analysis }^{\mathrm{a}}\end{array}$} & \multicolumn{2}{|c|}{$\begin{array}{l}\text { Cancer incidence } \\
\text { analysis }^{\mathrm{b}}\end{array}$} & \multicolumn{2}{|c|}{$\begin{array}{l}\text { Mortality } \\
\text { analysis }^{c}\end{array}$} \\
\hline & $\mathbf{n}$ & (\%) & $\mathbf{n}$ & (\%) & $\mathbf{n}$ & (\%) \\
\hline Total & 605 & $(100.0)$ & 561 & $(100.0)$ & 626 & $(100.0)$ \\
\hline \multicolumn{7}{|l|}{ Sex } \\
\hline Males & 325 & $(53.7)$ & 292 & $(52.0)$ & 341 & $(54.5)$ \\
\hline Females & 280 & $(46.3)$ & 269 & $(48.0)$ & 285 & $(45.5)$ \\
\hline $\begin{array}{l}\text { Age at diagnosis of Barrett's esophagus, mean } \\
(\text { SD })^{d}\end{array}$ & 71.2 & $(5.3)$ & 71.1 & $(5.3)$ & 71.2 & $(5.3)$ \\
\hline \multicolumn{7}{|l|}{ Incidence year } \\
\hline 1986-1990 & 72 & (11.9) & 68 & $(12.1)$ & 75 & $(12.0)$ \\
\hline 1991-1994 & 145 & $(24.0)$ & 138 & $(24.6)$ & 149 & $(23.8)$ \\
\hline 1995-1998 & 214 & (35.4) & 193 & $(34.4)$ & 222 & (35.5) \\
\hline 1999-2002 & 174 & $(28.8)$ & 162 & $(28.9)$ & 180 & $(28.8)$ \\
\hline \multicolumn{7}{|l|}{ Histology } \\
\hline Intestinal metaplasia & 446 & (73.7) & 415 & $(74.0)$ & 456 & $(72.8)$ \\
\hline Barrett's esophagus NOS & 159 & (26.3) & 146 & $(26.0)$ & 170 & $(27.2)$ \\
\hline \multicolumn{7}{|l|}{ Dysplasia } \\
\hline No dysplasia & 493 & $(81.5)$ & 457 & $(81.5)$ & 508 & $(81.2)$ \\
\hline Low-grade dysplasia & 92 & $(15.2)$ & 88 & $(15.7)$ & 97 & $(15.5)$ \\
\hline High-grade dysplasia & 8 & $(1.3)$ & 7 & $(1.2)$ & 9 & $(1.4)$ \\
\hline Unspecified dysplasia & 12 & $(2.0)$ & 9 & $(1.6)$ & 12 & (1.9) \\
\hline Follow-up years ${ }^{\mathrm{e}}$, mean (SD) & 6.4 & (3.9) & 6.0 & (3.9) & 7.2 & $(4.2)$ \\
\hline
\end{tabular}

${ }^{a}$ Cohort used for esophageal and gastric cancer analysis, start of follow-up a half year after diagnosis of Barrett's esophagus; ${ }^{b}$ Cohort used for cancer incidence analysis, only patients who were cancer-free at diagnosis of the Barrett's esophagus; ${ }^{c}$ Cohort used for mortality analysis; ${ }^{d}$ SD $=$ Standard Deviation; NOS= Not Otherwise Specified; ${ }^{e}$ Calculated from diagnosis of Barrett's esophagus. 
In the Barrett's cohort, 13 cases of esophageal cancer and 5 cases of gastric cancer were reported during follow-up (Table 4.2). The 13 esophageal cancer cases were all located in the lower third of the esophagus and the histological type was adenocarcinoma. Based on national incidence rates only 1.3 cases of esophageal cancer were expected, and the O/E-ratio was statistically significantly increased: 10.0 (95\% Cl: 5.3-17.1). The O/E-ratios were higher in males than in females and in cases with a BE diagnosis at age 68 to 72 years (Table 4.2). The O/E ratios were higher in cases with intestinal metaplasia, and higher in cases with unspecified dysplasia or highgrade dysplasia, although numbers were small. O/E-ratios were lower after five years of follow-up.

The O/E-ratio was 1.8 (95\% Cl: 0.6-4.2) for gastric cancer (Table 4.2). Four of the five observed gastric cancer cases were located in the gastric cardia; the subsite of the remaining case was unspecified. All cases of gastric cancer in the follow-up were detected in males and in cases with intestinal metaplasia.

The incidence rate of esophageal cancer was 3.7 per 1000 person-years and the absolute excess risk was 3.3 per 1000 person-years (95\% Cl: 1.6-5.9 per 1000 personyears). The incidence rate of gastric cancer was 1.4 per 1000 person-years and the absolute excess risk was 0.6 per 1000 person-years (95\% Cl: -0.3 to 2.5 per 1000 person-years) (Table 4.2).

In the dataset for cancer incidence follow-up 92 cases of invasive cancer were diagnosed during the follow-up (Table 4.3). The O/E-ratio was calculated to be 1.5 (95\% Cl: 1.2-1.8). Without the esophageal and gastric cancer cases the O/E-ratio was still increased but not statistically significantly anymore: O/E-ratio: 1.3 (95\% Cl: $1.0-$ 1.6). The cancer incidence rate was statistically significantly increased for small intestinal cancer (O/E-ratio: 11.8 ; $95 \% \mathrm{Cl}$ : 1.4-42.5) and pancreatic cancer (O/E-ratio: 3.1; $95 \% \mathrm{Cl}: 1.0-7.2)$. When cases diagnosed in the first six months of follow-up were excluded, the increased risks were no longer statistically significant: O/E-ratio 6.3 (95\% $\mathrm{Cl}$ : 0.2-35.3) for small intestinal cancer and O/E-ratio $2.7(95 \% \mathrm{Cl}: 0.7-6.8)$ for pancreatic cancer. Colorectal cancer incidence was not increased. The incidence rates of lung and prostate cancer were increased, but not statistically significantly.

The total mortality in the cohort was not statistically significantly increased ( $n=626$ at risk) (Table 4.4). During follow-up, 225 cases died ( $n=213.2$ expected) and the O/E-ratio was 1.1 (95\% Cl: 0.9-1.2). After exclusion of esophageal and gastric cancer deaths, there were 214 cases who died ( $\mathrm{n}=208.5$ expected). The O/E-ratio for this comparison was 1.0 (95\% Cl: 0.9-1.2). Mortality was not statistically significantly increased either for any of the specific causes of death (Table 4.4). 


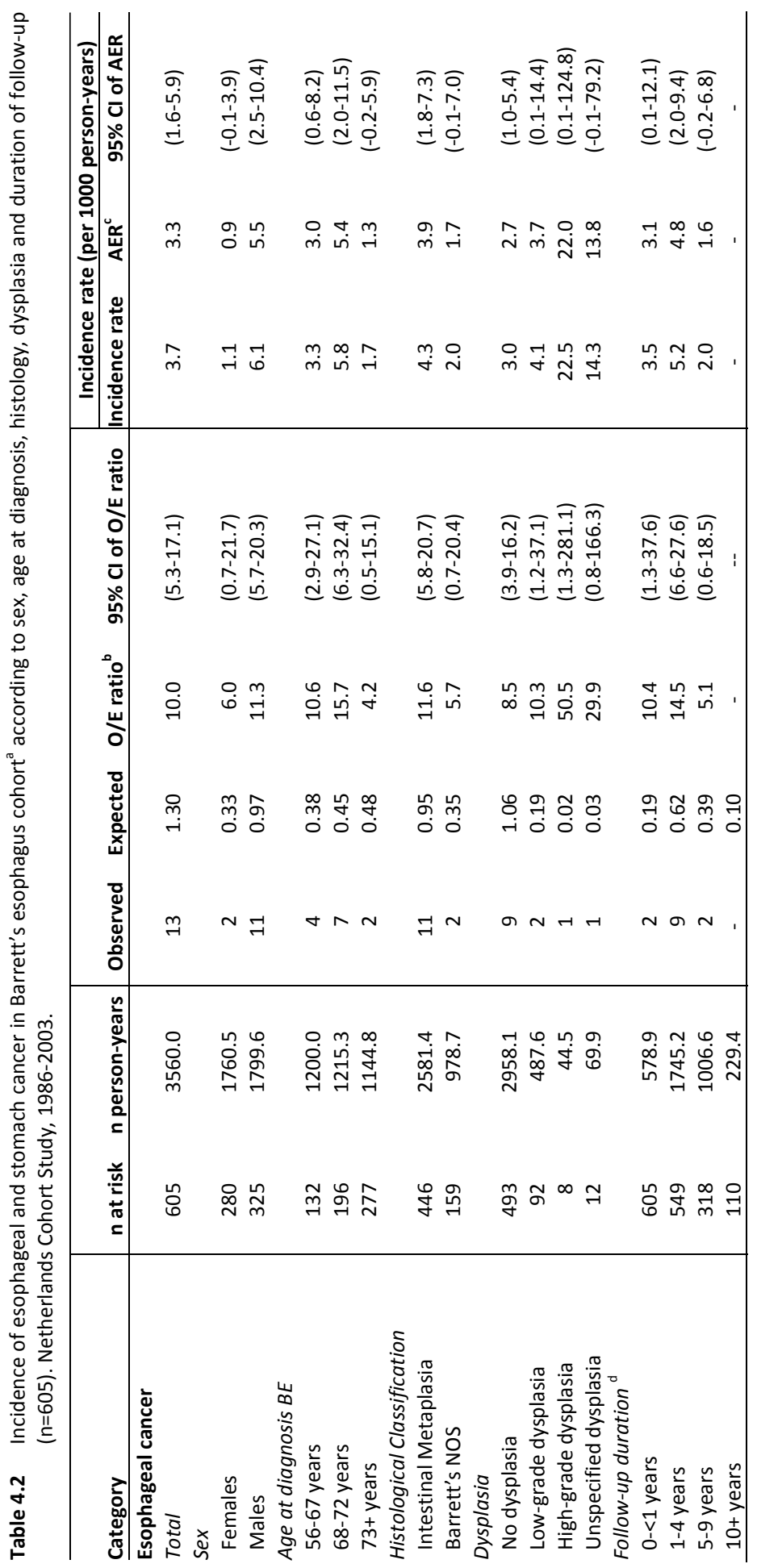




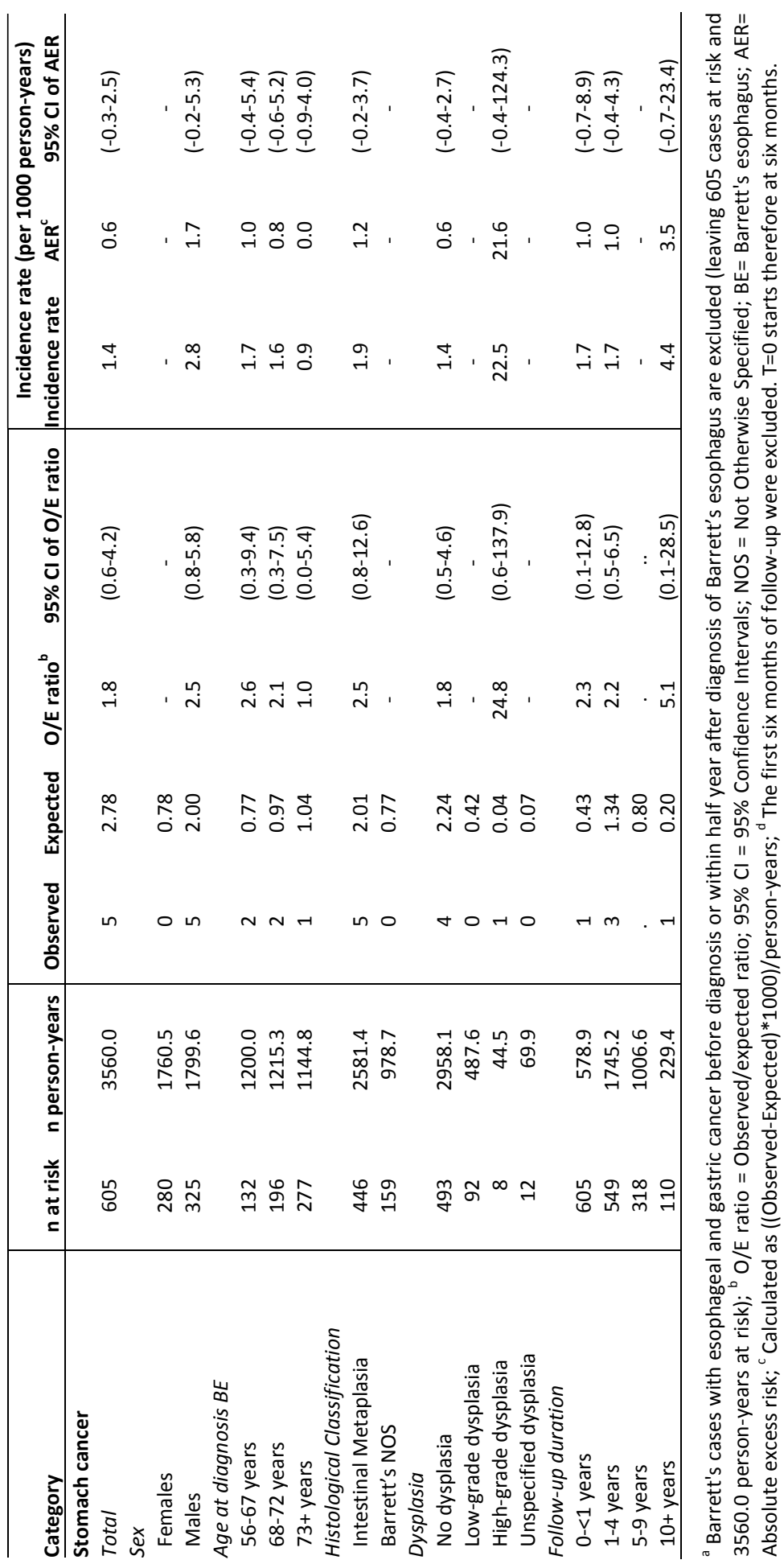




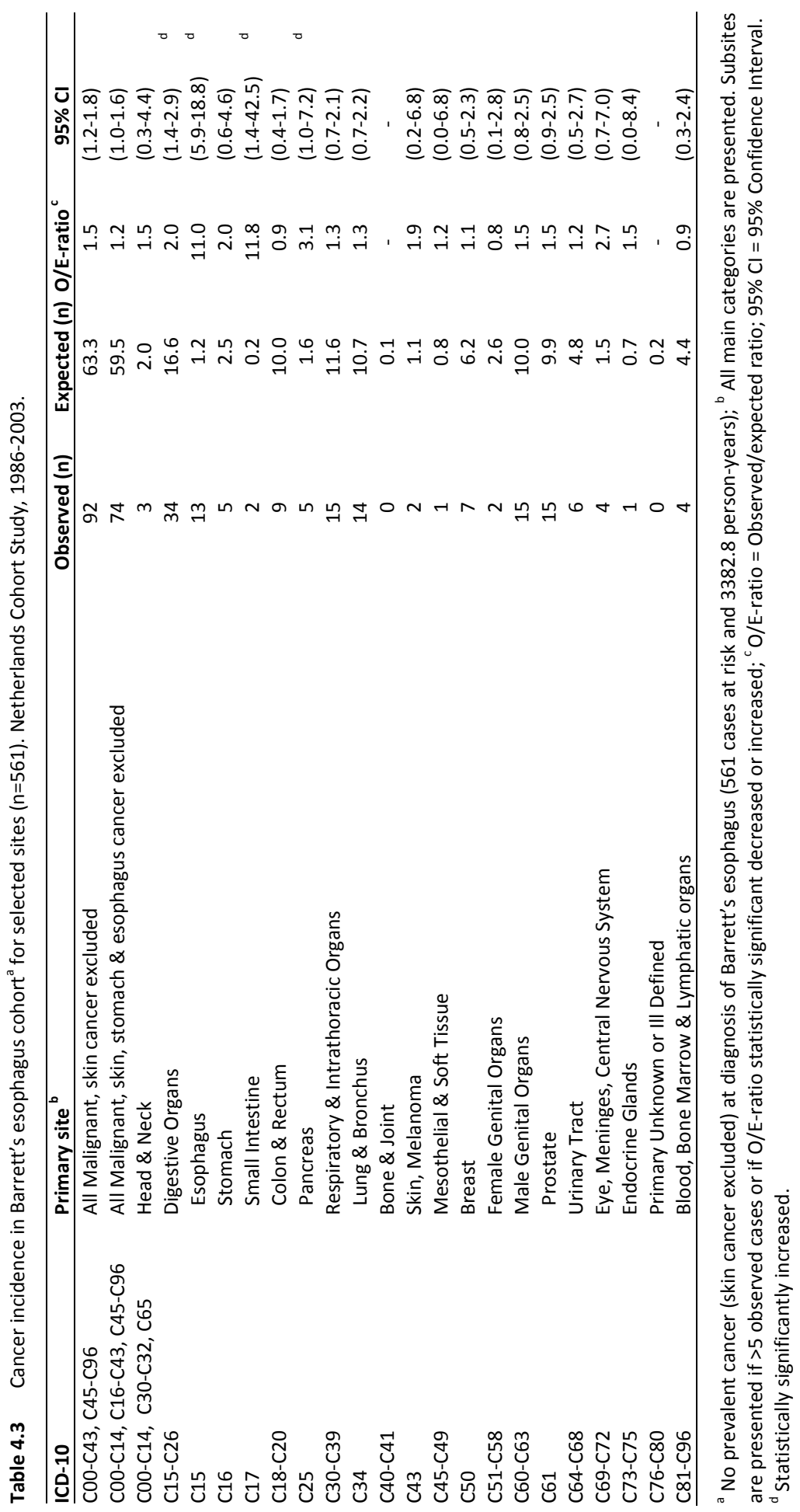




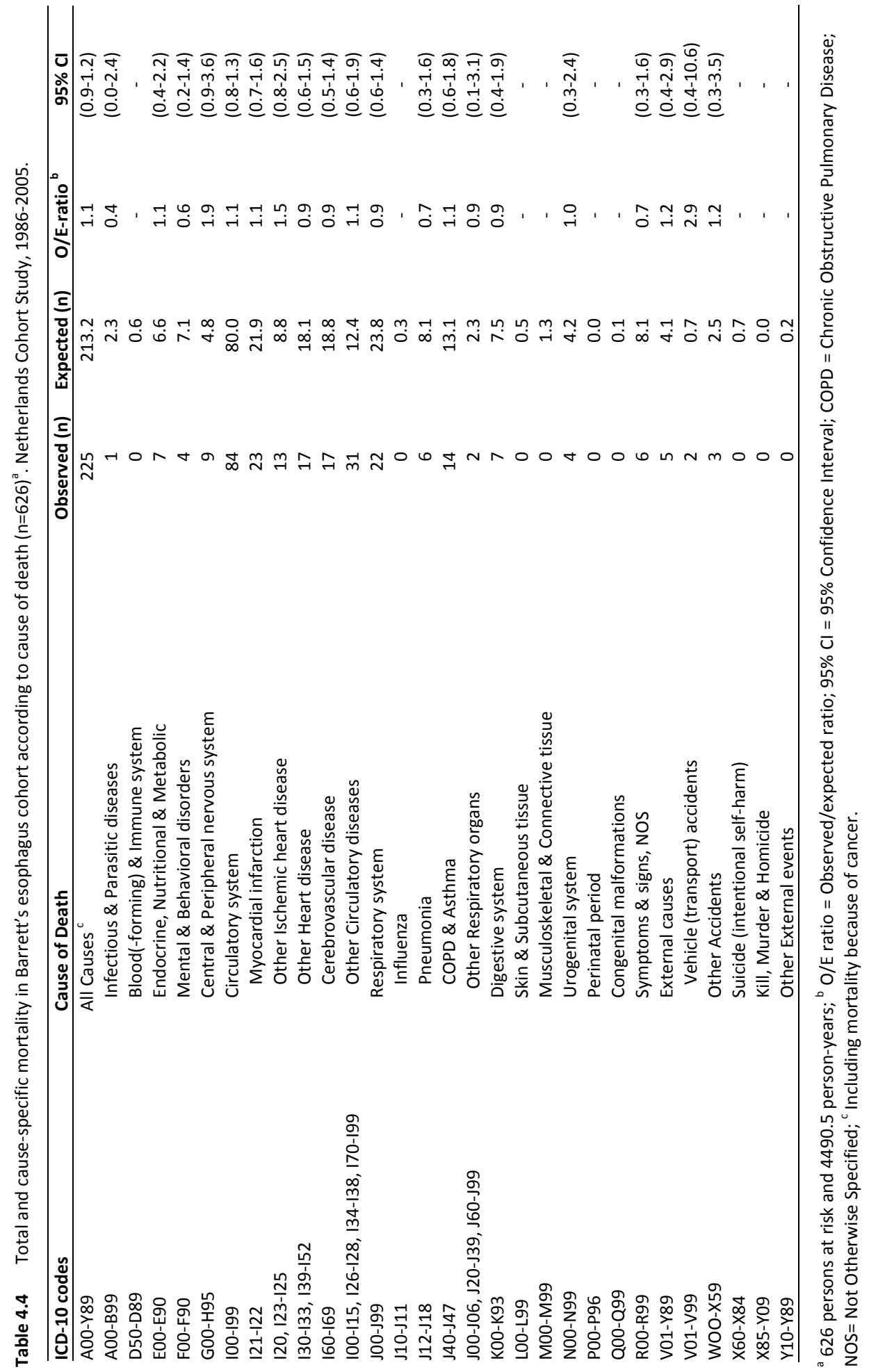




\section{DISCUSSION}

In this large population-based cohort of cases with Barrett's esophagus, only the O/Eratios of esophageal cancer were statistically significantly increased. Presence of intestinal metaplasia and unspecified or high-grade dysplasia were associated with the highest risks of esophageal cancer, although numbers were small. Cancer incidence without esophageal and gastric cancer incidence was slightly increased, but not statistically significantly. Incidence of small intestinal and pancreatic cancer was increased, but was based on small numbers and not statistically significant after excluding the first half year of follow-up. Cause-specific and overall mortality were not increased.

Barrett's esophagus is considered to be a precursor lesion of esophageal adenocarcinoma. $^{20}$ In agreement with this assumption, we observed a strongly increased risk of esophageal cancer during follow-up. The incidence rate in the cohort was 3.7 per 1000 person-years after excluding the first half year of follow-up. The pooled estimate in a recent meta-analysis was estimated to be 5.3 per 1000 personyears. ${ }^{4}$ However, when the pooled analysis was restricted to studies with a large study size ( $>500$ person-years), without possible selection bias ( $>70 \%$ follow-up) and a welldefined definition of Barrett's esophagus, the incidence was considerably lower and very close to the results in the current study: 3.9 per 1000 person-years. ${ }^{4}$ In a recent follow-up study, an even lower incidence of esophageal cancer was observed: only 1.6 per 1000 person-years. ${ }^{3}$ The largest follow-up study, using the same Pathology database as the current study, found an incidence rate of 4.3 per 1000 person-years. ${ }^{5}$ The relatively low incidence in these studies confirms the opinion that the incidence of esophageal cancer in Barrett's esophagus has been overestimated in the literature because of publication bias. ${ }^{20}$

In the current study, the incidence rate of esophageal cancer in males was much higher than that in females, which is in agreement with the meta-analysis. ${ }^{4}$ Cases with unspecified or high-grade dysplasia at baseline had a strongly increased risk of esophageal cancer, although the O/E-ratios were based on one case in each category. The increased risk is in accordance with the literature. ${ }^{21,22}$ The increased risk in cases with unspecified dysplasia is possibly explained by classification problems. In the summaries of the pathology reports of these cases, dysplasia was sometimes reported without specification as low- or high-grade, and we classified these cases as unspecified dysplasia. The elevated risk may therefore be explained by this misclassification. In contrast to findings from a recent large study, ${ }^{5}$ the $\mathrm{O} / \mathrm{E}$-ratios were highest during the first five years of follow-up. It is conceivable, that the incidence after five years of follow-up was underestimated in our study, because the number of BE cases and cancer events is small, especially regarding cases with a longer follow-up.

The incidence rate of gastric cancer was also slightly increased. In a recent cohort study from Cook et al the O/E-ratio of gastric cancer was 2.0 (7 cases of gastric cancer observed and 3.43 expected), ${ }^{3}$ which is comparable with the result in the current study 
(O/E-ratio: 1.8). Because most gastric cancers in the current study were located in the gastric cardia, the increased risk might be caused by misclassification of esophageal cancer as gastric cardia cancer. However, the Netherlands Cancer Registry has good access to clinical files and its data have been shown to be of good quality, ${ }^{23}$ making misclassification less likely.

Incidence rates of small intestinal and pancreatic cancer were also increased, but not statistically significantly after exclusion of the cases in the first six months after BE diagnosis. It is therefore conceivable that preclinical complaints of these cancers warranted endoscopy, in which the Barrett's esophagus was discovered. The number of observed cases in our study is also limited. However, in patients with Multiple Endocrine Neoplasia type 1 (MEN1) and the Zollinger Ellison Syndrome (ZES) the risks of both duodenal and endocrine pancreatic malignancies and of Barrett's esophagus were increased. ${ }^{24,25}$ In many patients with ZES, excess gastrin is produced by a gastrinoma in e.g. the duodenum. Gastrin increases gastric acid production and might therefore increase the risk of Barrett's esophagus. This is in agreement with the observation in the current study that one of the detected duodenal cancers was reported to be a neuroendocrine carcinoma (carcinoid). This finding should be replicated in other longitudinal studies, before it can be concluded whether a causal association is likely.

Barrett's esophagus has also been associated with an increased incidence of colorectal cancer. ${ }^{26}$ However, results since this first publication in 1985 have been inconsistent. ${ }^{3,7,27}$ The possible association between Barrett's esophagus and colorectal cancer has been attributed to common environmental exposures such as bile acids, vegetables and fruit intake, and shared genetic aberrations. ${ }^{26} \mathrm{~A}$ recent study, using data from the Netherlands Pathology Registry, showed a slightly increased risk of colorectal cancer, but incidence was especially increased in the first year of follow-up. ${ }^{6}$ The authors concluded that the greater part of the excess risk is most likely explained by diagnostic bias. We did not observe an increased risk at all, making it likely that there is no or only a small increased risk of colorectal cancer in patients with Barrett's esophagus.

The O/E-ratio for total mortality was slightly increased, but not statistically significantly. None of the specific causes of death (excluding cancer mortality) was increased. Some, but not all, recent studies observed moderately increased O/E-ratios for mortality. In a British cohort study with 502 patients, an increased mortality was observed (O/E ratio $1.21 ; 95 \% \mathrm{Cl}: 1.06-1.37){ }^{3}$ Several other studies also reported increased mortality rates. ${ }^{8-11}$ Risks in these studies remained elevated after exclusion of deaths that were related to esophageal cancer. Only one study did not observe an increased risk. ${ }^{12}$ In this study, data were used from the Northern Irish Registry of Barrett's esophagus, and the O/E ratio was 0.96 (95\% Cl, 0.84-1.07). The current study and the Irish study are the only studies that are population-based and not hospitalbased. A possible explanation for the observed discrepancies might therefore be selection bias. The hospital-based cohorts were assembled at hospitals and may 
include patients with more complicated disease or with more co-morbidities and were therefore at increased risk to die. Lack of power is not a likely explanation, as the current study has 225 deaths, which is comparable with the other published studies. $^{3,11,12}$

This study suffered from some limitations. Case definitions of Barrett's esophagus differ between the United States (USA) and the United Kingdom (UK). In the USA, the presence of goblet cells (indicating intestinal metaplasia) is required for the diagnosis of $B E{ }^{28}$ while in the UK any type of metaplasia is sufficient for the diagnosis of $B E .{ }^{29}$ Both the USA and UK definitions may have been used in the Netherlands. The use of definitions may have changed over time and different pathologists may have used different definitions. Cases were excluded from the analysis if the pathological summary only reported non-intestinal metaplasia (gastric or junctional metaplasia). In the pathology reports of approximately $25 \%$ of the cases the type of Barrett's esophagus was not specified. Some misclassification may therefore have occurred and this may have attenuated the risks slightly. A second limitation is that we only had access to summaries of the pathology reports as recorded in the pathology registry PALGA. However, we were able to compare the conclusions of 60 reports from 29 patients with the full reports from one hospital. In this substudy, the agreement on patient level was $29 / 29$ (100\%) with respect to the eligibility of the cases, $26 / 29$ (90\%) with respect to histology and $27 / 29$ (93\%) with respect to dysplasia.

Our study also has several strengths. The study is population-based and has a long follow-up. Follow-up for vital status was $100 \%$ complete and we were able to retrieve all causes of death from the death certificates. Follow-up for cancer is also presumed to be $>95 \%$ complete. $^{30}$

In conclusion, in this study we observed that patients with Barrett's esophagus had an increased risk of esophageal cancer and possibly also for stomach, small intestinal and pancreatic cancer. The incidence of colorectal cancer was not increased. Neither overall nor cause-specific mortality were increased. 


\section{REFERENCES}

1. Shaheen NJ, Richter JE. Barrett's oesophagus. Lancet 2009;373:850-861.

2. Wild CP, Hardie LJ. Reflux, Barrett's oesophagus and adenocarcinoma: burning questions. Nat Rev Cancer 2003;3:676-684.

3. Cook MB, Wild CP, Everett SM, Hardie L, Bani-Hani KE, Martin IG, Forman D. Risk of Mortality and Cancer Incidence in Barrett's Esophagus. Cancer Epidemiol Biomarkers Prev 2007.

4. Yousef F, Cardwell C, Cantwell MM, Galway K, Johnston BT, Murray L. The incidence of esophageal cancer and high-grade dysplasia in Barrett's esophagus: a systematic review and meta-analysis. Am J Epidemiol 2008;168:237-249.

5. De Jonge PJ, Van Blankenstein M, Looman CW, Casparie MK, Meijer GA, Kuipers EJ. Risk of Malignant Progression in Patients with Barrett's oesophagus: a Dutch nationwide cohort study. Gut 2010;59:1030-1036.

6. de Jonge PJ, van Blankenstein M, Looman CW, Casparie MK, Meijer GA, Kuipers EJ. Risk of colorectal cancer in patients with Barrett's esophagus: A Dutch population-based study. Am J Gastroenterol 2010;105:77-83.

7. Howden CW, Hornung CA. A systematic review of the association between Barrett's esophagus and colon neoplasms. Am J Gastroenterol 1995;90:1814-1819.

8. van der Burgh A, Dees J, Hop WC, van Blankenstein M. Oesophageal cancer is an uncommon cause of death in patients with Barrett's oesophagus. Gut 1996;39:5-8.

9. Solaymani-Dodaran M, Logan RF, West J, Card T. Mortality associated with Barrett's esophagus and gastroesophageal reflux disease diagnoses-a population-based cohort study. Am J Gastroenterol 2005;100:2616-2621.

10. Conio M, Cameron AJ, Romero Y, Branch CD, Schleck CD, Burgart LJ, Zinsmeister AR, Melton $L$, 3rd, Locke GR, 3rd. Secular trends in the epidemiology and outcome of Barrett's oesophagus in Olmsted County, Minnesota. Gut 2001;48:304-309.

11. Moayyedi P, Burch N, Akhtar-Danesh N, Enaganti SK, Harrison R, Talley NJ, Jankowski J. Mortality rates in patients with Barrett's oesophagus. Aliment Pharmacol Ther 2008;27:316-320.

12. Anderson LA, Murray LJ, Murphy SJ, Fitzpatrick DA, Johnston BT, Watson RG, McCarron P, Gavin AT. Mortality in Barrett's oesophagus: results from a population based study. Gut 2003;52:1081-1084.

13. van den Brandt PA, Goldbohm RA, van 't Veer P, Volovics A, Hermus RJ, Sturmans F. A large-scale prospective cohort study on diet and cancer in The Netherlands. J Clin Epidemiol 1990;43:285-295.

14. van den Brandt PA, Schouten LJ, Goldbohm RA, Dorant E, Hunen PM. Development of a record linkage protocol for use in the Dutch Cancer Registry for Epidemiological Research. Int J Epidemiol 1990;19:553-558.

15. Muir C, Waterhouse J, Mack T, Powell J, Whelan S. Cancer incidence in five continents. Volume V. Lyon: IARC Scientific publication no. 88, 1987.

16. Parkin DM, Whelan SL, Ferlay J, Raymond L, Young J. Cancer incidence in five continents. Volume VII. Lyon: IARC Scientific publications no. 143, 1997.

17. Parkin DM, Whelan SL, Ferlay J, Teppo L, Thomas DB. Cancer incidence in five continents. Volume VIII. Lyon: IARC Scientific publications no. 155, 2002.

18. Pearson ES, Hartley HO, (eds). Biometrika Tables for Statisticians. Biometrika Trust, 1976.

19. van Leeuwen FE, Klokman WJ, Hagenbeek A, Noyon R, van den Belt-Dusebout AW, van Kerkhoff EH, van Heerde P, Somers R. Second cancer risk following Hodgkin's disease: a 20-year follow-up study. J Clin Oncol 1994;12:312-325.

20. Shaheen NJ, Crosby MA, Bozymski EM, Sandler RS. Is there publication bias in the reporting of cancer risk in Barrett's esophagus? Gastroenterology 2000;119:333-338.

21. Schnell TG, Sontag SJ, Chejfec G, Aranha G, Metz A, O'Connell S, Seidel UJ, Sonnenberg A. Long-term nonsurgical management of Barrett's esophagus with high-grade dysplasia. Gastroenterology 2001;120:1607-1619.

22. Weston AP, Sharma P, Topalovski M, Richards R, Cherian R, Dixon A. Long-term follow-up of Barrett's high-grade dysplasia. Am J Gastroenterol 2000;95:1888-1893.

23. Schouten LJ, Jager JJ, van den Brandt PA. Quality of cancer registry data: a comparison of data provided by clinicians with those of registration personnel. Br J Cancer 1993;68:974-977. 
24. Hoffmann KM, Gibril F, Entsuah LK, Serrano J, Jensen RT. Patients with multiple endocrine neoplasia type 1 with gastrinomas have an increased risk of severe esophageal disease including stricture and the premalignant condition, Barrett's esophagus. J Clin Endocrinol Metab 2006;91:204-212.

25. Lindor NM, Lindor CJ, Greene MH. Hereditary Neoplastic Syndromes. In: Schottenfeld D, Fraumeni JF, Jr., eds. Cancer Epidemiology and Prevention. Third Edition. Oxford: Oxford University Press, 2006: 562-576.

26. Sontag SJ, Schnell TG, Chejfec G, O'Connell S, Stanley MM, Best W, Chintam R, Nemchausky B, Wanner J, Moroni B. Barrett's oesophagus and colonic tumours. Lancet 1985;1:946-949.

27. Bollschweiler E, Schloesser T, Leers J, Vallbohmer D, Schafer H, Holscher AH. High prevalence of colonic polyps in white males with esophageal adenocarcinoma. Dis Colon Rectum 2009;52:299-304.

28. Wang KK, Sampliner RE. Updated guidelines 2008 for the diagnosis, surveillance and therapy of Barrett's esophagus. Am J Gastroenterol 2008;103:788-797.

29. Playford RJ. New British Society of Gastroenterology (BSG) guidelines for the diagnosis and management of Barrett's oesophagus. Gut 2006;55:442-443.

30. Goldbohm R, van Den Brandt PA, Dorant E. Estimation of the coverage of Dutch municipalities by cancer registries and PALGA based on hospital discharge data. Tijdschr Soc Gezondheidsz 1994;72: 80-84. 


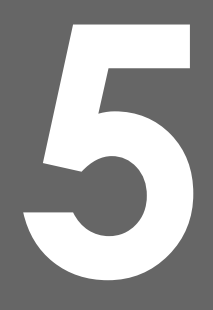

\title{
Trends in incidence of esophageal and stomach cancer subtypes in Europe
}

\author{
Jessie Steevens \\ Anita AM Botterweck \\ Miranda JM Dirx \\ Piet A van den Brandt \\ Leo J Schouten
}

European Journal of Gastroenterology and Hepatology 2010;22(6):669-678 


\section{ABSTRACT}

\section{Objective}

Time trend studies in the USA have shown that the incidences of adenocarcinomas of the esophagus and gastric cardia have risen strongly since the 1970s, whereas the incidence of squamous cell carcinomas of the esophagus has declined. Previously, we found that the incidence of these adenocarcinomas also rose in some European countries until the early 1990s. The main goal of this study was to investigate more recent trends in the incidence of esophageal and stomach cancer subtypes in European countries.

\section{Methods}

Eurocim cancer incidence data of 23 cancer registries from 13 European countries were used to investigate the incidence trends in esophageal and stomach cancer subtypes in the 1983-1997 period. We calculated estimated annual percent changes (EAPCs) in European age- standardized incidence rates and $95 \%$ confidence intervals.

\section{Results}

The incidence of adenocarcinomas of the esophagus and gastric cardia rose in most, but not all, registration areas (EAPCs were usually 1 to 7\%), the strongest in the UK and Ireland. Esophageal squamous cell carcinoma incidence rose mostly in Northern European and Slovakian men (EAPCs: 1 to 5\%) and in women (EAPCs: 1 to 8\%), but declined mostly in Southern and Western European men (EAPCs: -1 to $-5 \%$ ).

\section{Conclusions}

Our results are partly in line with earlier findings on adenocarcinomas of the esophagus and gastric cardia. There was, however, substantial heterogeneity in trends of subtypes of these cancers within Europe. There may be different risk factors for these cancers, and the prevalence of these risk factors may differ among countries. 


\section{INTRODUCTION}

These days, esophageal cancer and stomach cancer are often being considered to comprise more than two types of cancer (e.g. in epidemiology, pathology). Esophageal cancer is usually divided into histological subtypes, the two main types being adenocarcinoma and squamous cell carcinoma. Subtypes of stomach cancer are usually based on topography (i.e. the location of the tumor in the stomach), distinguishing cardia tumors from tumors in other parts of the stomach. The incidences of both esophageal and stomach cancers are relatively high $^{1}$ and the 5-year survival rates are very low: $12 \%$ for esophageal cancer and $24 \%$ for stomach cancer in Europe. ${ }^{2}$ Survival rates of gastric cardia adenocarcinoma are worse than those of other stomach cancers. $^{3,4}$

Time trend studies in the United Stated have shown that the incidences of adenocarcinomas of the esophagus and gastric cardia (AEGC) have risen strongly from the 1970s, whereas the incidence of squamous cell carcinomas of the esophagus has declined. ${ }^{5,6}$ In an earlier publication, we investigated whether these changes also took place in Europe. We showed that this rise in the incidence of AEGC did indeed occur in Denmark, part of Italy, Slovakia, England and Wales and Scotland, in the 1980s and early 1990s. ${ }^{7}$

Such time trends should always be interpreted cautiously, as an observed trend may reflect changes in diagnostics, in classification of tumors or in the quality of cancer registries. The quality and level of detail of data on esophageal and stomach cancer incidences have increased over time..$^{8-10}$ More esophageal tumors are being histologically verified and the exact topography of stomach tumors is more often being registered. ${ }^{8-10}$ In contrast, observed trends can of course also indicate a true change in the occurrence of the disease, which may follow a change in the prevalence of one or more risk factors. There are indications that the subtypes of esophageal and stomach cancer have different risk factors. ${ }^{\text {e.g.11 }}$

Two studies have investigated these trend in Europe in more recent years, ${ }^{12,13}$ but one did not include any Southern or Eastern European countries ${ }^{12}$ and the other studied only esophageal cancers. ${ }^{13}$

The main goals of the present study were therefore: (a) to study trends in the incidence of histological subtypes of esophageal cancer and topographical subtypes of stomach cancer, and (b) to include data from all European regions. This allowed a comparison between cancers and between regions as well. We used Eurocim ${ }^{14}$ data and we presented the results in a conveniently arranged way. 


\section{METHODS}

\section{Eurocim database}

Cancer registries that are members of the European Network of Cancer Registries are asked to regularly submit incidence, mortality and population data to a central databank (Eurocim ${ }^{14}$ ) held at the International Agency for Research on Cancer (IARC). We obtained permission from the steering committee of the European Network of Cancer Registries to use the Eurocim database, which contains incidence data from 118 population-based cancer registries in 25 countries. Available registration years range from 1953 to 1998. In addition, the National Cancer Registry of Ireland has extracted data for the area covered by the Southern Tumors Registry for the period 1983-1997, because these data were not available in the present version of the Eurocim database. We wanted to include this region, because it was also included in our earlier study. ${ }^{7}$

\section{Selection of cancer registries}

Figure 5.1 gives an overview of the registry selection, and Table 5.1 lists all registries included. A cancer registry had to be situated in Europe and had to have registration data available in Eurocim of esophageal and stomach cancer, for a period of at least 15 years. To ensure that all Europe was covered in this study, at least one registry in every country was selected. If several registries were available in one country, we selected those with best data quality. Data quality of cancer registries is defined by three indicators: (a) the percentage of histologically or microscopically verified cases (\%HV), (b) the percentage of cases derived from death certificates only (\%DCO) and (c) the ratio of mortality to incidence ( $\mathrm{M} / \mathrm{I}$ ratio). We looked at the indicator values from Cancer Incidence in Five Continents (CI-5) volumes IV-VIII..$^{8-10,15,16}$ Not all quality indices were available for all registries; mostly the \%DCO was missing and sometimes the $\mathrm{M} / \mathrm{I}$ ratio.

From 27 of 29 selected registries, we obtained permission to use their Eurocim data. The registries were asked some questions regarding registration practice, as this could be of importance when interpreting the results. Four registries were excluded from the study, because they did not have data that were detailed enough in terms of esophageal cancer histology or stomach cancer topography. Data of 23 cancer registries from 13 countries were available for analysis and all included the 1983-1997 period. When compared with the earlier analyses, ${ }^{7}$ this study covered more countries and five more years. 


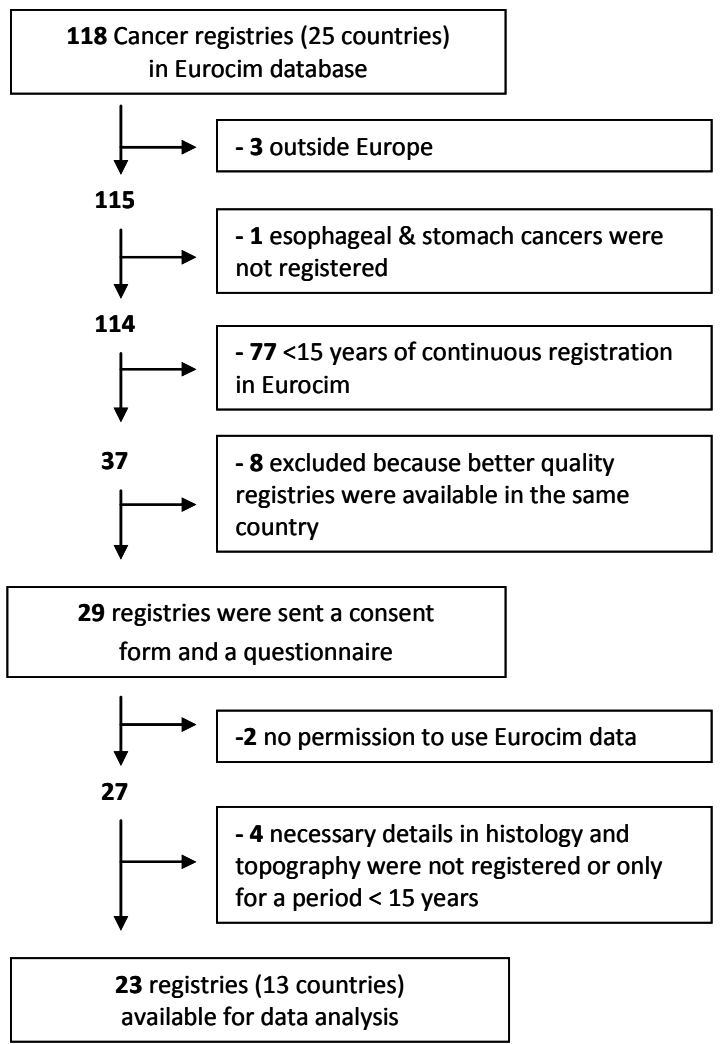

Figure 5.1 Selection of cancer registries and reasons for exclusion.

\section{Selection of tumors}

We included all primary tumors of the esophagus and stomach (International Classification of Diseases for Oncology version 2 (ICD-O-2) ${ }^{17}$ codes $\mathrm{C} 15$ and C16, respectively). Esophageal cancers were divided in three histological subgroups: (a) squamous cell carcinomas (ESCC), (b) adenocarcinomas and (c) other esophageal cancers. Stomach cancers were divided into three topographical subgroups: (a) cardia, (b) other specified sites (OSS) and (c) not otherwise specified (NOS) (Appendix).

We then combined AEGC to form one group (Appendix). Although it is subject of discussion whether or not these diseases are the same, ${ }^{4,18,19}$ it was necessary to combine them, because some cancer registries used to classify adenocarcinomas of the lower esophagus as cardia tumors, as was also advised by the International Classification of Diseases version 9 (ICD-9). In the analysis, we distinguished stomach tumors OSS from NOS, so that we could examine whether trends observed in cardia 
tumors could be partly explained by increasing registry quality or specification of tumor sublocalisation.

Table 5.1 Characteristics of selected cancer registries, by region.

\begin{tabular}{|c|c|c|c|c|c|}
\hline & \multirow[t]{2}{*}{$\begin{array}{l}\text { Population size in } \\
1997 \text { (x } 1 \text { million) }\end{array}$} & \multicolumn{2}{|c|}{$\begin{array}{c}\text { Esophageal } \\
\text { cancer cases ( } \mathrm{n} / \text { year) }\end{array}$} & \multicolumn{2}{|c|}{$\begin{array}{c}\text { Stomach } \\
\text { cancer cases ( } \mathrm{n} / \text { year) }\end{array}$} \\
\hline & & male & female & male & female \\
\hline \multicolumn{6}{|l|}{ Northern Europe } \\
\hline Denmark & 5.3 & 167 & 75 & 470 & 310 \\
\hline Estonia & 1.5 & 47 & 11 & 290 & 245 \\
\hline Iceland & 0.3 & 7 & 5 & 44 & 23 \\
\hline Ireland, Southern ${ }^{\mathrm{b}}$ & 0.6 & 23 & 18 & 46 & 26 \\
\hline Sweden & $8.8^{\mathrm{c}}$ & 225 & 96 & 1034 & 664 \\
\hline UK England, East Anglia ${ }^{d}$ & 2.2 & 126 & 82 & 266 & 140 \\
\hline UK England, Merseyside and Cheshire ${ }^{\mathrm{e}}$ & 2.4 & 152 & 117 & 358 & 249 \\
\hline UK England, South Thames Region & 6.9 & 306 & 235 & 868 & 599 \\
\hline UK England, Yorkshire ${ }^{f}$ & 3.7 & 196 & 138 & 477 & 304 \\
\hline UK Scotland & 5.1 & 333 & 274 & 684 & 509 \\
\hline \multicolumn{6}{|l|}{ Central \& Eastern Europe } \\
\hline Slovakia & 5.4 & 138 & 18 & 903 & 555 \\
\hline \multicolumn{6}{|l|}{ Southern Europe } \\
\hline Italy, Parma & 0.4 & 14 & 4 & 146 & 103 \\
\hline Italy, Lombardy (Varese) & 0.8 & 37 & 7 & 168 & 130 \\
\hline Slovenia & 2.0 & 77 & 13 & 294 & 202 \\
\hline Spain, Navarra & 0.5 & 23 & 4 & 102 & 60 \\
\hline Spain, Catalonia, Tarragona & 0.6 & 21 & 2 & 64 & 37 \\
\hline \multicolumn{6}{|l|}{ Western Europe } \\
\hline France, Bas-Rhin & 1.0 & 88 & 8 & 82 & 55 \\
\hline France, Calvados & 0.6 & 86 & 8 & 55 & 37 \\
\hline France, Côte d'Or & 0.5 & 37 & 4 & 43 & 25 \\
\hline France, Doubs & $0.5^{\mathrm{c}}$ & 34 & 4 & 39 & 23 \\
\hline the Netherlands, Eindhoven & 1.0 & 16 & 7 & 99 & 59 \\
\hline Switzerland, Geneva & 0.4 & 18 & 5 & 34 & 27 \\
\hline Switzerland, St Gallen Appenzell & 0.5 & 17 & 3 & 44 & 32 \\
\hline
\end{tabular}

a Average number of cases in the 1983-1996 period. This period is available in Eurocim for all selected registries; ${ }^{b}$ Data were obtained from the National Cancer Registry of Ireland. Southern Ireland represents the area formerly covered by the Southern Tumour Registry; ${ }^{\mathrm{C}}$ Population size of 1998 (Sweden), population size of 1996 (France, Doubs). These years were the latest available in Eurocim; ${ }^{d}$ The registry's current name is Eastern Cancer Registration \& Information Service (ECRIC); ${ }^{e}$ This registry is now part of the North West Cancer Intelligence Service (NWCIS); ${ }^{\mathrm{f}}$ This registry is now part of the Northern and Yorkshire Cancer Registry and Information Service (NYCRIS).

\section{Statistical analyses}

Data analyses were performed using Eurocim version 4.0 and Stata 9.2 (StataCorp, College Station, Texas, USA). We calculated age-standardized incidence rates (ESR) according to the European Standard Population. ${ }^{14}$ A graph of these rates against time was plotted for each registry and sex, showing trends in the five tumor groups mentioned above. These graphs were inspected to see whether the trends were linear and whether a change in trend (a joinpoint) seemed to be present. In case a joinpoint 
seemed to be present, we used the Joinpoint regression program (Version 3.0, Statistical Research and Applications Branch, National Cancer Institute, Bethesda, MD, USA) to test whether the trend change was statistically significant. ${ }^{20}$ The minimal number of joinpoints was set to zero, and the maximum to three; which are the default values of the program.

Estimated annual percentage changes (EAPC) and corresponding 95\% confidence intervals $(95 \% \mathrm{Cl})$ were calculated for each registry, sex and cancer subtype, using the following formulae: $\ln ($ rate $)=a x$ period $+b$ and EAPC $=100\left(e^{a}-1\right)$, where $a$ is regression coefficient and $b$ is intercept. The EAPCs were calculated for the same 15-year period (1983-1997) for all registries to make these comparable with one another. Data of different cancer registries within one country were not pooled before analysis for two reasons: (a) this would make differences within in a country indiscernible and (b) regional registries included do not always cover the whole country (e.g. France, UK). In addition, French regional cancer registries are not representative for the national population. ${ }^{21}$ The EAPCs were visualized in forest plots, to facilitate comparisons of the trends in Europe. Results are presented by regions of Europe, according to the United Nations classification. ${ }^{22}$ For each region, a summary estimate is presented, which was obtained by a fixed effects model using the method of Mantel and Haenszel. The I-squared measure is shown to quantify the heterogeneity within the regions. ${ }^{23}$

\section{RESULTS}

\section{Descriptives}

Table 5.1 lists some characteristics of the 23 cancer registries included. The population size covered by the cancer registries ranged from 0.3 to 8.8 million. The average numbers of cancer cases per year are listed in Table 5.1. For esophageal cancer, these ranges were 7-333 cases per year in men and 2-274 cases per year in women and for stomach cancer, these ranges were 34-1034 and 23-664 cases per year in men and women, respectively. ESRs, averaged over three-year periods, were higher among men than among women (for details, see Tables 5.2A and 5.2B). Figure 5.2 shows two examples of ESR graphs.

The male-to-female ratios of ESRs varied greatly between countries and between the cancer subtypes. These were highest for ESCC: about six to nine, averaged for all registries. Very high ratios were seen in France, Spain, Switzerland (St Gallen Appenzell) and Slovakia. In contrast, the ratios were just above one in Great Britain and Southern Ireland. Much less variation was observed in the male-to-female ratios of AEGC, with an average ratio of approximately five. Lower average ratios (approximately two) were found for stomach cancers OSS and NOS. 


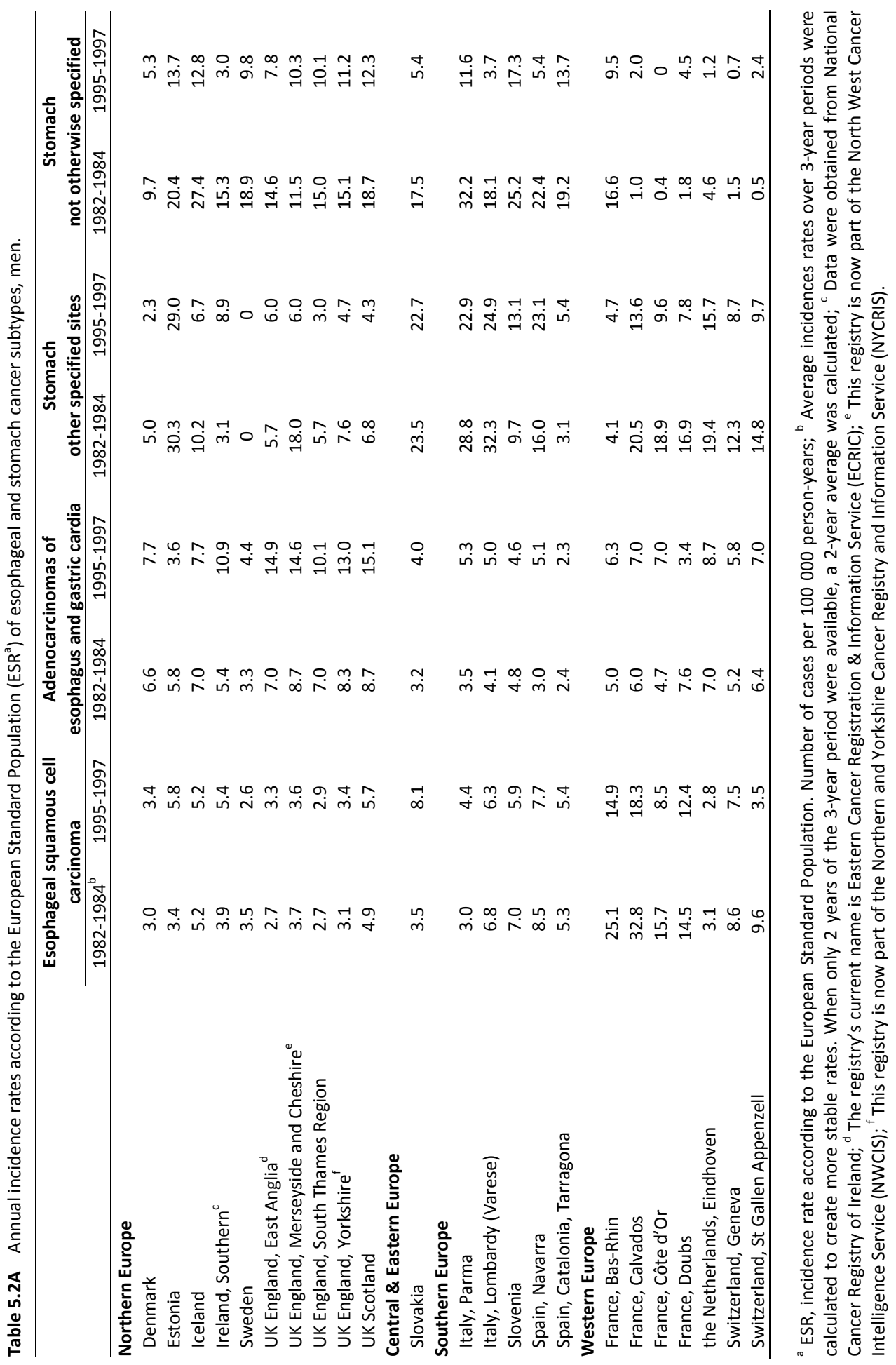




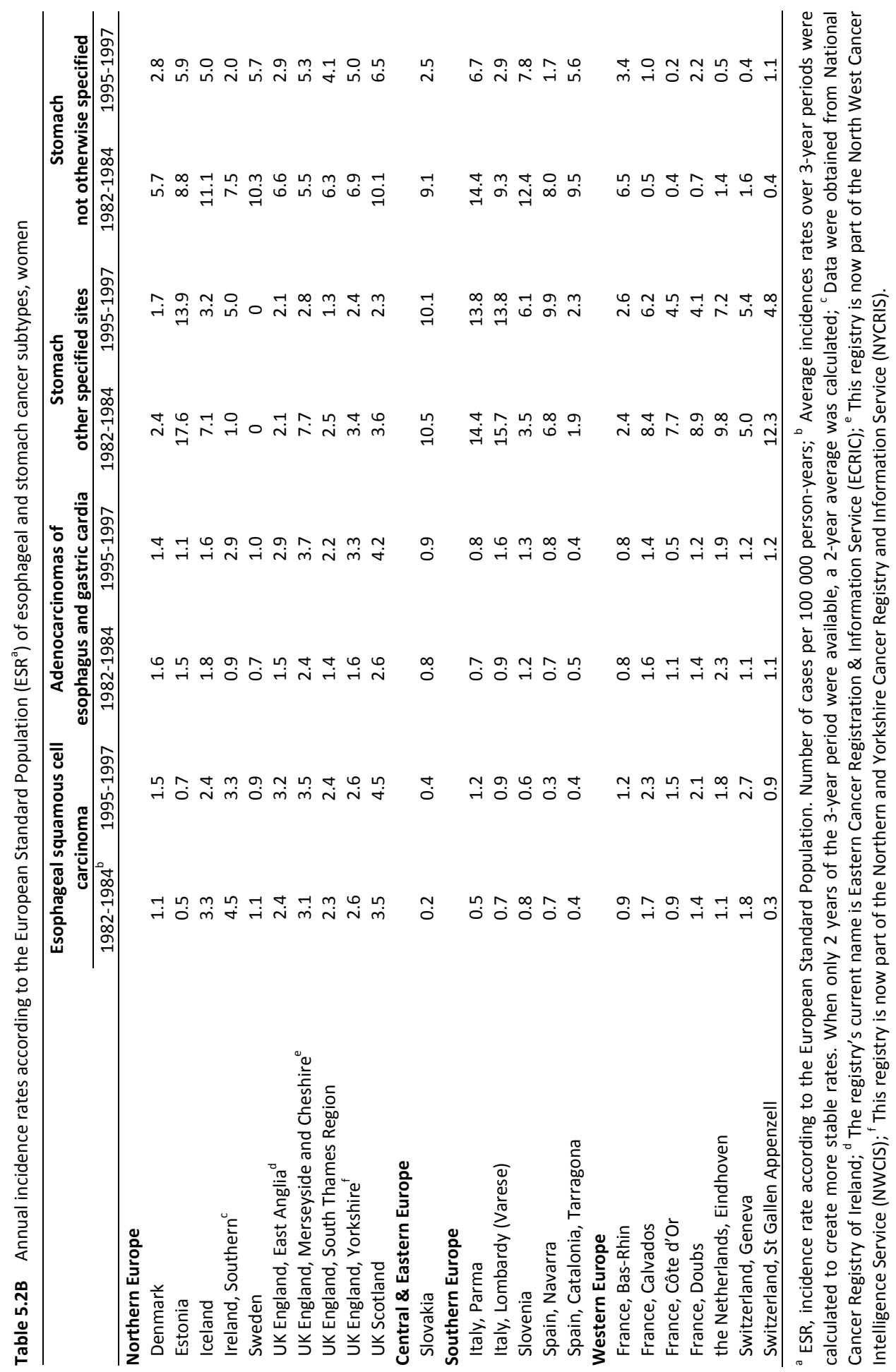



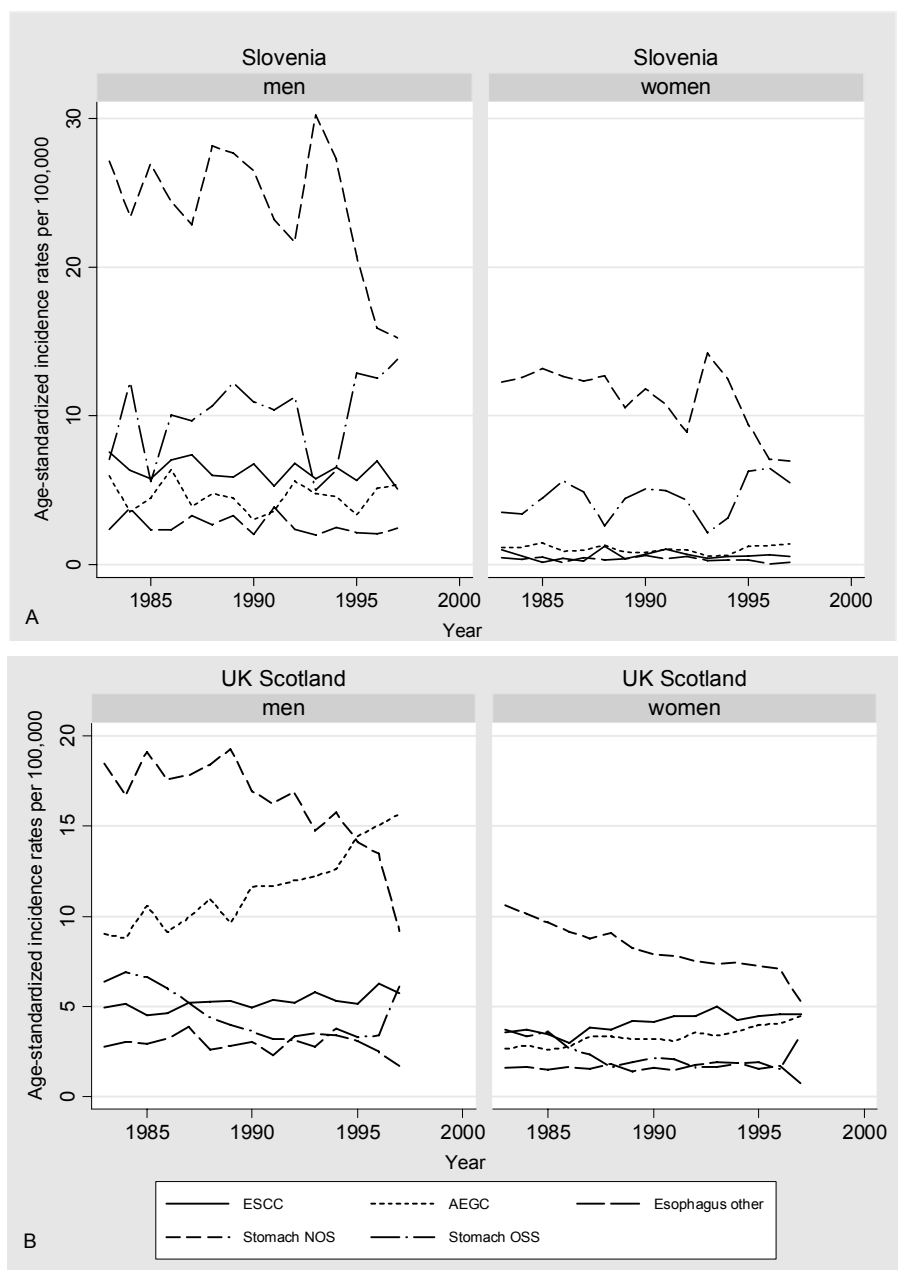

Figure 5.2 Trends in incidence rates (according to the European Standard Population, ESR) of esophageal and stomach cancer subtypes for men and women in Slovenia (A) and UK Scotland (B), 19831997

\section{Estimated annual percentage changes}

Figures 5.3A to $5.3 \mathrm{H}$ show EAPCs and 95\% Cls for ESCC (Figures 5.3A and 5.3B), AEGC (5.3C and 5.3D), stomach tumors OSS (5.3E and 5.3F) and stomach tumors NOS (5.3G and $5.3 \mathrm{H}$ ), for men and women separately, during the 1983-1997 period. The EAPCs were calculated for all groups, but the incidence rates for women were often very low, which resulted in wide confidence intervals for these EAPCs.

ESCC incidence rose slightly; approximately 1 to $2 \%$ per year in most Northern European countries and Slovakia in men and women, but none of the EAPCs was 
statistically significant. In Southern and Western Europe the incidence declined approximately 1 to $5 \%$ per year in men, and mostly rose in women. The latter EAPCs were based on less than 10 cases per year, which is reflected by the wide $95 \% \mathrm{Cls}$. AEGC incidence rose in men and women in most (but not all) European regions covered by the cancer registries. The increases were strongest in Northern Europe (1 to $7 \%$ per year), specifically in Great Britain and Southern Ireland (approximately 3 to $7 \%$ ). Smaller increases (1 to $3 \%$ per year) were seen in the other European regions. Individual cancer registration areas where the incidence of AEGC did not rise were: Estonia, Iceland, Slovenia, Spain Navarra (women), Spain Tarragona, France Doubs, Netherlands Eindhoven (women) and Switzerland Geneva (men). The above trends were not always statistically significant; for details see Figures $5.3 \mathrm{~A}-\mathrm{H}$.

In Northern European men and Southern European women, AEGC was more common than ESCC. This difference had become larger during the 1983-1997 period. In Northern European women, AEGC also became more frequent relative to ESCC, and by the end of the 1990s both types had become equally common. A similar tendency was seen in men from Southern and Western Europe, although AEGC had not, or not yet, outnumbered ESCC. In contrast, the ratio of ESCC to AEGC increased in Western European women. The incidence of other esophageal tumors was considerably low in most countries, when compared with AEGC and ESCC (data not shown).

Stomach tumors OSS showed a declining incidence in nearly all registration areas, in men as well as in women. The greatest declines were seen in Western and Northern Europe, but the picture was less clear for Southern Europe and Slovakia. A remarkable exception was Southern Ireland, where a strong and statistically significant increase in this type of cancer was found (EAPCs: $16 \%$ in men and $18 \%$ in women).

Incidence of stomach tumors NOS declined (approximately 2 to 10\% per year) in both sexes in practically all registration areas in Northern, Central \& Eastern, and Southern Europe, and the decline was often statistically significant. In Western Europe, the incidence of these tumors also declined in some areas but, in contrast, increased in some parts of France and Switzerland. In the latter regions, however, this relative increase represents a small absolute increase, as the percentage of stomach tumors NOS was already low in the early 1980s, because of a good topographic specification.

\section{Joinpoint analyses}

Results of the Joinpoint analyses showed that when a change in trend seemed present, it was mostly also statistically significant (data not shown). The majority of trend changes were seen in stomach tumors NOS and some in stomach tumors OSS. A strong decline in the incidence of stomach tumors NOS was mostly followed by a weaker decline. We did not observe any trend changes in the incidence of AEGC. In only one registration area (France Bas-Rhin) a trend change was observed in ESCC incidence in men: it rose until 1984 and declined thereafter. 
A

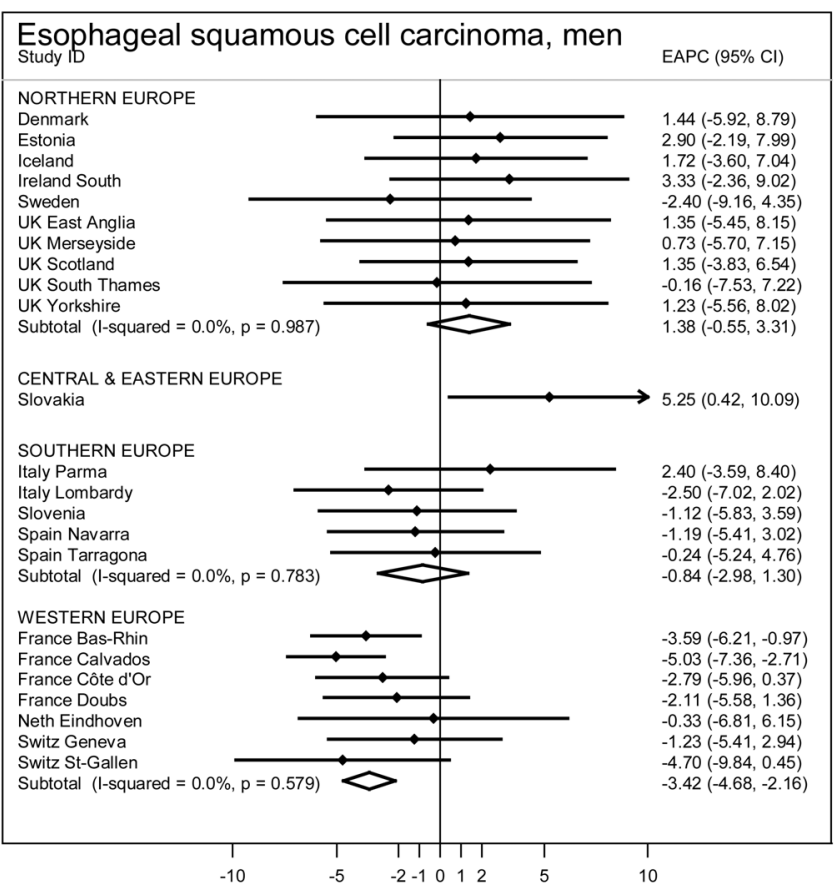

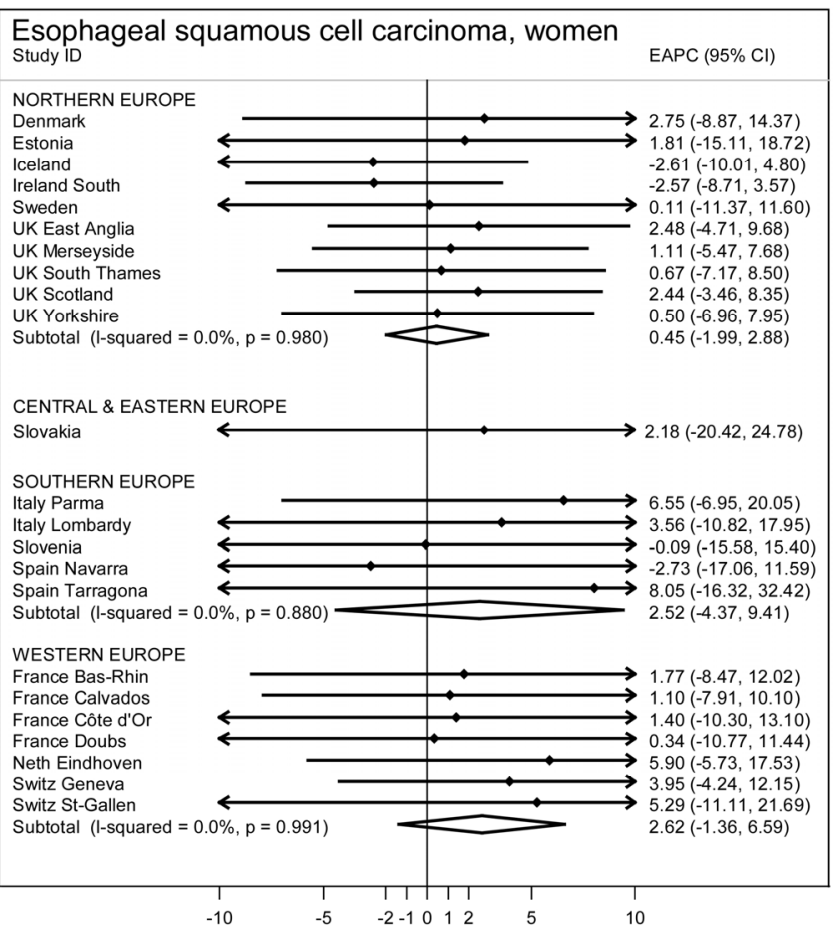




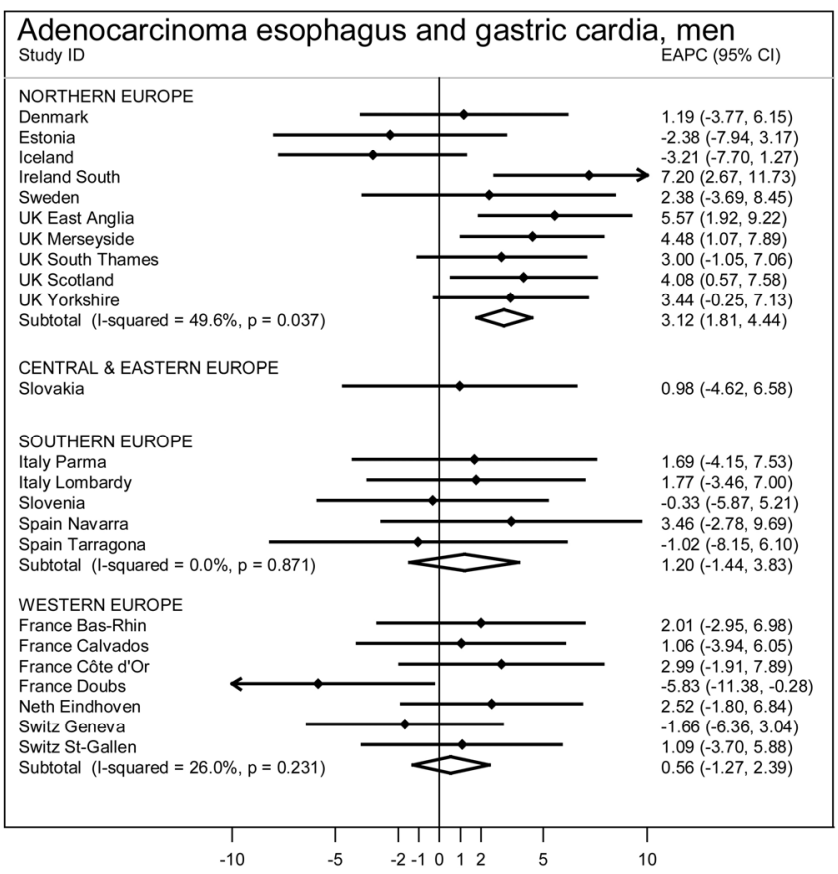

D

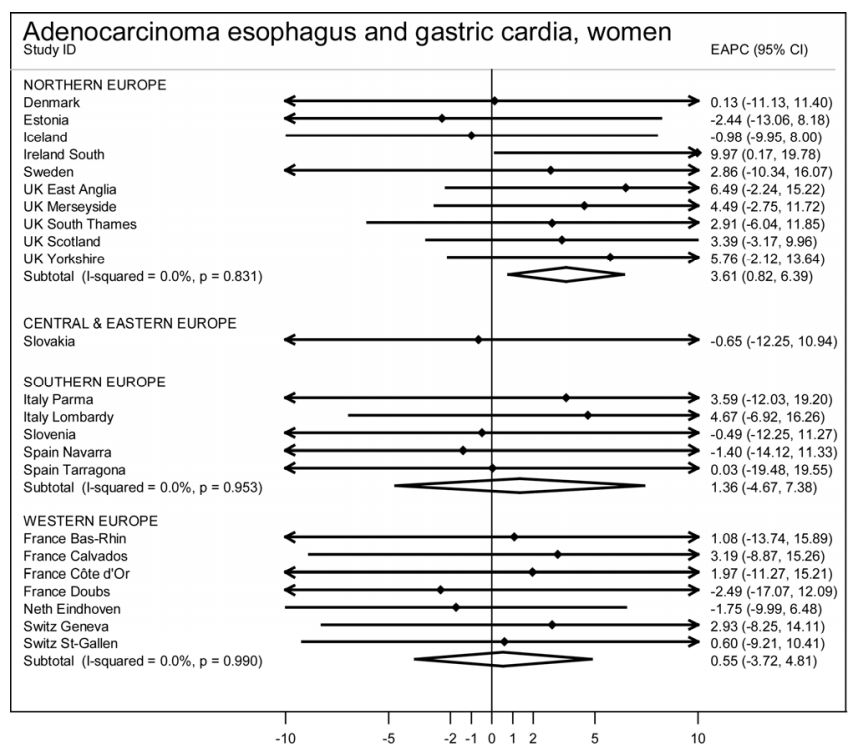




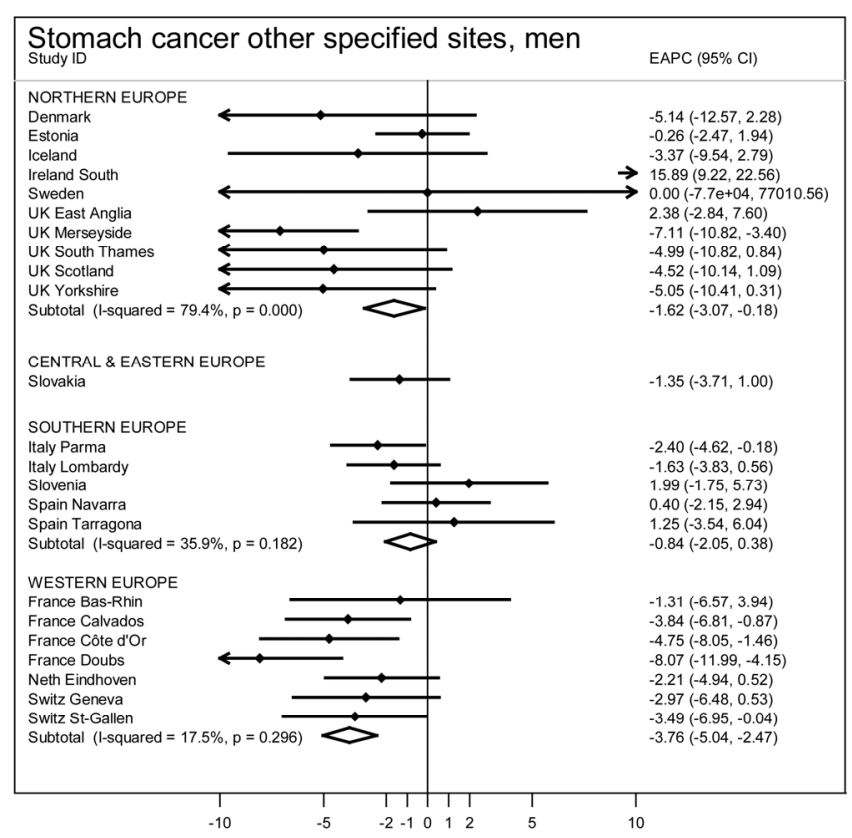

F

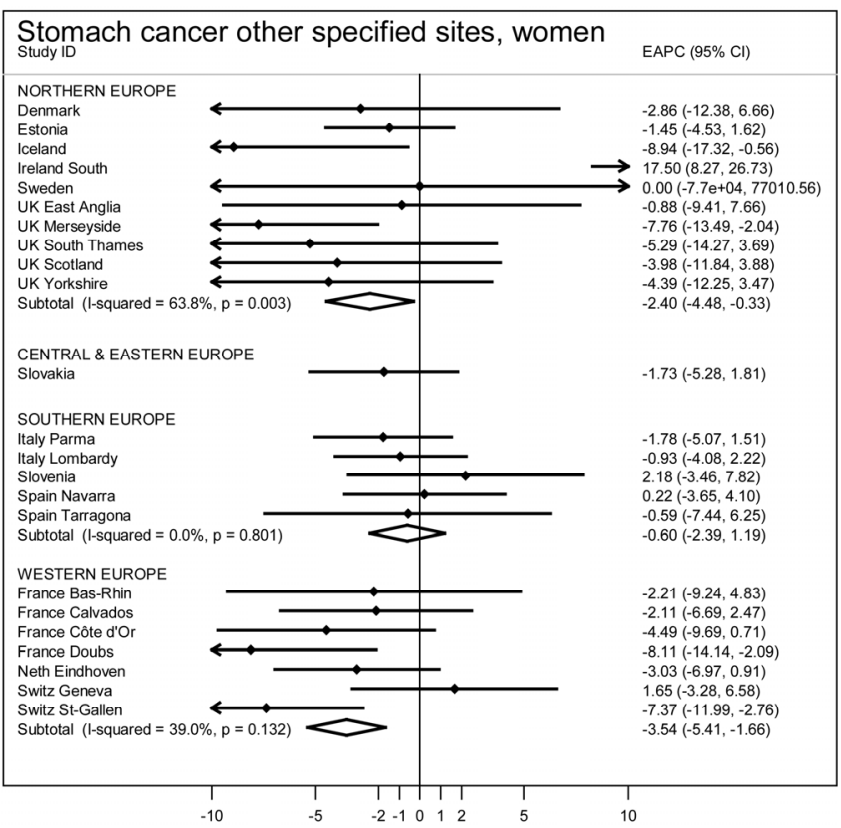




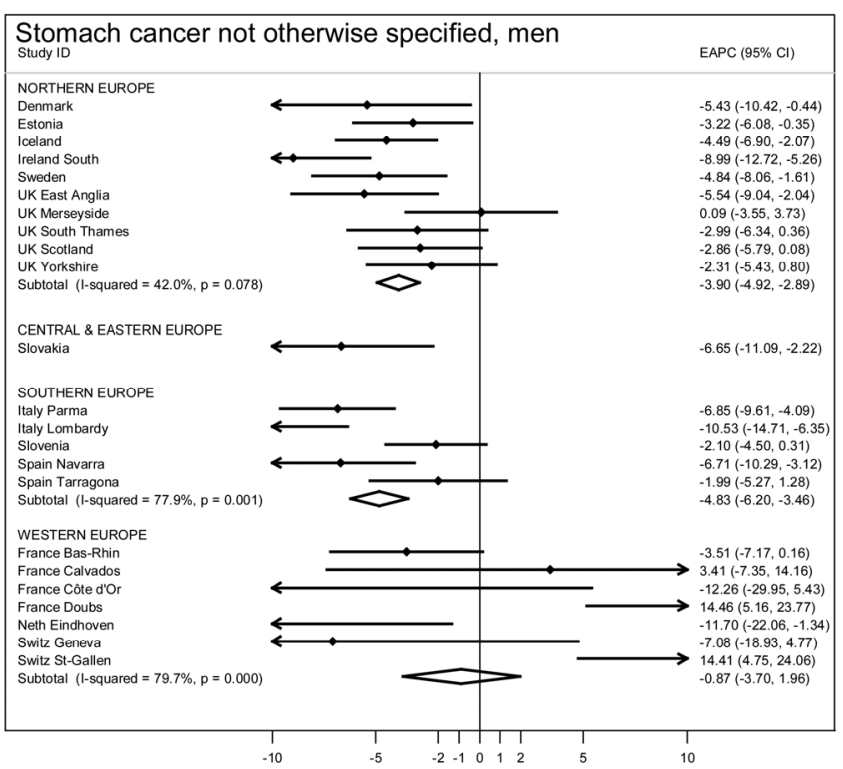

$\mathrm{H}$

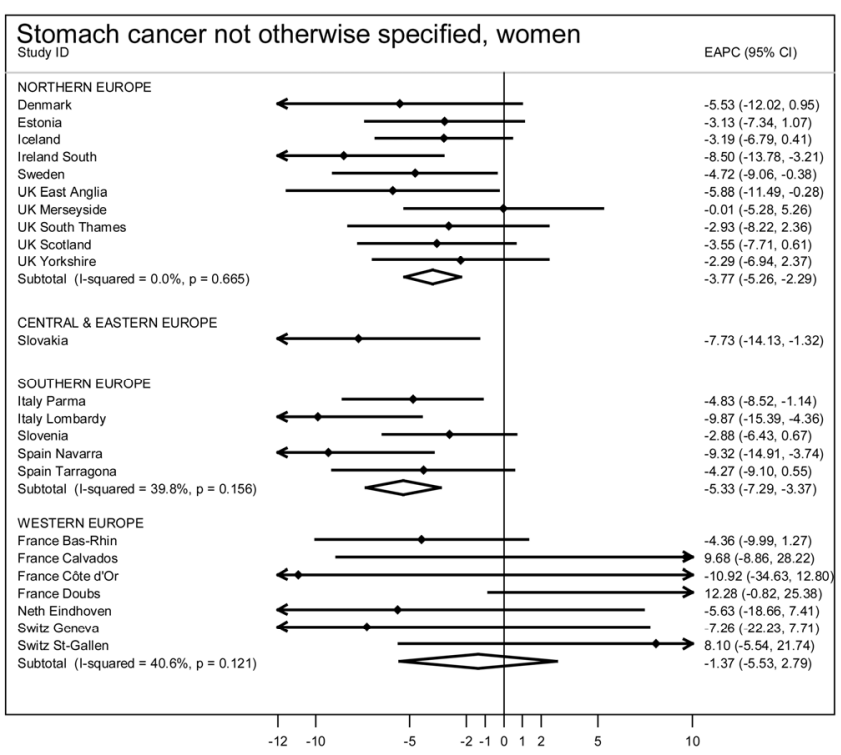

Figure 5.3 Estimated annual percent changes (EAPCs) and 95\% confidence intervals of standardized incidence rates (according to the European Standard Population, ESR) of esophageal and stomach cancer subtypes in European countries, 1983-1997.

A summary estimate of the EAPCs is depicted for each European region, which was obtained by a fixed effects model using the method of Mantel and Haenszel. The I-squared measure quantifies the heterogeneity within the regions. 


\section{DISCUSSION}

\section{Summary of results}

This study showed that the incidence of adenocarcinomas of esophagus and gastric cardia (AEGC) rose for both sexes in many, but not all, European countries during the 1983-1997 period. The magnitude of this increase differed among countries. Incidence rates of ESCC rose in some European regions, but declined in others, and there was a difference between men and women. In nearly all regions, the ratio of AEGC to ESCC incidence was increasing.

\section{Interpretation of trends in incidence}

When interpreting results of studies on trends in incidence rates, one always has to be cautious. A careful look should be taken at possible explanations, other than a true increase of the disease. The growing use of endoscopies may have caused more tumors of the esophagus to be histologically verified, but we do not expect this growing use of endoscopies to have caused much overdiagnosis of esophageal cancers. The attention for esophageal and stomach cancer increased and might have influenced pathologists, and the histological description of the tumors became more detailed. This may have led to improved detection of these tumors. In some countries the incidence of not specified esophageal tumors indeed decreased, but mainly before the period studied and the incidence of these tumors is generally low.

A better specification and registration of the topography of tumors could in part explain the decreasing trend in stomach cancers NOS, which goes together with the increase of cardia tumors. However, the decline of stomach cancers NOS is often much stronger than the increase in cardia tumors. Furthermore, one would then expect stomach cancers OSS to increase as well, but in most countries these showed a decreasing incidence instead. In Southern Ireland, the trends (rising AEGC and stomach cancers OSS and declining stomach cancers NOS) may in part have been caused by a better topography registration. However, we do not know the quality indices of the mid 1990s to support this.

In this study we did not separate adenocarcinomas of the esophagus from tumors of the gastric cardia. Some studies have made this separation and have found different trends in incidence for these tumors. ${ }^{5,12,18,24}$ There are studies indicating that these two cancers have a different etiology, ${ }^{\text {e.g. } 25}$ but other studies point to similar risk factors. ${ }^{\text {e.g.11 }}$ It is difficult to distinguish tumors of the lower esophagus from those of the gastric cardia. This applies in the clinic and in cancer registration, because registration differs among registries and over time. Therefore, combining the two tumors was the best solution. 


\section{Comparison with other studies}

In the literature, rising incidences in AEGC were found in the USA, Australia and New Zealand, ${ }^{5,12,18,24}$ but no such trend was found in Hong Kong and Taiwan. ${ }^{26,27}$ The results of our study show that beside heterogeneity in trends between continents, heterogeneity can also be found within Europe, which is consistent with results from our earlier study. ${ }^{7}$

Eurocim database only contains data up to 1997 , but it is a valuable source of data for trend studies in which sublocalisation and histological subgroups are needed, and should therefore be updated regularly. A comparison with more recent data from individual countries is limited, because, to our knowledge there are only very few studies available. In Sweden, the trends in the incidences of ESCC, esophageal adenocarcinoma, and gastric cardia adenocarcinoma, continued in the same direction until 2004. ${ }^{28}$ In the Netherlands, trends were described for AEGC until 2003, showing a further increase in incidence in men, and in women as well. ${ }^{29}$ In France, the incidences of esophageal cancer and stomach cancer were estimated until 2000 and were expected to decrease, except for stomach cancer in women, which was thought to rise. ${ }^{30}$ These figures, however, are estimated for the whole country, whereas individual regions may have different trends, as we also found in our study. In Italy, the incidence of stomach cancer was estimated until 2010 and was thought to further decrease. ${ }^{31}$

\section{Possible explanations for the trends observed}

If the observed trends represent real changes in incidence, what then underlies these changes? Ecological studies compare trends in the prevalence of possible risk factors with the observed trends in cancer incidence. Trend data of these factors however, are mostly not available until the 1980s, whereas earlier data are probably more relevant, because one expects a certain latency time before changes in risk factors have their effect on cancer incidence. Therefore, the following must be interpreted cautiously. Results from the MONICA study showed that the prevalence of obesity increased between the mid 1980 s and late $1990 \mathrm{~s}^{32}$ most strongly in the UK. This may explain part of the trends in incidence of AEGC as overweight and obesity are strong risk factors for these tumors. ${ }^{11}$ The rising prevalence described in that study can affect AEGC incidence later on. The decreasing prevalence of Helicobacter pylori infection in developed countries ${ }^{33}$ could also be important, because this infection is related to increased risk of noncardia stomach cancer, but to decreased risk of AEGC. ${ }^{34,35}$ Smoking and alcohol consumption are differently related to the subtypes of esophageal and stomach cancer ${ }^{36,37}$ and Bosetti et al. concluded that these factors might explain trends in incidence. ${ }^{13}$ In addition, other factors (e.g. diet and nutrition) could explain the observed trends. 


\section{Suggestions for the future}

Eurocim database is a valuable source of information for all kinds of studies, and should therefore be updated regularly. If the Eurocim database would be updated, data from more countries could be used because they will then have data available for a longer period. This is especially important with respect to Eastern Europe, which was not well represented in this study. Thus there is a need for better standards in timeliness and comparability in cancer registry datasets.

Etiological epidemiological research can identify environmental risk factors for esophageal and stomach cancer and its subtypes and should be applied in primary prevention, as survival is still very low. 


\section{APPENDIX}

\section{Classification of tumors of the esophagus and stomach}

\begin{tabular}{|c|c|c|c|}
\hline Description of tumor & $\begin{array}{l}\text { Topography codes } \\
\text { ICD-O- } 2^{17}\end{array}$ & $\begin{array}{l}\text { Morphology codes } \\
\text { ICD-O-2 }{ }^{17}\end{array}$ & Eurocim entities $^{14}$ \\
\hline $\begin{array}{l}\text { Esophagus, squamous } \\
\text { cell carcinoma (ESCC) }\end{array}$ & C15.0-C15.9 & $8050-8082$ & $134,141,148$ \\
\hline $\begin{array}{l}\text { Esophagus, } \\
\text { adenocarcinoma }^{\text {a }}\end{array}$ & C15.0-C15.9 & $\begin{array}{l}8140-8473,8480-8490 \\
8500-8550\end{array}$ & $\begin{array}{l}\text { 135-136, 142-143, } \\
149-150\end{array}$ \\
\hline $\begin{array}{l}\text { Esophagus, other } \\
\text { subtypes }\end{array}$ & C15.0-C15.9 & All other morphologies & $\begin{array}{l}\text { 137-140, 144-147, } \\
151-154\end{array}$ \\
\hline Stomach, cardia $^{a}$ & C16.0 & All morphologies & $155-161$ \\
\hline $\begin{array}{l}\text { Stomach, other } \\
\text { specified sites (OSS) }\end{array}$ & C16.1-C16.8 & All morphologies & $162-175$ \\
\hline $\begin{array}{l}\text { Stomach, not otherwise } \\
\text { specified (NOS) }\end{array}$ & C16.9 & All morphologies & $176-182$ \\
\hline
\end{tabular}

a These tumors were combined in analyses into adenocarcinomas of the esophagus and gastric cardia (AEGC). 


\section{REFERENCES}

1. Ferlay J, Autier P, Boniol M, Heanue M, Colombet M, Boyle P. Estimates of the cancer incidence and mortality in Europe in 2006. Ann Oncol 2007;18:581-592.

2. Berrino F, De Angelis R, Sant M, Rosso S, Bielska-Lasota M, Coebergh JW, Santaquilani M. Survival for eight major cancers and all cancers combined for European adults diagnosed in 1995-99: results of the EUROCARE-4 study. Lancet Oncol 2007;8:773-783.

3. Verdecchia A, Corazziari I, Gatta G, Lisi D, Faivre J, Forman D. Explaining gastric cancer survival differences among European countries. Int J Cancer 2004;109:737-741.

4. Dolan K, Sutton R, Walker SJ, Morris Al, Campbell F, Williams EM. New classification of oesophageal and gastric carcinomas derived from changing patterns in epidemiology. Br J Cancer 1999;80:834-842.

5. Devesa SS, Blot WJ, Fraumeni JF, Jr. Changing patterns in the incidence of esophageal and gastric carcinoma in the United States. Cancer 1998;83:2049-2053.

6. Trivers KF, Sabatino SA, Stewart SL. Trends in esophageal cancer incidence by histology, United States, 1998-2003. Int J Cancer 2008;123:1422-1428.

7. Botterweck AA, Schouten LJ, Volovics A, Dorant E, van Den Brandt PA. Trends in incidence of adenocarcinoma of the oesophagus and gastric cardia in ten European countries. Int J Epidemiol 2000;29:645-654.

8. Ferlay J, Muir CS, Whelan SL, Gao Y-T. Cancer incidence in five continents. Volume VI. Lyon: IARC Scientific publications no. 120, 1992.

9. Parkin DM, Whelan SL, Ferlay J, Raymond L, Young J. Cancer incidence in five continents. Volume VII. Lyon: IARC Scientific publications no. 143, 1997.

10. Parkin DM, Whelan SL, Ferlay J, Teppo L, Thomas DB. Cancer incidence in five continents. Volume VIII. Lyon: IARC Scientific publications no. 155, 2002.

11. Merry AH, Schouten $\amalg$, Goldbohm RA, van den Brandt PA. Body mass index, height and risk of adenocarcinoma of the oesophagus and gastric cardia: a prospective cohort study. Gut 2007;56:15031511.

12. Vizcaino AP, Moreno V, Lambert R, Parkin DM. Time trends incidence of both major histologic types of esophageal carcinomas in selected countries, 1973-1995. Int J Cancer 2002;99:860-868.

13. Bosetti C, Levi F, Ferlay J, Garavello W, Lucchini F, Bertuccio P, Negri E, La Vecchia C. Trends in oesophageal cancer incidence and mortality in Europe. Int J Cancer 2008;122:1118-1129.

14. European Network of Cancer Registries. European incidence database V2.3. Eurocim version 4. Lyon: IARC, 2001.

15. Waterhouse J, Muir C, Shanmugaratnam K, Powell J. Cancer incidence in five continents. Volume IV. Lyon: IARC Scientific publication no. 42, 1982.

16. Muir C, Waterhouse J, Mack T, Powell J, Whelan S. Cancer incidence in five continents. Volume V. Lyon: IARC Scientific publication no. 88, 1987.

17. Percy C, van Holten V, Muir C. International classification of diseases for oncology, Second edition. Geneva: World Health Organization, 1990.

18. Crane SJ, Richard Locke G, 3rd, Harmsen WS, DiehI NN, Zinsmeister AR, Joseph Melton L, 3rd, Romero $\mathrm{Y}$, Talley NJ. The changing incidence of oesophageal and gastric adenocarcinoma by anatomic sub-site. Aliment Pharmacol Ther 2007;25:447-453.

19. Rusch VW. Are cancers of the esophagus, gastroesophageal junction, and cardia one disease, two, or several? Semin Oncol 2004;31:444-449.

20. Kim HJ, Fay MP, Feuer EJ, Midthune DN. Permutation tests for joinpoint regression with applications to cancer rates. Stat Med 2000;19:335-351.

21. Remontet L, Esteve J, Bouvier AM, Grosclaude P, Launoy G, Menegoz F, Exbrayat C, Tretare B, Carli PM, Guizard AV, Troussard X, Bercelli P, Colonna M, Halna JM, Hedelin G, Mace-Lesec'h J, Peng J, Buemi A, Velten $M$, Jougla E, Arveux P, Le Bodic L, Michel E, Sauvage M, Schvartz C, Faivre J. Cancer incidence and mortality in France over the period 1978-2000. Rev Epidemiol Sante Publique 2003;51:3-30.

22. United Nations. http://unstats.un.org/unsd/methods/m49/m49regin.htm\#europe, date accessed: 30 September 2008.

23. Higgins JP, Thompson SG, Deeks JJ, Altman DG. Measuring inconsistency in meta-analyses. Bmj 2003;327:557-560. 
24. Armstrong RW, Borman B. Trends in incidence rates of adenocarcinoma of the oesophagus and gastric cardia in New Zealand, 1978-1992. Int J Epidemiol 1996;25:941-947.

25. Brewster DH, Fraser LA, McKinney PA, Black RJ. Socioeconomic status and risk of adenocarcinoma of the oesophagus and cancer of the gastric cardia in Scotland. Br J Cancer 2000;83:387-390.

26. Chang SS, Lu CL, Chao JY, Chao Y, Yen SH, Wang SS, Chang FY, Lee SD. Unchanging trend of adenocarcinoma of the esophagus and gastric cardia in Taiwan: a 15-year experience in a single center. Dig Dis Sci 2002;47:735-740.

27. Yee YK, Cheung T, Chan AO, Yuen M, Wong BC. Decreasing trend of esophageal adenocarcinoma in Hong Kong. Cancer Epidemiol Biomarkers Prev 2007;16:2637-2640.

28. Falk J, Carstens $\mathrm{H}$, Lundell L, Albertsson M. Incidence of carcinoma of the oesophagus and gastric cardia. Changes over time and geographical differences. Acta Oncologica 2007;46:1070-1074.

29. van Blankenstein M, Looman CW, Siersema PD, Kuipers EJ, Coebergh JW. Trends in the incidence of adenocarcinoma of the oesophagus and cardia in the Netherlands 1989-2003. Br J Cancer 2007;96:1767-1771.

30. Bouvier AM, Remontet L, Jougla E, Launoy G, Grosclaude P, Buemi A, Tretarre B, Velten M, Dancourt V, Menegoz F, Guizard AV, Mace Lesec'h J, Peng J, Bercelli P, Arveux P, Esteve J, Faivre J. Incidence of gastrointestinal cancers in France. Gastroenterol Clin Biol 2004;28:877-881.

31. Inghelmann R, Grande E, Francisci S, Verdecchia A, Micheli A, Baili P, Capocaccia R, De Angelis R. Regional estimates of stomach cancer burden in Italy. Tumori 2007;93:367-373.

32. Seidell JC. Prevalence and time trends of obesity in Europe. J Endocrinol Invest 2002;25:816-822.

33. Everhart JE. Recent developments in the epidemiology of Helicobacter pylori. Gastroenterol Clin North Am 2000;29:559-578.

34. Helicobacter and Cancer Collaborative Group. Gastric cancer and Helicobacter pylori: a combined analysis of 12 case control studies nested within prospective cohorts. Gut 2001;49:347-353.

35. Islami F, Kamangar F. Helicobacter pylori and esophageal cancer risk: a meta-analysis. Cancer Prev Res (Phila Pa) 2008;1:329-338.

36. Lindblad M, Rodriguez LA, Lagergren J. Body mass, tobacco and alcohol and risk of esophageal, gastric cardia, and gastric non-cardia adenocarcinoma among men and women in a nested case-control study. Cancer Causes Control 2005;16:285-294.

37. Freedman ND, Abnet CC, Leitzmann MF, Mouw T, Subar AF, Hollenbeck AR, Schatzkin A. A prospective study of tobacco, alcohol, and the risk of esophageal and gastric cancer subtypes. Am J Epidemiol 2007;165:1424-1433. 


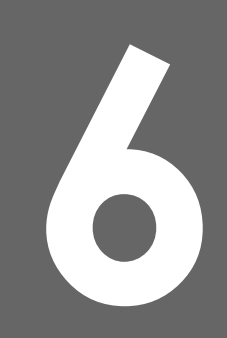

\title{
Alcohol consumption, cigarette smoking and risk of subtypes of esophageal and gastric cancer: a prospective cohort study
}

\author{
Jessie Steevens \\ Leo J Schouten \\ R Alexandra Goldbohm \\ Piet $A$ van den Brandt
}

Gut 2010;59:39-48 


\section{ABSTRACT}

\section{Objective}

Alcohol consumption and cigarette smoking may be differentially associated with esophageal squamous cell carcinoma (ESCC), esophageal adenocarcinoma (EAC), gastric cardia adenocarcinoma (GCA), and gastric non-cardia adenocarcinoma (GNCA). However, because this was based on retrospective studies, these hypotheses were examined in a prospective cohort.

\section{Methods}

The prospective Netherlands Cohort Study consists of 120852 participants who completed a baseline questionnaire on diet and other cancer risk factors in 1986. After 16.3 years of follow-up, 107 ESCC, 145 EAC, 164 GCA, and 491 GNCA cases were available for analysis using Cox proportional hazards models and the case-cohort approach.

\section{Results}

The multivariable adjusted incidence rate ratio (RR) for ESCC was 4.61 (95\% confidence interval (Cl) 2.24-9.50) for $\geq 30 \mathrm{~g}$ ethanol/day compared with abstainers ( $p$ trend<0.001), while no associations with alcohol were found for EAC, GCA or GNCA. Compared with never smokers, current smokers had RRs varying from 1.60 for GCA to 2.63 for ESCC, and were statistically significant or borderline statistically significant. Frequency, duration, and pack-years of smoking were independently associated with risk of all four cancers. A positive interaction was found between alcohol consumption and smoking status regarding ESCC risk. The RR for current smokers who consumed $>15 \mathrm{~g} /$ day of ethanol was 8.05 (95\% Cl 3.89-16.60; $\mathrm{p}$ interaction=0.65), when compared with never smokers who consumed $<5 \mathrm{~g} /$ day of ethanol.

\section{Conclusions}

This prospective study found alcohol consumption to be associated with increased risk of only ESCC. Cigarette smoking was associated with risk of all four cancers. 


\section{INTRODUCTION}

In the past, esophageal and gastric cancer have been regarded as two disease entities, but nowadays it is becoming clearer that probably each represents several diseases. The two main subtypes of esophageal cancer are squamous cell carcinoma (ESCC) and adenocarcinoma (EAC). Gastric cancer can be subdivided into gastric cardia adenocarcinomas (GCA) and gastric non-cardia adenocarcinomas (GNCA).

The incidence rates of EAC and GCA have risen greatly in the USA and Europe during the past decades. ${ }^{1,2}$ For ESCC, conversely, rates declined or remained stable, and rates of GNCA declined greatly. ${ }^{1,2}$ These differences in trends indicate that these cancer subtypes may have a different etiology and thus differential associations with lifestyle factors such as alcohol consumption and cigarette smoking.

On this topic, mainly case-control studies have been performed, but only few have compared subtypes of esophageal and gastric cancer. ${ }^{3-6}$ This study design is sensitive for misclassification, ${ }^{7}$ which might be of importance in studies investigating smoking and alcohol consumption, because of participants' awareness of the established health risks of these exposures. ${ }^{8}$ Prospective cohort studies are less susceptible to this bias. However, only two cohort studies ${ }^{9,10}$ have reported on alcohol consumption and risk of ESCC, EAC, GCA and GNCA, and three cohort studies have reported on cigarette smoking. ${ }^{9-11}$ These studies often lacked sufficient information on confounders. $^{9,11}$ We therefore investigated this association within a large-scale prospective cohort: the Netherlands Cohort Study on diet and cancer (NLCS). ${ }^{12}$

We hypothesized that: (1) alcohol consumption and cigarette smoking are strongly positively associated with ESCC risk, with multiplicative interaction; (2) alcohol consumption is not associated with EAC, GCA, and GNCA; and (3) cigarette smoking is positively associated with EAC, GCA, and GNCA, but less strongly than with ESCC.

\section{METHODS}

\section{Study design and participants}

This study was conducted within the NLCS, which started in September 1986 with the enrolment of Dutch men ( $n=58$ 279) and women ( $n=62$ 573) women aged 55-70 years. $^{12}$

For reasons of efficiency, the case-cohort approach was used for data processing and analysis. ${ }^{13}$ Cases were derived from the entire cohort, and the number of personyears at risk for the entire cohort was estimated from a subcohort of 5000, who were randomly sampled from the total cohort at baseline. Person-years at risk were calculated from the start of the study until esophageal or gastric cancer diagnosis, death, emigration, loss to follow-up or end of follow-up, whichever occurred first. 
Follow-up for cancer incidence was performed by record linkage to the Netherlands Cancer Registry (NCR) and the nationwide network and registry of histopathology and cytopathology in the Netherlands (PALGA). ${ }^{14}$ The completeness of cancer follow-up is $\geq 96 \%,{ }^{15}$ and follow-up of the subcohort was nearly $100 \%$ complete (only one male subcohort member was lost to follow-up) after 16.3 years (from 17 September 1986 until 31 December 2002). The following numbers of incident, microscopically confirmed, primary carcinomas were identified: $130 \mathrm{ESCC}^{16}$ (ICD-O-3 C15), $181 \operatorname{EAC}^{16}$ (C15), 206 GCA (C16.0) and 594 GNCA (C16.1-C16.9) (Figure 6.1). Excluded were non-microscopically confirmed cancers, which formed $1 \%$ of both esophageal and gastric cancers. The group of GNCA included cancers with a lesion with overlapping subsites of the stomach $(\mathrm{C} 16.8, \mathrm{n}=160)$ and some gastric not otherwise specified cancers $(\mathrm{C} 16.9, \mathrm{n}=75)$, raising the possibility that some cardia cancers might be included in de non-cardia category. However, as we found risk estimates to be similar in separate analyses of gastric cancers of specified sites (C16.1-C16.5) and other gastric cancers (C16.6-C16.9) (data not shown), we combined the groups in the analysis.

We excluded subcohort members who reported having prevalent cancer other than skin cancer at baseline. Also excluded were cases and subcohort members with incomplete or inconsistent dietary data ${ }^{17}$ or missing data on exposure or confounding variables. Figure 6.1 shows that 3962 subcohort members and 107 ESCC, 145 EAC, 164 GCA, and 491 GNCA cases were available for analysis.

\section{Exposure information}

All cohort members completed a self-administered questionnaire at baseline. This questionnaire included a 150-item food frequency questionnaire (FFQ), with questions on alcohol consumption, and questions on other cancer risk factors, such as smoking habits, level of education, body mass index (BMI), physical activity, family history of cancer and use of medication.

We asked about the habitual consumption of alcohol during the year preceding the start of the study, and this was measured by six items: (1) beer, (2) red wine, (3) white wine, (4) sherry and other fortified wines, (5) liquor types containing on average 16 alcohol and (6) (Dutch) gin, brandy and whisky. Questions were asked about the frequency of consumption and the number of glasses consumed on each drinking occasion. For analysis, we combined (2), (3) and (4) into "wine", and (5) and (6) into "liquor". Mean daily alcohol consumption was calculated using the Dutch foodcomposition table. ${ }^{18}$ Based on a pilot study, a glass of beer, wine and liquor was assumed to contain 200, 105 and $45 \mathrm{ml}$ of the beverage, respectively (unpublished findings). For "beer" and "other alcoholic beverages", participants could indicate whether five years ago, they drunk (1) more than, (2) equal amounts of or (3) less than today. The fourth answering option was (4) "I never use this". Using these questions, 
we selected those participants with stable alcohol consumption to perform a sensitivity analysis to investigate the robustness of our results.

\begin{tabular}{|c|c|c|c|c|}
\hline \multicolumn{5}{|c|}{ Netherlands cohort study on diet and cancer $(120,852)$} \\
\hline$\downarrow$ & & & $\downarrow$ & \\
\hline \begin{tabular}{|c|} 
Subcohort \\
randomly drawn \\
from total cohort
\end{tabular} & \multicolumn{4}{|c|}{ Record linkage with Netherlands Cancer Registry and PALGA* } \\
\hline$\downarrow$ & $\downarrow$ & $\downarrow$ & $\downarrow$ & $\downarrow$ \\
\hline 5000 & $\begin{array}{l}\text { Esophageal } \\
\text { squamous cell } \\
\text { carcinoma }\end{array}$ & $\begin{array}{c}\text { Esophageal } \\
\text { adenocarcinoma }\end{array}$ & $\begin{array}{c}\text { Gastric cardia } \\
\text { adenocarcinoma }\end{array}$ & $\begin{array}{l}\text { Gastric noncardia } \\
\text { adenocarcinoma }\end{array}$ \\
\hline \multicolumn{5}{|c|}{ Exclusion of participants with prevalent cancer at baseline } \\
\hline$\downarrow$ & $\downarrow$ & $\downarrow$ & $\downarrow$ & $\downarrow$ \\
\hline 4774 & 130 & 181 & 206 & 594 \\
\hline \multicolumn{5}{|c|}{ Exclusion of participants with incomplete or inconsistent dietary data } \\
\hline$\downarrow$ & $\downarrow$ & $\downarrow$ & $\downarrow$ & $\downarrow$ \\
\hline 4438 & 120 & 168 & 187 & 551 \\
\hline \multicolumn{5}{|c|}{ Exclusion of participants with missing data on alcohol consumption or cigarette smoking } \\
\hline$\downarrow$ & $\downarrow$ & $\downarrow$ & $\downarrow$ & $\downarrow$ \\
\hline 4111 & 111 & 153 & 168 & 512 \\
\hline \multicolumn{5}{|c|}{ Exclusion of participants with missing data on confounders } \\
\hline$\downarrow$ & $\downarrow$ & $\downarrow$ & $\downarrow$ & $\downarrow$ \\
\hline 3962 & 107 & 145 & 164 & 491 \\
\hline
\end{tabular}

Figure 6.1 Flow diagram of subcohort members and cases on whom the analyses were based. *PALGA: nationwide network and registry of histopathology and cytopathology in The Netherlands.

Regarding cigarette smoking, questions were asked about the following: whether the subject was a smoker at baseline, age at which they started smoking, age at smoking cessation, the number of cigarettes smoked daily and the number of smoking years (excluding stopping periods). Based on these questions, the following variables were constructed: smoking status (never, former, current), current smoking (yes/no), frequency (number of cigarettes/day), duration (number of years), pack-years of cigarette smoking (number), and time since cessation (years).

The FFQ has been validated against a 9-day diet record, and the Spearman correlation coefficient between the alcohol intake assessed by the questionnaire and that estimated by the diet record was 0.89 for all subjects and 0.85 for users of alcoholic beverages. ${ }^{17}$ The reproducibility of the FFQ was established and the testretest correlation was 0.90 for alcohol intake, and this correlation declined only 0.01 0.02 per year. ${ }^{19}$ This indicates that the single FFQ measurement was able to rank 
subjects according to alcohol intake and this ability dropped only slightly over time. The single FFQ measurement that is used in our cohort study can characterize dietary habits for a period of at least 5 years. ${ }^{19}$

Questionnaire data were key-entered and processed in a standardized manner, blinded with respect to case/subcohort status in order to minimize observer bias in coding and data interpretation.

\section{Data analysis}

The confounders considered were: ${ }^{20-22}$ age (years), sex, level of education (primary, lower vocational, secondary and medium vocational, and university and higher vocational), BMI $\left(\mathrm{kg} / \mathrm{m}^{2}\right)$, non-occupational physical activity $(<30,30$ to $<60,60$ to $<90$, $\geq 90 \mathrm{~min} /$ day), energy intake (kJ), tea consumption (cups/day), intakes of fruit, vegetables, legumes, fish, red meat and meat products (all g/day), family history of esophageal or gastric cancer (yes/no in first-degree relatives), reported long-term (>0.5 years) use of non-steroidal anti-inflammatory drugs (NSAIDs) or aspirin (ATC codes M01A, N02B) (yes/no), and reported long-term use (yes/no) of lower esophageal sphincter (LES)-relaxing medication. ${ }^{23-25}$ Alcohol consumption and cigarette smoking were mutually adjusted in the statistical models. A variable was considered a confounder if including it in the model changed the rate ratio (RR) for any of the cancer types by $>5 \%$. For all four cancers, the same confounders were used in analyses.

Incidence RRs and corresponding 95\% Cls for alcohol consumption and cigarette smoking were estimated in age- and sex-adjusted and multivariable adjusted casecohort analyses using Cox proportional hazards models. ${ }^{26}$ Analyses were done using Stata 9.2 statistical software package (StataCorp, College Station, Texas, USA). Standard errors were estimated using the robust Huber-White sandwich estimator to account for additional variance introduced by sampling from the cohort. This method is equivalent to the variance-covariance estimator by Barlow. ${ }^{27}$ The proportional hazards assumption was tested using the scaled Schoenfeld residuals. ${ }^{28}$ If the assumption was violated for a confounder, a time-varying covariate was added to the model. In case the assumption was violated for the exposure variable, it was checked whether the time-varying covariate for this variable was statistically significant in the model. Tests for dose-response trends were assessed by fitting ordinal exposure variables as continuous terms. Two-sided $p$ values are reported throughout the article.

To evaluate whether substances in alcoholic beverages, other than ethanol, have an effect on the risk of ESCC, EAC, GCA, or GNCA, we also analyzed beer, wine, and liquor consumption, adjusted for ethanol intake.

In smoking analyses, the different aspects of smoking were mutually adjusted for, to investigate which aspect is most important in terms of esophageal or gastric cancer risk. 


\section{Interaction}

To evaluate possible interaction between alcohol and cigarette smoking status, we estimated RRs of all four cancers for combinations of these exposures. The $p$ value for interaction was assessed by including a cross-product term in the model. In the interaction analyses it was necessary to change the alcohol categories to include subjects with low alcohol consumption in the reference category, besides abstainers, because of too low numbers of cases per stratum.

\section{RESULTS}

\section{Descriptives}

Table 6.1 presents the characteristics of the subcohort members and cases, including all variables that were considered potential confounders. Esophageal and gastric cancer cases were more often men, especially EAC and GCA cases. Alcohol consumption was higher in cases, especially ESCC cases, than in subcohort members, while the proportion of alcohol abstainers was higher in the subcohort. About $60 \%$ of subcohort members and cases were stable alcohol consumers. Cases were exposed more to cigarette smoke in terms of smoking status, frequency, duration, and packyears compared with the subcohort.

Cases also differed from subcohort members with respect to some other characteristics: EAC and GCA cases had a higher BMI than subcohort members. All cases consumed less fruit and slightly less vegetables than the subcohort, but cases more often reported a family history of esophageal or gastric cancer and use of LESrelaxing medication (Table 6.1).

The proportional hazards assumption was violated only in a few analyses (see footnotes in Table 6.2 and Supplemental Table 6.1 available online).

\section{Alcohol consumption}

A daily alcohol consumption of $\geq 30 \mathrm{~g}$, when compared with abstaining, was associated with a significantly increased risk of ESCC (multivariable adjusted RR=4.61, 95\% $\mathrm{Cl} 2.24$ to $9.50, p$ trend<0.001) (Table 6.2). Women were at somewhat higher risk than men, and the interaction with sex was statistically significant in continuous analyses $(p=0.04)$, but not in categorical analyses $(p=0.68)$. No association was observed between alcohol consumption and EAC (RR for $\geq 30 \mathrm{~g} /$ day=1.04, 95\% Cl 0.54 to 2.02), GCA (RR=0.90, $95 \% \mathrm{Cl} 0.50$ to 1.64 ) or GNCA ( $R R=1.00,95 \% \mathrm{Cl} 0.68$ to 1.47 ).

Multivariable RRs for alcohol consumption and ESCC were slightly attenuated when compared with age- and sex-adjusted RRs (see Supplemental Table 6.1). For EAC, GCA, and GNCA, age- and sex-adjusted RRs were very similar to multivariable adjusted RRs. 
Table 6.1 Characteristics of cases and subcohort members in the Netherlands Cohort Study on diet and cancer (NLCS), 1986-2002.

\begin{tabular}{|c|c|c|c|c|c|}
\hline \multirow[b]{2}{*}{$\begin{array}{l}\text { Exposure variables and potential } \\
\text { confounders }\end{array}$} & \multirow{2}{*}{$\begin{array}{l}\text { Subcohort } \\
(n=3962)^{a}\end{array}$} & \multicolumn{4}{|c|}{ Cases } \\
\hline & & $\begin{array}{c}\text { ESCC } \\
(n=107)^{a}\end{array}$ & $\begin{array}{c}\text { EAC } \\
(n=145)^{a}\end{array}$ & $\begin{array}{c}\text { GCA } \\
(n=164)^{a}\end{array}$ & $\begin{array}{c}\text { GNCA } \\
(\mathrm{n}=491)^{\mathrm{a}}\end{array}$ \\
\hline age at baseline (years) & $61.3(4.2)$ & $62.5(4.2)$ & $61.6(4.1)$ & $61.5(4.1)$ & $62.5(4.1)$ \\
\hline \multicolumn{6}{|l|}{ sex } \\
\hline men (n (\%)) & 1944 (49.1) & $59(55.1)$ & $114(78.6)$ & $140(85.4)$ & $331(67.4)$ \\
\hline women (n (\%)) & $2018(50.9)$ & $48(44.9)$ & $31(21.4)$ & $24(14.6)$ & $160(32.6)$ \\
\hline abstainer from alcohol (n (\%)) & $943(23.8)$ & $16(15.0)$ & $25(17.2)$ & $29(17.7)$ & $107(21.8)$ \\
\hline \multicolumn{6}{|l|}{ alcohol consumers: } \\
\hline ethanol intake (g/day) & $13.6(15.1)$ & $27.6(27.9)$ & $17.3(18.3)$ & $16.6(15.5)$ & $15.9(17.2)$ \\
\hline beer intake (glasses/day) & $0.3(0.8)$ & $0.8(1.8)$ & $0.5(1.1)$ & $0.5(1.0)$ & $0.5(1.2)$ \\
\hline wine intake (glasses/day) & $0.5(0.8)$ & $0.6(1.1)$ & $0.4(0.7)$ & $0.4(0.7)$ & $0.4(0.8)$ \\
\hline liquor intake (glasses/day) & $0.5(0.8)$ & $1.1(1.7)$ & $0.7(1.0)$ & $0.7(0.9)$ & $0.6(0.9)$ \\
\hline \multicolumn{6}{|l|}{ cigarette smoking status } \\
\hline never smoker (n (\%)) & $1460(36.9)$ & $22(20.6)$ & $28(19.3)$ & $28(17.1)$ & $113(23.0)$ \\
\hline former smoker (n (\%)) & $1425(36.0)$ & $31(29.0)$ & $70(48.3)$ & $80(48.8)$ & 201 (40.9) \\
\hline current smoker (n (\%)) & $1077(27.2)$ & $54(50.5)$ & $47(32.4)$ & $56(34.2)$ & $177(36.1)$ \\
\hline \multicolumn{6}{|l|}{ ever cigarette smokers: } \\
\hline frequency of cigarette smoking (n/day) & $15.3(10.3)$ & $18.3(10.3)$ & $20.1(12.6)$ & $17.5(11.1)$ & $16.5(10.4)$ \\
\hline duration of cigarette smoking (years) & $31.6(12.2)$ & $36.9(10.5)$ & $34.0(11.0)$ & $34.9(11.4)$ & $34.7(11.8)$ \\
\hline pack-years of cigarette smoking (n) & $22.7(17.7)$ & $30.3(19.0)$ & $30.9(20.4)$ & $27.2(18.0)$ & $26.3(19.2)$ \\
\hline \multicolumn{6}{|l|}{ level of education } \\
\hline primary (n (\%)) & 1104 (27.9) & $34(31.8)$ & $37(25.5)$ & $45(27.4)$ & $185(37.7)$ \\
\hline lower vocational (n (\%)) & $868(21.9)$ & $22(20.6)$ & $37(25.5)$ & $42(25.6)$ & $117(23.8)$ \\
\hline secondary and medium vocational ( $\mathrm{n}(\%))$ & $1420(35.8)$ & $38(35.5)$ & $49(33.8)$ & $45(27.4)$ & $142(28.9)$ \\
\hline university and higher vocational (n (\%)) & $570(14.4)$ & $13(12.2)$ & $22(15.2)$ & $32(19.5)$ & $47(9.6)$ \\
\hline body mass index $\left(\mathrm{kg} / \mathrm{m}^{2}\right)$ & $25.0(3.1)$ & $24.2(3.6)$ & $26.3(3.4)$ & $25.7(3.0)$ & $24.9(3.2)$ \\
\hline non-occupational physical activity & $73(60)$ & $68(65)$ & $74(58)$ & $86(78)$ & $80(71)$ \\
\hline
\end{tabular}

(min/day)

energy intake (kJ/day)

men

women

tea consumption (cups/day)

fruit consumption (g/day)

vegetable consumption (g/day)

legumes consumption (g/day)

fish consumption (g/day)

red meat consumption (g/day)

meat products consumption (g/day)

9090 (2130) 8703 (2033) 9054 (2025) 8834 (2160) 9166 (2112)

7063 (1651) $7406(1806) 6981$ (1807) 7445 (1510) 6995 (1510)

$\begin{array}{ccccc}2.8(2.0) & 2.7(2.4) & 2.6(2.3) & 2.3(1.8) & 2.8(1.9) \\ 177(120) & 130(108) & 169(135) & 154(116) & 164(125) \\ 194(83) & 189(76) & 187(83) & 188(84) & 188(81) \\ 8(12) & 7(10) & 10(12) & 9(13) & 8(11) \\ 13(15) & 14(13) & 15(19) & 15(20) & 14(19) \\ 87(40) & 93(41) & 90(37) & 92(45) & 91(41) \\ 13(15) & 14(14) & 14(15) & 15(16) & 15(16) \\ 296(7.5) & 10(9.4) & 18(12.4) & 14(8.5) & 63(12.8) \\ & & & & \\ 262(6.6) & 7(6.5) & 11(7.6) & 9(5.5) & 23(4.7) \\ 564(14.2) & 17(15.9) & 28(19.3) & 25(15.2) & 77(15.7)\end{array}$

family history of esophageal or gastric

cancer ( $\mathrm{n}(\%))$

reported long-term use of NSAIDs ( $\mathrm{n}(\%)$ )

reported long-term use of LES relaxing

medication ( $\mathrm{n}(\%))$

a The number of subcohort members or cases used in age- and sex-adjusted analyses and multivariable analyses of alcohol consumption and cigarette smoking. Values are given as mean (SD); for categorical variable $\mathrm{n}(\%)$ is presented. EAC, esophageal adenocarcinoma; ESCC, esophageal squamous cell carcinoma; GCA, gastric cardia adenocarcinoma; GNCA, gastric non-cardia adenocarcinoma; LES, lower esophageal sphincter; NSAIDs, non-steroidal anti-inflammatory drugs. 
When the analyses were restricted to stable alcohol consumers, the association with ESCC became somewhat stronger. The results for EAC, GCA, and GNCA barely changed (Table 6.2).

Results regarding alcoholic beverages are shown in table 2. After adjustment for total alcohol intake, beer consumption was associated with an increased risk of ESCC ( $p$ trend $=0.23$ ) and GNCA ( $p$ trend $=0.06$ ). Wine consumption was inversely associated with risk of ESCC (RR per 1 glass/day increment $=0.67,95 \% \mathrm{Cl} 0.50$ to 0.90 ), but was not associated with EAC, GCA or GNCA. Consumption of liquor was not significantly associated with risks of ESCC, EAC, and GCA, and with a reduced risk of GNCA.

\section{Cigarette smoking}

Current and former cigarette smoking were associated with an increased risk of all four cancer types, when compared with never smokers (Table 6.3). The strongest associations were found for ESCC and GNCA.

Frequency of cigarette smoking was found to be associated with increased risks of all four cancers, independent of other smoking aspects. The association was statistically significant for ESCC and EAC. The RRs for the gastric cancers were lower than for the esophageal cancers (Table 6.3). Duration of cigarette smoking was independently associated with increased risks of ESCC, GCA, and GNCA, but the RR was only statistically significant for GNCA. Pack-years of smoking were associated with increased risks (mostly statistically significant) of all four cancers. The highest RRs were found in those who smoked $\geq 40$ pack-years.

We also looked into the effect of cigarette smoking cessation on the risk of esophageal and gastric cancers. The risks of all four cancer types declined for smokers who had stopped since $<10,10$ to $<20$ or $\geq 20$ years ( $p$ trend $<0.05$ for all four cancers), when compared with current smokers. However, when compared with never smokers, the risks were still elevated for ESCC, EAC, and GNCA. For ESCC, EAC, and GCA, the RRs of time since smoking cessation were attenuated when we adjusted for smoking duration (data not shown).

Multivariable RRs for cigarette smoking were attenuated when compared with age- and sex-adjusted RRs (Supplemental Table 6.2). This difference could largely be explained by the mutual adjustment of cigarette smoking aspects. For ESCC, confounding by alcohol consumption also caused attenuation of the associations. 


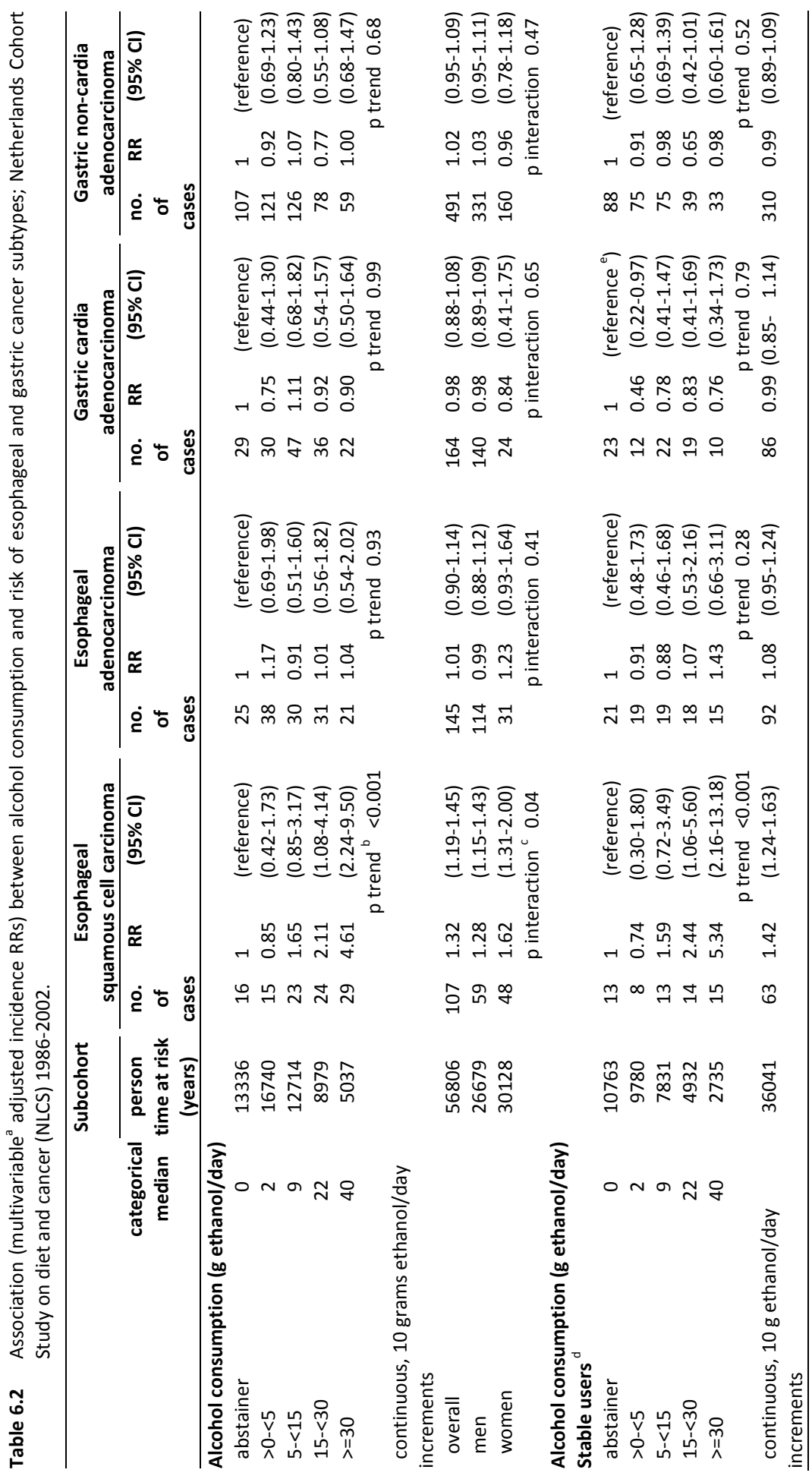




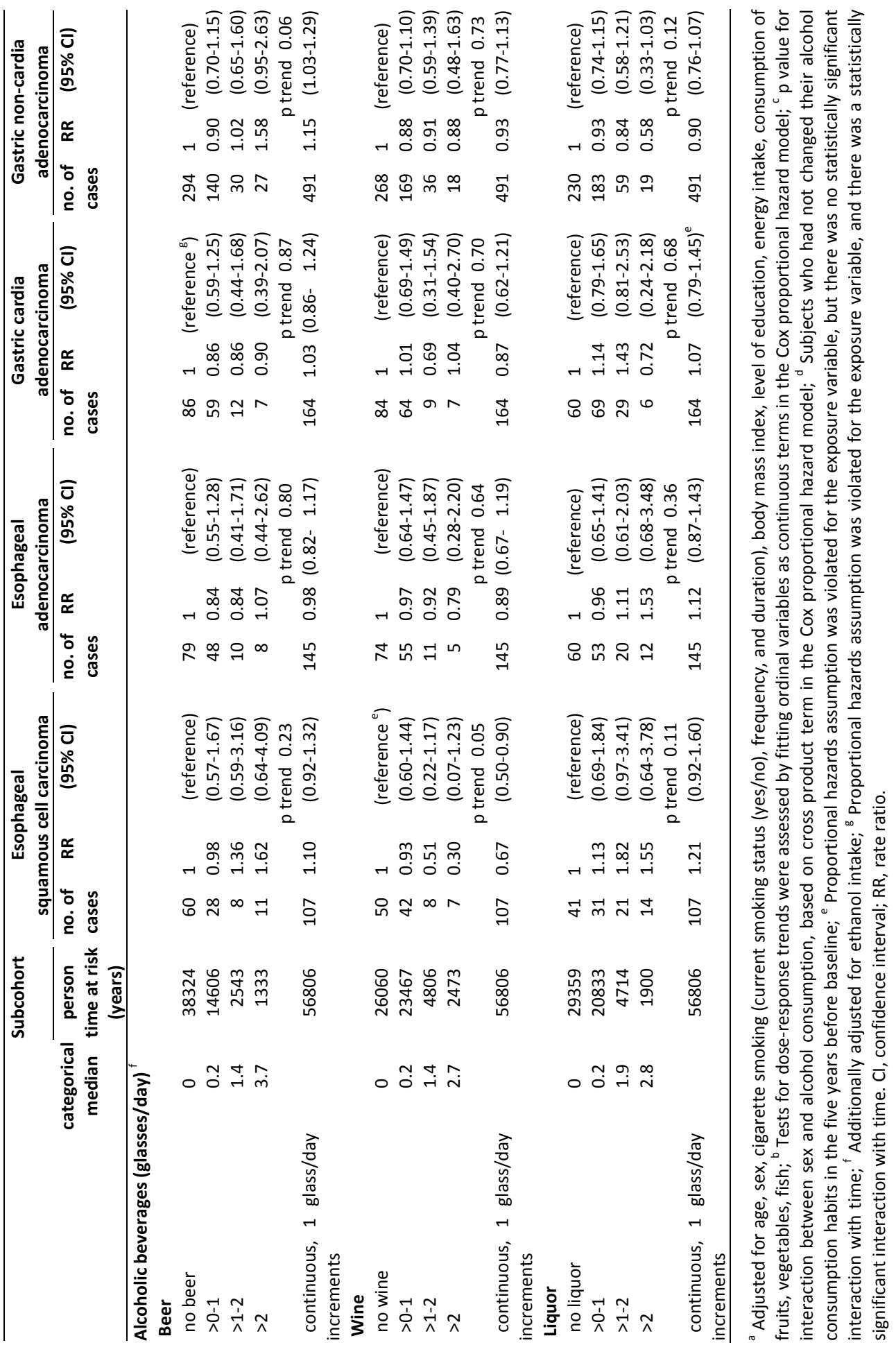




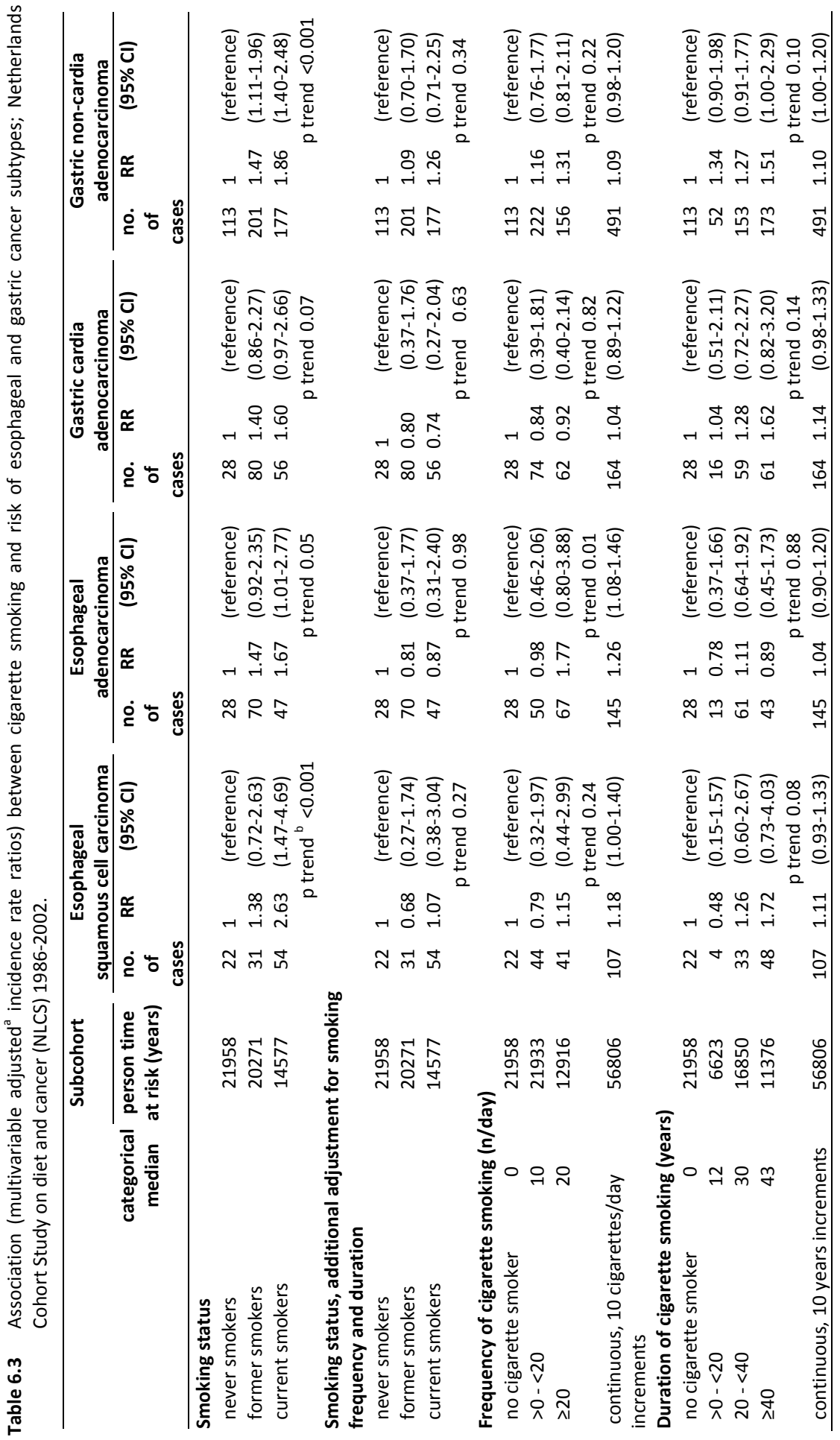




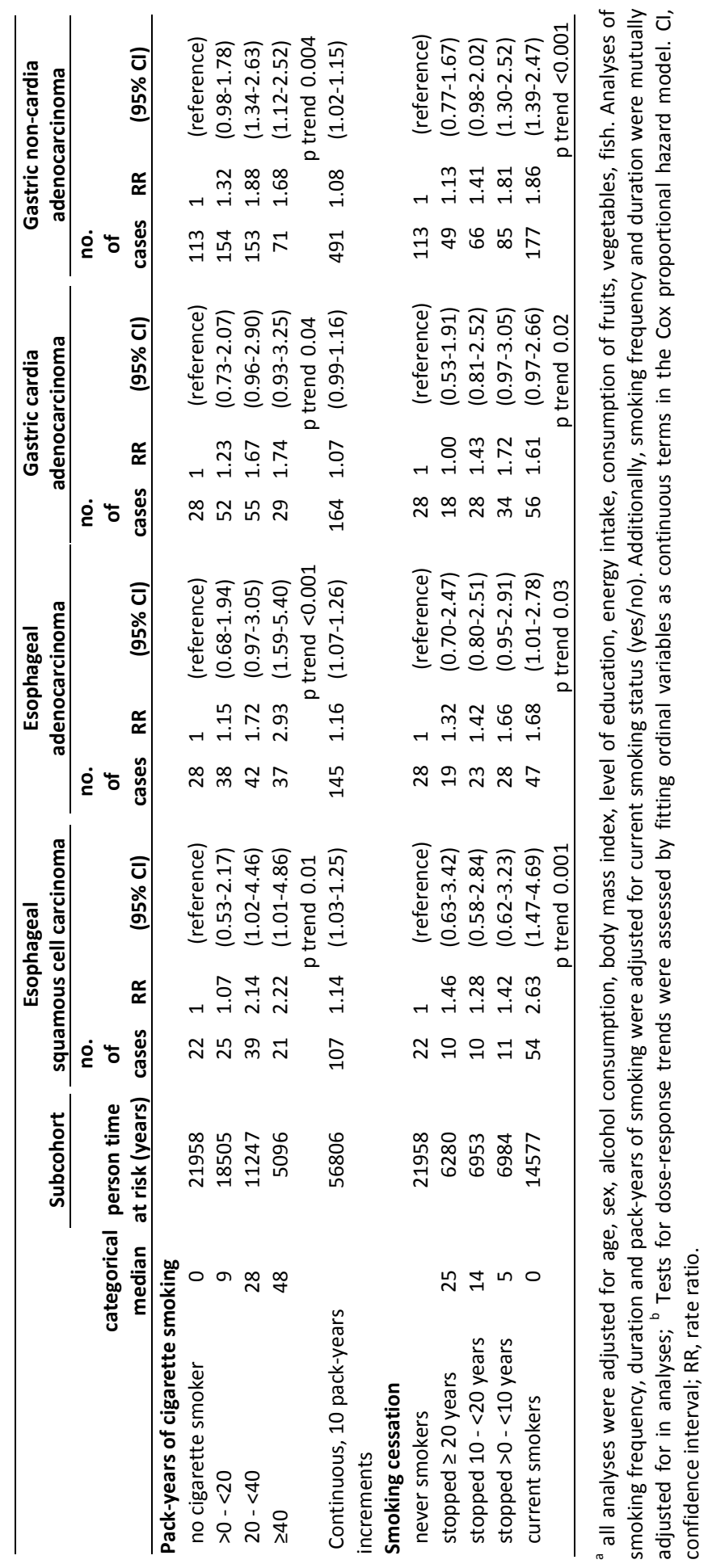




\section{Interaction}

Table 6.4 shows RRs for several exposure combinations of alcohol consumption and cigarette smoking, using never smokers and low alcohol consumers as a reference. A graphical presentation of these results can be found in Figure 6.2A-D.

The RR of ESCC was 8.05 ( $95 \% \mathrm{Cl} 3.89$ to 16.60$)$ in the category of current smokers who consumed $>15 \mathrm{~g} /$ day of ethanol. This RR is compatible with multiplicative interaction, but was not statistically significant ( $p$ interaction $=0.65$ ). We found no evidence for interaction between alcohol consumption and cigarette smoking on risk of EAC, GCA, or GNCA.
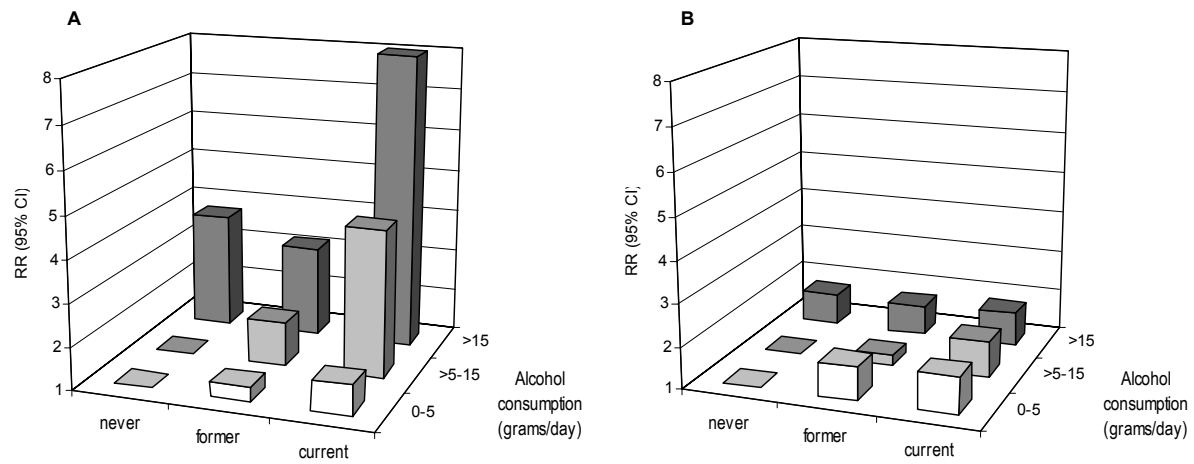

Cigarette smoking status

Cigarette smoking status

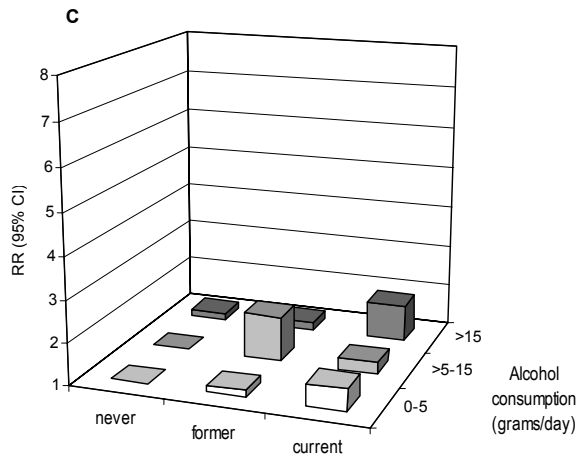

Cigarette smoking status

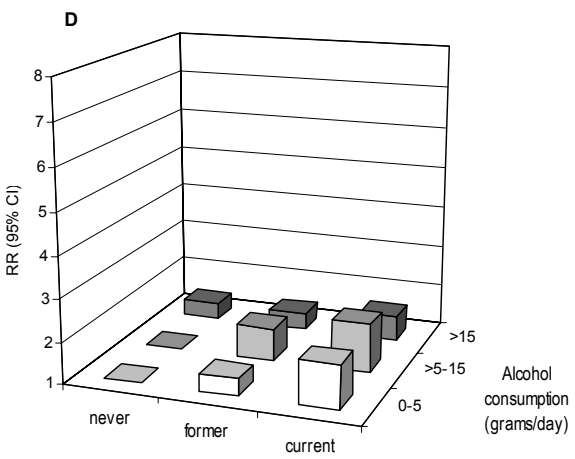

Cigarette smoking status

Figure 6.2 Combined exposure to alcohol and cigarette smoking and risk of esophageal and gastric cancer subtypes; Netherlands Cohort Study on diet and cancer, 1986-2002. (A) Esophageal squamous cell carcinoma, (B) Esophageal adenocarcinoma, (C) Gastric cardia adenocarcinoma, (D) Gastric non-cardia adenocarcinoma. Multivariable RRs: adjusted for age, sex, body mass index, level of education, energy intake, consumption of fruits, vegetables, fish. 


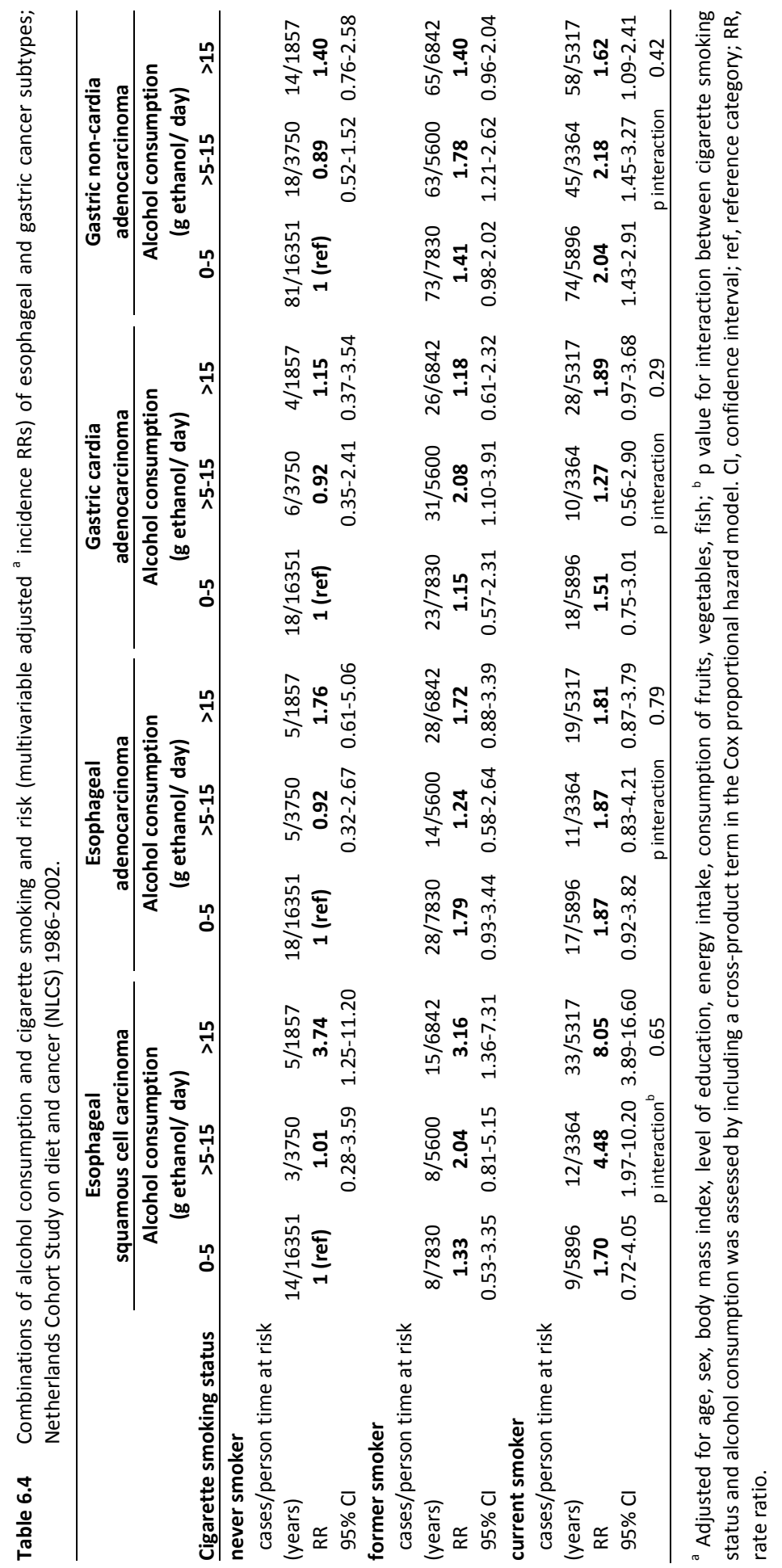




\section{DISCUSSION}

\section{Main findings}

In this study, which is one of the first prospective cohort studies on the topic, we found the following results. Alcohol consumption was related to a strongly increased risk of ESCC, whereas it was unrelated to EAC, GCA, or GNCA. Cigarette smoking status, frequency, duration, and pack-years were associated with increased risks of all four cancer types. A multiplicative interaction was found between alcohol consumption and cigarette smoking on the risk of ESCC, but no such interaction existed for EAC, GCA, or GNCA.

\section{Strengths and limitations}

A strength of our study includes the prospective character, which makes selection and information bias unlikely. Moreover, the division we made into histological subtypes of esophageal cancer and localizations of gastric cancer is important, as this allows the evaluation of different risk factors for the cancer subtypes and more precise estimates of the strength of the associations. Our study is also one of the largest prospective cohort studies investigating this topic.

The ranges of the participants' alcohol consumption and cigarette smoking habits were wide, which gave good contrasts between high and low exposures. Also, alcohol consumption and cigarette smoking habits were addressed extensively in the questionnaire. We lack data on smoking and alcohol consumption after baseline, but we did ask participants about their habits during a long period before baseline. As the development of a tumor probably takes several decades, we believe we asked about the exposure in a relevant time window.

Participants could have changed their alcohol consumption and smoking habits due to preclinical cancer, which may influence results. This is unlikely though, because the smoking data reflect the lifetime exposure of the participants. As for alcohol, results were robust for restriction of analyses to stable users.

In this epidemiological study, we analyze the possibility of residual confounding, by, for example, Helicobacter pylori infection. This infection is associated with increased risk of $\mathrm{GNCA}^{29}$ and possibly with decreased risk of $\mathrm{EAC}{ }^{30,31}$ while it is not associated with $\mathrm{GCA}^{29}$ or ESCC risk. ${ }^{31}$ Unfortunately, we lack data on $\mathrm{H}$ pylori infection, but we estimate the prevalence to have been $\sim 50 \% .^{32}$ The infection might have confounded the associations if it is correlated with alcohol consumption or smoking. However, studies investigating this correlation have been inconsistent. ${ }^{33-35}$ Residual confounding by other variables cannot be completely ruled out, but the associations found were strong and residual confounding probably cannot explain these associations entirely. Moreover, the true associations may be stronger than observed, because we probably underestimated their strength due to random measurement error. 


\section{Comparison with previous research: alcohol}

The strong positive association between alcohol consumption and ESCC risk we found is in agreement with associations found in the other prospective cohorts. ${ }^{9,10,36}$ The association we found showed a statistically significant trend $(p<0.001)$, although low consumers of alcohol were found to be at slightly decreased ESCC risk, and this association remained when we restricted our analyses to the group of stable alcohol consumers. These findings are consistent with findings from two other cohorts, ${ }^{10,36}$ and an explanation was suggested by Freedman et al. ${ }^{10}$ Possibly, some of the subjects who were abstainers at baseline used to be heavy drinkers long $>5$ years) before baseline. These drinkers remain at increased risk for a decade after cessation of alcohol consumption. ${ }^{37}$

Our findings that alcohol was not associated with EAC, GCA and GNCA confirm the null results found in two other Western cohorts. ${ }^{9,10}$

To investigate whether substances in alcoholic beverages other than ethanol are relevant for cancer risk, we adjusted analyses of these beverages for total ethanol intake. This approach has not been used for esophageal or gastric cancers before and gave some new insights. For the beverages, ESCC risk was lower compared with the association with ethanol. This suggests that ethanol is probably the key substance in these beverages, and this suggestion is strengthened by the fact that associations have been found across the world, for many different alcoholic beverages. ${ }^{10,38,39}$ Still, other substances in alcoholic beverages might be relevant. For instance, flavonoids ${ }^{40}$ in wine might explain the inverse association we found with ESCC. This inverse association has also been found by a case-control study, ${ }^{41}$ but this association was unadjusted for ethanol intake. Regarding beer, $\mathrm{N}$-nitroso compounds present in this beverage may be partly responsible for the positive associations with ESCC and GNCA. ${ }^{42}$

\section{Comparison with previous research: cigarette smoking}

We found that cigarette smoking was associated with an increased risk of all esophageal and gastric cancer subtypes. For these cancer subtypes, we are the first cohort study to analyze the association with all kinds of smoking aspects. Our findings are consistent with previous reviews. ${ }^{43-45}$ It appeared that smoking frequency as well as duration were important in terms of increasing a person's risk. Therefore, the number pack-years smoked may be a good indicator of a person's total exposure.

The relationships we found between smoking and esophageal cancer types were weaker compared with a previous case-control ${ }^{45}$ and two cohort ${ }^{10,11}$ studies, but similar to the results of a third cohort study. ${ }^{9}$ There may be several reasons why other studies found stronger associations: under-reporting of smoking habits in case-control studies, no mutual adjustment for smoking aspects, or no or insufficient adjustment for confounding (e.g., by alcohol consumption). Our RRs might be attenuated because some smokers may have stopped smoking after baseline, but this is unlikely because after smoking cessation people stay at risk for a long period. 
Our results showed that smoking cessation decreased risks of all four cancers, but only after one to two decades and these results are in agreement with two reviews. $^{43,46}$

\section{Interaction}

This is the first prospective study to investigate the interaction between alcohol consumption and cigarette smoking and the risk of ESCC. An interaction for ESCC has been established by previous case-control studies (see, for example, ${ }^{4,41,47,48}$ ). We confirm this interaction, although this was not statistically significant, probably due to low power. Yet, for EAC, GCA and GNCA it was uncertain whether a similar interaction is present, as only one study examined this. ${ }^{10}$ According to our findings, no interaction was present.

The interaction between alcohol consumption and cigarette smoking can be explained biologically. Cigarette smoke contains many carcinogens, and the ethanol from alcoholic beverages is metabolized to acetaldehyde, which was classified as human carcinogen by the International Agency for Research on Cancer (IARC). ${ }^{49}$ Acetaldehyde can circulate in the blood after formation in the liver, but can also be formed locally by oral bacteria. ${ }^{50}$ Ethanol itself can cause local irritation of the upper gastrointestinal tract ${ }^{51}$ and may facilitate the uptake of the carcinogens present in cigarette smoke. $^{50}$

In conclusion, alcohol and cigarette smoke each have an individual effect on ESCC risk, but, when combined, they act synergistically. We found no interaction for EAC, GCA, or GNCA.

\section{Conclusions and recommendations}

In summary, we found alcohol to be positively associated with ESCC risk, but not with EAC, GCA or GNCA. Cigarette smoking was positively associated with risk of all four cancer types. Alcohol consumption and smoking interacted in a multiplicative way on the risk of ESCC.

Alcohol consumption cannot explain the previously mentioned rising incidences of EAC and GCA, because it was not associated with risk of either. Cigarette smoking habits cannot explain the increasing trends either, because these habits have not increased over time in Western countries. Therefore, we suggest that further research should focus on other risk factors for esophageal and gastric cancer subtypes, to search for explanations for these increases. 


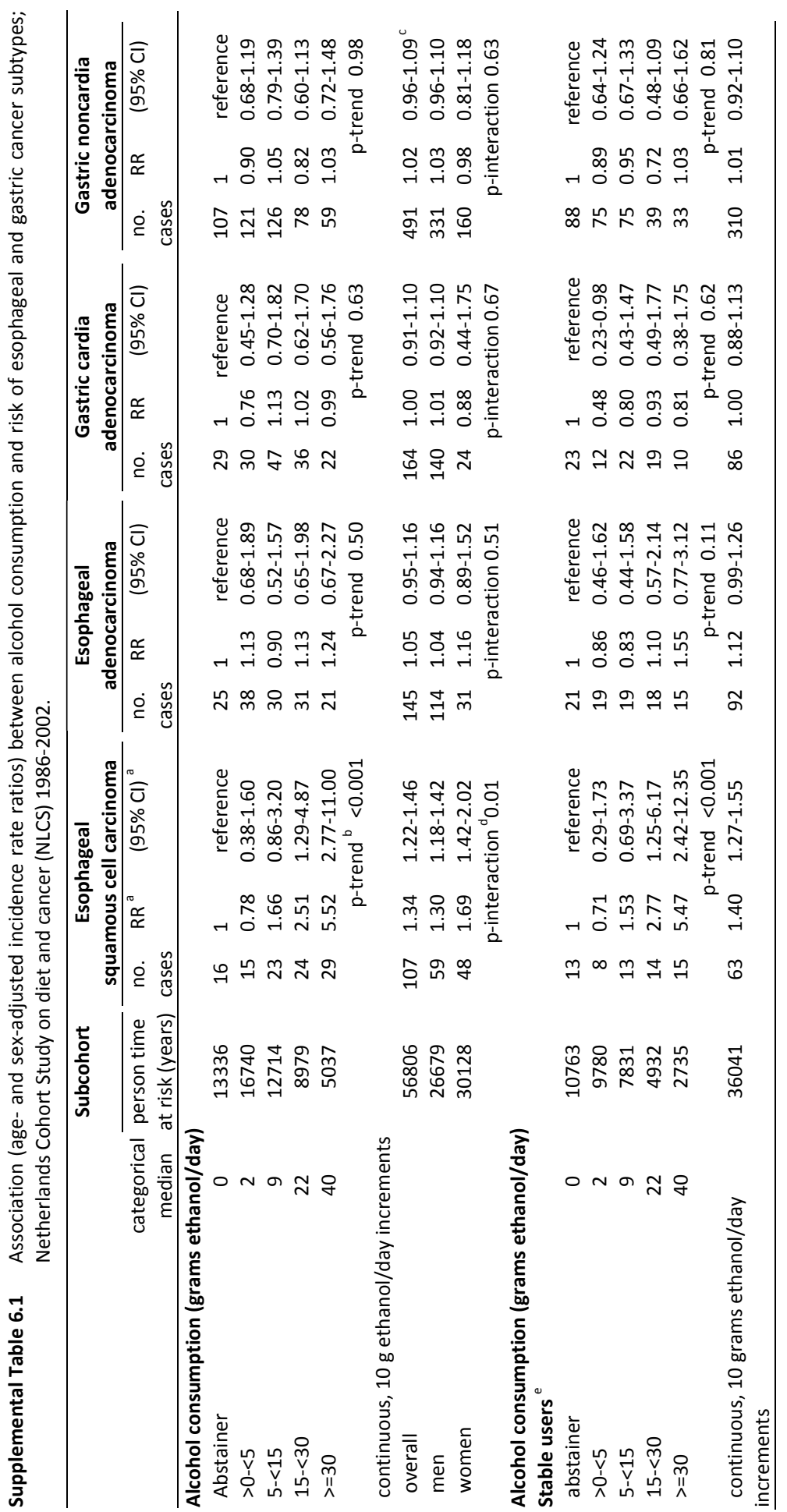




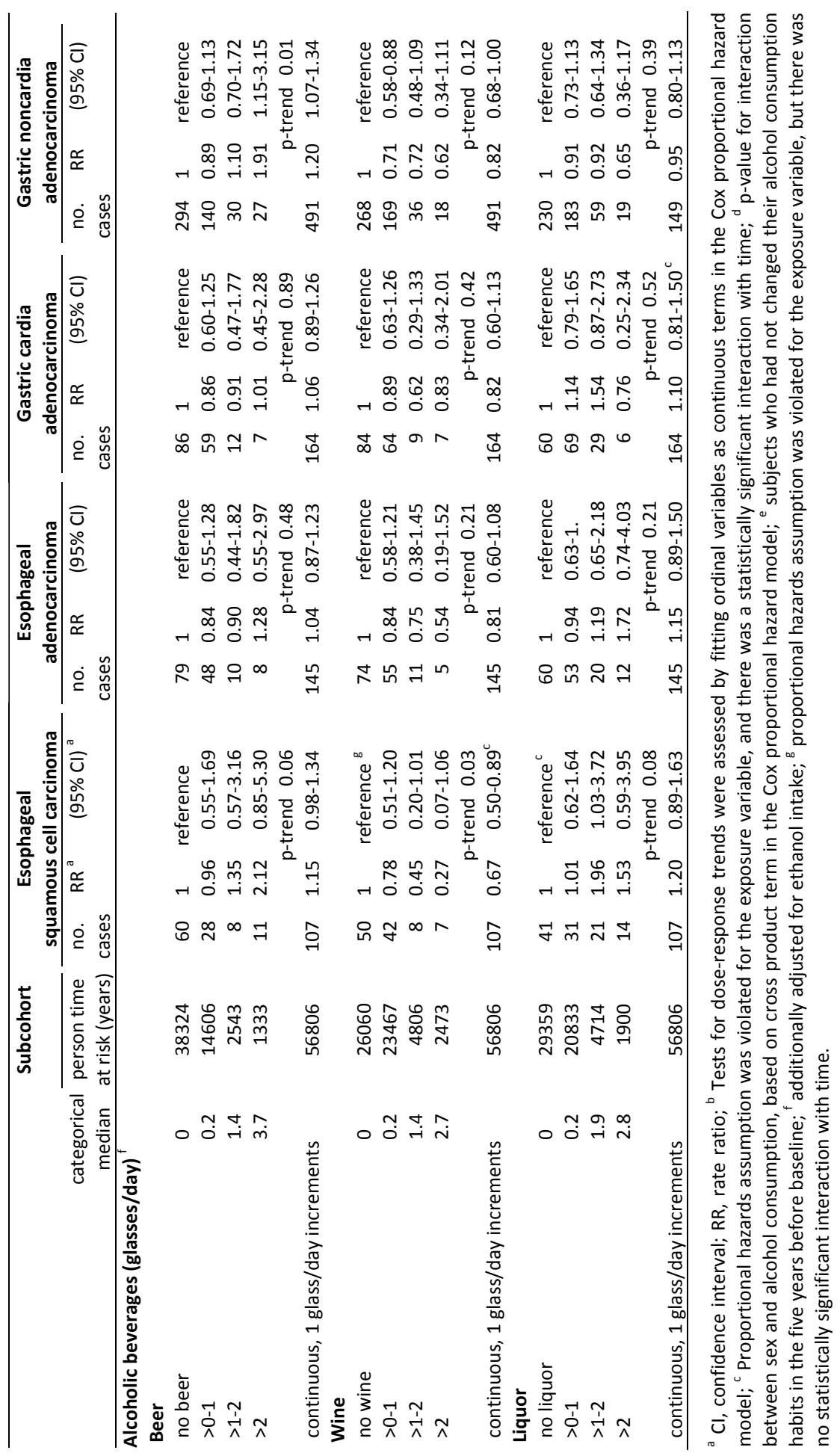




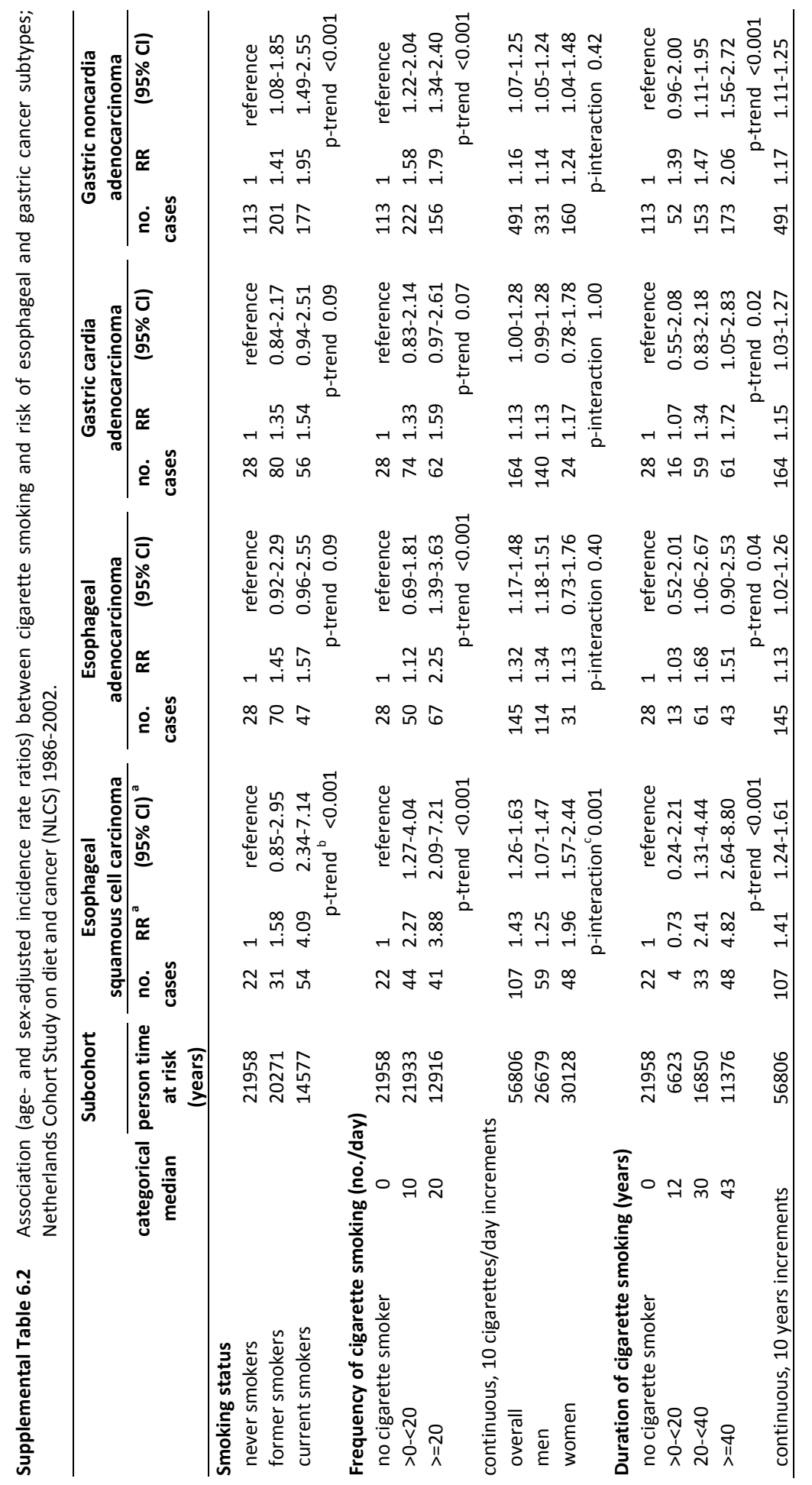




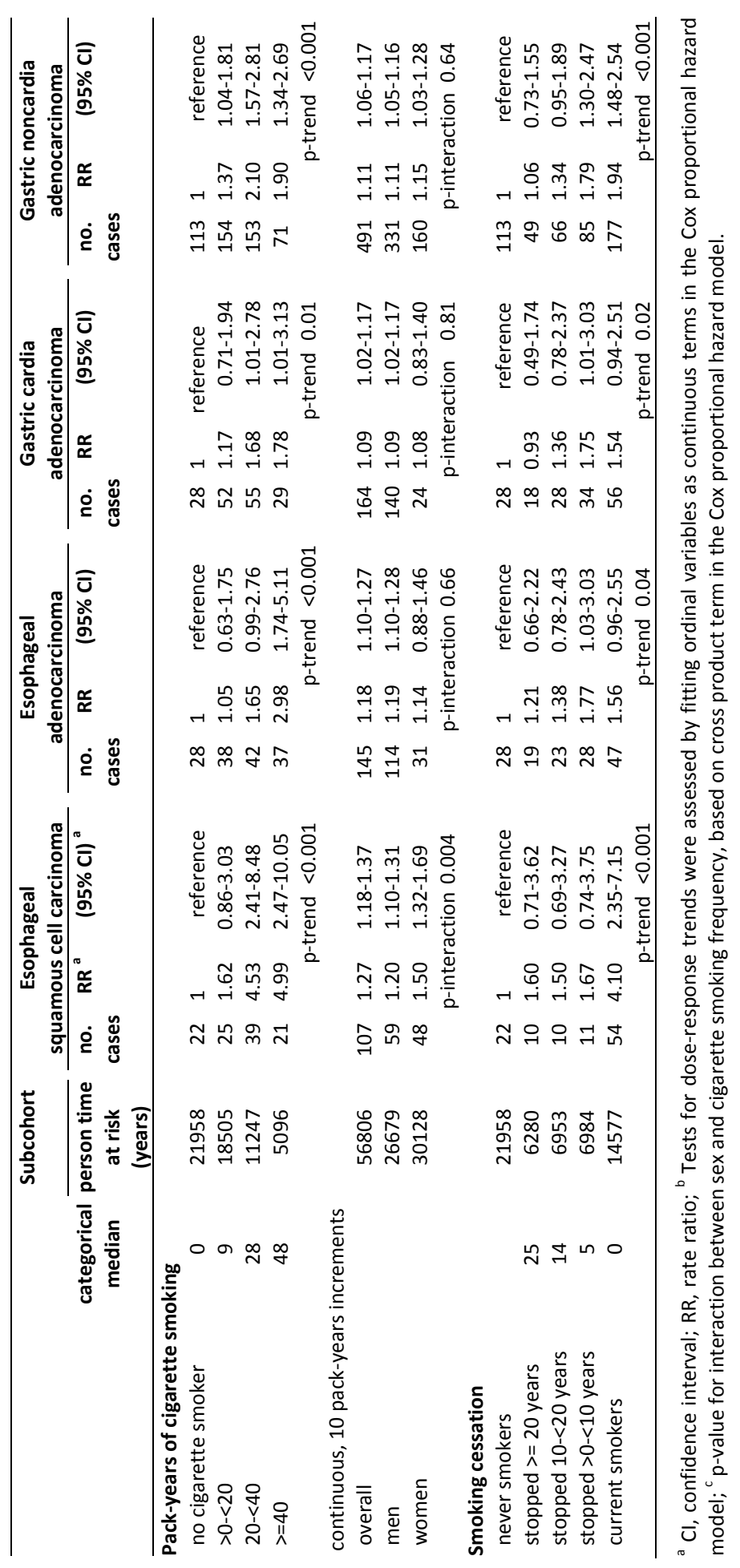




\section{REFERENCES}

1. Botterweck AA, Schouten $\amalg$, Volovics A, Dorant $E$, van Den Brandt PA. Trends in incidence of adenocarcinoma of the oesophagus and gastric cardia in ten European countries. Int J Epidemiol 2000;29:645-654.

2. Vizcaino AP, Moreno V, Lambert R, Parkin DM. Time trends incidence of both major histologic types of esophageal carcinomas in selected countries, 1973-1995. Int J Cancer 2002;99:860-868.

3. Gammon MD, Schoenberg JB, Ahsan H, Risch HA, Vaughan TL, Chow WH, Rotterdam $H$, West $A B$, Dubrow R, Stanford JL, Mayne ST, Farrow DC, Niwa S, Blot WJ, Fraumeni JF, Jr. Tobacco, alcohol, and socioeconomic status and adenocarcinomas of the esophagus and gastric cardia. J Natl Cancer Inst 1997;89:1277-1284.

4. Lagergren J, Bergstrom R, Lindgren A, Nyren $O$. The role of tobacco, snuff and alcohol use in the aetiology of cancer of the oesophagus and gastric cardia. Int J Cancer 2000;85:340-346.

5. Pandeya N, Williams GM, Sadhegi S, Green AC, Webb PM, Whiteman DC. Associations of duration, intensity, and quantity of smoking with adenocarcinoma and squamous cell carcinoma of the esophagus. Am J Epidemiol 2008;168:105-114.

6. Wu AH, Wan P, Bernstein L. A multiethnic population-based study of smoking, alcohol and body size and risk of adenocarcinomas of the stomach and esophagus (United States). Cancer Causes Control 2001;12:721-732.

7. Rothman KJ, Greenland S. Modern epidemiology. Lippincott, 1998.

8. Pell JP, Haw SJ, Cobbe SM, Newby DE, Pell AC, Oldroyd KG, Murdoch DL, Pringle SD, Dunn FG, Macintyre PD, Gilbert TJ, Fischbacher CM, Borland W. Validity of self-reported smoking status: Comparison of patients admitted to hospital with acute coronary syndrome and the general population. Nicotine Tob Res 2008;10:861-866.

9. Lindblad M, Rodriguez LA, Lagergren J. Body mass, tobacco and alcohol and risk of esophageal, gastric cardia, and gastric non-cardia adenocarcinoma among men and women in a nested case-control study. Cancer Causes Control 2005;16:285-294.

10. Freedman ND, Abnet CC, Leitzmann MF, Mouw T, Subar AF, Hollenbeck AR, Schatzkin A. A prospective study of tobacco, alcohol, and the risk of esophageal and gastric cancer subtypes. Am J Epidemiol 2007;165:1424-1433.

11. Zendehdel K, Nyren O, Luo J, Dickman PW, Boffetta P, Englund A, Ye W. Risk of gastroesophageal cancer among smokers and users of Scandinavian moist snuff. Int J Cancer 2008;122:1095-1099.

12. van den Brandt PA, Goldbohm RA, van 't Veer P, Volovics A, Hermus RJ, Sturmans F. A large-scale prospective cohort study on diet and cancer in The Netherlands. J Clin Epidemiol 1990;43:285-295.

13. Barlow WE, Ichikawa L, Rosner D, Izumi S. Analysis of case-cohort designs. J Clin Epidemiol 1999;52:1165-1172.

14. Van den Brandt PA, Schouten L, Goldbohm RA, Dorant E, Hunen PM. Development of a record linkage protocol for use in the Dutch Cancer Registry for Epidemiological Research. Int J Epidemiol 1990;19: 553-558.

15. Goldbohm RA, van den Brandt PA, Dorant E. Estimation of the coverage of Dutch municipalities by cancer registries and PALGA based on hospital discharge data. Tijdschr Soc Gezondheidsz 1994;72: 80-84.

16. Parkin DM, Shanmugaratnam K, Sobin L, Ferlay J, Whelan SL. Histological Groups for comparative studies. IARC Technical reports. Volume 31. Lyon: International Agency for Research on Cancer, 1998.

17. Goldbohm RA, van den Brandt PA, Brants HA, van't Veer P, Al M, Sturmans F, Hermus RJ. Validation of a dietary questionnaire used in a large-scale prospective cohort study on diet and cancer. Eur J Clin Nutr 1994;48:253-265.

18. Nevo table: Dutch food composition table, 1986-1987. (Dutch). Voorlichtingbureau Voor de Voeding, 1986.

19. Goldbohm RA, van 't Veer P, van den Brandt PA, van 't Hof MA, Brants HA, Sturmans F, Hermus RJ. Reproducibility of a food frequency questionnaire and stability of dietary habits determined from five annually repeated measurements. Eur J Clin Nutr 1995;49:420-429.

20. World Cancer Research Fund, American Institute for Cancer Research. Food, nutrition, physical activity and the prevention of cancer: a global perspective. AICR, 2007. 
21. Schottenfeld D, Fraumeni JF, Jr. Cancer epidemiology and prevention. Oxford University Press, 2006.

22. Zeegers MP, Schouten $\amalg$, Goldbohm RA, van den Brandt PA. A compendium of familial relative risks of cancer among first degree relatives: a population-based study. Int J Cancer 2008;123:1664-1673.

23. Merry AH, Schouten LJ, Goldbohm RA, van den Brandt PA. Body mass index, height and risk of adenocarcinoma of the oesophagus and gastric cardia: a prospective cohort study. Gut 2007;56: 1503-1511.

24. Lagergren J, Bergstrom R, Adami HO, Nyren O. Association between medications that relax the lower esophageal sphincter and risk for esophageal adenocarcinoma. Ann Intern Med 2000;133:165-175.

25. WHO Collaborating Centre for Drug Statistics Methodology. http://www.whocc.no/atcddd/ welcome.html (accessed 15 Oct, 2009).

26. Cox DR. Regression models and life-tables (with discussion). J R Stat Soc Ser B 1972;34:187-220.

27. Barlow WE. Robust variance estimation for the case-cohort design. Biometrics 1994;50:1064-1072.

28. Schoenfeld D. Partial residuals for the proportional hazards regression model. Biometrica 1982;69: 239-241.

29. Helicobacter and Cancer Collaborative Group. Gastric cancer and Helicobacter pylori: a combined analysis of 12 case control studies nested within prospective cohorts. Gut 2001;49:347-353.

30. Islami F, Kamangar F. Helicobacter pylori and esophageal cancer risk: a meta-analysis. Cancer Prev Res (Phila Pa) 2008;1:329-338.

31. Rokkas T, Pistiolas D, Sechopoulos P, Robotis I, Margantinis G. Relationship between Helicobacter pylori infection and esophageal neoplasia: a meta-analysis. Clin Gastroenterol Hepatol 2007;5:1413-1417, 1417 e1411-1412.

32. Taylor DN, Blaser MJ. The epidemiology of Helicobacter pylori infection. Epidemiol Rev 1991;13:42-59.

33. Tsugane S, Tei Y, Takahashi T, Watanabe S, Sugano K. Salty food intake and risk of Helicobacter pylori infection. Jpn J Cancer Res 1994;85:474-478.

34. Siman $\mathrm{JH}$, Forsgren A, Berglund $\mathrm{G}$, Floren $\mathrm{CH}$. Tobacco smoking increases the risk for gastric adenocarcinoma among Helicobacter pylori-infected individuals. Scand J Gastroenterol 2001;36: 208-213.

35. Brenner H, Rothenbacher D, Bode G, Adler G. Relation of smoking and alcohol and coffee consumption to active Helicobacter pylori infection: cross sectional study. Bmj 1997;315:1489-1492.

36. Ishiguro S, Sasazuki S, Inoue M, Kurahashi N, Iwasaki M, Tsugane S. Effect of alcohol consumption, cigarette smoking and flushing response on esophageal cancer risk: a population-based cohort study (JPHC study). Cancer Lett 2009;275:240-246.

37. Castellsague X, Munoz N, De Stefani E, Victora CG, Castelletto R, Rolon PA, Quintana MJ. Independent and joint effects of tobacco smoking and alcohol drinking on the risk of esophageal cancer in men and women. Int J Cancer 1999;82:657-664.

38. Zambon P, Talamini R, La Vecchia C, Dal Maso L, Negri E, Tognazzo S, Simonato L, Franceschi S. Smoking, type of alcoholic beverage and squamous-cell oesophageal cancer in northern Italy. Int J Cancer 2000;86:144-149.

39. Znaor A, Brennan P, Gajalakshmi V, Mathew A, Shanta V, Varghese C, Boffetta P. Independent and combined effects of tobacco smoking, chewing and alcohol drinking on the risk of oral, pharyngeal and esophageal cancers in Indian men. Int J Cancer 2003;105:681-686.

40. Neuhouser ML. Dietary flavonoids and cancer risk: evidence from human population studies. Nutr Cancer 2004;50:1-7.

41. Pandeya N, Williams G, Green AC, Webb PM, Whiteman DC. Alcohol Consumption and the Risks of Adenocarcinoma and Squamous Cell Carcinoma of the Esophagus. Gastroenterology 2009;136: 1215-1224.

42. Liu C, Russell RM. Nutrition and gastric cancer risk: an update. Nutr Rev 2008;66:237-249.

43. IARC. Monographs on the evaluation of carcinogenic risks to humans: Tobacco smoke and involuntary smoking. Volume 83. Lyon: International Agency for Research on Cancer, 2004.

44. Ladeiras-Lopes R, Pereira AK, Nogueira A, Pinheiro-Torres T, Pinto I, Santos-Pereira R, Lunet N. Smoking and gastric cancer: systematic review and meta-analysis of cohort studies. Cancer Causes Control 2008;19:689-701.

45. Pelucchi C, Gallus S, Garavello W, Bosetti C, La Vecchia C. Alcohol and tobacco use, and cancer risk for upper aerodigestive tract and liver. Eur J Cancer Prev 2008;17:340-344. 
46. Bosetti C, Gallus S, Garavello W, La Vecchia C. Smoking cessation and the risk of oesophageal cancer: An overview of published studies. Oral Oncol 2006;42:957-964.

47. Gallus S, Bosetti C, Franceschi S, Levi F, Simonato L, Negri E, La Vecchia C. Oesophageal cancer in women: tobacco, alcohol, nutritional and hormonal factors. Br J Cancer 2001;85:341-345.

48. Lee CH, Wu DC, Lee JM, Wu IC, Goan YG, Kao EL, Huang HL, Chan TF, Chou SH, Chou YP, Lee CY, Chen PS, Ho CK, He J, Wu MT. Carcinogenetic impact of alcohol intake on squamous cell carcinoma risk of the oesophagus in relation to tobacco smoking. Eur J Cancer 2007;43:1188-1199.

49. IARC. Monographs on the evaluation of carcinogenic risks to humans: re-evaluation ofsome organic chemicals, hydrazine and hydrogen peroxide. Volume 71. Lyon: International Agency for Research on Cancer, 1999.

50. Poschl G, Seitz HK. Alcohol and cancer. Alcohol Alcohol 2004;39:155-165.

51. IARC. Monographs on the evaluation of carcinogenic risks to humans: alcohol drinking. Volume 44. Lyon: International Agency for Research on Cancer, 1988. 


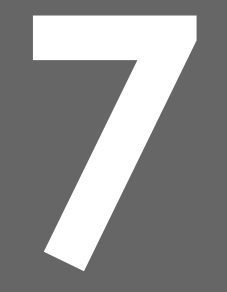

\section{Selenium status and the risk of esophageal and gastric cancer subtypes: the Netherlands Cohort Study}

Jessie Steevens

Piet $A$ van den Brandt

R Alexandra Goldbohm

Leo J Schouten 


\section{ABSTRACT}

\section{Background \& Aims}

Selenium may protect against the development of esophageal squamous cell carcinoma (ESCC), esophageal adenocarcinoma (EAC) and gastric cardia adenocarcinoma (GCA). Only in very few studies have the associations with ESCC and GCA been investigated, and no epidemiologic studies exist on EAC.

\section{Methods}

We studied the association between selenium and risk of ESCC, EAC, and GCA within the prospective Netherlands Cohort Study, conducted among 120,852 men and women aged 55-69 years at baseline. In September 1986, the cohort members completed a questionnaire on risk factors for cancer and provided toenail clippings for determination of baseline selenium status. After 16.3 years of follow-up, 64 ESCC, 112 EAC, and 114 GCA cases and 2072 subcohort members were available for case-cohort analysis. Incidence rate ratios (RR) were calculated using Cox proportional hazards models.

\section{Results}

In multivariable analyses of selenium status, we found an inverse association with

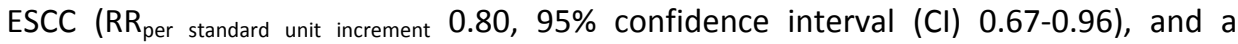
borderline significant inverse association with GCA (RR 0.91, 95\% Cl 0.80-1.02). No overall association was observed for EAC (RR 1.05, 95\% Cl 0.95-1.15), but for women and never smokers, significant inverse associations were found $\left(R_{\text {per standard unit increment }}\right.$ $0.72,95 \% \mathrm{Cl} 0.61-0.84$ and $0.74,95 \% \mathrm{Cl} 0.64-0.86$, respectively).

\section{Conclusions}

This prospective study supports an inverse association between toenail selenium and risk of ESCC and GCA and suggests an inverse association with risk of EAC in subgroups (women, never smokers, and low antioxidant consumers). These associations need confirmation. 


\section{INTRODUCTION}

Selenium has been studied in relation to cancer risk, and most epidemiologic studies have been performed on breast, colorectal, lung, gastric, bladder, and prostate cancer. ${ }^{1}$ Evidence from observational studies so far suggests that selenium is inversely associated with prostate cancer, and possibly with lung and gastric cancer. ${ }^{1}$ The reason for the interest in selenium in relation to cancer etiology is the antioxidant capacity of the selenium-dependent glutathione peroxidase enzymes. ${ }^{2,3}$ Other possible mechanisms through which selenium could be associated with lower cancer risk include reduction of inflammation, induction of detoxifying phase II enzymes, increase of p53, alteration of DNA methylation, blockage of the cell cycle, induction of apoptosis of cancer cells and inhibition of angiogenesis. ${ }^{3}$

The mineral is an essential trace element present in food. The selenium content of foods depends on the selenium content of the soil on which the food is grown. Regions with very low soil selenium levels $(<0.05 \mathrm{ppm})$ are New Zealand, parts of China, and Finland, while high levels ( $>5 \mathrm{ppm}$ ) are found in Canada, parts of the western United States, parts of China, Ireland, France, and Germany. ${ }^{4}$ The recommended daily allowance for selenium is $55 \mu \mathrm{g} /$ day in the United States ${ }^{5}$, and $50-150 \mu \mathrm{g} / \mathrm{day}$ in The Netherlands. ${ }^{6}$ For the Dutch population, the most important sources of selenium are meat, bread, milk, and milk product, fish, eggs, and cheese. ${ }^{7}$ Generally high serum selenium levels are reported in the United States, whereas in The Netherlands, blood and toenail selenium levels are intermediate between those reported from New Zealand and the United States. ${ }^{8}$ In epidemiologic research, the measurement of selenium status through biomarkers is preferred over the measurement of selenium intake through questionnaires because of the high variability of food selenium content. ${ }^{9}$ Toenails are a suitable biomarker because they reflect the intake of selenium for a period up to 1 year. ${ }^{10,11}$

Data on possible associations between selenium and esophageal and gastric cancer are sparse, and even less is known about the subtypes of these cancers. A few epidemiologic studies ${ }^{12-16}$ of different design found indications for an inverse association between selenium and total esophageal cancer. Limited evidence suggestive of an inverse association with esophageal squamous cell carcinoma (ESCC) arises from studies in Chinese populations. ${ }^{17-20}$ We could not find any case-control or cohort studies on selenium and esophageal adenocarcinoma (EAC) risk, but 1 US crosssectional study found an inverse association between serum selenium and markers of neoplastic progression in Barrett's esophagus cases (a precursor lesion of EAC). ${ }^{21}$ Selenium and its association with gastric cancer risk has been described in a review, ${ }^{22}$ but most studies, including ours, ${ }^{23}$ did not study the cardia specifically. In our case, this was due to the limited number of cases after 3.3 years of follow-up of our cohort. A cohort study $^{17}$ and trial ${ }^{24}$ in Linxian, China, studying gastric cardia adenocarcinoma (GCA) specifically, were able to identify an inverse association. 
It is important to study subtypes of esophageal and gastric cancer separately in analysis because these probably differ with regard to their etiology. ${ }^{25,26}$ EAC and GCA are specifically of interest because the incidences of these cancers have risen strongly in the United States and Europe during the past decades. ${ }^{27,28}$

The purpose of this study was to prospectively investigate the association between prediagnostic toenail selenium levels and risk of ESCC, EAC, and GCA. For this investigation, we used 16.3-year follow-up data from The Netherlands Cohort Study on diet and cancer (NLCS).

Our hypothesis was that toenail selenium levels are inversely associated with risk of ESCC, EAC, and GCA. The association with ESCC was expected to be the strongest because ESCC is strongly associated with smoking, which causes oxidative stress. This oxidative stress may be counteracted by the antioxidant capacity of selenium.

We studied the potential interaction between selenium and cigarette smoking, intake of vitamins C, E, and several carotenoids. These factors were chosen because they may all be involved in an antioxidant mechanism, ${ }^{3,29}$ and evidence suggestive of these interactions was previously found for total and prostate cancer. ${ }^{30,31}$ Additionally, potential interaction with body mass index (BMI) was investigated because of its association with esophageal cancer.

\section{PATIENTS AND METHODS}

\section{Study design and participants}

In September 1986, the prospective NLCS was initiated when 58,279 Dutch men and 62,573 women aged 55-69 years were enrolled. The subjects were randomly selected from 204 Dutch municipal registries. At baseline, all cohort members completed a selfadministered questionnaire and were asked to provide toenail clippings. A detailed description of the study was previously published. ${ }^{32}$

The case-cohort approach is used for data processing and analysis, for reasons of efficiency. ${ }^{33}$ Cases are derived from the entire cohort. A subcohort of 3500 subjects was selected at random from the total cohort at baseline. These 3500 subjects were used for the estimation of person-years at risk in the total cohort. Person-years at risk were calculated from the start of the study until esophageal or gastric cancer diagnosis, death, emigration, loss to follow-up or end of follow-up (December 31, 2002), whichever occurred first. Follow-up of the subcohort was established by linkage to Dutch municipal population registries and after 16.3 years (September 1986 to December 2002), only 1 male subcohort member was lost to follow-up. We excluded subcohort members $(n=154)$ who reported at baseline to have prevalent cancer (other than skin cancer), leaving 3346 subcohort members.

The entire cohort was linked to The Netherlands Cancer Registry and the nationwide network and registry of histopathology and cytopathology in The 
Netherlands ${ }^{34}$ for cancer incidence. ${ }^{35}$ Follow-up for cancer incidence was $\geq 96 \%$ complete, ${ }^{36}$ and after 16.3 years, the following numbers of incident, microscopically confirmed, primary carcinomas were identified: $130 \mathrm{ESCC}^{37}$ [International Classification of Diseases (ICD) for Oncology (O)-3, C15], 181 EAC $^{37}$ (C15), and 206 GCA (C16.0). The Medical Ethics Committee of Maastricht University, The Netherlands, has approved the study.

\section{Exposure data}

At baseline, all cohort members completed a self-administered questionnaire. The questionnaire consisted of a 150-item food frequency questionnaire and other questions on cancer risk factors, eg, smoking habits, alcohol consumption, height, and weight. The food frequency questionnaire asked about habitual consumption in the year preceding the start of the study. Mean daily nutrient intakes were calculated using the Dutch food-composition table. ${ }^{38}$ The questionnaire data were key entered and processed in a standardized manner, blinded with respect to cases/subcohort status to minimize observer bias in coding and interpretation of the data.

In our cohort, about $75 \%$ of the subjects provided toenail clippings. Toenail selenium determinations were carried out by the Reactor Institute Delft (Delft University of Technology, Delft, The Netherlands). The determination was based on instrumental neutron activation analysis of the ${ }^{77 \mathrm{~m}} \mathrm{Se}$ isotope (metastable selenium-77 isotope, half-life 17.5 seconds). Each sample went through 6 cycles of 17-second irradiation at a thermal neutron flux of $3 * 10^{16} \mathrm{~m}^{-2} \mathrm{~s}^{-1}, 3$-second decay, and 17-second counting at $1 \mathrm{~cm}$ from a $40 \%$ germanium detector. This method and the use in the NLCS have been described in more detail previously. ${ }^{23,39-41}$

In 1992, the toenail selenium determinations for the subcohort members and gastric cancer cases diagnosed until 3.3 years of follow-up (until December 31, 1990) were carried out. In 2008, the selenium determinations were carried out for all esophageal cancer cases and the gastric cardia cancer cases occurring from 3.3-16.3 years of follow-up (December 31, 1990, until December 31, 2002). In 1992, the "SBP" (abbreviation of Snelle Buizen Post, Dutch for fast pneumatic system) facility was used for instrumental neutron activation analysis, and, since 1996, the "CAFIA" (Carbonfiber Autonomous Facility for Irradiation and Analysis) facility has been used. To assess the validity and comparability of these 2 methods, the toenail selenium levels for 40 subcohort members were assessed in 1996 with the "CAFIA" facility in addition to the original assessment with the "SBP" facility. ${ }^{39}$ The mean selenium level \pm standard deviation (SD) assessed by the "CAFIA" facility $(0.552 \pm 0.05 \mu \mathrm{g} / \mathrm{g})$ was comparable with mean selenium levels assessed by the "SBP" facility $(0.551 \pm 0.04 \mu \mathrm{g} / \mathrm{g})$ for these subjects. The Pearson correlation coefficient between toenail selenium levels assessed by the "CAFIA" facility and those estimated by the "SBP" facility was $0.95(p<0.01) .{ }^{39}$ It was concluded that both methods were valid and comparable. 
In 1992, all toenail clippings provided by cases and subcohort were sent to the Reactor Institute Delft for selenium determination. This determination, however, yields unreliable results if the nail samples weigh $<10 \mathrm{mg}$, and these measurements were thus excluded. In 2007, we discovered that toenail clippings can also be used as a source of DNA ${ }^{42}$. We therefore separated and saved 10-20 mg of toenail clippings from the cancer cases for future genetic research. If, afterwards, more than $10 \mathrm{mg}$ of toenail clippings was left, we sent them to the Reactor Institute Delft. In case there were problems with the determination of toenail selenium due to very high calcium contents, the subject was excluded. Complete selenium data were available for 2426 subcohort members, and 71 ESCC, 129 EAC, and 127 GCA cases.

\section{Statistical analysis}

To evaluate the potential influence of prediagnostic cancer at baseline on toenail selenium levels, cases were categorized according to the year of follow-up in which they were diagnosed. Mean toenail selenium levels of ESCC, EAC and GCA cancer cases were compared according to year of follow-up, and differences were tested using a t-test. For the t-test, selenium levels were In (natural logarithm)-transformed to normalize the distribution. For the case-cohort analyses, toenail selenium levels were categorized into quartiles according to the distribution in the subcohort. For continuous analyses, the selenium levels were standardized to the average size of the 2 central quartiles in the subcohort. One standardized selenium unit is equal to $0.06 \mu \mathrm{g} / \mathrm{g}$.

Excluded were subcohort members and cases with inconsistent or incomplete dietary questionnaire data ${ }^{43}$ and those with missing data on the confounders. Complete data for statistical analysis was available for 2072 subcohort members, and 64 ESCC, 112 EAC, and 114 GCA cases.

The following variables were considered confounders because of their established association with esophageal or gastric cancer: ${ }^{44}$ age, sex, cigarette smoking (current yes/no, number of cigarettes smoked daily, and number of smoking years), alcohol consumption (g/day), and $\mathrm{BMI}\left(\mathrm{kg} / \mathrm{m}^{2}\right)$. The following variables were considered potential confounders but were eventually not included in the models because they did not change the incidence rate ratio (RR) by $>5 \%$ : nonoccupational physical activity; highest level of education; daily intakes of vitamin $C$, vitamin $E, \alpha$-carotene, $\beta$-carotene, $\beta$-cryptoxanthin, lycopene, and lutein/zeaxanthin; family history of esophageal or gastric cancer; reported long-term ( $>0.5$ years) use of nonsteroidal antiinflammatory drugs or aspirin (Anatomical therapeutic chemical (ATC) codes M01A, N02B); or lower esophageal sphincter relaxing medication.

Cox proportional hazards models were used to estimate age- and sex-adjusted and multivariable adjusted incidence RRs and corresponding $95 \%$ confidence intervals (CI). ${ }^{48}$ Analyses were done using Stata 9.2 statistical software package (StataCorp, College Station, Texas, USA). Standard errors were estimated using the robust Huber- 
White sandwich estimator to account for additional variance introduced by sampling from the cohort. This method is equivalent to the variance-covariance estimator by Barlow. ${ }^{49}$ The proportional hazards assumption was tested using the scaled Schoenfeld residuals, ${ }^{50}$ and $-\log (-\log )$ plots. Tests for dose-response trends were assessed by fitting ordinal exposure variables as continuous terms. Two-sided p-values are reported throughout the article.

Because of the limited numbers of cases, all analyses were carried out for both sexes combined. Nevertheless, tests for interaction between toenail selenium and sex were performed using the continuous selenium variable. We only report results stratified by sex for the continuous selenium variable.

We investigated possible interactions between toenail selenium status and cigarette smoking status (current, former, never), BMI, and intakes of several vitamins and carotenoids by estimating RRs in strata of these exposures. The p-value for interaction was assessed by including a cross-product term in the model. In the interaction analyses, we used a continuous selenium variable, because of the limited numbers of cases. To evaluate potential bias introduced by prediagnostic cancer at baseline, which may influence toenail selenium levels, we performed sensitivity analyses, excluding cases from the first 2 years of follow-up.

\section{RESULTS}

Table 7.1 shows that, when the cases were categorized according to 2-year follow-up periods in which they were diagnosed, there was no clear trend towards lower toenail selenium levels in cases occurring during early follow-up, indicating no effect of preclinical disease on toenail selenium levels. The t-tests were also not statistically significant.

The median toenail selenium level (in micrograms/grams) of all subcohort members was 0.552 . The levels were lower in men (0.538) than in women (0.564). For the cases, the following median toenail selenium levels (in $\mu \mathrm{g} / \mathrm{g}$ ) were observed: ESCC, 0.493; EAC, 0.532; and GCA, 0.529 (Table 7.2).

Table 7.2 presents some characteristics of the subcohort members and ESCC, EAC, and GCA cases. The most salient differences are described hereafter. There were far more men than women among the EAC and GCA cases. Among the subcohort members, there were relatively more never cigarette smokers, and subcohort members had, on average, higher intakes of vitamins $C$ and $E$, and carotenoids than the cases. With respect to separate cancer groups, we found that ESCC cases consumed much more alcohol and more often had a low level of education compared with the subcohort. EAC cases had a higher BMI, and more often reported a family history of esophageal or gastric cancer and use of lower esophageal sphincter relaxing medication. GCA cases spent more time on nonoccupational physical activity than the subcohort. 
Table 7.1 Toenail selenium levels $(\mu \mathrm{g} / \mathrm{g})$ in esophageal and gastric cancer cases according to sex and time between baseline and esophageal or gastric cancer diagnosis; Netherlands Cohort Study (19862002).

\begin{tabular}{|c|c|c|c|c|c|c|c|c|c|c|c|c|}
\hline \multirow{3}{*}{ Cases $^{a}$} & \multicolumn{4}{|c|}{$\begin{array}{l}\text { Esophageal squamous } \\
\text { cell carcinoma }\end{array}$} & \multicolumn{4}{|c|}{$\begin{array}{c}\text { Esophageal } \\
\text { adenocarcinoma }\end{array}$} & \multicolumn{4}{|c|}{$\begin{array}{c}\text { Gastric cardia } \\
\text { adenocarcinoma }\end{array}$} \\
\hline & \multirow[t]{2}{*}{$\begin{array}{l}\text { No. } \\
\text { cases }\end{array}$} & \multicolumn{3}{|c|}{$\begin{array}{c}\text { Toenail selenium level } \\
(\mu \mathrm{g} / \mathrm{g})\end{array}$} & \multirow[t]{2}{*}{$\begin{array}{l}\text { No. } \\
\text { cases }\end{array}$} & \multicolumn{3}{|c|}{$\begin{array}{c}\text { Toenail selenium level } \\
(\mu \mathrm{g} / \mathrm{g})\end{array}$} & \multirow[t]{2}{*}{$\begin{array}{l}\text { No. } \\
\text { cases }\end{array}$} & \multicolumn{3}{|c|}{$\begin{array}{c}\text { Toenail selenium level } \\
(\mu \mathrm{g} / \mathrm{g})\end{array}$} \\
\hline & & mean & sd & $\mathbf{p}^{b}$ & & mean & sd & $\mathbf{p}^{b}$ & & mean & sd & $p^{b}$ \\
\hline All cases & 71 & 0.514 & 0.088 & & 129 & 0.564 & 0.163 & & 127 & 0.535 & 0.080 & \\
\hline Men & 44 & 0.505 & 0.092 & & 106 & 0.571 & 0.177 & & 109 & 0.536 & 0.082 & \\
\hline Women & 27 & 0.527 & 0.081 & & 23 & 0.533 & 0.049 & & 18 & 0.532 & 0.071 & \\
\hline \multicolumn{13}{|c|}{ Year of follow-up } \\
\hline $0-2$ & 4 & 0.462 & 0.103 & 0.20 & 8 & 0.514 & 0.065 & 0.30 & 12 & 0.537 & 0.085 & 0.96 \\
\hline$>2-4$ & 9 & 0.568 & 0.144 & & 12 & 0.549 & 0.070 & & 17 & 0.573 & 0.087 & \\
\hline$>4-6$ & 8 & 0.446 & 0.051 & & 15 & 0.617 & 0.296 & & 11 & 0.534 & 0.093 & \\
\hline$>6-8$ & 11 & 0.509 & 0.072 & & 20 & 0.590 & 0.162 & & 17 & 0.534 & 0.082 & \\
\hline$>8-10$ & 9 & 0.535 & 0.090 & & 14 & 0.537 & 0.081 & & 18 & 0.509 & 0.069 & \\
\hline$>10-12$ & 11 & 0.531 & 0.077 & & 20 & 0.612 & 0.244 & & 24 & 0.550 & 0.077 & \\
\hline$>12-14$ & 7 & 0.523 & 0.058 & & 19 & 0.515 & 0.063 & & 12 & 0.538 & 0.083 & \\
\hline$>14-17$ & 12 & 0.503 & 0.066 & & 21 & 0.547 & 0.064 & & 16 & 0.502 & 0.061 & \\
\hline
\end{tabular}

${ }^{\mathrm{a}}$ Mean $\pm \mathrm{sd}$ selenium levels in subcohort members were $0.547 \pm 0.126 \mu \mathrm{g} / \mathrm{g}$ for men $(\mathrm{n}=1211)$ and $0.575 \pm$ $0.109 \mu \mathrm{g} / \mathrm{g}$ for women $(\mathrm{n}=1248) ;{ }^{\mathrm{b}}$ T-test of mean toenail selenium level (In-transformed) in first 2 years of follow-up versus rest of follow-up years.

Table 7.3 reports on the association between quartiles of toenail selenium levels and risk of ESCC, EAC, and GCA. For ESCC, an inverse association was found with toenail selenium (multivariable RR for the highest vs the lowest quartile $0.37,95 \% \mathrm{Cl}$ $0.16-0.86$ ), and the test for trend was statistically significant ( $p$-trend=0.02). The association was nearly the same in age- and sex-adjusted analyses, and the results were also robust to the exclusion of the first 2 years of follow-up.

No clear association was found between toenail selenium levels and EAC risk (multivariable RR for the highest vs the lowest quartile $0.76,95 \% \mathrm{Cl} 0.41-1.40$ ). The results from age- and sex-adjusted analyses and analyses excluding the first 2 years of follow-up showed no association either. However, a statistically significant $(p<0.001)$ interaction was found between toenail selenium and sex: an inverse association was observed in women, but not in men (Table 7.3). As mentioned before, we analyzed men and women together in further analyses because of the small number of cases. 
Table 7.2 Characteristics of cases and subcohort members in the Netherlands Cohort Study (1986-2002).

\begin{tabular}{|c|c|c|c|c|}
\hline \multirow[b]{2}{*}{ Exposure variables and potential confounders } & \multirow{2}{*}{$\begin{array}{l}\text { Subcohort } \\
(\mathrm{n}=2072)^{a}\end{array}$} & \multicolumn{3}{|c|}{ Cases } \\
\hline & & $\begin{array}{c}\text { ESCC }^{b} \\
(n=64)^{a}\end{array}$ & $\begin{array}{c}\text { EAC }^{b} \\
(n=112)^{a}\end{array}$ & $\begin{array}{c}\text { GCA }^{b} \\
(n=114)^{a}\end{array}$ \\
\hline & $\begin{array}{c}\text { median } \\
\text { (IQR) }\end{array}$ & $\begin{array}{c}\text { median } \\
\text { (IQR) }\end{array}$ & $\begin{array}{c}\text { median } \\
\text { (IQR) }\end{array}$ & $\begin{array}{c}\text { median } \\
\text { (IQR) }\end{array}$ \\
\hline \multicolumn{5}{|l|}{ Toenail selenium level $(\mu \mathrm{g} / \mathrm{g})$} \\
\hline \multirow[t]{2}{*}{ total } & 0.552 & 0.493 & 0.532 & 0.529 \\
\hline & $(0.498-0.613)$ & $(0.453-0.583)$ & $(0.488-0.584)$ & $(0.477-0.582)$ \\
\hline \multirow[t]{2}{*}{ men } & 0.538 & 0.490 & 0.536 & 0.529 \\
\hline & $(0.483-0.602)$ & $(0.448-0.558)$ & $(0.485-0.588)$ & $(0.477-0.581)$ \\
\hline \multirow[t]{3}{*}{ women } & 0.564 & 0.524 & 0.516 & 0.518 \\
\hline & $(0.514-0.623)$ & $(0.473-0.597)$ & $(0.501-0.564)$ & $(0.485-0.583)$ \\
\hline & $\operatorname{mean}(\mathbf{s d})^{c}$ & mean (sd) & mean (sd) & mean (sd) \\
\hline Age at baseline (y) & $61.2(4.2)$ & $62.2(4.0)$ & $61.5(4.1)$ & $61.3(4.2)$ \\
\hline \multicolumn{5}{|l|}{ Sex } \\
\hline Men (n (\%)) & $1020(49)$ & $40(63)$ & $93(83)$ & $97(85)$ \\
\hline Women (n (\%)) & $1052(51)$ & $24(37)$ & $19(17)$ & $17(15)$ \\
\hline \multicolumn{5}{|l|}{ Cigarette smoking status } \\
\hline Never smoker (n (\%)) & $782(38)$ & $11(17)$ & $19(17)$ & $15(13)$ \\
\hline Former smoker (n (\%)) & $760(37)$ & $21(33)$ & $61(54)$ & $57(50)$ \\
\hline Current smoker (n (\%)) & $530(25)$ & $32(50)$ & $32(29)$ & $42(37)$ \\
\hline \multicolumn{5}{|l|}{ Ever cigarette smokers } \\
\hline Frequency of cigarette smoking (no./d) & $15(10)$ & $17(10)$ & $21(14)$ & $17(11)$ \\
\hline Duration of cigarette smoking $(y)$ & $31(12)$ & $37(10)$ & $34(11)$ & $35(11)$ \\
\hline Ethanol intake $(\mathrm{g} / \mathrm{d})$ & $10(14)$ & $24(29)$ & $15(18)$ & $13(14)$ \\
\hline Body mass index (BMI) $\left(\mathrm{kg} / \mathrm{m}^{2}\right)$ & $25.0(3.1)$ & $23.9(3.0)$ & $26.4(3.3)$ & $25.5(2.6)$ \\
\hline Nonoccupational physical activity $(\mathrm{min} / \mathrm{d})$ & $73(58)$ & $74(62)$ & $77(58)$ & $89(82)$ \\
\hline \multicolumn{5}{|l|}{ Highest level of education $^{d}$} \\
\hline Primary (n (\%)) & $565(27)$ & $23(36)$ & $25(23)$ & $26(23)$ \\
\hline Lower vocational (n (\%)) & $457(22)$ & $12(19)$ & $26(24)$ & $34(30)$ \\
\hline Secondary and medium vocational (n (\%)) & $754(37)$ & $21(33)$ & $40(36)$ & $32(28)$ \\
\hline University and higher vocational (n (\%)) & $283(14)$ & $8(12)$ & $19(17)$ & $22(19)$ \\
\hline Vitamin C intake (mg/d) & $104(42)$ & $100(47)$ & $98(50)$ & $90(40)$ \\
\hline Vitamin E intake (mg/d) & $14(6)$ & $13(5)$ & $14(6)$ & $14(7)$ \\
\hline$\alpha$-carotene intake $(\mu \mathrm{g} / \mathrm{d})$ & 711 (587) & $680(513)$ & 701 (539) & $659(555)$ \\
\hline$\beta$-carotene intake $(\mu \mathrm{g} / \mathrm{d})$ & $3001(1600)$ & 2869 (1359) & $2970(1525)$ & $2924(1597)$ \\
\hline$\beta$-cryptoxanthin intake $(\mu \mathrm{g} / \mathrm{d})$ & $181(165)$ & $174(194)$ & $150(174)$ & $131(146)$ \\
\hline Lycopene intake $(\mu \mathrm{g} / \mathrm{d})$ & $1210(1762)$ & 1056 (1297) & $985(1722)$ & $1067(1118)$ \\
\hline Lutein/zeaxanthin intake $(\mu \mathrm{g} / \mathrm{d})$ & $2520(1096)$ & $2411(925)$ & $2567(1140)$ & 2555 (1317) \\
\hline $\begin{array}{l}\text { Family history of esophageal or gastric cancer } \\
(\mathrm{n}(\%))\end{array}$ & $173(8)$ & $7(11)$ & $15(13)$ & $10(9)$ \\
\hline Reported long-term use of NSAIDs ${ }^{b}(n(\%))$ & $152(7)$ & $5(8)$ & $10(9)$ & $5(4)$ \\
\hline $\begin{array}{l}\text { Reported long-term use of LES }{ }^{b} \text { relaxing } \\
\text { medication }(\mathrm{n}(\%))\end{array}$ & $288(14)$ & $9(14)$ & $27(24)$ & $18(16)$ \\
\hline
\end{tabular}

${ }^{a}$ Presented are the number of subcohort members or cases with complete data on toenail selenium level, age, sex, cigarette smoking (current yes/no, number of cigarettes smoked daily, number of smoking years), alcohol consumption and BMI. Subcohort members and cases with incomplete or inconsistent questionnaire data are excluded; ${ }^{b}$ ESCC: esophageal squamous cell carcinoma, EAC: esophageal adenocarcinoma, GCA: gastric cardia adenocarcinoma, LES: lower esophageal sphincter, NSAIDs: nonsteroidal anti-inflammatory drugs; ${ }^{\mathrm{C}}$ For categorical variables $\mathrm{n}(\%)$ is presented; ${ }^{\mathrm{d}}$ Numbers do not always add up to the total, because of missing values on this variable. 


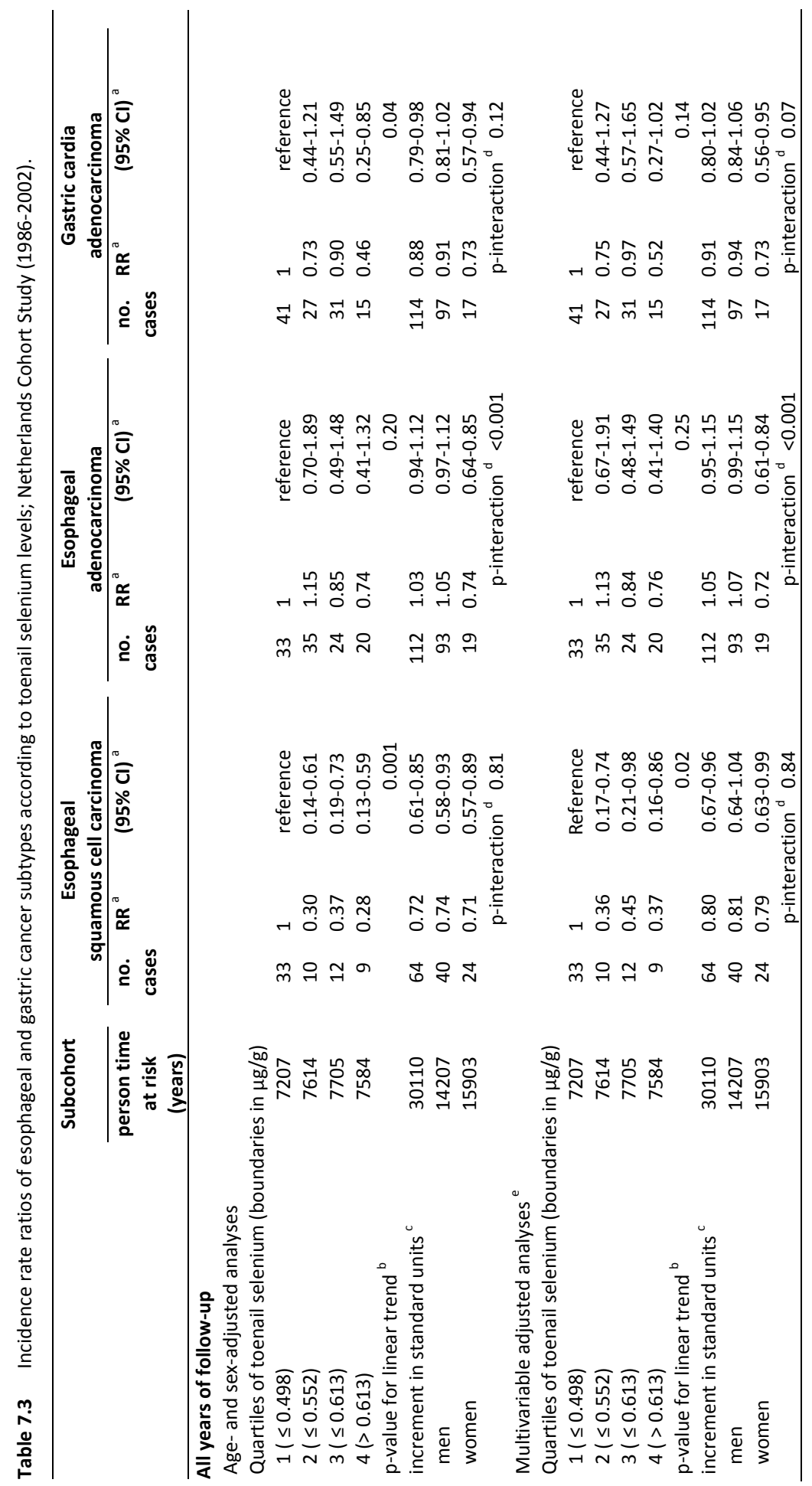




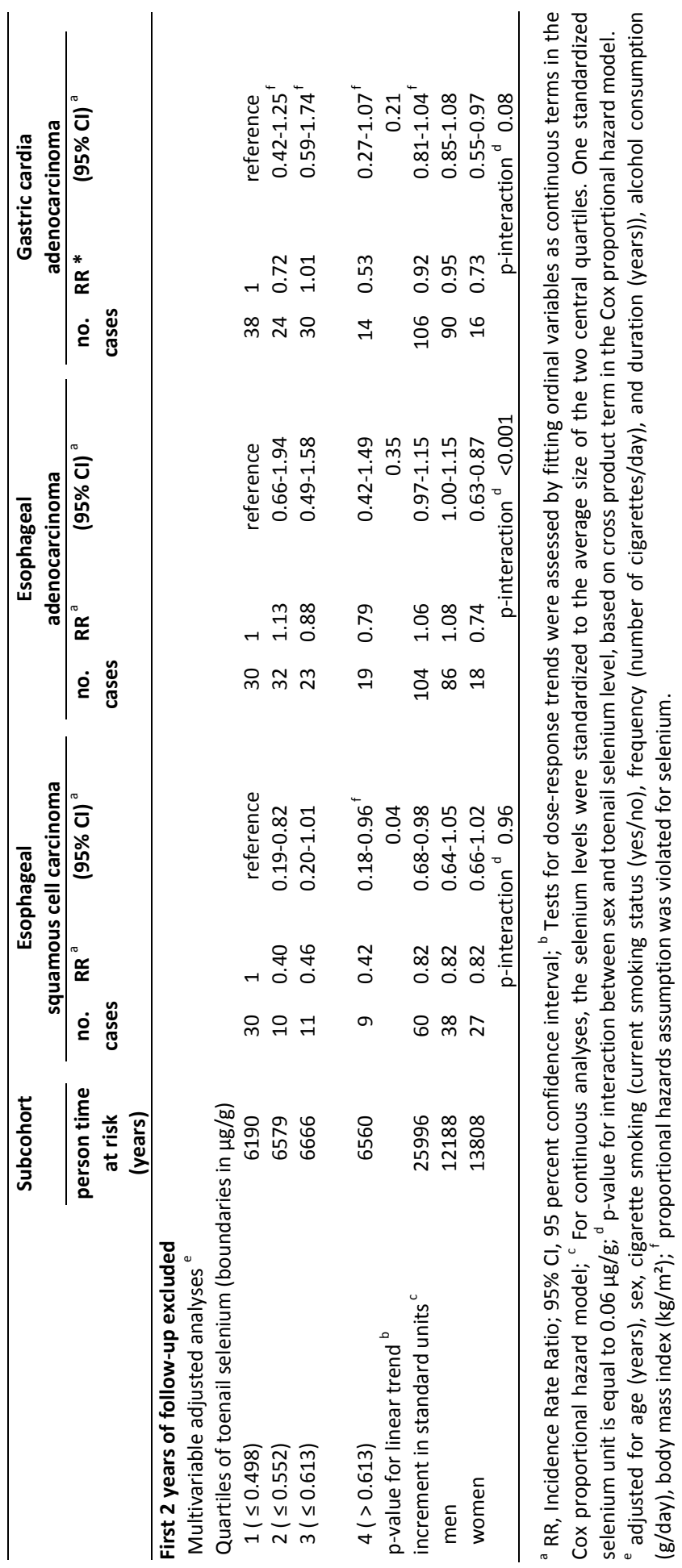




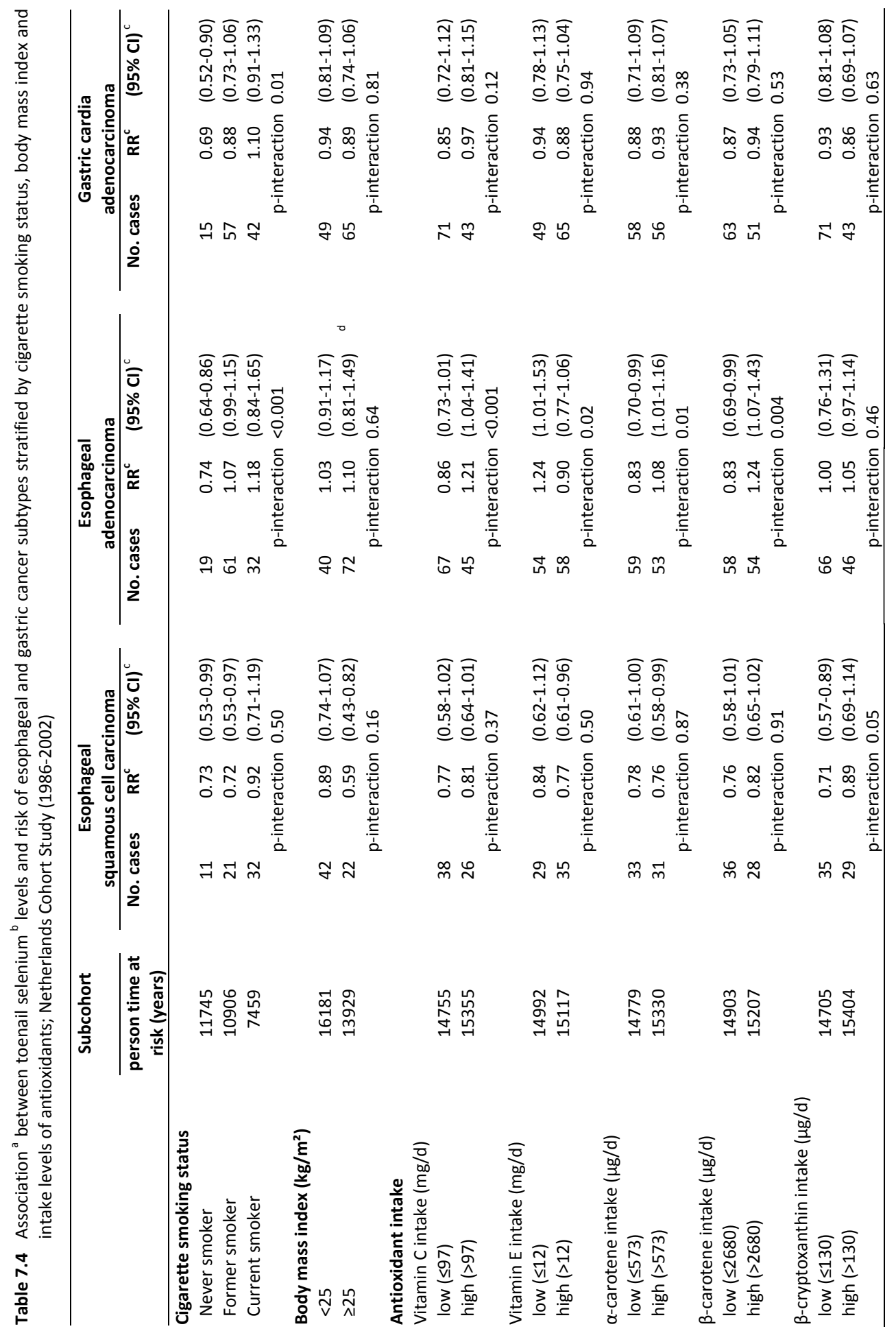




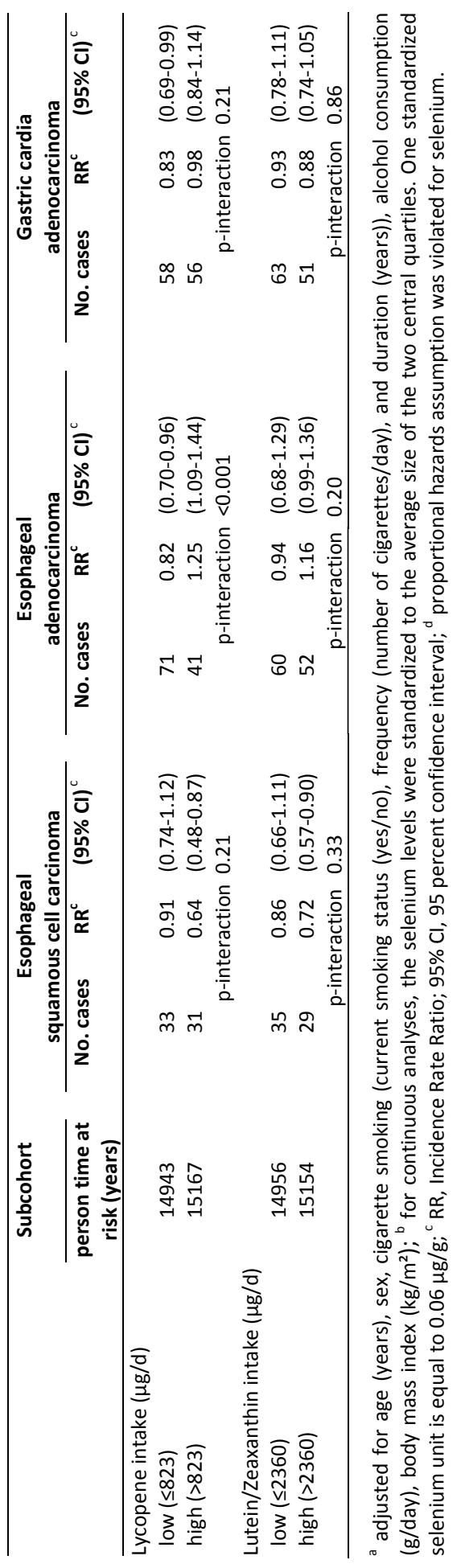


We found an inverse association between toenail selenium levels and risk of GCA (multivariable $\mathrm{RR}$ for the highest vs the lowest quartile $0.52,95 \% \mathrm{Cl} 0.27-1.02$ ), although the test for trend was not statistically significant $(p=0.14)$. As for EAC, the RRs in women were lower (and statistically significant) than in men, and the interaction between selenium and sex was borderline significant $(p=0.07)$. The age- and sexadjusted results were nearly the same as the multivariable results, but statistical significance was only reached in the former. Exclusion of the first 2 years of follow-up did not alter the results (Table 7.3). Because the t-tests (Table 7.1) and the exclusion of the first 2 years of follow-up indicated that selenium levels were not affected by prediagnostic disease, all following analyses are based on the complete 16.3-year follow-up data.

Presented in Table 7.4 are the results of the interaction analyses. For EAC and GCA, a statistically significant interaction was found between selenium and smoking status: only for never smokers was an inverse association with selenium present. The RRs for 1 standardized selenium unit increment were $0.74(95 \% \mathrm{Cl} 0.64-0.86)$ for EAC and 0.69 (95\% $\mathrm{Cl} 0.52-0.90)$ for GCA for never smokers. No interaction was found for ESCC ( $p$-interaction=0.50), although an inverse association was more apparent for never and former smokers.

With regard to $\mathrm{BMI}$, no interaction with selenium was observed for ESCC, EAC, or GCA (Table 7.4). From Table 7.4, which presents results stratified by intake of several antioxidants, it can be seen that the inverse association we observed between toenail selenium levels and risk of ESCC did not differ between strata, defined by low or high intake of these antioxidants. However, for EAC we found several statistically significant interactions between selenium and antioxidant intake. For subjects with a low intake of vitamin $\mathrm{C}, \alpha$-carotene, $\beta$-carotene, or lycopene, (borderline) significant inverse associations with selenium were present. For GCA, no appreciable differences in associations were found between strata of antioxidant intake.

\section{DISCUSSION}

This study is the first prospective cohort study into selenium and risk of subtypes of esophageal and gastric cancer in a Western population, and the first to separately investigate ESCC, EAC, and GCA. Our study provides evidence for an inverse association between toenail selenium levels and risk of ESCC and GCA. The association with GCA was more apparent in women, and only in women was an inverse association found with EAC risk, but this was based on small numbers. We found these results in a Dutch population with a median toenail selenium level of $0.522 \mu \mathrm{g} / \mathrm{g}$ (subcohort). This is a low to moderate toenail selenium level when compared to mean levels found in other populations (general population or control subjects): China (Sichuan province), $0.211 \mu \mathrm{g} / \mathrm{g} ;{ }^{51}$ Finland, $0.47 \mu \mathrm{g} / \mathrm{g} ;{ }^{52}$ United States, $0.83-0.92 \mu \mathrm{g} / \mathrm{g} ;{ }^{.3}$ Colombia, $0.945 \mu \mathrm{g} / \mathrm{g} ;{ }^{54}$ and USA (South Dakota/Wyoming), $1.517 \mu \mathrm{g} / \mathrm{g}^{11}$ 
Only 1 case-control study, in a Chinese population with low selenium intake, investigated selenium intake, measured by means of a food frequency questionnaire, in relation to ESCC risk. ${ }^{20}$ Intake of selenium, measured by questionnaires, correlates poorly with actual selenium intake. ${ }^{55}$ However, the Chinese study was able to find a statistically significant inverse association $(p$-trend $<0.001) .{ }^{20}$ In the Chinese Linxian trial cohort, $^{17,}{ }^{18}$ which is a population with low selenium levels, a significant inverse association between serum selenium and ESCC was also found, and the range of selenium levels in that population was comparable to the range in our cohort. ${ }^{8}$ Two other case-control studies investigated esophageal cancer, but did not make a distinction between ESCC and EAC. ${ }^{12,16}$ However, these esophageal cancer cases were presumably mostly ESCC cases. One of these studies was performed in a Japanese population with a moderate selenium status ${ }^{12}$ and the other in an Indian population with a high selenium status. ${ }^{16}$ These studies reported significantly lower blood selenium levels in esophageal cancer cases than in controls, but did not report rate ratios or odds ratios. Also, the US Nutritional Prevention of Cancer trial found lower esophageal cancer risk in subjects who received daily selenium supplements. ${ }^{15}$ The results of the studies mentioned above suggest inverse associations with ESCC over the range from low to high selenium status, whereas too few studies have been performed to make any inferences on EAC.

For GCA, the Linxian trial cohort reported a statistically significant inverse association with serum selenium. ${ }^{17}$ Two other studies, in a Chinese and Finnish population with a relatively low selenium status, found an inverse association between serum selenium levels and total gastric cancer. ${ }^{12,30}$ Within the NLCS, we previously found evidence suggestive of an inverse association with total gastric cancer. ${ }^{23}$ In contrast, no inverse association was found between serum or toenail selenium levels and gastric cancer in 3 other studies in Japanese, Hawaiian (with Japanese ancestry) and Colombian populations with a higher selenium status. ${ }^{54,56,57}$ This suggests that a ceiling effect may exist, such that selenium is only associated with gastric cancer risk in populations with relatively low selenium levels.

If selenium is associated with lower esophageal and gastric cancer risk, the question arises by which mechanism selenium exerts its effect and in which stage of carcinogenesis. Two studies, investigating subjects with Barrett's esophagus ${ }^{21}$ and with dysplasia of the squamous epithelium, ${ }^{19}$ can give clues about the timing of the effect of selenium. The former study found less signs of progression in subjects with the highest serum selenium levels, whereas the latter found that selenium supplements were associated with less progression and more regression of the dysplasia. These findings may mean that selenium can have an effect after the epithelium of the esophagus has already changed. No effect, however, of selenium containing supplements was found in a third study among subjects with dysplasia. ${ }^{58}$

The possibility for a selenium effect earlier in the carcinogenesis also remains open. Any antioxidant effects ${ }^{2,3}$ of selenium, for instance, might occur early in carcinogenesis. In our interaction analyses of EAC, we found inverse associations 
specifically for those subjects with a low intake of antioxidants. This finding could indicate an antioxidant mechanism of selenium for EAC. Other findings, however, did not match an antioxidant mechanism. We found an inverse association with EAC and GCA only in never smokers, whereas, in case of an antioxidant mechanism, one would expect these associations with selenium in the current smokers because smokers are exposed to oxidative stress, ${ }^{29}$ and this oxidative stress could be counteracted by antioxidants.

The associations we observed between selenium and esophageal and gastric cancers may also be a result of other mechanisms. In fact, it has been suggested that selenium may act at a number of stages in carcinogenesis and by a number of different mechanisms (see introduction) that may operate simultaneously, or consecutively. ${ }^{3}$ The few in vitro and vivo studies that have been performed on selenium and esophageal carcinogenesis, show effects on different processes in early and late stages (eg, mutagenesis, development of precancerous lesions and cancer, cancer cell proliferation, and tumor growth). ${ }^{59-62}$

To learn more about the possible role of selenium in the etiology of ESCC, EAC, and GCA, the observations reported here need confirmation or refutation from other epidemiologic studies. Additionally, it would be interesting to study selenium in association with risk of Barrett's esophagus. A comparison of both associations may give more insight into the mechanism of action of selenium and the stage in the development of normal esophageal epithelium into EAC at which selenium exerts its effect.

Two strengths of our study are the size and the division of esophageal cancer into 2 main histologic subtypes: ESCC and EAC. This division enables the identification of possible differences in the etiology of these cancers. Thirdly, we are the first to investigate selenium in relation to risk of ESCC, EAC, and GCA in a Western population. Most previous studies were performed in Asia. A fourth strength is the prospective character of our study, which prevents bias by reverse causation, a concern in casecontrol studies. We investigated whether undiagnosed cancer at baseline may have influenced our results, by excluding cases diagnosed in the first 2 years of follow-up, but the results proved robust to this exclusion. Finally, the observation that our results hardly changed after adjustment for confounders, makes residual confounding unlikely.

Our study has some limitations that should be described. Toenail selenium levels were measured only once in our cohort. In the Nurses' Health Study, a correlation coefficient of 0.48 was found between toenail selenium levels for specimens taken 6 years apart. ${ }^{53}$ This moderate reliability may have resulted in some misclassification of exposure. This misclassification is nondifferential and thus may have attenuated the association. Another limitation to our study was the relatively low number of female EAC and GCA cases, which prevented a more detailed investigation of the association with selenium by sex. As a final point, many statistical tests were performed, which increases the chance of false positive results. 
In conclusion, this prospective study supports an inverse association between toenail selenium levels and risk of ESCC and GCA and suggests an inverse association with risk of EAC in subgroups (women, never smokers, and low antioxidant consumers). 


\section{REFERENCES}

1. Navarro Silvera SA, Rohan TE. Trace elements and cancer risk: a review of the epidemiologic evidence. Cancer Causes Control 2007;18:7-27.

2. Jackson MI, Combs GF, Jr. Selenium and anticarcinogenesis: underlying mechanisms. Curr Opin Clin Nutr Metab Care 2008;11:718-726.

3. Rayman MP. Selenium in cancer prevention: a review of the evidence and mechanism of action. Proc Nutr Soc 2005;64:527-542.

4. Navarro-Alarcon M, Cabrera-Vique C. Selenium in food and the human body: a review. Sci Total Environ 2008;400:115-141.

5. Institute of Medicine. Dietary reference intakes for vitamin C, vitamin E, selenium, and carotenoids. Washington, D.C., 2000.

6. Netherlands Nutrition Centre. http://www.voedingscentrum.nl/nl/eten-gezondheid/voedingstoffen/ vitamines-en-mineralen/hoeveel-heb-je-nodig.aspx\#c (accessed 13 August 2009)

7. Hulshof KFAM, Kistemaker C, Kruizinga AG. [The contribution of food groups to the intake of energy and nutrients. Dutch National Food Consumption Survey 1997-1998]. Zeist: TNO, 1998.

8. van 't Veer P, van der Wielen RP, Kok FJ, Hermus RJ, Sturmans F. Selenium in diet, blood, and toenails in relation to breast cancer: a case-control study. Am J Epidemiol 1990;131:987-994.

9. Willett WC, Buzzard IM. Foods and nutrients. In: Willett WC, ed. Monographs in Epidemiology and Biostatistics. Volume 30. Nutritional epidemiology. New York: Oxford Universtiy Press, 1998:18-32.

10. Hunter DJ, Morris JS, Chute CG, Kushner E, Colditz GA, Stampfer MJ, Speizer FE, Willett WC. Predictors of selenium concentration in human toenails. Am J Epidemiol 1990;132:114-122.

11. Longnecker MP, Stram DO, Taylor PR, Levander OA, Howe M, Veillon C, McAdam PA, Patterson KY, Holden JM, Morris JS, Swanson CA, Willett WC. Use of selenium concentration in whole blood, serum, toenails, or urine as a surrogate measure of selenium intake. Epidemiology 1996;7:384-390.

12. Ujiie $\mathrm{S}$, Kikuchi $\mathrm{H}$. The relation between serum selenium value and cancer in Miyagi, Japan: 5-year follow up study. Tohoku J Exp Med 2002;196:99-109.

13. Jaskiewicz K, Marasas WF, Rossouw JE, van Niekerk FE, Heine Tech EW. Selenium and other mineral elements in populations at risk for esophageal cancer. Cancer 1988;62:2635-2639.

14. Knekt P, Aromaa A, Maatela J, Alfthan G, Aaran RK, Nikkari T, Hakama M, Hakulinen T, Teppo L. Serum micronutrients and risk of cancers of low incidence in Finland. Am J Epidemiol 1991;134:356-361.

15. Clark LC, Combs GF, Jr., Turnbull BW, Slate EH, Chalker DK, Chow J, Davis LS, Glover RA, Graham GF, Gross EG, Krongrad A, Lesher JL, Jr., Park HK, Sanders BB, Jr., Smith CL, Taylor JR. Effects of selenium supplementation for cancer prevention in patients with carcinoma of the skin. A randomized controlled trial. Nutritional Prevention of Cancer Study Group. Jama 1996;276:1957-1963.

16. Krishnaswamy K, Prasad MP, Krishna TP, Pasricha S. A case control study of selenium in cancer. Indian J Med Res 1993;98:124-128.

17. Mark SD, Qiao YL, Dawsey SM, Wu YP, Katki H, Gunter EW, Fraumeni JF, Jr., Blot WJ, Dong ZW, Taylor PR. Prospective study of serum selenium levels and incident esophageal and gastric cancers. J Natl Cancer Inst 2000;92:1753-1763.

18. Wei WQ, Abnet CC, Qiao YL, Dawsey SM, Dong ZW, Sun XD, Fan JH, Gunter EW, Taylor PR, Mark SD. Prospective study of serum selenium concentrations and esophageal and gastric cardia cancer, heart disease, stroke, and total death. Am J Clin Nutr 2004;79:80-85.

19. Limburg PJ, Wei W, Ahnen DJ, Qiao Y, Hawk ET, Wang G, Giffen CA, Wang G, Roth MJ, Lu N, Korn EL, Ma Y, Caldwell KL, Dong Z, Taylor PR, Dawsey SM. Randomized, placebo-controlled, esophageal squamous cell cancer chemoprevention trial of selenomethionine and celecoxib. Gastroenterology 2005; 129:863-873.

20. Lu H, Cai L, Mu LN, Lu QY, Zhao J, Cui Y, Sul JH, Zhou XF, Ding BG, Elashoff RM, Marshall J, Yu SZ, Jiang $\mathrm{QW}$, Zhang ZF. Dietary mineral and trace element intake and squamous cell carcinoma of the esophagus in a Chinese population. Nutr Cancer 2006;55:63-70.

21. Rudolph RE, Vaughan TL, Kristal AR, Blount PL, Levine DS, Galipeau PC, Prevo LJ, Sanchez CA, Rabinovitch PS, Reid BJ. Serum selenium levels in relation to markers of neoplastic progression among persons with Barrett's esophagus. J Natl Cancer Inst 2003;95:750-757.

22. Liu C, Russell RM. Nutrition and gastric cancer risk: an update. Nutr Rev 2008;66:237-249. 
23. van den Brandt PA, Goldbohm RA, van 't Veer P, Bode P, Dorant E, Hermus RJ, Sturmans F. A prospective cohort study on toenail selenium levels and risk of gastrointestinal cancer. J Natl Cancer Inst 1993;85:224-229.

24. Blot WJ, Li JY, Taylor PR, Guo W, Dawsey S, Wang GQ, Yang CS, Zheng SF, Gail M, Li GY, et al. Nutrition intervention trials in Linxian, China: supplementation with specific vitamin/mineral combinations, cancer incidence, and disease-specific mortality in the general population. J Natl Cancer Inst 1993;85:1483-1492.

25. Holmes RS, Vaughan TL. Epidemiology and pathogenesis of esophageal cancer. Semin Radiat Oncol 2006;17:2-9.

26. Kelley JR, Duggan JM. Gastric cancer epidemiology and risk factors. J Clin Epidemiol 2003;56:1-9.

27. Vizcaino AP, Moreno V, Lambert R, Parkin DM. Time trends incidence of both major histologic types of esophageal carcinomas in selected countries, 1973-1995. Int J Cancer 2002;99:860-868.

28. Steevens J, Botterweck AA, Dirx MJ, van den Brandt PA, Schouten LJ. Trends in incidence of oesophageal and stomach cancer subtypes in Europe. Eur J Gastroenterol Hepatol 2010;22:669-678.

29. Mena S, Ortega A, Estrela JM. Oxidative stress in environmental-induced carcinogenesis. Mutat Res 2009;674:36-44.

30. Knekt P, Aromaa A, Maatela J, Alfthan G, Aaran RK, Hakama M, Hakulinen T, Peto R, Teppo L. Serum selenium and subsequent risk of cancer among Finnish men and women. J Natl Cancer Inst 1990;82:864-868.

31. van den Brandt PA, Zeegers MP, Bode P, Goldbohm RA. Toenail selenium levels and the subsequent risk of prostate cancer: a prospective cohort study. Cancer Epidemiol Biomarkers Prev 2003;12: 866-871.

32. van den Brandt PA, Goldbohm RA, van 't Veer P, Volovics A, Hermus RJ, Sturmans F. A large-scale prospective cohort study on diet and cancer in The Netherlands. J Clin Epidemiol 1990;43:285-295.

33. Barlow WE, Ichikawa L, Rosner D, Izumi S. Analysis of case-cohort designs. J Clin Epidemiol 1999;52:1165-1172.

34. Casparie M, Tiebosch AT, Burger G, Blauwgeers H, van de Pol A, van Krieken JH, Meijer GA. Pathology databanking and biobanking in The Netherlands, a central role for PALGA, the nationwide histopathology and cytopathology data network and archive. Cell Oncol 2007;29:19-24.

35. van den Brandt PA, Schouten LJ, Goldbohm RA, Dorant E, Hunen PM. Development of a record linkage protocol for use in the Dutch Cancer Registry for Epidemiological Research. Int J Epidemiol 1990;19:553-558.

36. Goldbohm R, van Den Brandt PA, Dorant E. Estimation of the coverage of Dutch municipalities by cancer registries and PALGA based on hospital discharge data. Tijdschr Soc Gezondheidsz 1994;72: 80-84.

37. Parkin DM, Shanmugaratnam K, Sobin L, Ferlay J, Whelan SL. Histological Groups for comparative studies. IARC Technical reports. Volume 31. Lyon: International Agency for Research on Cancer, 1998.

38. Nevo table: Dutch food composition table, 1986-1987. (Dutch). Voorlichtingbureau Voor de Voeding, 1986.

39. Zeegers MP, Goldbohm RA, Bode P, van den Brandt PA. Prediagnostic toenail selenium and risk of bladder cancer. Cancer Epidemiol Biomarkers Prev 2002;11:1292-1297.

40. Bode P. Automation and quality assurance in the Neutron Activation Facilities in Delft. J Radioanal Nucl Chem 2000;245:127-132.

41. van den Brandt PA, Goldbohm RA, van't Veer P, Bode P, Hermus RJ, Sturmans F. Predictors of toenail selenium levels in men and women. Cancer Epidemiol Biomarkers Prev 1993;2:107-112.

42. van Breda SG, Hogervorst JG, Schouten LJ, Knaapen AM, van Delft JH, Goldbohm RA, van Schooten FJ, van den Brandt PA. Toenails: an easily accessible and long-term stable source of DNA for genetic analyses in large-scale epidemiological studies. Clin Chem 2007;53:1168-1170.

43. Goldbohm RA, van den Brandt PA, Brants HA, van't Veer P, Al M, Sturmans F, Hermus RJ. Validation of a dietary questionnaire used in a large-scale prospective cohort study on diet and cancer. Eur J Clin Nutr 1994;48:253-265.

44. Schottenfeld D, Fraumeni JF, Jr. Cancer epidemiology and prevention. Oxford University Press, 2006.

45. Merry AH, Schouten L, Goldbohm RA, van den Brandt PA. Body mass index, height and risk of adenocarcinoma of the oesophagus and gastric cardia: a prospective cohort study. Gut 2007;56: 1503-1511. 
46. Lagergren J, Bergstrom R, Adami HO, Nyren O. Association between medications that relax the lower esophageal sphincter and risk for esophageal adenocarcinoma. Ann Intern Med 2000;133:165-175.

47. WHO Collaborating Centre for Drug Statistics Methodology. http://www.whocc.no/atcddd/ welcome.html (accessed 15 Oct, 2009).

48. Cox DR. Regression models and life-tables. J Roy Statistical Society 1972;34:187-220.

49. Barlow WE. Robust variance estimation for the case-cohort design. Biometrics 1994;50:1064-1072.

50. Schoenfeld D. Partial residuals for the proportional hazards regression model. Biometrica 1982;69: 239-241.

51. Gao S, Jin Y, Hall KS, Liang C, Unverzagt FW, Ji R, Murrell JR, Cao J, Shen J, Ma F, Matesan J, Ying B, Cheng Y, Bian J, Li P, Hendrie HC. Selenium level and cognitive function in rural elderly Chinese. Am J Epidemiol 2007;165:955-965.

52. Ovaskainen ML, Virtamo J, Alfthan G, Haukka J, Pietinen P, Taylor PR, Huttunen JK. Toenail selenium as an indicator of selenium intake among middle-aged men in an area with low soil selenium. Am J Clin Nutr 1993;57:662-665.

53. Garland M, Morris JS, Rosner BA, Stampfer MJ, Spate VL, Baskett CJ, Willett WC, Hunter DJ. Toenail trace element levels as biomarkers: reproducibility over a 6-year period. Cancer Epidemiol Biomarkers Prev 1993;2:493-497.

54. Koriyama C, Campos FI, Yamamoto M, Serra M, Carrasquilla G, Carrascal E, Akiba S. Toenail selenium levels and gastric cancer risk in Cali, Colombia. J Toxicol Sci 2008;33:227-235.

55. Zhang ZW, Shimbo S, Qu JB, Watanabe T, Nakatsuka H, Matsuda-Inoguchi N, Higashikawa K, Ikeda M. Dietary selenium intake of Chinese adult women in the 1990s. Biol Trace Elem Res 2001;80:125-138.

56. Kabuto M, Imai H, Yonezawa C, Neriishi K, Akiba S, Kato H, Suzuki T, Land CE, Blot WJ. Prediagnostic serum selenium and zinc levels and subsequent risk of lung and stomach cancer in Japan. Cancer Epidemiol Biomarkers Prev 1994;3:465-469.

57. Nomura A, Heilbrun LK, Morris JS, Stemmermann GN. Serum selenium and the risk of cancer, by specific sites: case-control analysis of prospective data. J Natl Cancer Inst 1987;79:103-108.

58. Li JY, Taylor PR, Li B, Dawsey S, Wang GQ, Ershow AG, Guo W, Liu SF, Yang CS, Shen Q, et al. Nutrition intervention trials in Linxian, China: multiple vitamin/mineral supplementation, cancer incidence, and disease-specific mortality among adults with esophageal dysplasia. J Natl Cancer Inst 1993;85: 1492-1498.

59. Xiao HJ, Huang CY, Wang HY, Li M. [Effect of selenium and zinc on the proliferation of human esophageal cancer Eca109 cell line in vitro]. Nan Fang Yi Ke Da Xue Xue Bao 2008;28:2117-2120.

60. Guttenplan JB, Kosinska W, von Pressentin MM, Rosa J, El-Bayoumy K. Effects of 1,4phenylenebis(methylene)selenocyanate ( $\mathrm{p}$-XSC) and vitamin E on 4-nitroquinoline-N-oxide (4-NQO)induced mutagenesis in lacZ mouse upper aerodigestive tissue. Mutat Res 2002;518:85-93.

61. Guttenplan JB, Spratt TE, Khmelnitsky M, Kosinska W, Desai D, El-Bayoumy K. Effects of 3H-1,2dithiole-3-thione, 1,4-phenylenebis(methylene)selenocyanate, and selenium-enriched yeast individually and in combination on benzo[a]pyrene-induced mutagenesis in oral tissue and esophagus in lacZ mice. Mutat Res 2004;559:199-210.

62. Bogden JD, Chung HR, Kemp FW, Holding K, Bruening KS, Naveh Y. Effect of selenium and molybdenum on methylbenzylnitrosamine-induced esophageal lesions and tissue trace metals in the rat. J Nutr $1986 ; 116: 2432-2442$. 


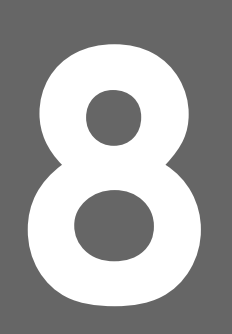

Vegetables and fruits consumption and risk of esophageal and gastric cancer subtypes in the Netherlands Cohort Study

\author{
Jessie Steevens \\ Leo J Schouten \\ R Alexandra Goldbohm \\ Piet A van den Brandt
}

Submitted 


\section{ABSTRACT}

Prospective epidemiologic data on vegetables and fruits consumption and risk of subtypes of esophageal and gastric cancer are sparse. We studied the association between vegetables and fruits consumption and risk of esophageal squamous cell carcinoma (ESCC), esophageal adenocarcinoma (EAC), gastric cardia adenocarcinoma (GCA), and gastric noncardia adenocarcinoma (GNCA) in the Netherlands Cohort Study. In 1986, 120852 Dutch men and women aged 55-69 filled out a questionnaire on diet and other cancer risk factors. After 16.3 years of follow-up, 101 ESCC, 144 EAC, 156 GCA, 460 GNCA cases and 4035 subcohort members were available for case-cohort analysis using Cox proportional hazards models. Multivariable adjusted incidence rate ratios (RR) were generally below unity. Significant inverse associations were observed for raw vegetables and EAC risk [RR per 25g/day: 0.81, 95\% confidence interval (Cl) $0.68-0.98$ ], and Brassica vegetables and GCA risk (RR per 25g/day: $0.72,95 \% \mathrm{Cl}$ 0.54-0.95). Citrus fruits were inversely associated with EAC and GCA risk (RRs for highest vs. lowest intake: $0.55,95 \% \mathrm{Cl} 0.31-0.98$ and $0.38,95 \% \mathrm{Cl} 0.21-0.69$, respectively). Specifically for current smokers, vegetables and fruits intake was inversely associated with ESCC and EAC risk. Consumption of vegetables and fruits may protect against subtypes of esophageal and gastric cancer. 


\section{INTRODUCTION}

Vegetables and fruits have been of interest for their possible favorable influence on risk of cancer and other diseases for some decades. These foods contain many substances that are potentially anticarcinogenic, such as vitamins, carotenoids, and flavonoids. Possible mechanisms of action include modulation of DNA methylation, protection from and repair of DNA damage, induction of detoxifying phase II enzymes, and promotion of apoptosis. ${ }^{1,2}$. A recent expert report concluded that consumption of vegetables and fruits probably protects against development of esophageal and gastric cancer. ${ }^{2}$ Unfortunately, in this report, no distinction was made between the main subtypes of these cancers: esophageal squamous cell carcinoma (ESCC), esophageal adenocarcinoma (EAC), gastric cardia adenocarcinoma (GCA), and gastric noncardia adenocarcinoma (GNCA). It is interesting and important to look into subtypes of these cancers, as the evidence is growing that there are differences in risk factors between these cancers. ${ }^{3-5}$ Case-control studies on vegetables or fruits consumption and ESCC, ${ }^{6-9}$ $\mathrm{EAC}^{7,8,10,11} \mathrm{GCA}^{7,8,12}$ or $\mathrm{GNCA}^{7,12}$ mostly reported inverse associations. However, casecontrol studies are vulnerable for biases because of their retrospective nature. This can specifically be a problem when investigating diet and gastrointestinal cancer. ${ }^{13}$ Cohort studies are less vulnerable for biases. Cohort studies that reported on ESCC have mostly found inverse associations, ${ }^{14-16}$ but some cohorts found no association with vegetables ${ }^{16,17}$ or fruits ${ }^{17}$ consumption. For EAC, ${ }^{14,18}$ GCA, ${ }^{16,18-21}$ and GNCA $^{16,18-21}$ mainly null associations have been observed, except for two studies that found inverse associations for fruits consumption and $\mathrm{GCA}^{16}{ }^{16}$ and $\mathrm{GNCA}^{20}$.

Using $3.3^{22}$ and $6.3^{13}$ year follow-up data of the Netherlands Cohort Study on diet and cancer (NLCS), we have previously reported on the associations between vegetables and fruits consumption and risk of total gastric cancer. ${ }^{13}$ Only for Allium vegetables, separate results for GCA and GNCA were presented. ${ }^{22}$

The aim of this study was to prospectively investigate the role of vegetables and fruits consumption in the development of ESCC, EAC, GCA, and GNCA. Also, we aimed to study several groups of vegetables and fruits and individual vegetable and fruit items separately, as few studies have performed such comprehensive analyses. For this study, we used 16.3-year follow-up data from the NLCS.

\section{MATERIALS AND METHODS}

\section{Study design and participants}

This study was conducted within the prospective Netherlands Cohort Study, which started in September 1986 with the inclusion of 58279 men and 62573 women aged 55-69 years, who were randomly sampled from Dutch municipal registries. ${ }^{23}$ At 
baseline, all subjects completed a self-administered questionnaire on dietary and lifestyle habits and other cancer risk factors.

For reasons of efficiency, the case-cohort approach was used for data processing and analysis. ${ }^{24,25}$ Cases were derived from the entire cohort, and the number of person-years at risk for the entire cohort was estimated from a subcohort of 5000, who were randomly sampled from the total cohort at baseline. The subcohort has been followed up by contacting the participants and using data from municipal population registries. ${ }^{23}$ Person-years at risk were calculated from the start of the study until esophageal or gastric cancer diagnosis, death, emigration, loss to follow-up or end of follow-up, whichever occurred first. Only one male subcohort member was lost to follow-up after 16.3 years.

Follow-up for cancer incidence was performed by record linkage ${ }^{26}$ to the Netherlands Cancer Registry (NCR) and PALGA, the nationwide network and registry of histopathology and cytopathology in the Netherlands. ${ }^{27}$ Data of 16.3 years of follow-up (baseline to December 31, 2002) were used. The completeness of cancer follow-up is $\geq 96 \%$. ${ }^{28}$ The following numbers of incident, microscopically confirmed, primary carcinomas were identified: $130 \mathrm{ESCC}^{29}$ (ICD-O-3 C15), $181 \mathrm{EAC}^{29}$ (C15), 206 GCA (C16.0) and 594 GNCA (C16.1-C16.9) (Figure 8.1). The group of GNCA included cancers with a lesion with overlapping subsites of the stomach $(C 16.8, n=160)$ and some gastric, not otherwise specified cancers $(C 16.9, n=75)$, raising the possibility that some cardia cancers might be included in the non-cardia category. However, as we found risk estimates to be similar in separate analyses of gastric cancers of specified sites (C16.1-C16.5) and other gastric cancers (C16.6-C16.9) (data not shown), we combined the groups in the analysis.

We excluded subjects who reported having prevalent cancer other than skin cancer at baseline. Also excluded were cases and subcohort members with incomplete or inconsistent dietary data. ${ }^{30}$ Further details on the design of the study and methods of follow-up have been published previously. ${ }^{23,26}$ The Medical Ethics Committee of Maastricht University has approved the study.

\section{Questionnaire data}

The self-administered questionnaire included a 150-item food frequency questionnaire (FFQ). The FFQ concentrated on the habitual consumption of foods and beverages during the year preceding the start of the study.

With regard to vegetables consumption, subjects were asked to report their frequency of consumption of a number of vegetables (see Table 8.2), both in summer and in winter. They could choose one of six categories, ranging from "never or less than 1x per month" to "3-7x per week". Subjects were asked about usual serving sizes only for string beans and cooked endive; the mean of these values served as an indicator to derive the serving sizes of all cooked vegetables, according to a vegetablespecific algorithm based on results of a pilot study. For onions and tomatoes, 
participants were asked to report their consumption in number per week; for sweet peppers per month, and for mushrooms the number of $250 \mathrm{~g}$ boxes per month. Subjects with inconsistent vegetable data were excluded from analysis.

With regard to fruits consumption, subjects were asked to report the frequency and amount of consumption of a number of fruits (listed in Table 8.2). Categories ranged from "never or less than $1 x$ per month" to "6-7x per week". Using household units, these frequencies and amounts have been converted to consumption in grams/day.

The choice of items in the questionnaire was such that it covered almost all vegetables and fruits eaten regularly, with the exception of chicory, red cabbage, and cucumber. Furthermore, in an open-ended question, participants could fill in other foods they consumed regularly as well as the frequency and amount consumed on each occasion.

Questionnaire data were key-entered and processed in a standardized manner, blinded with respect to case/subcohort status to minimize observer bias in the coding and interpretation of the data.

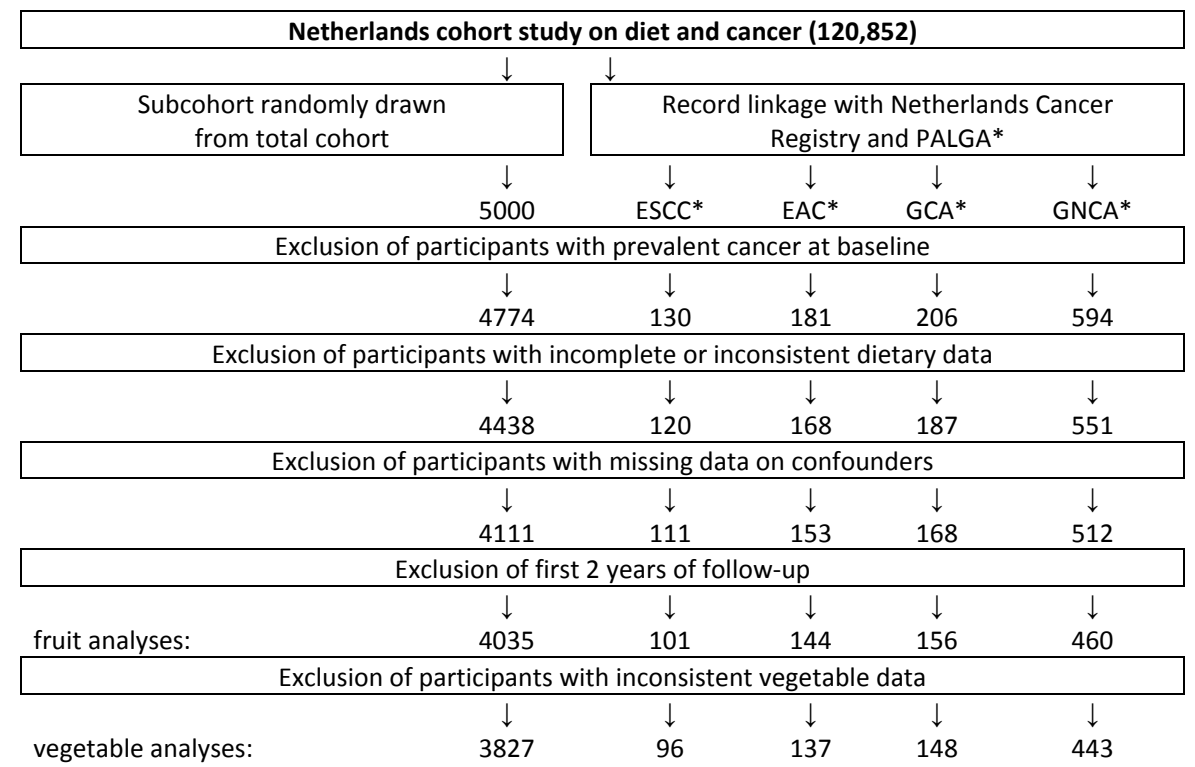

Figure 8.1 Flow diagram of subcohort members and cases on whom the analyses were based. *PALGA: nationwide network and registry of histo- and cytopathology in the Netherlands, ESCC: esophageal squamous cell carcinoma, EAC: esophageal adenocarcinoma, GCA: gastric cardia adenocarcinoma, GNCA: gastric noncardia adenocarcinoma. 
The FFQ was validated against a 9-day diet record. ${ }^{30}$ The Spearman correlation coefficients were 0.38 for total vegetables consumption and 0.60 for total fruits consumption. On average, vegetables consumption appeared to be slightly overestimated and fruits consumption to be underestimated by the FFQ as compared with the diet records.

\section{Statistical analysis}

We checked for possible influence of preclinical cancer at baseline on the consumption of vegetables and fruits. ${ }^{13}$ This was done by comparing the mean consumption of vegetables and fruits for cases that were diagnosed during the first 2 years of followup with the mean consumption for cases diagnosed later in follow-up. An independent samples t-test was used to test for statistical significance of differences, after a squareroot transformation was applied to normalize the distribution of the vegetables and fruits variables. Vegetables consumption was statistically significantly lower among early vs. late GCA (difference $43 \mathrm{~g} /$ day, $\mathrm{P}=0.04$ ) and GNCA (difference $22 \mathrm{~g} /$ day, $\mathrm{P}=0.02$ ) cases, while fruits consumption was lower among early vs. late ESCC cases (difference $74 \mathrm{~g} /$ day, $\mathrm{P}=0.01$ ). Based on these observations, we decided to exclude the first 2 years of follow-up from all analyses, to prevent bias caused by reversed causation due to preclinical cancer.

Analyses were performed for total vegetables consumption, cooked and raw vegetables, several vegetable subgroups, and the most frequently consumed individual vegetables. Furthermore, we analyzed total fruits consumption, citrus fruits and the most frequently consumed individual fruits. The composition of each vegetable and fruit group can be found in the Appendix. For categorical analyses, vegetables and fruits consumption levels were categorized into quintiles according to the distribution in the subcohort. For continuous analyses, an increment of $25 \mathrm{~g} /$ day was chosen.

The following confounders were included in all models because they changed the incidence rate ratios (RR) by more than 5\%: age (years), sex, cigarette smoking (current yes/no, number of cigarettes smoked daily, and number of smoking years), and consumption of alcohol (g/day), red meat (g/day), and fish (g/day). The following variables were considered potential confounders but were not included in the models because they did not change the RRs by more than 5\%: consumption of tea, consumption of meat products, non-occupational physical activity, body mass index (BMI), highest educational level, family history of esophageal or gastric cancer, longterm use of non-steroidal anti-inflammatory drugs or aspirin, or lower esophageal sphincter (LES) relaxing medication. ${ }^{31,32}$ Analyses of vegetables were adjusted for fruits consumption and vice versa. For exact model specifications, see the table footnotes.

Cox proportional hazards models were used to estimate age- and sex-adjusted and multivariable adjusted RRs and corresponding 95\% confidence intervals $(\mathrm{Cl}) .^{33}$ Standard errors were estimated using a robust covariance matrix estimator to account for increased variance due to sampling from the cohort. ${ }^{24}$ The proportional hazards 
assumption was tested using the scaled Schoenfeld residuals. ${ }^{34}$ Tests for doseresponse trends were assessed by fitting ordinal exposure variables as continuous terms.

Because of the limited numbers of cases, specifically female cases, all analyses were carried out for both sexes combined. Nevertheless, analyses stratified by sex were performed for total vegetables and fruits consumption using continuous variables. We also investigated possible interaction between vegetables and fruits consumption and cigarette smoking status (current, former, never) by performing stratified analyses. P-values for interaction were assessed by including a cross-product term in the models.

All analyses were done using Stata 9.2 statistical software package (StataCorp, College Station, Texas, USA). The significance level $\alpha$ was set at 0.05 . All reported $p$ values are two-sided.

\section{RESULTS}

\section{Characteristics of the study population}

Baseline characteristics of the subcohort and case groups are presented in Table 8.1. The most striking difference is the high percentage of men among EAC (78\%) and GCA cases (85\%), compared with the subcohort (49\% men). Furthermore, cases were more likely current cigarette smokers than subcohort members and among ever smokers, cases smoked longer and more cigarettes than did subcohort members. Ethanol intake was also higher in all case groups than in the subcohort, particularly among ESCC cases. EAC cases had a higher BMI than the subcohort.

\section{Baseline vegetables and fruits consumption}

Table 8.2 presents baseline intakes of the individual vegetables and fruits that were listed in the questionnaire. Because the vegetables and fruits had a right-skewed distribution, we present medians and interquartile ranges. The vegetables and fruits are ranked by increasing percentage of nonusers in the subcohort. The median daily consumption of the subcohort was 179 grams of vegetables and 157 grams of fruits. The most frequently eaten vegetables in our population were string beans, cauliflower, and lettuce. When we look at the median daily consumption among users, the vegetables eaten in the largest amounts were tomatoes, onions, and string beans. The fruits eaten in the largest amounts were apples and pears, and oranges. 


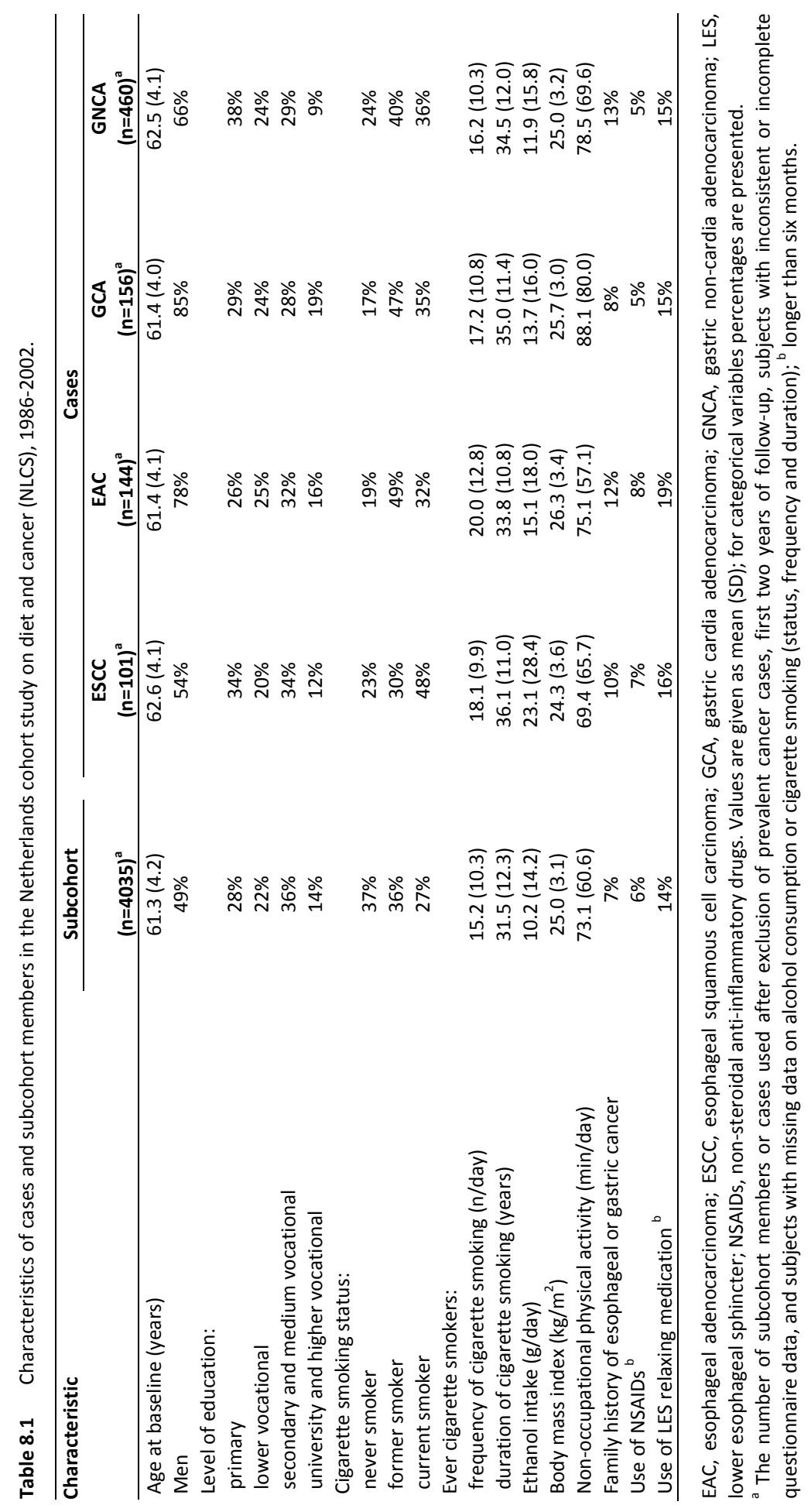


Table 8.2 Vegetables and fruit consumption of the subcohort members in the Netherlands Cohort Study on diet and cancer (NLCS), 1986-2002.

\begin{tabular}{|c|c|c|c|}
\hline \multirow[t]{2}{*}{ Food group or food item } & \multirow{2}{*}{$\begin{array}{c}\text { Nonusers } \\
\%\end{array}$} & \multicolumn{2}{|c|}{ Users: daily intake (g) } \\
\hline & & median & (P25-P75) \\
\hline Total vegetables consumption $(n=3827)^{a}$ & 0 & 179 & $(137-229)$ \\
\hline String/French beans & 2 & 17 & $(10-25)$ \\
\hline Cauliflower & 7 & 13 & $(8-20)$ \\
\hline Lettuce & 9 & 7 & $(4-11)$ \\
\hline Carrots, cooked & 12 & 8 & $(4-13)$ \\
\hline Endive, cooked & 14 & 12 & $(7-19)$ \\
\hline Brussels sprouts & 15 & 8 & $(5-12)$ \\
\hline Sauerkraut & 16 & 6 & $(3-9)$ \\
\hline Tomatoes & 18 & 24 & $(14-33)$ \\
\hline Onion & 20 & 22 & $(11-33)$ \\
\hline Spinach & 20 & 10 & $(6-16)$ \\
\hline Beetroot & 25 & 9 & $(5-14)$ \\
\hline Kale & 25 & 4 & $(2-5)$ \\
\hline Cabbage & 29 & 8 & $(4-13)$ \\
\hline Leek & 32 & 10 & $(5-17)$ \\
\hline Dried pulses ${ }^{b}$ & 39 & 11 & $(4-17)$ \\
\hline Mushrooms & 39 & 4 & $(4-9)$ \\
\hline Broad beans & 43 & 6 & $(3-11)$ \\
\hline Sweet peppers & 47 & 4 & $(3-6)$ \\
\hline Endive, raw & 56 & 4 & $(2-7)$ \\
\hline Rhubarb & 59 & 3 & $(1-6)$ \\
\hline Carrots, raw & 67 & 5 & $(2-10)$ \\
\hline Gherkins & 70 & 3 & $(1-6)$ \\
\hline Vegetable juices $^{\text {b }}$ & 90 & 12 & $(5-25)$ \\
\hline Total fruit consumption $(n=4035)^{c}$ & 1 & 157 & $(96-236)$ \\
\hline Apples and pears & 13 & 80 & $(45-116)$ \\
\hline Strawberries & 14 & 7 & $(4-11)$ \\
\hline Oranges and fresh orange juice & 16 & 42 & $(15-83)$ \\
\hline Grapes & 37 & 3 & $(1-8)$ \\
\hline Mandarins & 41 & 4 & $(2-8)$ \\
\hline Bananas & 47 & 11 & $(4-19)$ \\
\hline Processed fruit juices ${ }^{b}$ & 51 & 23 & $(12-63)$ \\
\hline Grapefruits and fresh grapefruit juice & 70 & 16 & $(7-40)$ \\
\hline Raisins and other dried fruits & 75 & 1 & $(1-3)$ \\
\hline
\end{tabular}

${ }^{a}$ The number of subcohort members used after exclusion of prevalent cancer cases, first two years of followup, subjects with inconsistent or incomplete questionnaire data, or inconsistent vegetable data, and subjects with missing data on alcohol consumption or cigarette smoking (status, frequency and duration); ${ }^{\text {b }}$ Dried pulses and vegetable juices are not included in total vegetables consumption. Processed fruit juices are not included in total fruits consumption; ${ }^{\mathrm{C}}$ The number of subcohort members used after exclusion of prevalent cancer cases, first two years of follow-up, subjects with inconsistent or incomplete questionnaire data, and subjects with missing data on alcohol consumption or cigarette smoking (status, frequency and duration).

\section{Main analyses}

Results of the multivariable Cox regression analyses on total vegetables and fruits and subgroups of vegetables and fruits are shown in Table 8.3. The results from the ageand sex-adjusted analyses are presented in Supplementary Table 8.1, due to limited space. These results were comparable with the multivariable adjusted results. 
For total vegetables consumption we observed that subjects in quintiles 2 to 5 had lower risks of esophageal and gastric cancers, when compared with quintile 1 . The clearest inverse association was observed for EAC (RR for Q5 vs. Q1: 0.59, 95\% Cl 0.331.06), while the association was weakest for GNCA (RR for Q5 vs. Q1: $0.90,95 \% \mathrm{Cl}$ 0.64-1.26). RRs or trends were not statistically significant for any tumor type.

For specific groups of vegetables, we can see that the majority of the RRs observed were below unity. These inverse associations, however, mostly did not reach statistical significance. No clear associations were observed for cooked vegetables, while for raw vegetables we found a significant inverse trend $(P=0.05)$ for EAC risk (RR per $25 \mathrm{~g}$ /day increment: $0.80,95 \% \mathrm{Cl} 0.68-0.98)$. Decreased risks associated with raw vegetables were also observed for ESCC and GCA, but these were not statistically significant. A quite strong, but not statistically significant, inverse association was observed between consumption of legumes and pulses and ESCC risk, while for GNCA this association was weaker, and no apparent associations were present for EAC and GCA. Consumption of Brassica vegetables was associated with a statistically significantly decreased risk of GCA (RR per $25 \mathrm{~g} /$ day: $0.72,95 \% \mathrm{Cl} 0.54-0.95$, ptrend=0.01), and slightly decreased risk of EAC (RR per $25 \mathrm{~g} /$ day: $0.85,95 \% \mathrm{Cl} 0.49$ 1.48), while Brassicas were not clearly associated with risk of ESCC or GNCA. No clear associations were seen for consumption of Allium vegetables or cooked leafy vegetables and any tumor type, while for raw leafy vegetables inverse associations were seen for ESCC and EAC.

Also shown in Table 8.3 are RRs for consumption of total fruits and citrus fruits. Total fruits consumption was nonsignificantly inversely associated with ESCC risk (RR for Q5 vs. Q1: $0.62,95 \% \mathrm{Cl} 0.32-1.22$ ), while RRs only slightly below unity were seen for EAC, GCA, and GNCA. Citrus fruits were quite consistently associated with a decreased risk of all tumors: for ESCC, the RR for Q5 vs. Q1 was 0.54 (95\% Cl 0.27 1.07), for EAC this RR was 0.55 (95\% Cl 0.31-0.98), for GCA 0.38 (95\% Cl 0.21-0.69), and finally for GNCA this RR was 0.80 ( $95 \% \mathrm{Cl}, 0.56-1.15)$.

In Table 8.4, we present multivariable adjusted results for the individual vegetable and fruit items that were most frequently consumed in our cohort. Again, the age- and sex-adjusted results can be found in a supplement (i.e. Supplementary Table 8.2). None of the individual vegetable or fruit items was statistically significantly associated with risk of ESCC or EAC. For GCA, we observed inverse associations for cauliflower (RR per $25 \mathrm{~g}$ /day increment: $0.58,95 \% \mathrm{Cl} 0.35-0.96)$, and oranges and fresh orange juices (RR per $25 \mathrm{~g} /$ day: $0.86,95 \% \mathrm{Cl} 0.77-0.95)$. Positive associations were observed for tomato consumption and GNCA risk (RR per $25 \mathrm{~g} /$ day: 1.13, 95\% $\mathrm{Cl} 1.00-1.28$ ), for spinach consumption and GCA risk (RR per $25 \mathrm{~g} /$ day: 1.77, 95\% $\mathrm{Cl} 1.04-3.02$ ), and for apples and pears consumption and GCA risk (RR per 25 g/day: 1.05, 95\% Cl 1.00-1.09). 


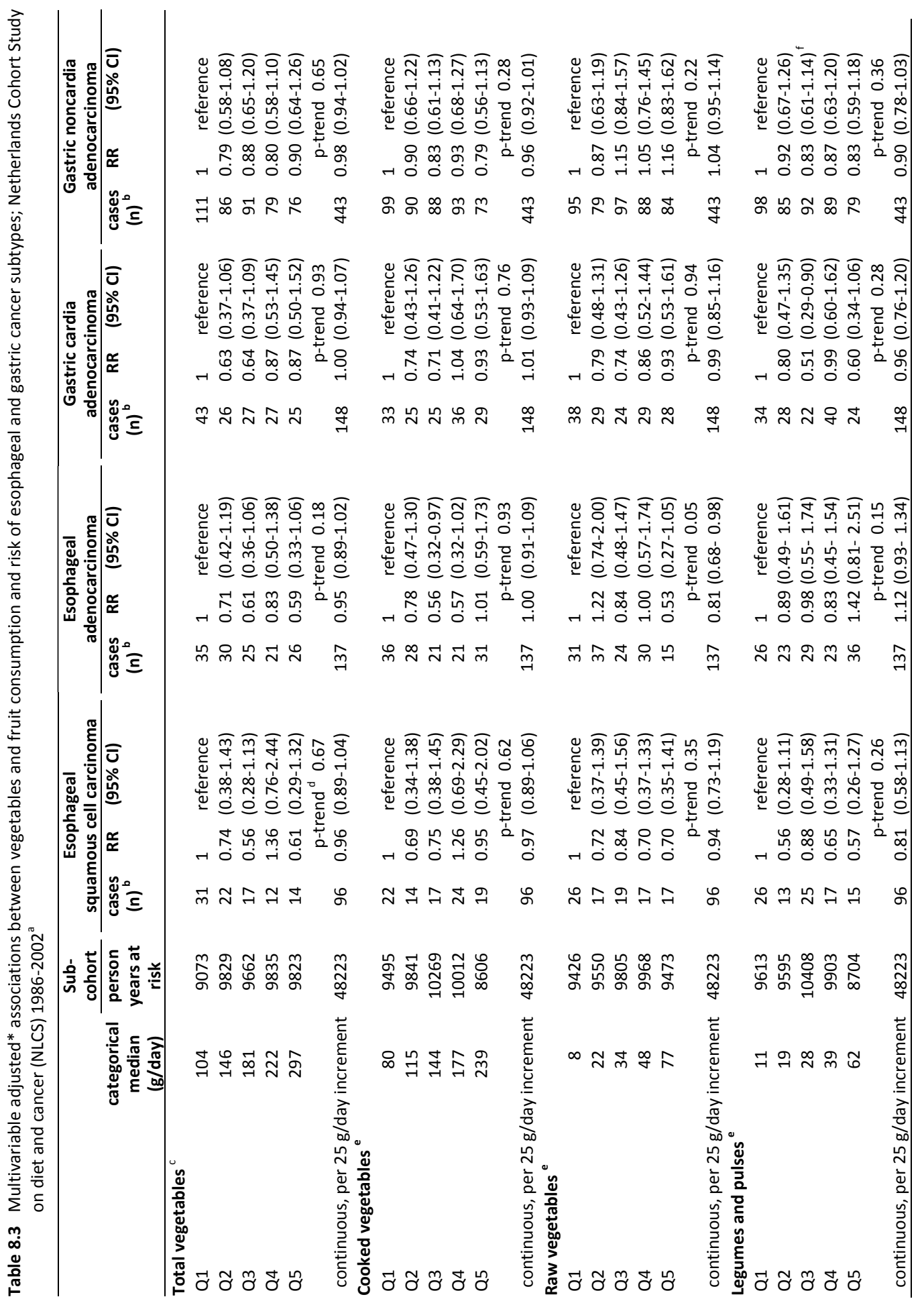




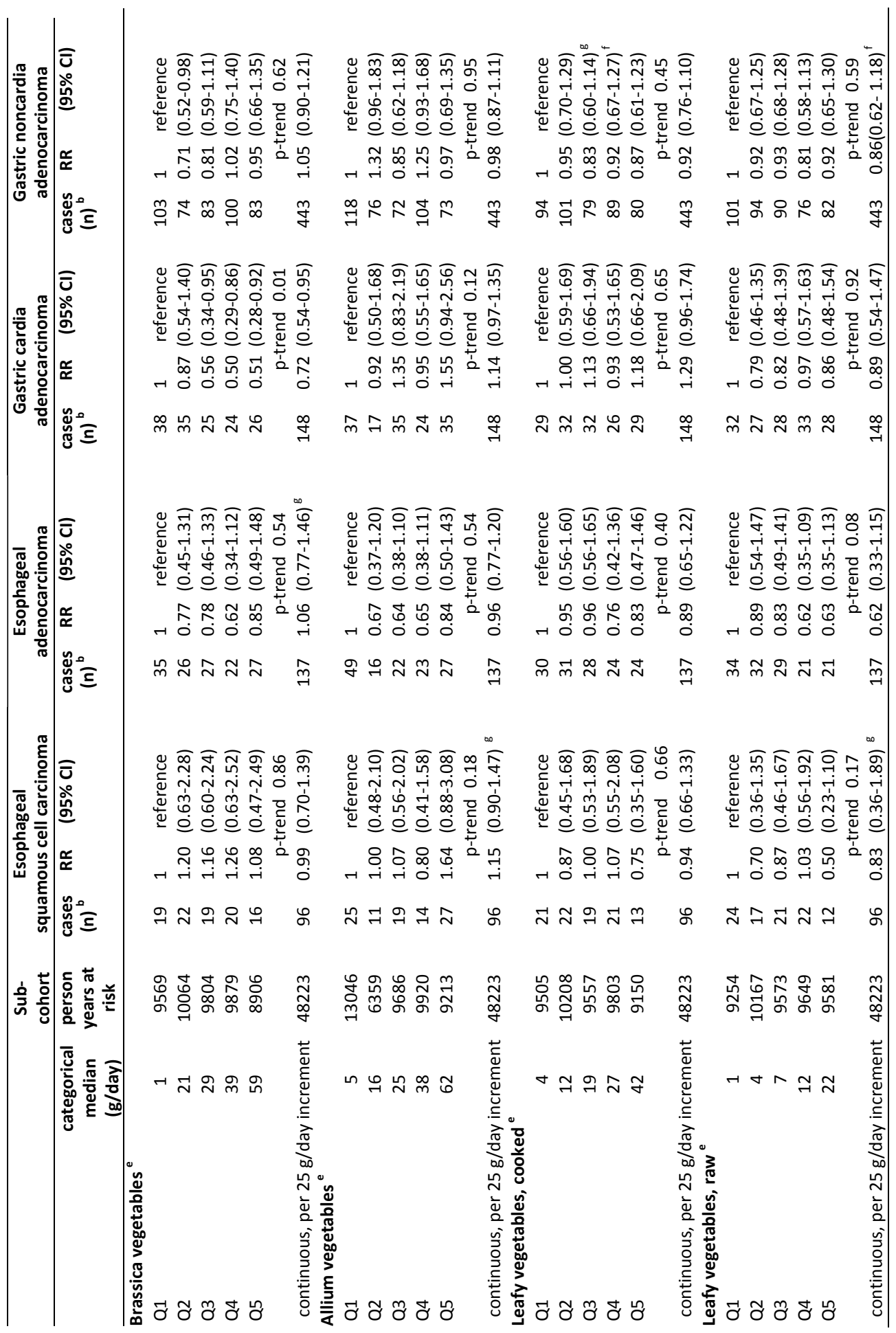




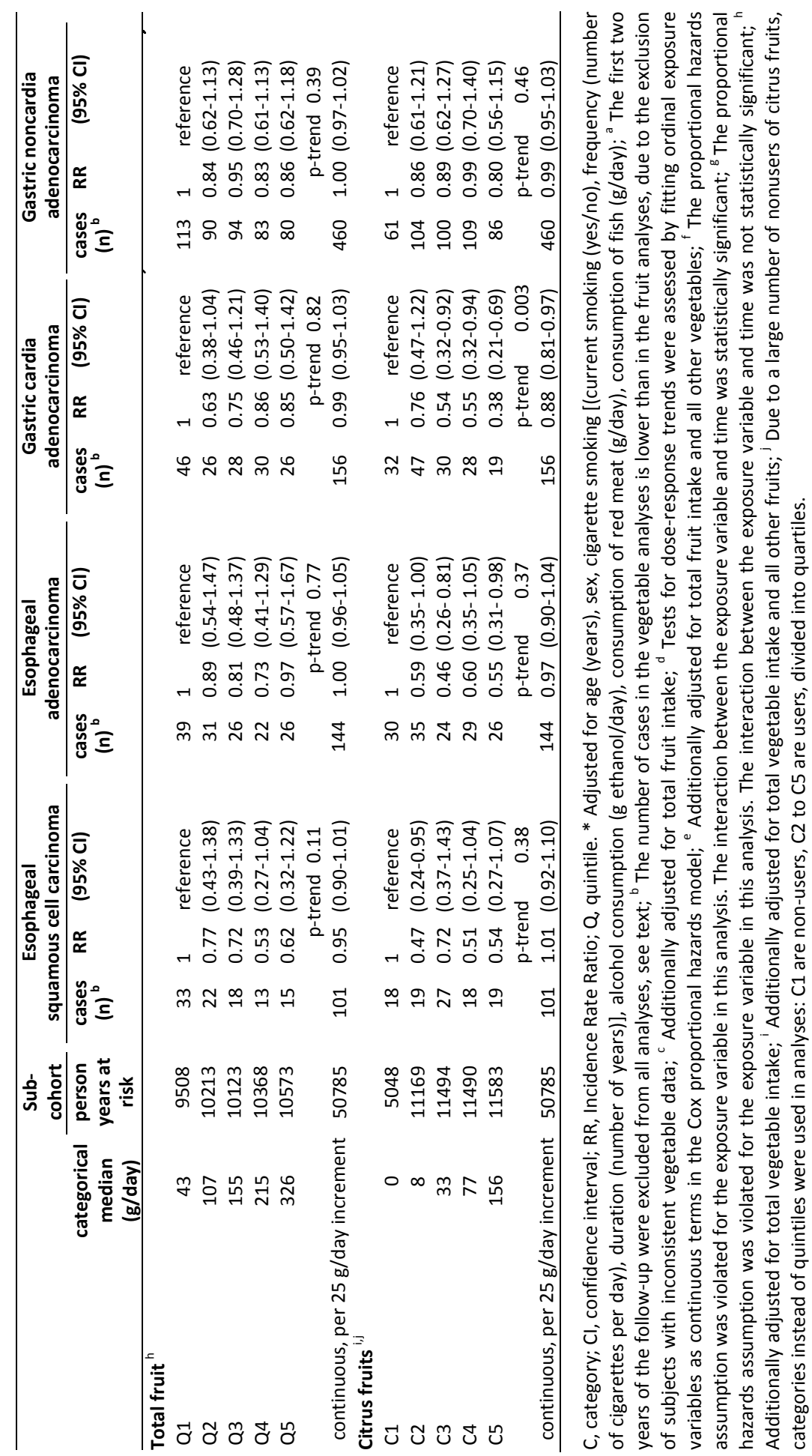




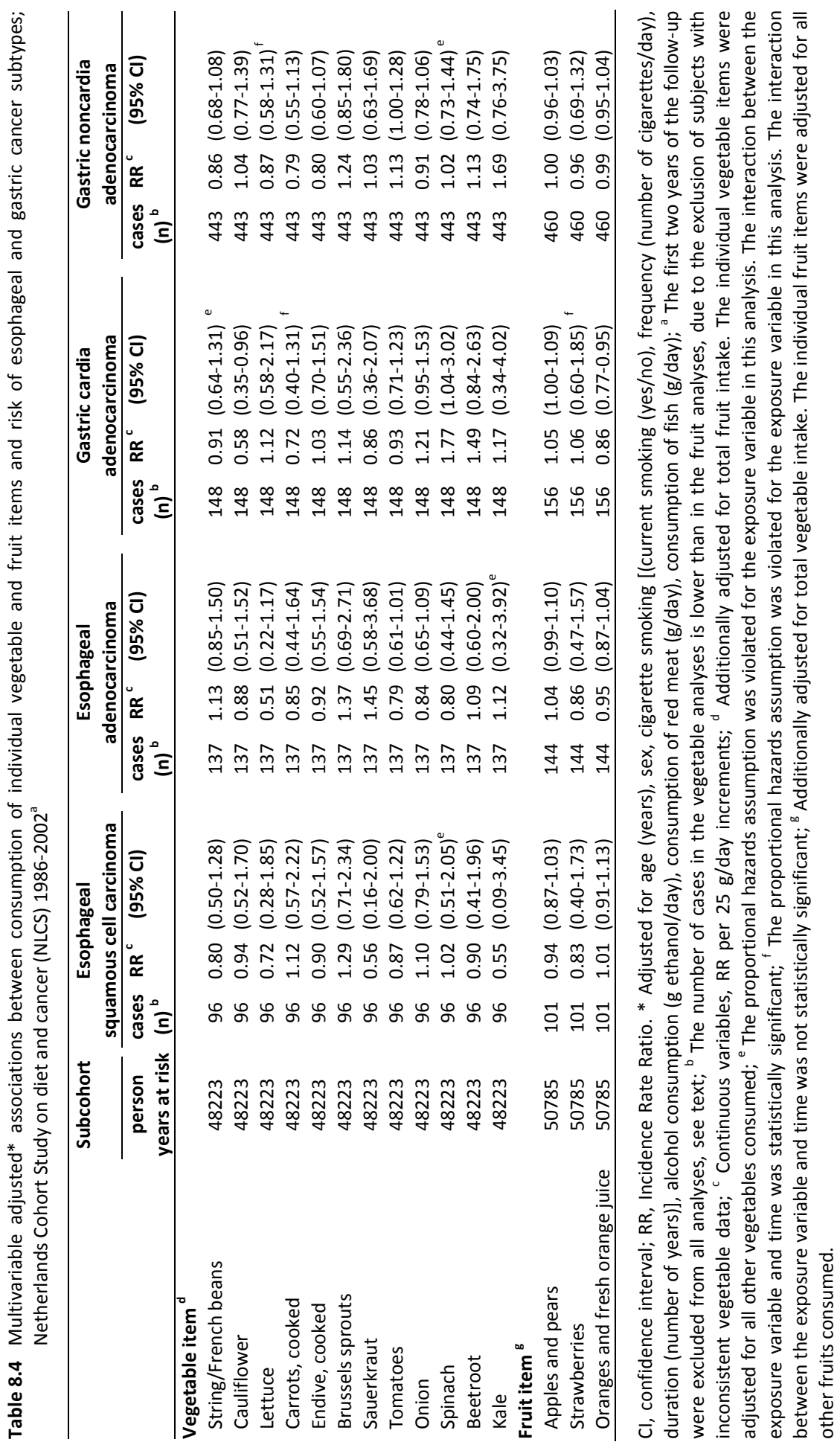




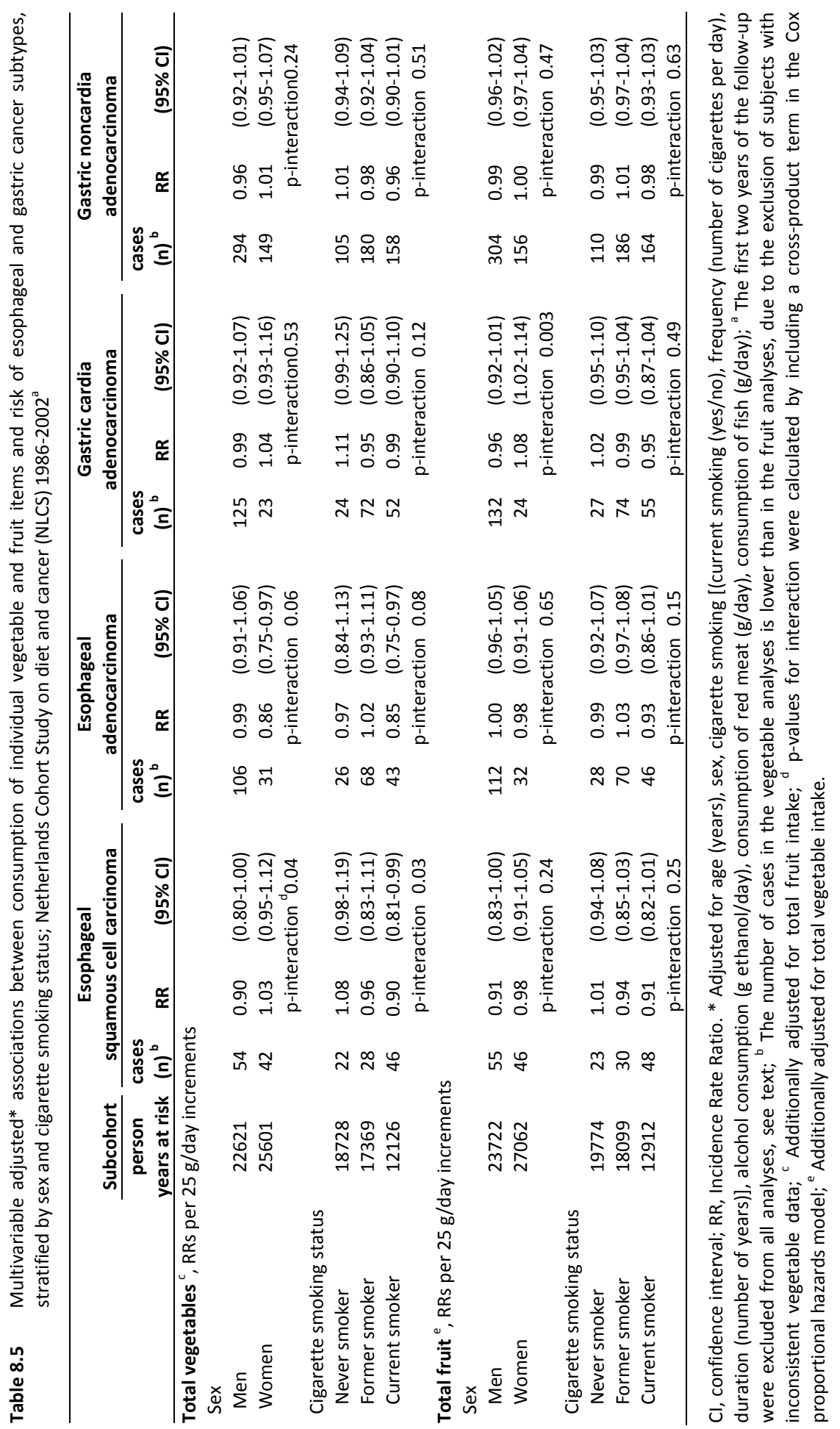




\section{Interaction analyses}

Results of analyses stratified by sex and smoking status are presented in Table 8.5 (multivariable adjusted) and Supplemental Table 8.3 (age- and sex-adjusted). Adjustment for confounding variables did not change the RRs.

Total vegetables consumption was associated with risk of ESCC only in men (RR per $25 \mathrm{~g}$ /day increment: $0.90,95 \% \mathrm{Cl} 0.80-1.00$, p-interaction=0.04), whereas for EAC an inverse association was observed in women only (RR per $25 \mathrm{~g} /$ day: $0.86,95 \% \mathrm{Cl}$ 0.75-0.97, p-interaction=0.06). For GCA and GNCA, no clear sex differences were observed. In current cigarette smokers only, we found significant inverse associations between vegetables consumption and risk of ESCC (RR per $25 \mathrm{~g} /$ day: $0.90,95 \% \mathrm{Cl}$ 0.81-0.99, p-interaction=0.03) and EAC (RR per $25 \mathrm{~g} /$ day: $0.85,95 \% \mathrm{Cl} 0.75-0.97$, $\mathrm{p}$-interaction=0.08). We found no interaction between vegetables consumption and smoking for GCA and GNCA.

An inverse association between consumption of fruits and ESCC was present in women (RR per $25 \mathrm{~g} /$ day: $0.91,95 \% \mathrm{Cl} 0.83-1.00$ ), but the interaction with sex was not statistically significant ( $p$-interaction=0.24). For women, a positive association between fruits consumption and GCA risk was observed (RR per $25 \mathrm{~g} /$ day: 1.08, 95\% Cl $1.02-1.14, p$-interaction $=0.003$ ). No significant interactions between smoking status and fruits consumption were observed, although for ESCC, EAC, and GCA the risk estimates were further below one for current smokers than for never and former smokers.

\section{DISCUSSION}

In the Netherlands Cohort Study, we found mostly inverse associations between vegetables and fruits consumption and risk of esophageal and gastric cancer subtypes. Most RRs were not statistically significant. However, our extensive questions on specific vegetables and fruits allowed us to study these foods in more detail. We identified significant inverse associations for raw vegetables and EAC risk, Brassicas and GCA risk, and citrus fruits and EAC and GCA risk. Associations were generally stronger inverse in current smokers, but the interaction tests were not always statistically significant.

The current evidence from case-control and cohort studies does not clearly point to any specific group of vegetables that is responsible for the observed inverse associations. For ESCC, significant inverse associations have been observed with Cruciferous vegetables in one cohort study, ${ }^{15}$ and with cooked vegetables, ${ }^{35}$ raw vegetables, ${ }^{7,36}$ tomatoes $^{37}$ and spinach $^{37}$ in case-control studies. The few studies on EAC found significant inverse associations with raw and cooked spinach ${ }^{14}$, dark green vegetables, ${ }^{7}$ dark yellow vegetables, ${ }^{7,38}$ and raw vegetables. ${ }^{7}$ Only one study found significant inverse associations with GCA; for dark green vegetables and beetroot. ${ }^{39}$ 
Beetroot, carrots, Allium vegetables, ${ }^{39}$ dark green, light green, and yellow vegetables ${ }^{40}$ have shown significant inverse associations with GNCA in two studies. This diversity of vegetables for which significant inverse associations have been observed may have to do with the fact that vegetable consumption habits differ between continents, countries, and populations with respect to the amount and types eaten.

For fruit groups, the evidence is more consistent than for vegetable groups. Citrus fruits have been shown to be inversely associated with risk of ESCC, ${ }^{14,35,36} \mathrm{EAC}^{38} \mathrm{GCA},{ }^{18}$ and GNCA $^{18,39}$ by a considerable number of studies. Some other fruits that showed significantly lower risks were Rosaceae for $\mathrm{ESCC}^{14}{ }^{14}$ fruit juices for GCA and GNCA, ${ }^{39}$ and apples and pears for GNCA. ${ }^{39}$

Our data suggest that for current smokers, decreased risks of EAC and ESCC associated with vegetables and fruits consumption were more apparent than for never and former smokers. This finding is consistent with three case-control studies, ${ }^{6,8,36}$ which found inverse associations between vegetables consumption and ESCC only ${ }^{6}$ or most strongly ${ }^{8,36}$ in smokers. Cohort studies found no interactions for ESCC, ${ }^{14,15}$ EAC, $^{14}$ GCA, ${ }^{19}$ or GNCA. ${ }^{19}$ Smoking causes oxidative stress and DNA damage in the body. ${ }^{41}$ Substances in vegetables and fruits that have anticarcinogenic properties (e.g. vitamin C, carotenoids, flavonoids, folate) could counteract these effects. Smokers could therefore benefit most from consuming vegetables and fruits.

Case-control studies have generally found stronger and more often statistically significant associations compared with cohort studies. An explanation may be reversed causation. Individuals who are diagnosed with gastrointestinal cancer may already have experienced intestinal complaints quite some time before the diagnosis. This may have caused them to change their dietary habits, including consumption of vegetables and fruits, leading to biased measurement of the diet as it was before the onset of the disease. ${ }^{13}$ Asking about dietary habits long before the diagnosis will not solve this problem, as reporting past diet is influenced by current diet. ${ }^{42}$ Cohort studies have fewer problems with reversed causation thanks to their prospective nature. Additionally, we minimized the influence of reversed causation on our results by excluding early cases. On the other hand, measurement of vegetables and fruits in cohort studies is not perfect either. It is very difficult for persons to accurately report their intake, specifically of vegetables. This is reflected in the relatively low correlations in validation studies. ${ }^{43} \mathrm{~A}$ consequence of these low correlations is attenuation of risk estimates. Thus, the true associations may have been stronger than we observed, strengthening our conclusion of protective effects of some vegetables and fruits on esophageal and gastric cancers. Besides the attenuation of RRs, another explanation for the nonsignificance of the results is the limited power. Even though one strength of the NLCS is its large size, the number of ESCC, EAC, and GCA cases is limited. The large size of the study, combined with a long follow-up did allow for separate analysis of ESCC vs. EAC and GCA vs. GNCA. A strength of our study was the ability to check for confounding by several important risk factors (see methods), and to make adjustments if necessary. One factor that we did not measure and may have confounded the 
associations with GNCA in particular is infection with Helicobacter pylori, which is a risk factor for GNCA and may protect against GCA. We estimated that half of our study population might have been infected. ${ }^{44,45}$ It is not clear whether adjustment for Helicobacter pylori infection would have changed our results. One study that made this adjustment, ${ }^{46}$ found no effect on the estimates. Two studies that looked into interaction with Helicobacter pylori found no evidence of this. ${ }^{18,46}$

In conclusion, we observed significant inverse associations between some specific vegetables and fruits and risk of ESCC, EAC, GCA, and GNCA. Most other observed associations were inverse, but not statistically significant. Consumption of fruits and vegetables may specifically help protect smokers from developing ESCC, EAC, and GCA. 


\section{APPENDIX}

\section{Composition of vegetable and fruit groups}

\begin{tabular}{l} 
Food group \\
\hline Total vegetables \\
Cooked vegetables \\
\\
Raw vegetables \\
Brassica vegetables \\
Leafy vegetables, cooked \\
Leafy vegetables, raw \\
Legumes and pulses \\
Allium vegetables \\
Total fruit
\end{tabular}

Citrus fruits

\section{Composition}

Cooked vegetables plus raw vegetables

Beetroot, broad beans, Brussels sprouts, cauliflower, cabbage (white/green), cooked carrots, cooked endive, kale, leek, mushrooms, onions, rhubarb, sauerkraut, spinach, string beans, sweet peppers, and other cooked vegetables originating from an open-ended question on frequently consumed items not listed in the questionnaire.

Gherkins, lettuce, raw carrots, raw endive, tomatoes, and other raw vegetables originating from an open ended question on frequently consumed items not listed in the questionnaire Brussels sprouts, cabbage (white/green), cauliflower, kale Cooked endive, spinach Lettuce, raw endive Broad beans, dried pulses, string beans Leek, onions Apples/pears, bananas, grapefruits and fresh grapefruit juice, grapes, mandarins, oranges and fresh orange juice, raisins/other dried fruit, strawberries, and other fruits originating from an open ended question on frequently consumed items not listed in the questionnaire.

Fresh lemon juice, grapefruits and fresh grapefruit juice, mandarins, oranges and fresh orange juice 


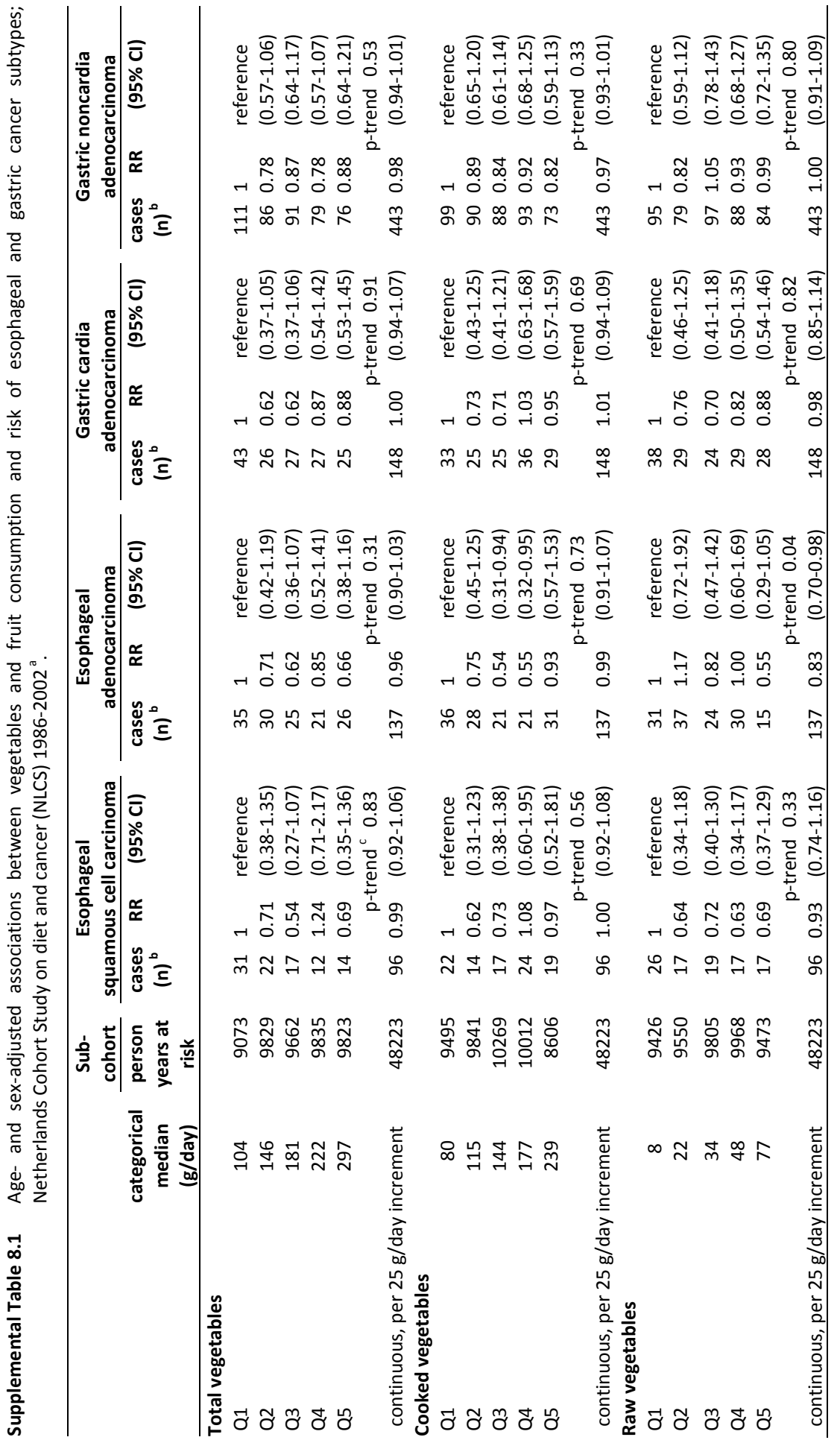




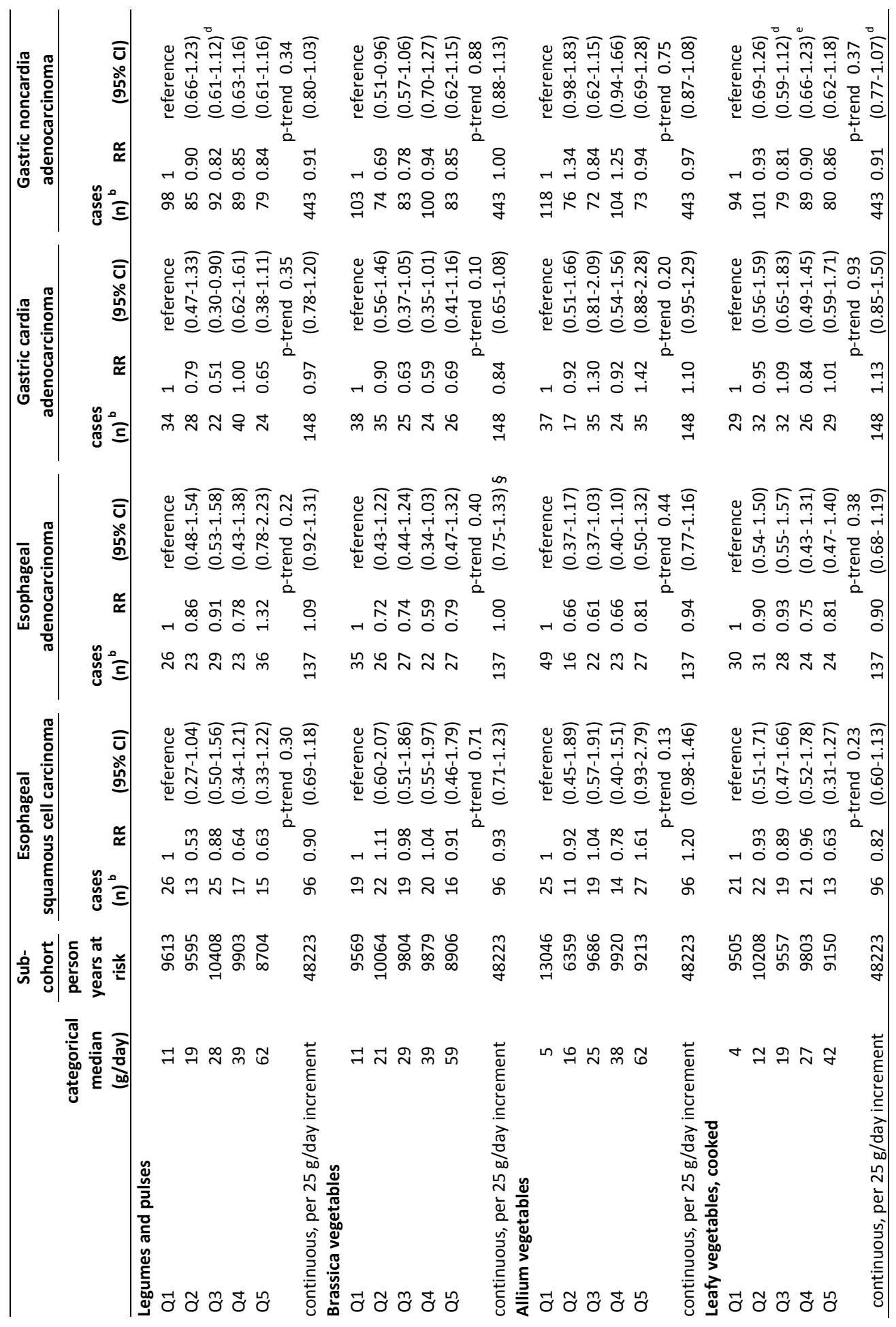




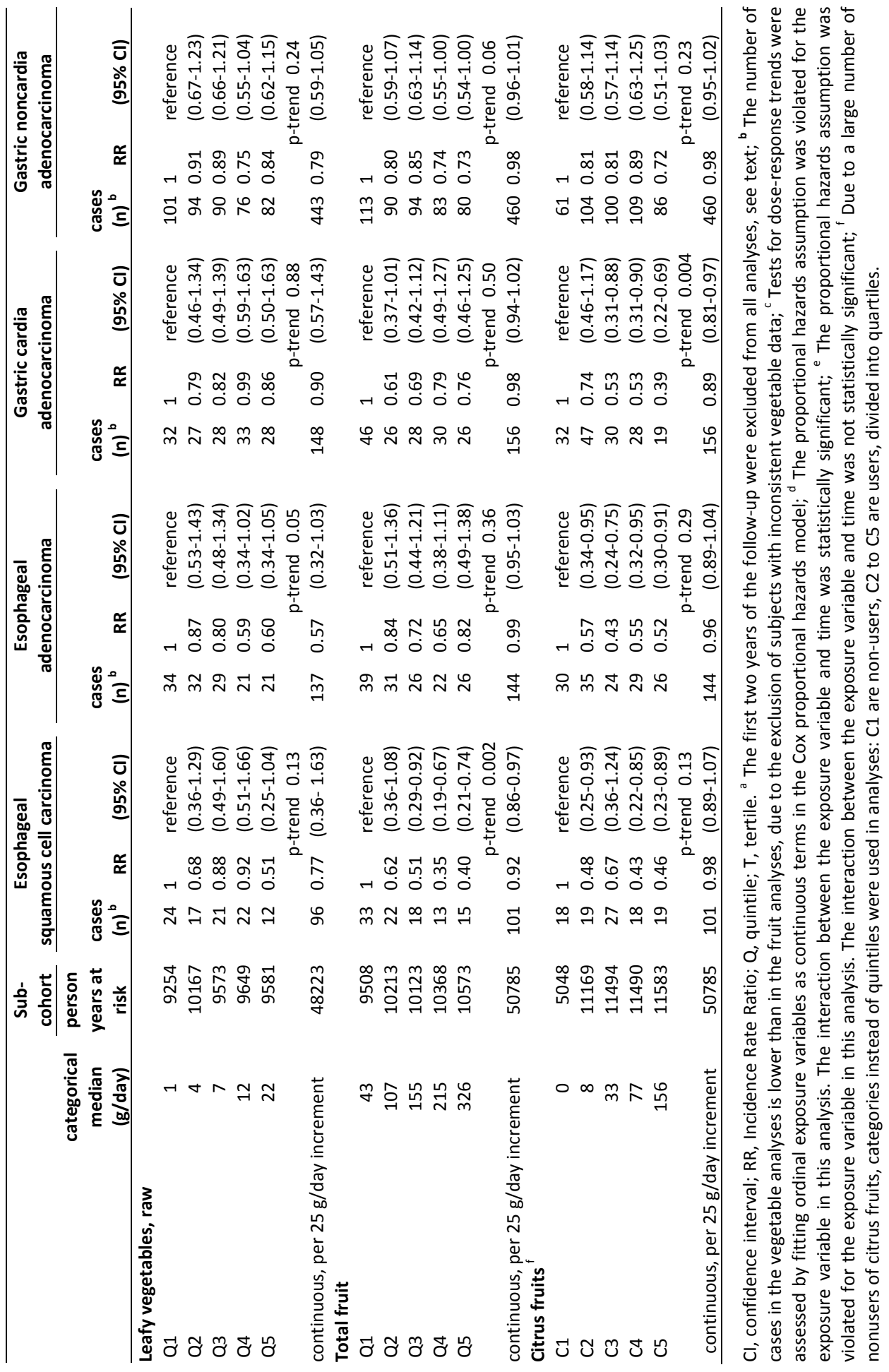




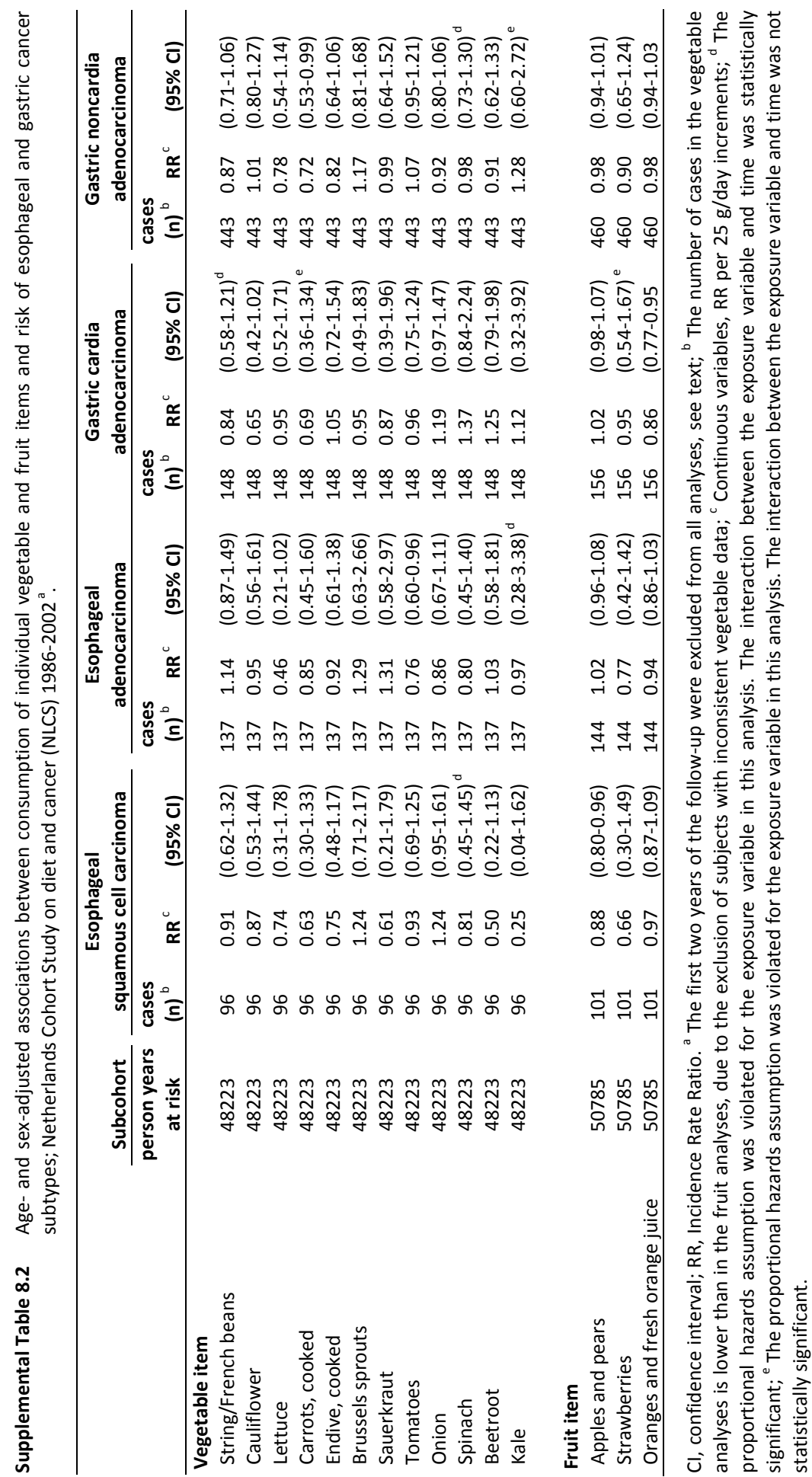




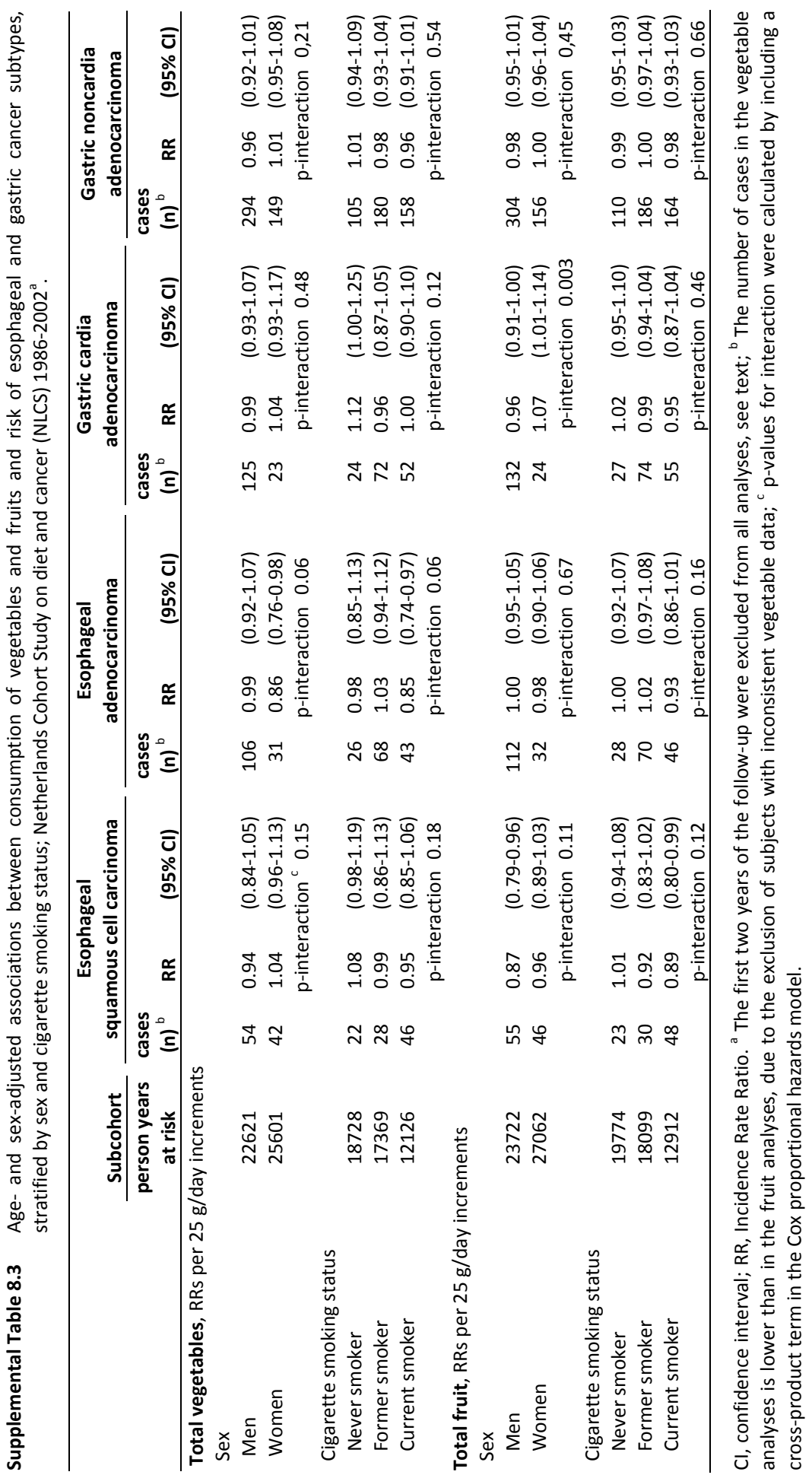




\section{REFERENCES}

1. McCullough ML, Giovannucci EL. Diet and cancer prevention. Oncogene 2004;23:6349-6364.

2. World Cancer Research Fund, American Institute for Cancer Research. Food, nutrition, physical activity and the prevention of cancer: a global perspective. AICR, 2007.

3. Steevens J, Botterweck AA, Dirx MJ, van den Brandt PA, Schouten LJ. Trends in incidence of oesophageal and stomach cancer subtypes in Europe. Eur J Gastroenterol Hepatol 2010;22:669-678.

4. Kamangar F, Chow WH, Abnet CC, Dawsey SM. Environmental causes of esophageal cancer. Gastroenterol Clin North Am 2009;38:27-57, vii.

5. Forman D, Burley VJ. Gastric cancer: global pattern of the disease and an overview of environmental risk factors. Best Pract Res Clin Gastroenterol 2006;20:633-649.

6. Yang CX, Wang HY, Wang ZM, Du HZ, Tao DM, Mu XY, Chen HG, Lei Y, Matsuo K, Tajima K. Risk factors for esophageal cancer: a case-control study in South-western China. Asian Pac J Cancer Prev 2005;6:48-53.

7. Navarro Silvera SA, Mayne ST, Risch H, Gammon MD, Vaughan TL, Chow WH, Dubrow R, Schoenberg $J B$, Stanford JL, West AB, Rotterdam H, Blot WJ, Fraumeni JF, Jr. Food group intake and risk of subtypes of esophageal and gastric cancer. Int J Cancer 2008;123:852-860.

8. Terry $\mathrm{P}$, Lagergren J, Hansen $\mathrm{H}$, Wolk A, Nyren O. Fruit and vegetable consumption in the prevention of oesophageal and cardia cancers. Eur J Cancer Prev 2001;10:365-369.

9. Hung HC, Huang MC, Lee JM, Wu DC, Hsu HK, Wu MT. Association between diet and esophageal cancer in Taiwan. J Gastroenterol Hepatol 2004;19:632-637.

10. Anderson LA, Watson RG, Murphy SJ, Johnston BT, Comber H, Mc Guigan J, Reynolds JV, Murray L. Risk factors for Barrett's oesophagus and oesophageal adenocarcinoma: results from the FINBAR study. World J Gastroenterol 2007;13:1585-1594.

11. Cheng KK, Sharp L, McKinney PA, Logan RF, Chilvers CE, Cook-Mozaffari P, Ahmed A, Day NE. A casecontrol study of oesophageal adenocarcinoma in women: a preventable disease. $\mathrm{Br} \mathrm{J}$ Cancer 2000;83:127-132.

12. Lunet N, Valbuena C, Vieira AL, Lopes C, Lopes C, David L, Carneiro F, Barros H. Fruit and vegetable consumption and gastric cancer by location and histological type: case-control and meta-analysis. European Journal of Cancer Prevention 2007;16:312-327.

13. Botterweck AA, van den Brandt PA, Goldbohm RA. A prospective cohort study on vegetable and fruit consumption and stomach cancer risk in The Netherlands. Am J Epidemiol 1998;148:842-853.

14. Freedman ND, Park Y, Subar AF, Hollenbeck AR, Leitzmann MF, Schatzkin A, Abnet CC. Fruit and vegetable intake and esophageal cancer in a large prospective cohort study. Int J Cancer 2007;121:2753-2760.

15. Yamaji T, Inoue M, Sasazuki S, Iwasaki M, Kurahashi N, Shimazu T, Tsugane S. Fruit and vegetable consumption and squamous cell carcinoma of the esophagus in Japan: the JPHC study. Int J Cancer 2008;123:1935-1940.

16. Tran GD, Sun XD, Abnet CC, Fan JH, Dawsey SM, Dong ZW, Mark SD, Qiao YL, Taylor PR. Prospective study of risk factors for esophageal and gastric cancers in the Linxian general population trial cohort in China. Int J Cancer 2005;113:456-463.

17. Guo W, Blot WJ, Li JY, Taylor PR, Liu BQ, Wang W, Wu YP, Zheng W, Dawsey SM, Li B, et al. A nested case-control study of oesophageal and stomach cancers in the Linxian nutrition intervention trial. Int J Epidemiol 1994;23:444-450.

18. Gonzalez CA, Pera G, Agudo A, Bueno-De-Mesquita HB, Ceroti M, Boeing H, Schulz M, Del Giudice G, Plebani M, Carneiro F, Berrino F, Sacerdotde C, Tumino R, Panico S, Berglund G, Siman H, Hallmans G, Stenling R, Martinez C, Dorronsoro M, Barricarte A, Navarro C, Quiros JR, Allen N, Key TJ, Bingham S, Day NE, Linseisen J, Nagel G, Overvad K, Jensen MK, Olsen A, Tjonneland A, Buchner FL, Peeters PH, Numans ME, Clavel-Chapelon F, Boutron-Ruault MC, Roukos D, Trichopolou A, Psaltopoulou T, Lund E, Casagrande C, Slimani N, Jenab M, Riboli E. Fruit and vegetable intake and the risk of stomach and oesophagus adenocarcinoma in the European Prospective Investigation into Cancer and Nutrition (EPIC-EURGAST). International Journal of Cancer 2006;118:2559-2566. 
19. Freedman ND, Subar AF, Hollenbeck AR, Leitzmann MF, Schatzkin A, Abnet CC. Fruit and vegetable intake and gastric cancer risk in a large United States prospective cohort study. Cancer Causes Control 2008;19:459-467.

20. Nouraie M, Pietinen P, Kamangar F, Dawsey SM, Abnet CC, Albanes D, Virtamo J, Taylor PR. Fruits, vegetables, and antioxidants and risk of gastric cancer among male smokers. Cancer Epidemiol Biomarkers Prev 2005;14:2087-2092.

21. Kobayashi M, Tsubono Y, Sasazuki S, Sasaki S, Tsugane S. Vegetables, fruit and risk of gastric cancer in Japan: a 10-year follow-up of the JPHC Study Cohort I. Int J Cancer 2002;102:39-44.

22. Dorant E, van den Brandt PA, Goldbohm RA, Sturmans F. Consumption of onions and a reduced risk of stomach carcinoma. Gastroenterology 1996;110:12-20.

23. van den Brandt PA, Goldbohm RA, van 't Veer P, Volovics A, Hermus RJ, Sturmans F. A large-scale prospective cohort study on diet and cancer in The Netherlands. J Clin Epidemiol 1990;43:285-295.

24. Barlow WE. Robust variance estimation for the case-cohort design. Biometrics 1994;50:1064-1072.

25. Barlow WE, Ichikawa L, Rosner D, Izumi S. Analysis of case-cohort designs. J Clin Epidemiol 1999;52:1165-1172.

26. van den Brandt PA, Schouten LJ, Goldbohm RA, Dorant E, Hunen PM. Development of a record linkage protocol for use in the Dutch Cancer Registry for Epidemiological Research. Int J Epidemiol 1990;19:553-558.

27. Casparie M, Tiebosch AT, Burger G, Blauwgeers H, van de Pol A, van Krieken JH, Meijer GA. Pathology databanking and biobanking in The Netherlands, a central role for PALGA, the nationwide histopathology and cytopathology data network and archive. Cell Oncol 2007;29:19-24.

28. Goldbohm RA, van den Brandt PA, Dorant E. Estimation of the coverage of Dutch municipalities by cancer registries and PALGA based on hospital discharge data. Tijdschr Soc Gezondheidsz 1994;72:8084.

29. Parkin DM, Shanmugaratnam K, Sobin L, Ferlay J, Whelan SL. Histological Groups for comparative studies. IARC Technical reports. Volume 31. Lyon: International Agency for Research on Cancer, 1998.

30. Goldbohm RA, van den Brandt PA, Brants HA, van't Veer P, Al M, Sturmans F, Hermus RJ. Validation of a dietary questionnaire used in a large-scale prospective cohort study on diet and cancer. Eur J Clin Nutr 1994;48:253-265.

31. Merry AH, Schouten $\amalg$, Goldbohm RA, van den Brandt PA. Body mass index, height and risk of adenocarcinoma of the oesophagus and gastric cardia: a prospective cohort study. Gut 2007;56:15031511.

32. Lagergren J, Bergstrom R, Adami HO, Nyren O. Association between medications that relax the lower esophageal sphincter and risk for esophageal adenocarcinoma. Ann Intern Med 2000;133:165-175.

33. Cox DR. Regression models and life-tables. J Roy Statistical Society 1972;34:187-220.

34. Schoenfeld D. Partial residuals for the proportional hazards regression model. Biometrica 1982;69:239241.

35. De Stefani E, Boffetta P, Deneo-Pellegrini H, Ronco AL, Correa P, Mendilaharsu M. The role of vegetable and fruit consumption in the aetiology of squamous cell carcinoma of the oesophagus: a case-control study in Uruguay. Int J Cancer 2005;116:130-135.

36. Bosetti C, La Vecchia C, Talamini R, Simonato L, Zambon P, Negri E, Trichopoulos D, Lagiou P, Bardini R, Franceschi S. Food groups and risk of squamous cell esophageal cancer in northern Italy. Int J Cancer 2000;87:289-294.

37. Sapkota A, Hsu CC, Zaridze D, Shangina O, Szeszenia-Dabrowska N, Mates D, Fabianova E, Rudnai P, Janout V, Holcatova I, Brennan P, Boffetta P, Hashibe M. Dietary risk factors for squamous cell carcinoma of the upper aerodigestive tract in central and eastern Europe. Cancer Causes Control 2008;19:1161-1170.

38. Chen H, Ward MH, Graubard BI, Heineman EF, Markin RM, Potischman NA, Russell RM, Weisenburger DD, Tucker KL. Dietary patterns and adenocarcinoma of the esophagus and distal stomach. Am J Clin Nutr 2002;75:137-144.

39. Ekstrom AM, Serafini M, Nyren O, Hansson LE, Ye W, Wolk A. Dietary antioxidant intake and the risk of cardia cancer and noncardia cancer of the intestinal and diffuse types: a population-based case-control study in Sweden. Int J Cancer 2000;87:133-140. 
40. Nomura AM, Hankin JH, Kolonel LN, Wilkens LR, Goodman MT, Stemmermann GN. Case-control study of diet and other risk factors for gastric cancer in Hawaii (United States). Cancer Causes Control 2003;14:547-558.

41. Mena S, Ortega A, Estrela JM. Oxidative stress in environmental-induced carcinogenesis. Mutat Res 2009;674:36-44.

42. Willett WC. Recall of remote diet. In: Willett WC, ed. Monographs in Epidemiology and Biostatistics. Volume 30. Nutritional epidemiology. New York: Oxford Universtiy Press, 1998:148-156.

43. Vainio H, Bianchini F. Fruit and vegetables. IARC Handbooks of Cancer Prevention. Vol. 8. Lyon: IARC Press, 2003.

44. Taylor DN, Blaser MJ. The epidemiology of Helicobacter pylori infection. Epidemiol Rev 1991;13:42-59.

45. Loffeld RJ, Stobberingh E, van Spreeuwel JP, Flendrig JA, Arends JW. The prevalence of antiHelicobacter (Campylobacter) pylori antibodies in patients and healthy blood donors. J Med Microbiol 1990;32:105-109.

46. Machida-Montani A, Sasazuki S, Inoue M, Natsukawa S, Shaura K, Koizumi Y, Kasuga Y, Hanaoka T, Tsugane S. Association of Helicobacter pylori infection and environmental factors in non-cardia gastric cancer in Japan. Gastric Cancer 2004;7:46-53. 


\section{General discussion}


This chapter contains a discussion of the most important findings described in this thesis in relation to other published research. Methodological points related to the thesis topic are also discussed. In addition, strengths and weaknesses of the study design and analyses are considered. Finally, the implications of our findings, and suggestions for future research will be addressed.

\section{MAIN FINDINGS}

In this thesis, we described two studies into lifestyle factors and their association with risk of Barrett's esophagus (BE), using data from the Netherlands Cohort Study on Diet and Cancer (NLCS). We observed that being overweight or obese was a risk factor for $\mathrm{BE}$ in women, but not in men. Cigarette smoking moderately increased the risk of BE in both sexes. No association was observed between consumption of alcohol and risk of BE (Chapter 2). In Chapter 3 we described that toenail selenium status was not associated with the development of BE. However, in one subgroup, namely BE patients that progressed to high-grade dysplasia or esophageal adenocarcinoma (EAC), we did observe an inverse association with toenail selenium status. These findings are summarized in Table 9.1.

When we followed patients who were diagnosed with $\mathrm{BE}$, we found that these patients were at increased risk of not only esophageal cancer, but possibly also other cancers, specifically small intestinal and pancreatic cancer. Overall mortality of BE patients was not increased (Chapter 4).

In Chapter 5, we used data from European cancer registries to study trends in incidence of esophageal and gastric cancers during the 1983-1997 period. Adenocarcinomas of the esophagus and gastric cardia rose in incidence in most countries, the strongest in the UK and Ireland. Incidence of esophageal squamous cell carcinoma (ESCC) rose in women from all countries, and in men from Northern Europe and Slovakia, but declined mostly in men from Southern and Western Europe. In nearly all countries, the incidence of gastric non-cardia adenocarcinomas (GNCA) declined.

In the NLCS, we found that alcohol consumption was related to a strong increase in risk of ESCC, while it was not related to risk of EAC, gastric cardia adenocarcinoma (GCA), and GNCA (Table 9.1). Cigarette smoking clearly increased the risk of all four cancers. Furthermore, combined exposure to alcohol and cigarette smoking was associated with a very strong increase in ESCC risk, compatible with a multiplicative interaction model (Chapter 6). By contrast, a strong inverse association was described for higher toenail selenium status and risk of ESCC. A less strong inverse association was observed with GCA risk, while toenail selenium status was associated with EAC risk only in some groups: women, never smokers, and people with low antioxidant consumption (Chapter 7). Finally, Chapter 8 described the association between consumption of vegetables and fruits and risk of esophageal and gastric cancer subtypes. Associations were generally inverse, and some statistically significant inverse 
associations were found with risk of ESCC, EAC, and GCA for specific vegetables and fruits (Table 9.1). Specifically in smokers, vegetables and fruits consumption was inversely associated with ESCC and EAC risk.

Table 9.1 Main findings of the etiological studies described in this thesis.

\begin{tabular}{lcccccc}
\hline & \multicolumn{9}{c}{ Direction and strength of observed association } & \\
Risk factor & BE & ESCC & EAC & GCA & GNCA & Chapter \\
\hline Overweight & Men: 0 & - & ++ & ++ & - & 2 , Merry et al. ${ }^{1}$ \\
& Women: + & & & & & \\
Cigarette smoking & + & ++ & ++ & + & + & 2,6 \\
Alcohol consumption & 0 & ++ & 0 & 0 & 0 & 2,6 \\
Toenail selenium status & 0 & -- & - & - & Not studied & 3,7 \\
Vegetables consumption & Not studied & - & - & - & 0 & 8 \\
Fruits consumption & Not studied & - & - & - & 0 & 8 \\
\hline
\end{tabular}

++ strong positive association (RRs $\geq 2.0$ ), + positive association, 0 no association (RRs very close to 1 and no dose-response trends), - inverse association, -- strong inverse association (RRs $\leq 0.5$ ).

\section{STRENGTHS OF THE NETHERLANDS COHORT STUDY}

The Netherlands Cohort Study has a prospective cohort study design, which brings several advantages. Prospective cohort studies are less susceptible to information and selection bias compared with case-control studies. The validity of the former study design is therefore usually higher. A second major strength of the prospective character is the possibility to exclude cancer cases who were diagnosed early during follow-up. This exclusion can diminish or eliminate bias caused by reverse causation. Reverse causation can specifically be a problem in case-control studies on esophageal and gastric cancer, as we argued before. ${ }^{2,3}$ Third, in the NLCS there is much information available on potentially confounding variables. If necessary, we used this information to adjust the associations between risk factors and disease. This adjustment further increased the validity of our results.

\section{DIFFERENCES BETWEEN ESOPHAGEAL AND GASTRIC CANCER TYPES}

Based on the observed differences in time trends and risk factors, we understand more and more that ESCC and EAC are two different diseases and should be investigated as such. The same is true for gastric cancer, which is also more and more often being viewed as two separate diseases: GCA and GNCA. Below we will discuss the differences 
we observed in the light of findings by others. Also, some methodological issues related to our research into ESCC, EAC, GCA, and GNCA will be dealt with.

\section{ESCC versus EAC}

In our trend study, we observed differences in incidence trends for ESCC and EAC in many European countries. Incidence of EAC rose in most countries, while the incidence trends were mixed for ESCC. As mentioned in Chapter 1, this may indicate a different etiology of these two histologic types of esophageal cancer. ESCC and EAC also differ with respect to pathology, tumor biology, and prognosis. This is acknowledged in the newest TNM staging system, that provides separate stage groupings for ESCC and adenocarcinomas of the esophagus and esophagogastric junction. ${ }^{4}$ ESCC patients are on average somewhat younger than EAC patients. ${ }^{5,6}$ Also, some studies have reported a better prognosis of EAC than of ESCC, particularly in early stage disease. 5

In our studies on risk factors for ESCC and EAC, summarized in Table 9.1, we observed differences for overweight, alcohol consumption, and toenail selenium status. These differences are in agreement with observations in other studies. Positive associations are found between overweight and EAC, and inverse associations with ESCC. $^{7-9}$ Alcohol consumption is only associated with increased risk of ESCC, not with EAC. ${ }^{8,10,11}$ Because our study is the first to investigate selenium and EAC risk, we cannot compare our findings with the literature yet. We consequently recommend others to study selenium and EAC risk.

ESCC and EAC were similar with respect to their associations with cigarette smoking, vegetables consumption, and fruits consumption. Other cohort studies also found increased risks of ESCC and EAC for smokers, ${ }^{8,10,12}$ although in two out of three studies the risks were higher for ESCC than for EAC. ${ }^{10,12}$ In the literature, inverse associations with vegetables and fruits consumption are reported somewhat more frequently for ESCC than for EAC. . $^{\text {,13-16 }}$

From the above, we can conclude that ESCC and EAC are different with regard to various aspects: risk factors, incidence trends, pathology, tumor biology, and prognosis. We therefore believe that it is not informative to study esophageal cancers as one entity. ESCC and EAC should be regarded as two distinct diseases in future research.

\section{EAC versus GCA}

When making a comparison between EAC and GCA, one has to consider the classification of these cancers. EAC most commonly arises in the distal part of the esophagus, which is close to the gastric cardia. If an esophageal tumor is located near the gastroesophageal junction, it can grow into the cardia. The opposite is also possible: a tumor that originates from the gastric cardia can grow into the distal esophagus. At the time of diagnosis, however, it is sometimes impossible to determine whether a cancer has arisen from the distal esophagus or from the proximal 
stomach. ${ }^{17,18}$ Sometimes, a tumor is then classified as gastroesophageal junction cancer. $^{17}$

The cancer incidence data used in our study come from the Netherlands Cancer Registry. The Netherlands Cancer Registry is a high quality cancer registry. Specially trained registration clerks register directly from the medical records in the hospitals. Clinical information as well as pathology information are collected. ${ }^{19-22}$ The classification of EAC and GCA is based on these cancer registry data.

When our findings on EAC and GCA are compared, we can see that these cancers share all risk factors that we investigated, i.e., overweight, smoking, alcohol consumption, toenail selenium status, and vegetables and fruits consumption (Table 9.1). These findings are in agreement with other studies, which also found similarities in risk factors for EAC and GCA. e.g. $8-10,14,23^{2}$

Data on trends in incidence are not separately presented for EAC and GCA in the majority of trend studies. This has to do with the fact that in the past, adenocarcinomas of the lower esophagus had to be coded as cardia tumors, according to version 9 of the International Classification of Diseases. Also, researchers may not want to separate these cancers, because of possible misclassification.

To sum up, it may be said that in our studies based on high quality cancer registry data, we observed that EAC and GCA are etiologically very similar diseases. Further, clinically it is very difficult to distinguish these diseases. In view of these facts, we believe it may not be useful to keep trying to separate EAC and GCA, and therefore recommend treating these diseases as one entity: gastroesophageal junction adenocarcinomas.

\section{GCA versus GNCA}

In this thesis, we also found some differences between GCA and GNCA. Trends in incidence rates were strikingly different for adenocarcinomas of the esophagus and gastric cardia than for GNCA (the latter separately analyzed as gastric cancers of other specified sites and not otherwise specified gastric cancers) (Chapter 5). This observation is in agreement with studies on trends in gastric cancer subtypes in other countries. e.g. $24-28^{2}$

The associations we observed in the etiological analyses were indeed different for GCA and GNCA for some risk factors (Table 9.1), although the contrast is less sharp than for ESCC versus EAC. The largest difference was present for overweight, which was a strong risk factor for GCA but inversely associated with GNCA. Recent data from the prospective AARP Diet and Health study confirm our findings: increased BMI was found to be a risk factor for GCA, but not for GNCA. ${ }^{29}$ We are unsure whether toenail selenium status is differently associated with risk of GCA than with risk of GNCA. In a previous study, we found that selenium was inversely associated (not statistically significant) with risk of total gastric cancer, but we did not report on GNCA separately. ${ }^{30}$ Possibly, selenium is only inversely associated with GCA, and not with 
GNCA. This was observed by a prospective study in Linxian, China. ${ }^{23}$ Further, the associations between consumption of vegetables and fruits were inverse for GCA, while this was not the case for GNCA. Other prospective studies have generally found few associations between vegetables and fruits consumption and risk of GCA as well as GNCA. ${ }^{7,14,31-33}$

As mentioned in several chapters, we lack information on infection with Helicobacter $(\mathrm{H}$.$) pylori. On this subject, case-control studies have an advantage over$ cohort studies. Medical data, including data on $\mathrm{H}$. pylori infection, are more readily available in case-control studies. One reason is that these studies are often carried out in a medical setting, in contrast to the general population setting of cohort studies. Also, the number of participants is usually much lower in case-control studies than in cohort studies.

The lack of data on $\mathrm{H}$. pylori is particularly important for GNCA, as H. pylori is the main risk factor for this cancer. A recent review of epidemiologic studies that investigated interaction between $\mathrm{H}$. pylori infection and other risk factors for gastric cancer concluded that there is a suggestion of a positive interaction between $\mathrm{H}$. pylori infection and smoking on gastric cancer risk. Further, the potential protective effect of dietary antioxidants seemed to be observed only in subjects infected with $\mathrm{H}$. pylori, although the results were inconsistent. ${ }^{34}$ Analyzing the interaction between $\mathrm{H}$. pylori and other risk factors for GNCA within prospective studies would be of interest.

In accordance with our belief that it is not informative to study esophageal cancer as one entity, we neither believe it is informative to study gastric cancer as one entity. This thesis shows that GCA and GNCA are quite different diseases with respect to their etiology, and future research should therefore make a distinction between these two diseases.

\section{BARRETT'S ESOPHAGUS VERSUS ESOPHAGEAL ADENOCARCINOMA}

Besides making comparisons between subtypes of esophageal and gastric cancer, an important focus of this thesis is also to make a comparison between BE and EAC. We believe this thesis contributes significantly to the knowledge of these two diseases, also because the evidence is based on prospective data. The existence of the nationwide network and registry of histopathology and cytopathology in the Netherlands (PALGA) ${ }^{35}$ offered us the unique possibility to research BE in a prospective cohort study.

The results of the etiologic analyses on BE and EAC clearly show some differences between these diseases. In our cohort, overweight, cigarette smoking, and toenail selenium status all have a different association with BE than with EAC (Table 9.1). It seems that the associations found for EAC are less strong or not present for $\mathrm{BE}$, at least for the risk factors described in this thesis. In the literature, obese persons are 
generally found to have 3 times more risk of BE as well as EAC, and overweight persons are found to have 1.5 times the risk of BE and EAC compared with normal weight persons. $^{36-41}$ These risk estimates for $B E$ come from case-control studies. The only other cohort study found no association between BMI and BE risk. ${ }^{42}$ Therefore, the inconsistency between our results and most other studies may be due to the study design. Smoking is probably more strongly associated with EAC compared with $\mathrm{BE}$, although the exact risk estimates vary between studies. ${ }^{8,10,37,43-45}$ For selenium and risk of $B E$ and $E A C$, there are no other studies available for comparison. It would thus be interesting if others examined these associations.

The association between vegetables and fruits consumption and risk of $B E$ is not described in this thesis, but is certainly worthwhile investigating given the inverse associations we observed with EAC risk. More in general, epidemiological studies on (lifestyle) risk factors for $\mathrm{BE}$ are requested as the evidence is quite limited to date. It also remains important to compare $B E$ and $E A C$, to be able to find clues about the etiologically relevant time window for exposures.

In our analyses of risk factors for BE and EAC, we were able to check for possible confounding effects of various dietary and lifestyle habits of our cohort participants. No information, however, was available on the presence of gastroesophageal reflux disease (GERD). Use of medications for the treatment of reflux, such as antacids, histamine 2 receptor antagonists (H2RA), and proton pump inhibitors (PPI), were not measured well in our cohort. Here, case-control studies may have an advantage over cohort studies, because this medical information is generally more readily available in these studies. GERD or reflux symptoms may be confounders, effect-modifiers, or intermediates in the associations we investigated. Therefore, future studies are recommended to evaluate the role of GERD and reflux. This can best be done by comparing the results from different statistical models, with and without adjustment for these factors. This approach has already been applied by some researchers. ${ }^{43,46}$

Another point of interest is that there are some foods that have been associated with temporary symptoms of reflux. These include dietary fat, chocolate, mints, coffee, onions, citrus fruits, and tomatoes. ${ }^{47}$ Persons already suffering from reflux symptoms may therefore try to avoid eating these foods in order to reduce their complaints. This may influence not only our study, but all studies investigating diet and risk of BE, because the dietary habits of BE cases (who often have a history of reflux) will then be different from the habits of the non-cases. Specifically, cases may consume less refluxinducing foods than non-cases. In this way, reverse causation may play a role in the observed associations between diet and risk of $\mathrm{BE}$. We attempted to remove the effects of reverse causation from our results by excluding BE cases that were diagnosed in the first 2 years of the follow-up. These patients may be the patients that already had considerable complaints at the time they filled out our baseline food frequency questionnaire. These complaints may have influenced their diet and might also have led to their diagnosis of BE. Nevertheless, excluding these early cases may 
not have solved the problem entirely, as reflux symptoms can already be present a long time before BE diagnosis. ${ }^{48,49}$

\section{The paradox of Barrett's esophagus}

It has recently been proposed that BE is a successful adaptation to the harsh intraesophageal environment of chronic gastroesophageal reflux disease. The BE tissue has several functions not present in the normal squamous cell epithelium, that protect against further reflux injury. ${ }^{50}$ Besides being a successful adaptation, BE is also associated with increased risk of EAC, which is the reason that clinicians and researchers are interested in $\mathrm{BE}$. This increased risk of EAC is also the reason for regular endoscopic surveillance of $B E$ patients, to try to detect progression to EAC in an early stage. ${ }^{51,52}$ As mentioned before, the incidence of this highly lethal cancer is rising in the Western world. Making a valid estimate of the risk of EAC in BE patients is therefore essential for these patients, the cost-efficiency of surveillance, and the relevance of $\mathrm{BE}$ as a precancerous lesion. Quite some studies have tried to estimate the risk, but there are quite large differences between the estimates from different studies. ${ }^{53}$ A recent meta-analysis estimated the risk of esophageal adenocarcinoma in BE patients to be between 4.1 and $6.1 \%$ per 10 year. ${ }^{53}$ In our study described in Chapter 4, we have therefore tried to make a valid estimate of, among other things, EAC risk in BE using a population-based design. Our estimate of the incidence rate was $3.7 \%$ per 10 year, which is very close to the estimate from the meta-analysis.

Even though BE patients have a risk of EAC that is equal to or larger than 10 times the risk of the general population (Chapter 4), their absolute risk of EAC is still quite low. The majority of BE patients never develop EAC. ${ }^{53}$ Thus, one could say there is some overdiagnosis of BE. This overdiagnosis contrasts sharply to the underdiagnosis of early stage EAC. A large proportion of persons diagnosed with EAC has not had any previous complaints like reflux (50\%), has not been diagnosed with GERD (80\%), and did not have a prior diagnosis of BE (95\%). ${ }^{54}$ Because of the absence of early complaints and diagnosis of precursor lesions, these persons are not under surveillance and therefore the EAC is detected very late. By that time, the cancer is already advanced and the associated mortality high.

Reid et al. have recently nicely described this contrast between overdiagnosis of $B E$ and underdiagnosis of early EAC, which they named the paradox of Barrett's esophagus. ${ }^{54}$ Changing this paradox of BE is necessary to improve patient care and lower esophageal cancer mortality. One possibility to achieve this, is to identify those patients with BE that are at highest risk of progression, thus making a risk stratification. In our follow-up study in Chapter 4, we observed that male BE patients have a higher risk of progression to EAC than women. This was also reported in a metaanalysis on risk of progression in $\mathrm{BE} .^{53}$ Also, BE patients with high-grade dysplasia (HGD) were at greatest risk of progression. However, the assessment of the grade of dysplasia (negative, indefinite, low grade, or high grade) ${ }^{55}$ is subject to a large inter- 
observer variation. ${ }^{54}$ This assessment may thus be improved. Several researchers have studied biomarkers that may be valuable for risk stratification in BE. These biomarkers include measures of genomic instability, chromosomal alterations, chromosomal instability, microsatellite instability, mutations, and disruption of regulatory pathways in BE tissue. ${ }^{54}$ Future use of these biomarkers in clinical practice may be promising. Besides these biomarkers, other characteristics of the BE patient, such as demographic, lifestyle and medical characteristics might also be useful for risk stratification. However, the associations between these factors and risk of progression of $B E$ remain to be well assessed. Valuable information on this topic could be obtained by setting up a prospective cohort of BE patients. At the start of that cohort study, information on all kinds of possibly relevant factors for progression should be collected.

Ultimately, the results of all these investigations could be used to develop a risk score that clinicians can use to predict the individual risk of progression in their $\mathrm{BE}$ patient, communicate this risk to the patient, and apply personalized patient care. ${ }^{56}$ Patient care may include endoscopic surveillance, endoscopic treatment, chemoprevention with NSAIDs/aspirin, and advice to make lifestyle changes. For patients at low risk of progression, no intervention at all may be the best care. However, these options remain to be demonstrated as effective in trials. ${ }^{54}$

\section{IMPLICATIONS FOR PUBLIC HEALTH}

Naturally, the lifestyle factors described in this thesis are not only related to risk of Barrett's esophagus and esophageal and gastric cancer subtypes. Risk of many other diseases is influenced (increased or decreased) by smoking, overweight and obesity, alcohol consumption and dietary habits. The directions of the associations we observed with BE and esophageal and gastric cancers generally correspond to the direction of the associations with other diseases (Table 2). As a consequence of these diseases, individuals live some years of their lives in poor health. Further, a number of life years are lost due to early mortality. The National Institute for Public Health and the Environment (RIVM) in the Netherlands has quantified the contribution of several risk factors to the burden of disease (Table 2). ${ }^{57,58}$ For example, compared with never smokers, smokers lose on average 4.1 life years and 4.6 healthy life years. Overweight and obesity also cause significant loss of life years and healthy life years, while the effects of excess alcohol consumption are more limited. No figures were available for the effect of selenium status and vegetables and fruit consumption.

These figures stress the importance of recommendations and guidelines for healthy living, as described by e.g. the World Cancer Research Fund ${ }^{59}$, the National Health Council of the Netherlands, ${ }^{60}$ and the Dutch Cancer Society. ${ }^{61}$ Of course, only formulating these recommendations and guidelines is not sufficient. It is not always self-evident or easy for individuals to follow these recommendations and therefore 
they should be supported. ${ }^{58}$ The findings of the research described in this thesis underline the guidelines for a healthy lifestyle and the importance of motivating and helping the population to comply with these guidelines.

Table 9.2 Effects of risk factors on life years and healthy life years (with $95 \%$ confidence intervals) (Chronic Diseases Model). ${ }^{\text {a }}$

\begin{tabular}{lcc}
\hline Risk factor & Life years lost & $\begin{array}{c}\text { Healthy life years lost } \\
\text { (HALE) }\end{array}$ \\
\hline $\begin{array}{l}\text { Individuals in the risk groups: } \\
\quad \text { Smokers (including former smokers) }\end{array}$ & $4.1(3.7-4.6)$ & $4.6(4.1-5.4)$ \\
Overweight subjects $^{c}$ & $1.2(1.0-1.5)$ & $2.1(1.8-2.3)$ \\
Obese subjects $^{c}$ & $3.0(2.3-3.6)$ & $5.1(4.5-5.6)$ \\
Users of excess alcohol $^{d}$ & $0.6(0.5-0.7)$ & $0.9(0.8-1.0)$ \\
\hline
\end{tabular}

${ }^{a}$ Adapted from reference ${ }^{57 ; b}$ HALE, health-adjusted life expectancy: a measure for the number of healthy life years someone can expect to live from a certain age. This is calculated based on the prevalence and the seriousness of diseases; ${ }^{c}$ Overweight is defined as $\mathrm{BMI} \geq 25 \mathrm{~kg} / \mathrm{m}^{2}$. Obesity is defined as $\mathrm{BMI} \geq 30 \mathrm{~kg} / \mathrm{m}^{2}$. The reference group is normal weight (BMI $18.5-25 \mathrm{~kg} / \mathrm{m}^{2}$ ); ${ }^{d}$ Defined as $\geq 3$ glasses of alcohol per day for men, and $\geq 2$ glasses of alcohol per day for women.

\section{SUGGESTIONS FOR FUTURE RESEARCH}

Besides the suggestions for future research described in the texts above, below we formulated a few additional recommendations.

It is important to keep monitoring the incidence of histologic types of esophageal cancer and subsites of gastric cancer. Also in countries in which no changes have been observed yet, these can still take place later. Preferably, figures of recent date should be used in trends studies. Observed trends can further be extrapolated to make predictions about future trends. Results from trends studies can give clues about yet unknown risk factors, and moreover they can be used for e.g. future health care planning.

An exposure of interest that could be investigated further is physical activity, which might reduce risk of esophageal and gastric cancers independently of BMI. ${ }^{62,63}$ Additionally, reproductive and hormonal factors may be related to risk of esophageal and gastric cancer subtypes and may also explain the high male predominance of EAC and GCA. Only a few studies have been conducted on this topic and this requires further attention. ${ }^{64,65}$

Finally, besides studying $B E$, studying precursor lesions of other esophageal and gastric cancer subtypes (ESCC, GCA, and GNCA) may be valuable. Issues that deserve particular attention are the diagnosis and definition of the precursor lesion, risk factors for the development and malignant progression of the lesion, and the magnitude of the risk of progression to cancer. 


\section{REFERENCES}

1. Merry $A H$, Schouten $L$, Goldbohm RA, van den Brandt PA. Body mass index, height and risk of adenocarcinoma of the oesophagus and gastric cardia: a prospective cohort study. Gut 2007;56: 1503-1511.

2. Botterweck AA, van den Brandt PA, Goldbohm RA. A prospective cohort study on vegetable and fruit consumption and stomach cancer risk in The Netherlands. Am J Epidemiol 1998;148:842-853.

3. Botterweck AAM. Diet and risk of stomach cancer [dissertation]. Maastricht University, 2000.

4. Edge SB, Byrd DR, Compton CC, Fritz AG, Green FL, Trotti A. AJCC (American Joint Committee on Cancer) Cancer Staging Manual. New York: Springer, 2010.

5. Siewert JR, Ott K. Are squamous and adenocarcinomas of the esophagus the same disease? Semin Radiat Oncol 2007; 17:38-44.

6. Mariette C, Finzi L, Piessen G, Van Seuningen I, Triboulet JP. Esophageal carcinoma: prognostic differences between squamous cell carcinoma and adenocarcinoma. World J Surg 2005;29:39-45.

7. Tran GD, Sun XD, Abnet CC, Fan JH, Dawsey SM, Dong ZW, Mark SD, Qiao YL, Taylor PR. Prospective study of risk factors for esophageal and gastric cancers in the Linxian general population trial cohort in China. Int J Cancer 2005;113:456-463.

8. Lindblad M, Rodriguez LA, Lagergren J. Body mass, tobacco and alcohol and risk of esophageal, gastric cardia, and gastric non-cardia adenocarcinoma among men and women in a nested case-control study. Cancer Causes Control 2005;16:285-294.

9. Kubo A, Corley DA. Body mass index and adenocarcinomas of the esophagus or gastric cardia: a systematic review and meta-analysis. Cancer Epidemiol Biomarkers Prev 2006;15:872-878.

10. Freedman ND, Abnet CC, Leitzmann MF, Mouw T, Subar AF, Hollenbeck AR, Schatzkin A. A prospective study of tobacco, alcohol, and the risk of esophageal and gastric cancer subtypes. Am J Epidemiol 2007;165:1424-1433.

11. Ishiguro S, Sasazuki S, Inoue M, Kurahashi N, Iwasaki M, Tsugane S. Effect of alcohol consumption, cigarette smoking and flushing response on esophageal cancer risk: a population-based cohort study (JPHC study). Cancer Lett 2009;275:240-246.

12. Zendehdel K, Nyren O, Luo J, Dickman PW, Boffetta P, Englund A, Ye W. Risk of gastroesophageal cancer among smokers and users of Scandinavian moist snuff. Int J Cancer 2008;122:1095-1099.

13. Freedman ND, Park Y, Subar AF, Hollenbeck AR, Leitzmann MF, Schatzkin A, Abnet CC. Fruit and vegetable intake and esophageal cancer in a large prospective cohort study. Int J Cancer 2007;121:2753-2760.

14. Gonzalez CA, Pera G, Agudo A, Bueno-De-Mesquita HB, Ceroti M, Boeing H, Schulz M, Del Giudice G, Plebani M, Carneiro F, Berrino F, Sacerdotde C, Tumino R, Panico S, Berglund G, Siman H, Hallmans G, Stenling R, Martinez C, Dorronsoro M, Barricarte A, Navarro C, Quiros JR, Allen N, Key TJ, Bingham S, Day NE, Linseisen J, Nagel G, Overvad K, Jensen MK, Olsen A, Tjonneland A, Buchner FL, Peeters PH, Numans ME, Clavel-Chapelon F, Boutron-Ruault MC, Roukos D, Trichopolou A, Psaltopoulou T, Lund E, Casagrande C, Slimani N, Jenab M, Riboli E. Fruit and vegetable intake and the risk of stomach and oesophagus adenocarcinoma in the European Prospective Investigation into Cancer and Nutrition (EPIC-EURGAST). International Journal of Cancer 2006;118:2559-2566.

15. Yamaji T, Inoue M, Sasazuki S, Iwasaki M, Kurahashi N, Shimazu T, Tsugane S. Fruit and vegetable consumption and squamous cell carcinoma of the esophagus in Japan: the JPHC study. Int J Cancer 2008;123:1935-1940.

16. Guo W, Blot WJ, Li JY, Taylor PR, Liu BQ, Wang W, Wu YP, Zheng W, Dawsey SM, Li B, et al. A nested case-control study of oesophageal and stomach cancers in the Linxian nutrition intervention trial. Int J Epidemiol 1994;23:444-450.

17. McColl KE, Going JJ. Aetiology and classification of adenocarcinoma of the gastro-oesophageal junction/cardia. Gut 2010;59:282-284.

18. Rusch VW. Are cancers of the esophagus, gastroesophageal junction, and cardia one disease, two, or several? Semin Oncol 2004;31:444-449.

19. Parkin DM, Whelan SL, Ferlay J, Raymond L, Young J. Cancer incidence in five continents. Volume VII. Lyon: IARC Scientific publications no. 143, 1997. 
20. Parkin DM, Whelan SL, Ferlay J, Teppo L, Thomas DB. Cancer incidence in five continents. Volume VIII. Lyon: IARC Scientific publications no. 155, 2002.

21. Curado MP, Edwards B, Shin HR, Storm H, Ferlay J, Heanue M, Boyle P. Cancer incidence in five continents. Volume IX. Lyon: IARC Scientific publications no. 160, 2007.

22. Schouten LJ, Jager JJ, van den Brandt PA. Quality of cancer registry data: a comparison of data provided by clinicians with those of registration personnel. Br J Cancer 1993;68:974-977.

23. Mark SD, Qiao YL, Dawsey SM, Wu YP, Katki H, Gunter EW, Fraumeni JF, Jr., Blot WJ, Dong ZW, Taylor PR. Prospective study of serum selenium levels and incident esophageal and gastric cancers. J Natl Cancer Inst 2000;92:1753-1763.

24. Brown LM, Devesa SS. Epidemiologic trends in esophageal and gastric cancer in the United States. Surg Oncol Clin N Am 2002;11:235-256.

25. Hansen S, Wiig JN, Giercksky KE, Tretli S. Esophageal and gastric carcinoma in Norway 1958-1992: incidence time trend variability according to morphological subtypes and organ subsites. Int J Cancer 1997;71:340-344.

26. Levi F, La Vecchia C, Te VC. Descriptive epidemiology of adenocarcinomas of the cardia and distal stomach in the Swiss Canton of Vaud. Tumori 1990;76:167-171.

27. Harrison SL, Goldacre MJ, Seagroatt V. Trends in registered incidence of oesophageal and stomach cancer in the Oxford region, 1974-88. Eur J Cancer Prev 1992;1:271-274.

28. Moller $\mathrm{H}$. Incidence of cancer of oesophagus, cardia and stomach in Denmark. Eur J Cancer Prev 1992;1:159-164.

29. Abnet CC, Freedman ND, Hollenbeck AR, Fraumeni JF, Jr., Leitzmann M, Schatzkin A. A prospective study of BMI and risk of oesophageal and gastric adenocarcinoma. Eur J Cancer 2008;44:465-471.

30. van den Brandt PA, Goldbohm RA, van 't Veer P, Bode P, Dorant E, Hermus RJ, Sturmans F. A prospective cohort study on toenail selenium levels and risk of gastrointestinal cancer. J Natl Cancer Inst 1993;85:224-229.

31. Nouraie M, Pietinen P, Kamangar F, Dawsey SM, Abnet CC, Albanes D, Virtamo J, Taylor PR. Fruits, vegetables, and antioxidants and risk of gastric cancer among male smokers. Cancer Epidemiol Biomarkers Prev 2005;14:2087-2092.

32. Kobayashi M, Tsubono Y, Sasazuki S, Sasaki S, Tsugane S. Vegetables, fruit and risk of gastric cancer in Japan: a 10-year follow-up of the JPHC Study Cohort I. Int J Cancer 2002;102:39-44.

33. Freedman ND, Subar AF, Hollenbeck AR, Leitzmann MF, Schatzkin A, Abnet CC. Fruit and vegetable intake and gastric cancer risk in a large United States prospective cohort study. Cancer Causes Control 2008;19:459-467.

34. Gonzalez CA, Lopez-Carrillo L. Helicobacter pylori, nutrition and smoking interactions: their impact in gastric carcinogenesis. Scand J Gastroenterol 2010;45:6-14.

35. Casparie M, Tiebosch AT, Burger G, Blauwgeers H, van de Pol A, van Krieken JH, Meijer GA. Pathology databanking and biobanking in The Netherlands, a central role for PALGA, the nationwide histopathology and cytopathology data network and archive. Cell Oncol 2007;29:19-24.

36. Bu X, Ma Y, Der R, Demeester T, Bernstein L, Chandrasoma PT. Body mass index is associated with Barrett esophagus and cardiac mucosal metaplasia. Dig Dis Sci 2006;51:1589-1594.

37. Edelstein ZR, Farrow DC, Bronner MP, Rosen SN, Vaughan TL. Central adiposity and risk of Barrett's esophagus. Gastroenterology 2007;133:403-411.

38. Stein DJ, El-Serag HB, Kuczynski J, Kramer JR, Sampliner RE. The association of body mass index with Barrett's oesophagus. Aliment Pharmacol Ther 2005;22:1005-1010.

39. Hampel H, Abraham NS, El-Serag HB. Meta-analysis: obesity and the risk for gastroesophageal reflux disease and its complications. Ann Intern Med 2005;143:199-211.

40. Corley DA, Kubo A, Zhao W. Abdominal obesity and the risk of esophageal and gastric cardia carcinomas. Cancer Epidemiol Biomarkers Prev 2008;17:352-358.

41. Reeves GK, Pirie K, Beral V, Green J, Spencer E, Bull D. Cancer incidence and mortality in relation to body mass index in the Million Women Study: cohort study. Bmj 2007;335:1134.

42. Corley DA, Kubo A, Levin TR, Block G, Habel L, Zhao W, Leighton P, Quesenberry C, Rumore GJ, Buffler PA. Abdominal obesity and body mass index as risk factors for Barrett's esophagus. Gastroenterology 2007;133:34-41; quiz 311. 
43. Anderson LA, Watson RG, Murphy SJ, Johnston BT, Comber H, Mc Guigan J, Reynolds JV, Murray L. Risk factors for Barrett's oesophagus and oesophageal adenocarcinoma: results from the FINBAR study. World J Gastroenterol 2007;13:1585-1594.

44. Smith KJ, O'Brien SM, Green AC, Webb PM, Whiteman DC. Current and past smoking significantly increase risk for Barrett's esophagus. Clin Gastroenterol Hepatol 2009;7:840-848.

45. Kubo A, Levin TR, Block G, Rumore G, Quesenberry CP, Jr., Buffler P, Corley DA. Cigarette smoking and the risk of Barrett's esophagus. Cancer Causes Control 2009;20:303-311.

46. Whiteman DC, Sadeghi S, Pandeya N, Smithers BM, Gotley DC, Bain CJ, Webb PM, Green AC. Combined effects of obesity, acid reflux and smoking on the risk of adenocarcinomas of the oesophagus. Gut 2008;57:173-180.

47. Terry P, Lagergren J, Wolk A, Nyren O. Reflux-inducing dietary factors and risk of adenocarcinoma of the esophagus and gastric cardia. Nutr Cancer 2000;38:186-191.

48. Eisen GM, Sandler RS, Murray S, Gottfried M. The relationship between gastroesophageal reflux disease and its complications with Barrett's esophagus. Am J Gastroenterol 1997;92:27-31.

49. Conio M, Filiberti R, Blanchi S, Ferraris R, Marchi S, Ravelli P, Lapertosa G, laquinto G, Sablich R, Gusmaroli R, Aste H, Giacosa A. Risk factors for Barrett's esophagus: a case-control study. Int J Cancer 2002;97:225-229.

50. Orlando RC. Mucosal defense in Barrett's esophagus. In: Sharma P, Sampliner R, eds. Barrett's esophagus and esophageal adenocarcinoma. Massachusetts: Blackwell, 2006.

51. Wang KK, Sampliner RE. Updated guidelines 2008 for the diagnosis, surveillance and therapy of Barrett's esophagus. Am J Gastroenterol 2008;103:788-797.

52. Playford RJ. New British Society of Gastroenterology (BSG) guidelines for the diagnosis and management of Barrett's oesophagus. Gut 2006;55:442-443.

53. Yousef F, Cardwell C, Cantwell MM, Galway K, Johnston BT, Murray L. The incidence of esophageal cancer and high-grade dysplasia in Barrett's esophagus: a systematic review and meta-analysis. Am J Epidemiol 2008;168:237-249.

54. Reid BJ, Li X, Galipeau PC, Vaughan TL. Barrett's oesophagus and oesophageal adenocarcinoma: time for a new synthesis. Nat Rev Cancer 2010;10:87-101.

55. Schlemper RJ, Riddell RH, Kato Y, Borchard F, Cooper HS, Dawsey SM, Dixon MF, Fenoglio-Preiser CM, Flejou JF, Geboes K, Hattori T, Hirota T, Itabashi M, Iwafuchi M, Iwashita A, Kim YI, Kirchner T, Klimpfinger M, Koike M, Lauwers GY, Lewin KJ, Oberhuber G, Offner F, Price AB, Rubio CA, Shimizu M, Shimoda $T$, Sipponen $P$, Solcia $E$, Stolte $M$, Watanabe $H$, Yamabe $H$. The Vienna classification of gastrointestinal epithelial neoplasia. Gut 2000;47:251-255.

56. Prasad GA, Bansal A, Sharma P, Wang KK. Predictors of progression in Barrett's esophagus: current knowledge and future directions. Am J Gastroenterol 2010;105:1490-1502.

57. http://www.nationaalkompas.nl/gezondheid-en-ziekte/sterfte-levensverwachting-en-dalys/ziektelast-in-daly-s/wat-is-de-bijdrage-van-risicofactoren/ (accessed July 23, 2010).

58. van der Lucht F, Polder JJ. Rijksinstituut voor Volksgezondheid en Milieu (RIVM). Van gezond naar beter. Kernrapport Volksgezondheid Toekomst Verkenning 2010. Houten: Bohn Stafleu van Loghum, 2010.

59. World Cancer Research Fund, American Institute for Cancer Research. Food, nutrition, physical activity and the prevention of cancer: a global perspective. AICR, 2007.

60. Health Council of the Netherlands. [Guidelines for a healthy diet 2006]. Volume publication no. 2006/21. The Hague: Health Council of the Netherlands, 2006.

61. http://www.kwfkankerbestrijding.nl/index.jsp?objectid=16194 (accessed July 23, 2010).

62. Balbuena L, Casson AG. Physical activity, obesity and risk for esophageal adenocarcinoma. Future Oncol 2009;5:1051-1063. 
63. Huerta JM, Navarro C, Chirlaque MD, Tormo MJ, Steindorf K, Buckland G, Carneiro F, Johnsen NF, Overvad K, Stegger J, Tjonneland A, Boutron-Ruault MC, Clavel-Chapelon F, Morois S, Boeing H, Kaaks R, Rohrmann S, Vigl M, Lagiou P, Trichopoulos D, Trichopoulou A, Bas Bueno-de-Mesquita $H$, Monninkhof EM, Numans ME, Peeters PH, Mattiello A, Pala V, Palli D, Tumino R, Vineis $P$, Agudo A, Ardanaz E, Arriola L, Molina-Montes E, Rodriguez L, Lindkvist B, Manjer J, Stenling R, Lund E, Crowe FL, Key TJ, Khaw KT, Wareham NJ, Jenab M, Norat T, Romaguera D, Riboli E, Gonzalez CA. Prospective study of physical activity and risk of primary adenocarcinomas of the oesophagus and stomach in the EPIC (European Prospective Investigation into Cancer and nutrition) cohort. Cancer Causes Control 2010;21:657-669.

64. Freedman ND, Lacey JV, Jr., Hollenbeck AR, Leitzmann MF, Schatzkin A, Abnet CC. The association of menstrual and reproductive factors with upper gastrointestinal tract cancers in the NIH-AARP cohort. Cancer 2010;116:1572-1581.

65. Chandanos E, Lagergren J. Oestrogen and the enigmatic male predominance of gastric cancer. Eur J Cancer 2008;44:2397-2403. 
Summary / Samenvatting 


\section{SUMMARY}

Cancer affects millions of persons in the world. In the Netherlands, cancer has become the most important cause of death in 2008. This thesis concerns two types of cancer: cancer of the esophagus, and cancer of the stomach. Esophageal and gastric cancer are diseases with a poor prognosis: the 5 -year survival rate is only $14 \%$ for esophageal cancer and $21 \%$ for gastric cancer. Besides these cancers, this thesis also concerns Barrett's esophagus (BE). BE is a condition of the lower esophagus, in which the normal squamous epithelium is replaced by columnar epithelium. Patients with BE are at increased risk of developing esophageal adenocarcinoma (Chapter 1).

There are some indications that the two main subtypes of esophageal cancer, esophageal squamous cell carcinoma (ESCC) and esophageal adenocarcinoma (EAC), have a different etiology. This is also true for the two subtypes of gastric cancer: gastric cardia adenocarcinoma (GCA) and gastric non-cardia adenocarcinoma (GNCA). First, esophageal and gastric cancer subtypes are geographically differently distributed. Second, the trends in incidence rates of these cancer subtypes differ. Third, the maleto-female ratio of the incidence of these cancers differs by subtype.

In this thesis, we investigated whether the risk factors for ESCC, EAC, GCA, and GNCA are indeed different. We studied cigarette smoking, alcohol consumption, overweight, toenail selenium status, and consumption of vegetables and fruits. Further, we also looked into the association of these factors with the risk of BE. These lifestyle factors can potentially be modified and can thus have a role in primary prevention.

The research described in this thesis is based on a prospective cohort study: the Netherlands Cohort Study on diet and cancer (NLCS). The NLCS was initiated in September 1986, with the enrollment of 120,852 men and women aged 55-69 years. These subjects were randomly selected from Dutch municipal population registries. At baseline, all subjects filled out a questionnaire on dietary habits, lifestyle, and other risk factors for cancer. According to the case-cohort approach, data are processed and analyzed for a random sample of the cohort (the subcohort) and cases. The subcohort consists of 5,000 men and women who were sampled at baseline. This subcohort is followed-up for vital status and migration and is used to estimate the person-time at risk for the total cohort. Incident cases of $B E$ and cancer were identified in the whole cohort. BE cases were identified through record linkage with data from PALGA (the nationwide registry for histopathology and cytopathology in the Netherlands). The existence of this unique nationwide pathology registry offered us the opportunity to study BE within a prospective cohort study. A pathologist reviewed and coded further characteristics of the BE cases from the PALGA data. Incident cancer cases were identified through record linkages with PALGA and the Netherlands Cancer Registry. The cohort has been followed-up for vital status through record linkage with the Central Bureau of Genealogy and automated municipal population registries. For deceased cohort members we also obtained information on the cause of death from 
Statistics Netherlands. The research described in this thesis was based on 16.3-year follow-up data of the cohort (September 17, 1986 through December 31, 2002).

Chapter 2 describes the association between overweight, smoking, and alcohol consumption and the risk of BE. Overweight and obesity were associated with an increased risk of BE in women, but not in men. The association in women was not specifically due to abdominal overweight. Former cigarette smokers were at $30 \%$ increased risk of $\mathrm{BE}$, but current smokers were not. Smoking duration showed a positive association with BE risk, while alcohol consumption was not associated with an increased risk of $B E$.

A study on toenail selenium status and its relationship with risk of $B E$ is presented in Chapter 3. We did not find an association between selenium and risk of BE. No association was found either in subgroups defined by sex, smoking status, body mass index, or intake of antioxidants. For BE cases that later progressed to high-grade dysplasia or adenocarcinoma, we observed an inverse association with selenium.

In Chapter 4 we used the data of the NLCS to follow BE patients for incidence of esophageal and gastric cancer, other cancers, and cause-specific mortality. We found that esophageal and gastric cancer occurred 10 and nearly 2 times more frequently, respectively, in $\mathrm{BE}$ patients than in the general population. Total incidence of all other cancers was $30 \%$ increased in BE patients. Small intestinal and pancreatic cancer incidence were increased in particular. All-cause mortality and cause-specific mortality were not increased.

For the study in Chapter 5, we used data from the European Network of Cancer Registries. We described the incidence trends of esophageal and gastric cancers in 13 European countries in the period 1983-1997. The incidence of adenocarcinomas of the esophagus and gastric cardia rose in most, but not all, countries, mostly $1-7 \%$ per year. Incidence of ESCC rose in women from all countries and in men from Northern Europe and Slovakia, but declined mostly in men from Southern and Western Europe. In nearly all countries, the incidence of GNCA declined.

The results described in Chapter 6 indicate that consumption of 3 or more glasses alcoholic beverages per day was related to a 4- to 5-fold increase in risk of ESCC. Alcohol consumption was not related to risk of EAC, GCA, and GNCA, while cigarette smoking increased the risk of all four cancers 1.5 to 2 times. Furthermore, combined exposure to alcohol and cigarette smoking was associated with a very strong increase in ESCC risk: up to 8 times compared with people who did not drink or smoke.

In Chapter 7, the results are presented for the association between toenail selenium status and risk of ESCC, EAC, and GCA. These results indicate that a high selenium status is associated with a strong decrease in risk of ESCC. An inverse association was also found for GCA. For EAC, inverse associations with selenium were found in subgroups: women, never smokers, and persons with a low antioxidant intake.

The relation between consumption of vegetables and fruits and risk of ESCC, EAC, GCA, and GNCA is described in Chapter 8. The results generally indicated inverse 
associations. Specifically, raw vegetables were associated with a lower EAC risk and Brassica vegetables were associated inversely with GCA risk. Citrus fruits were inversely associated with EAC and GCA risk. Specifically for current smokers, vegetables and fruits intake was inversely associated with ESCC and EAC risk. Consumption of vegetables and fruits may therefore protect against development of esophageal and gastric cancer subtypes.

This thesis concludes with a discussion of the findings described in this thesis (Chapter 9). We make comparisons between ESCC and EAC, and conclude that these cancers are different with regard to various aspects, among others risk factors and incidence trends. GCA and GNCA are also compared, and here we also draw the conclusion that these cancers are different in these respects. Because of these observed differences, we believe it is neither informative to study esophageal cancer as one entity nor to study gastric cancer as one entity in etiologic research. Therefore, we recommend separate analyses of ESCC, EAC, GCA, and GNCA in future studies. Further, it appears that EAC and GCA are quite similar diseases that are very difficult to distinguish. It may therefore not be useful to keep trying to separate these, and we therefore suggest treating these diseases and one entity: gastroesophageal junction adenocarcinomas. Finally, we compare BE and EAC. It appears that the associations found for $E A C$ are less strong or not present for $B E$, for the risk factors described in this thesis. A comparison between BE and EAC in future studies is valuable, as it may give clues about the etiologically relevant time window for exposures. More - preferably high quality - research into the relation between lifestyle factors and risk of development and progression of BE is needed, as data are still very limited. 


\section{SAMENVATTING}

Kanker treft miljoenen mensen in de wereld. In Nederland is kanker in 2008 de belangrijkste doodsoorzaak geworden. Dit proefschrift gaat over twee vormen van kanker: slokdarmkanker en maagkanker. Slokdarm- en maagkanker zijn ziekten met een slechte prognose: de 5 -jaarsoverleving is slechts $14 \%$ voor slokdarm- en $21 \%$ voor maagkanker. Naast deze kankers gaat dit proefschrift ook over Barrett's slokdarm. Barrett's slokdarm is een aandoening van het onderste deel van de slokdarm, waarbij het normale plaveiselepitheel is vervangen door cilinderepitheel. Patiënten met Barrett's slokdarm hebben een verhoogd risico op het ontwikkelen van adenocarcinoom van de slokdarm (Hoofdstuk 1).

Er zijn aanwijzingen dat de twee belangrijkste vormen van slokdarmkanker, plaveiselcelcarcinoom (PC) en adenocarcinoom (AC), een verschillende ontstaansgeschiedenis hebben. Dit geldt ook voor de twee vormen van maagkanker: kanker van de cardia van de maag (CC) en kanker van andere delen van de maag (NCC). Ten eerste zijn de vier vormen van slokdarm- en maagkanker anders verdeeld over de wereld. Ten tweede zijn er verschillen in de tijdstrends in het vóórkomen van deze vormen van kanker. Ten derde is de man-vrouw verhouding van het vóórkomen van deze vormen van kanker verschillend.

In dit proefschrift onderzochten we of de risicofactoren voor PC, AC, CC en NCC inderdaad verschillend zijn. We bestudeerden het roken van sigaretten, alcohol consumptie, overgewicht, seleniumgehalte in teennagels, en groente- en fruitconsumptie. Verder bekeken we ook het verband tussen deze risicofactoren en de kans op het krijgen van Barrett's slokdarm. Deze leefstijlfactoren kunnen mogelijk worden veranderd en kunnen daarom een rol spelen bij het voorkómen van ziekten.

Het onderzoek dat is beschreven in dit proefschrift is voornamelijk gebaseerd op een prospectief cohortonderzoek: de Nederlandse Cohort Studie naar voeding en kanker (NLCS). De NLCS is in 1986 gestart met 120.852 mannen en vrouwen van 55-69 jaar oud. Deze deelnemers zijn willekeurig geselecteerd uit Nederlandse bevolkingsregisters. Aan het begin van de studie hebben alle deelnemers een vragenlijst ingevuld die ging over voedingsgewoonten, leefstijl en andere risicofactoren voor kanker. De verwerking en analyse van de onderzoeksgegevens gebeurde volgens de 'case-cohort' benadering. Daarbij worden de kankergevallen uit het gehele cohort geanalyseerd samen met het subcohort. Dit subcohort bestaat uit een willekeurige steekproef van 5.000 mannen en vrouwen, die aan het begin van de studie getrokken is uit het cohort. Het subcohort wordt opgevolgd voor informatie over overlijden en emigratie en het wordt gebruikt om de persoonstijd 'at risk' in het gehele cohort te schatten. Nieuwe gevallen van Barrett's slokdarm en kanker worden opgespoord in het gehele cohort. De identificatie van patiënten met Barrett's slokdarm vond plaats door koppeling met gegevens van PALGA (Pathologisch-Anatomisch Landelijk Geautomatiseerd Archief). Het bestaan van dit unieke landelijke archief gaf ons de mogelijkheid om Barrett's slokdarm te bestuderen in een prospectief 
cohortonderzoek. Een patholoog bekeek de PALGA gegevens en codeerde verdere kenmerken van de patiënten met Barrett's slokdarm. Het cohort is ook opgevolgd voor informatie over nieuwe kankergevallen, die verkregen is via PALGA en de Nederlandse Kanker Registratie. Via het Centraal Bureau voor de Genealogie en het bevolkingsregister (GBA) is informatie verkregen over welke deelnemers zijn overleden. Met betrekking tot overleden cohortleden hebben we van het Centraal Bureau voor de Statistiek informatie verkregen over de doodsoorzaak. Voor het in dit proefschrift beschreven onderzoek is het cohort gedurende 16,3 jaar gevolgd (17 september $1986 \mathrm{t} / \mathrm{m} 31$ december 2002).

Hoofdstuk 2 beschrijft het verband tussen overgewicht, roken en alcohol consumptie en het risico op Barrett's slokdarm. Overgewicht en obesitas waren geassocieerd met een verhoogd risico op Barrett's slokdarm bij vrouwen, maar niet bij mannen. Het verband bij vrouwen werd niet specifiek veroorzaakt door overgewicht in de buik. Ex-rokers hadden 30\% meer risico op Barrett's slokdarm, maar er was geen hoger risico voor huidig rokers. Rookduur verhoogde het risico op Barrett's slokdarm, terwijl alcohol consumptie niet geassocieerd was met een verhoogd risico op Barrett's slokdarm.

Onze studie naar het seleniumgehalte van teennagels en de relatie met risico op Barrett's slokdarm wordt gepresenteerd in Hoofdstuk 3. We vonden geen verband tussen selenium en risico op Barrett's slokdarm. Ook vonden we geen verband in subgroepen gedefinieerd op basis van geslacht, rookstatus, overgewicht, of inname van antioxidanten. Voor patiënten met Barrett's slokdarm waarbij later voortgang werd gezien naar hooggradige dysplasie of $A C$ vonden we een beschermend verband met selenium.

In Hoofdstuk 4 gebruikten we de NLCS gegevens om patiënten met Barrett's slokdarm te volgen voor informatie over het optreden van slokdarm- en maagkanker, andere kankers, en oorzaakspecifieke sterfte. We vonden dat slokdarm- en maagkanker respectievelijk 10 en bijna 2 keer zoveel voorkwamen bij patiënten met Barrett's slokdarm als bij de algemene bevolking. Het vóórkomen van totaal kanker (exclusief slokdarm- en maagkanker) was 30\% verhoogd onder patiënten met Barrett's slokdarm. Dunne darm- en alvleesklierkanker kwamen vaker voor. Totale sterfte en oorzaakspecifieke sterfte waren niet verhoogd.

Voor de studie beschreven in Hoofdstuk 5 gebruikten we gegevens van het Europese Netwerk van Kanker Registraties. We beschreven de trends in het vóórkomen van slokdarm- en maagkanker in 13 Europese landen in de periode 19831997. Het vóórkomen van adenocarcinomen van de slokdarm en cardia van de maag steeg in de meeste, maar niet alle landen, meestal 1-7\% per jaar. Het vóórkomen van PC steeg bij vrouwen uit alle landen en bij mannen uit Noord-Europa en Slowakije, maar daalde meestal bij mannen uit Zuid- en West-Europa. In bijna alle landen nam het vóórkomen van NCC af.

De resultaten die beschreven zijn in Hoofdstuk 6 geven aan dat het drinken van 3 of meer glazen alcoholische drank per dag was gerelateerd aan een 4- tot 5-maal 
verhoogd risico op PC. Alcoholconsumptie was niet gerelateerd aan het risico op AC, CC en NCC. Het roken van sigaretten verhoogde het risico op alle vier vormen van kanker 1.5 tot 2 maal. Bovendien was een gecombineerde bloostelling aan alcohol en sigaretten geassocieerd met een zeer sterke verhoging van het risico op PC: tot 8 maal vergeleken met mensen die niet dronken noch rookten.

In Hoofdstuk 7 worden de resultaten gepresenteerd voor het verband tussen het seleniumgehalte van teennagels en risico op PC, AC en CC. Deze resultaten geven aan dat een hoog seleniumgehalte het risico op PC sterk verlaagt. Een beschermend effect werd ook gevonden voor CC. Voor AC werden er specifiek bij vrouwen, nooit rokers en mensen met een lage inname van antioxidanten beschermende effecten van selenium gevonden.

De relatie tussen groente- en fruitconsumptie en risico op PC, AC, CC en NCC is beschreven in Hoofdstuk 8. De resultaten geven over het algemeen beschermende effecten aan. Specifiek werden verbanden gevonden tussen rauwe groenten en een lager AC risico en koolsoorten en een lager CC risico. Citrusfruit verlaagde het risico op AC en CC. Specifiek bij huidig rokers waren groente- en fruitconsumptie geassocieerd met een lager risico op PC en AC. Consumptie van groente en fruit zou kunnen beschermen tegen het krijgen van vormen van slokdarm- en maagkanker.

Dit proefschrift eindigt met een discussie van de beschreven bevindingen (Hoofdstuk 9). We maken een vergelijking tussen PC en AC en concluderen dat deze kankers verschillend zijn op diverse aspecten, onder andere risicofactoren en tijdstrends in het vóórkomen. CC en NCC worden ook vergeleken en ook hier trekken we de conclusie dat deze kankers verschillend zijn op deze aspecten. Vanwege de verschillen die wij hebben gevonden, geloven wij dat het noch informatief is om slokdarmkanker als één ziekte te bestuderen, noch om maagkanker als één ziekte te bestuderen, wanneer men de risicofactoren onderzoekt. Daarom stellen we voor om in toekomstige studies aparte analyses te doen voor PC, AC, CC en NCC. Verder lijkt het dat $A C$ en $C C$ zeer vergelijkbare ziekten zijn, die moeilijk te onderscheiden zijn. Daarom is het misschien niet zinvol om te blijven proberen deze te scheiden. Vandaar bevelen we aan om deze ziekten als één te beschouwen: adenocarcinomen van de slokdarmmaag overgang. Als laatste vergelijken we Barrett's slokdarm met AC. Het blijkt dat de verbanden die we vonden voor AC, minder sterk of afwezig waren voor Barrett's slokdarm, voor de in dit proefschrift beschreven risicofactoren. Het vergelijken van Barrett's slokdarm en AC in toekomstige studies is waardevol, omdat het aanwijzingen kan geven over de periode die relevant is voor blootstellingen. Meer - bij voorkeur kwalitatief hoogstaand - onderzoek naar de relatie tussen leefstijlfactoren en het risico op het ontwikkelen en de voortgang van Barrett's slokdarm is nodig, want de gegevens zijn nu erg beperkt. 
Dankwoord 


\section{DANKWOORD}

Mijn promotietraject, vier jaar onderzoek doen aan de universiteit. De tijd is voorbij gevlogen. De artikelen zijn geschreven, presentaties gegevens, het boekje is af. In de afgelopen vier jaar hebben vele mensen hieraan bijgedragen. Als ik je onverhoopt vergeet te noemen hieronder, bedankt voor jouw bijdrage!

Als eerste wil ik mijn promotor en copromotoren bedanken.

Piet, jij overzag altijd het geheel en lette goed op de planning. Je maakte steeds genoeg tijd vrij voor een overleg en ik kon laagdrempelig binnenlopen om een vraagje te stellen. Bedankt.

Leo, elke week een uur om te overleggen over belangrijke dingen en allerlei details. Wat een luxe, dat kan niet iedere promovendus zeggen. Je hield me goed in de gaten: 'lukt het nog allemaal?'. Dankjewel voor alle hulp.

Sandra, het meeste contact hadden we door de afstand via de mail. Zeker tegen het einde van het project bleef ik je maar stukken sturen. Bedankt voor je kritische blik op de artikelen.

Janneke, vier jaar lang zaten we bij elkaar op de kamer. Je bent een super kamergenoot: genoeg tijd om te kletsen en te discussiëren, maar ook om rustig door te werken. En het raam kon altijd open voor frisse lucht, ook in de winter. Dankjewel voor je plezierige gezelschap! Ik hoop dat we elkaar nog spreken.

Een bedankje ook voor alle NLCS leden. Allemaal hebben jullie bijgedragen aan mijn onderzoek, in de vorm van het invoeren van duizenden vragenlijsten, beantwoorden van mijn vraagjes, zoeken van nagels of op welke manier ook.

Epidemiologie AIO's en oud-AIO's Audrey, Mirjam, Laura, Colinda, Brenda, Stefan, Esther, Monique, Karolien, Karolina, Sander, Paul, Anne, Nadine en Milan: bedankt voor alle gezellige lunches en gesprekken bij de koffiehoek of op de gang. Succes met jullie promotieonderzoek - voor zover dat niet al lang af is :-).

Angela, José en Marionne, ik hoop dat jullie de yogalessen tijdens de lunchpauze net zo relaxed vonden als ik.

Andere collega's van epidemiologie: bedankt voor jullie collegialiteit!

Anita, Miranda, Ann, Clément, Yolande en Menno: heel fijn dat ik gebruik kon maken van jullie expertise! Dank voor de vruchtbare samenwerking. Professor Murray, thank you for the interesting and helpful discussion during your visit in Maastricht.

Vrienden zijn heel belangrijk voor de nodige ontspanning in de vrije tijd. Gezellige etentjes, bezoekjes en feestjes genoeg.

Saskia, Ingrid, Susan, Ingrid, Irene en Argonde: door de vaste jaarclub dinsdagavond hoefde ik het studentenleven nog niet helemaal los te laten terwijl ik 
wende aan het werkende leven. Hopelijk zien we elkaar nog vaak, waar dan ook in Nederland, met of zonder de mannen!

Karin, Renske en Jeroen, Kim en Hans, met jullie is het altijd gezellig. Jullie zijn altijd te vinden om iets te leuks te gaan doen. Bedankt ook voor de interesse in mijn onderzoek. Op een vriendschap die nog lang mag duren!

Caroline en Ilona, superleuk dat jullie mijn paranimfen zijn! De lunches in het azM waren altijd te kort om goed bij te kletsen... Ik verwacht het komende jaar trouwens wel twee cocktailavonden ter gelegenheid van 'het boekje af' :-).

Papa en mama, vier jaar geleden wisten jullie niks over promoveren. Nu ietsje meer denk ik. Leuk dat jullie iedereen zo trots vertellen over mijn onderzoek. Ik ben heel blij dat ik jullie als ouders heb!

Bram en Anne, het is telkens lekker vertrouwd en gezellig met jullie, of we elkaar nu in Breda, Nijmegen of Maastricht zien.

Yvonne en Rico, Bram en Vianna, Tessa, het is fijn om een schoonfamilie in de buurt te hebben als je eigen familie ver weg woont.

Bram, supercool dat je deze mooie kaft voor me wilde ontwerpen!

Lieve Joep, wat ben ik toch gelukkig met jou! Je weet wel hoe belangrijk jij voor me bent geweest tijdens mijn promotieonderzoek. Ik hou van je, monster van me! X

\section{Jessie}


Curriculum Vitae / List of publications 


\section{CURRICULUM VITAE}

Jessie Steevens was born on December 14, 1981 in Breda, the Netherlands. She completed secondary school (Gymnasium) at the Mencia de Mendoza lyceum in Breda in 2000. That year, she started studying Health Sciences at Maastricht University. As a part of this study, she fulfilled an internship at the Municipal Health Service (GGD) in Rotterdam in 2004. In 2005, she obtained her Master's degree in Health Sciences, specialization Environmental Health Science. From January through May 2005, she worked as employee environmental health at the Regional Health Service in Arnhem (Hulpverlening Gelderland Midden). In September 2005, she started studying for a Master's degree in Epidemiology at Maastricht University. At the Department of Epidemiology, Jessie fulfilled an internship on the topic of coffee and tea consumption in relation to ovarian cancer risk, and in September 2006, she graduated (cum laude). From August 2006 until August 2010, she worked on the PhD project entitled "Risk factors for Barrett's esophagus, adenocarcinoma of the esophagus and gastric cardia: a prospective cohort study", described in this thesis at the Department of Epidemiology, GROW - School for Oncology and Developmental Biology, Maastricht University Medical Centre +. Since October 2010 Jessie has worked at the Comprehensive Cancer Centre Limburg (IKL) as an epidemiologist. Jessie is living with her husband Joep Urlings. 


\section{LIST OF PUBLICATIONS}

\section{Submitted manuscripts}

Steevens J, Schouten LJ, Goldbohm RA, Van den Brandt PA. Vegetables and fruits consumption and risk of esophageal and gastric cancer subtypes in the Netherlands Cohort Study.

Schouten LJ, Steevens J, Huysentruyt CJR, Coffeng C, Keulemans YCA, van Leeuwen FE, Driessen ALC, van den Brandt PA. Cancer incidence and total and causespecific mortality in patients with Barrett's esophagus.

Steevens J, Schouten LJ, Driessen ALC, Huysentruyt CJR, Keulemans YCA, Goldbohm RA, Van den Brandt PA. A prospective cohort study on overweight, smoking, alcohol consumption, and risk of Barrett's esophagus.

\section{Peer reviewed publications}

Steevens J, Schouten LJ, Driessen ALC, Huysentruyt CJR, Keulemans YCA, Goldbohm RA, Van den Brandt PA. Toenail selenium status and the risk of Barrett's esophagus: the Netherlands Cohort Study. Cancer Causes Control 2010; in press

Steevens J, van den Brandt PA, Goldbohm RA, Schouten LJ. Selenium status and the risk of esophageal and gastric cancer subtypes: the Netherlands cohort study. Gastroenterology 2010;138:1704-13.

Steevens J, Schouten L, Goldbohm RA, van den Brandt PA. Alcohol consumption, cigarette smoking and risk of subtypes of oesophageal and gastric cancer: a prospective cohort study. Gut 2010;59:39-48.

Steevens J, Botterweck AA, Dirx MJ, van den Brandt PA, Schouten L. Trends in incidence of oesophageal and stomach cancer subtypes in Europe. Eur J Gastroenterol Hepatol 2010;22:669-78.

Steevens J, Schouten L, Verhage BA, Goldbohm RA, van den Brandt PA. Tea and coffee drinking and ovarian cancer risk: results from the Netherlands Cohort Study and a meta-analysis. Br J Cancer 2007;97:1291-4. 